\section{Pacific Northwest}

National Laboratory

Operated by Battelle for the

U.S. Department of Energy

\title{
Strategy Plan
}

\section{A Methodology to Predict the Uniformity of Double-Shell Tank Waste Slurries Based on Mixing Pump Operation}

\author{
J.A. Bamberger \\ L.M. Liljegren \\ P.S. Lowery
}

December 1990

Cleared for public distribution

September 2007

Prepared for the U.S. Department of Energy under Contract DE-AC06-76RL01830 


\title{
DISCLAIMER
}

This report was prepared as an account of work sponsored by an agency of the United States Government. Neither the United States Government nor any agency thereof, nor Battelle Memorial Institute, nor any of their employees, makes any warranty, express or implied, or assumes any legal liability or responsibility for the accuracy, completeness, or usefulness of any information, apparatus, product, or process disclosed, or represents that its use would not infringe privately owned rights. Reference herein to any specific commercial product, process, or service by trade name, trademark, manufacturer, or otherwise does not necessarily constitute or imply its endorsement, recommendation, or favoring by the United States Government or any agency thereof, or Battelle Memorial Institute. The views and opinions of authors expressed herein do not necessarily state or reflect those of the United States Government or any agency thereof.

\author{
PACIFIC NORTHWEST NATIONAL LABORATORY \\ operated by \\ BATTELLE \\ for the \\ UNITED STATES DEPARTMENT OF ENERGY
}

under Contract DE-AC06-76RL01830

Printed in the United States of America

Available to DOE and DOE contractors from the

Office of Scientific and Technical Information,

P.O. Box 62, Oak Ridge, TN 37831-0062;

ph: (865) 576-8401

fax: (865) 576-5728

email: reports@adonis.osti.gov

\begin{abstract}
Available to the public from the National Technical Information Service, U.S. Department of Commerce, 5285 Port Royal Rd., Springfield, VA 22161 ph: (800) 553-6847 fax: (703) 605-6900

email: orders@ntis.fedworld.gov

online ordering: http://www.ntis.gov/ordering.htm
\end{abstract}

This document was printed on recycled paper.

$(8 / 00)$ 


\title{
Strategy Plan
}

\section{A Methodology to Predict the Uniformity of Double-Shell Tank Waste Slurries Based on Mixing Pump Operation}

\author{
J.A. Bamberger \\ L.M. Liljegren \\ P.S. Lowery
}

December 1990

Cleared for public distribution

September 2007

Prepared for the U.S. Department of Energy

under Contract DE-AC06-76RL01830 


\section{SUMMARY}

This document presents an analysis of the mechanisms influencing mixing within double-shell slurry tanks. A research program to characterize mixing of slurries within tanks has been proposed. The research program presents a combined experimental and computational approach to produce correlations describing the tank slurry concentration profile (and therefore uniformity) as a function of mixer pump operating conditions.

The TEMPEST computer code was used to simulate both a full-scale (prototype) and scaled (model) double-shell waste tank to predict flow patterns resulting from a stationary jet centered in the tank. The simulation results were used to evaluate flow patterns in the tank and to determine whether flow patterns are similar between the full-scale prototype and an existing 1/12-scale model tank. The flow patterns were sufficiently similar to recommend conducting scoping experiments at 1/12-scale. Also, TEMPEST modeled velocity profiles of the near-floor jet were compared to experimental measurements of the near-floor jet with good agreement (Bamberger, Bates, and Waters 1990).

Reported values of physical properties of double-shell tank slurries were analyzed to evaluate the range of properties appropriate for conducting scaled experiments. One-twelfth scale scoping experiments are recommended to confirm the prioritization of the dimensionless groups (gravitational settling, Froude, and Reynolds numbers) that affect slurry suspension in the tank. Two of the proposed 1/12-scale test conditions were modeled using the TEMPEST computer code to observe the anticipated flow fields. This information will be used to guide selection of sampling probe locations.

Additional computer modeling is being conducted to model a particulate laden, rotating jet centered in the tank. The results of this modeling effort will be compared to the scaled experimental data to quantify the agreement between the code and the 1/12-scale experiment.

The scoping experiment results will guide selection of parameters to be varied in the follow-on experiments. Data from the follow-on experiments will be used to develop correlations to describe slurry concentration profile as a 
function of mixing pump operating conditions. This data will also be used to further evaluate the computer model applications. If the agreement between the experimental data and the code predictions is good, the computer code will be recommended for use to predict slurry uniformity in the tanks under various operating conditions. If the agreement between the code predictions and experimental results is not good, the experimental data correlations will be used to predict slurry uniformity in the tanks within the range of correlation applicability. 


\section{CONTENTS}

SUMMARY ................................. $i$ i

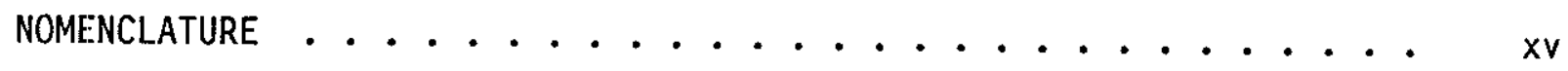

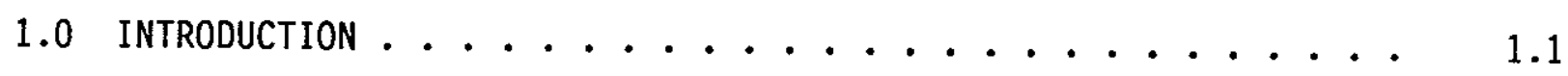

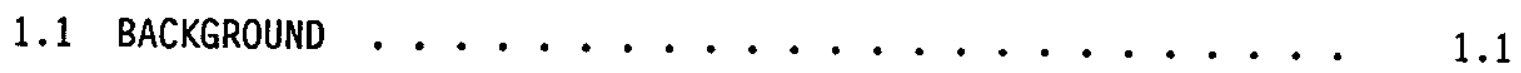

1.2 OBJECTIVE OF TANK UNIFORMITY INVESTIGATION ....... 1.3

1.3 TEST STRATEGY PLAN ORGANIZATION . . . . . . . . . . . 1.6

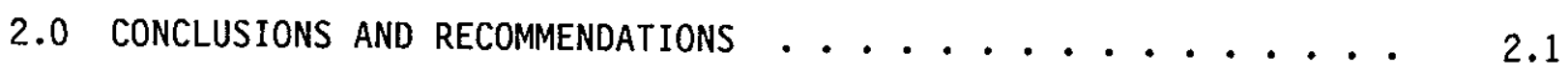

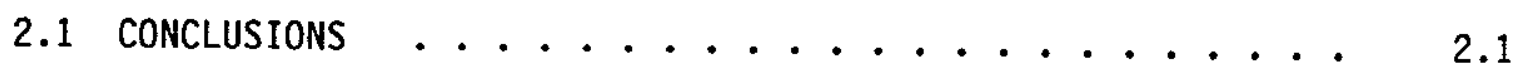

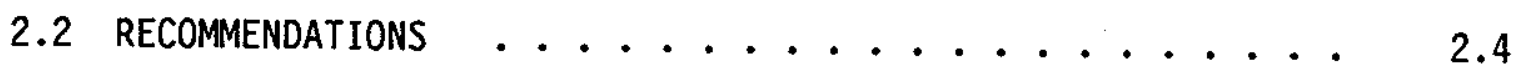

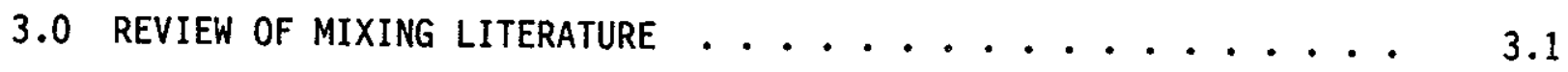

3.1 MIXING OF LIQUID/LIQUID MIXTURES ............... 3.1

3.1.1 Parameters That Affect Mixing in Mechanically Agitated Systems ............ 3.2

3.1.2 Jet Mixing of Liquid/Liquid and Single-Phase Fluids ................... 3.11

3.1.3 Summary of Factors Affecting Mixing in Liquid/Liquid and Single-Phase Fluids ........ 3.17

3.1.4 Mixing in Solid/Liquid Suspensions ....... 3.17

3.2 DIMENSIONAL ANALYSIS OF FACTORS AFFECTING SLURRY

UNIFORMITY ............................. 3.19

3.3 WASTE CHARACTERISTICS ...................... 3.43

3.3.1 Double-Shell Tank Slurries .......... 3.43

3.4 REVIEW OF TESTING .................... 3.50

3.4.1 Tests Conducted in Tank TK-102-AP ....... 3.50

3.4.2 Table Top Experiments on Froude Number Effect . . 3.54

3.5 DESCRIPTION OF TEMPEST COMPUTER MODEL . . . . . . . 3.57 
4.0 OUTLINE OF STRATEGY ....................... 4.1

4.1 COMPUTATIONAL MODELING . . . . . . . . . . 4.1

4.1 .1 Model Evaluation ............... 4.4

4.1 .2 Model Validation .............. 4.5

4.1.3 Computational Prediction of Full-Scale Operation $\quad 4.5$

4.2 EXPERIMENTS ........................... 4.6

4.2.1 Scoping Experiments ............ 4.6

4.2.2 Defining Experiments ........... 4.6

4.2.3 Retrieval Experiments ........... 4.7

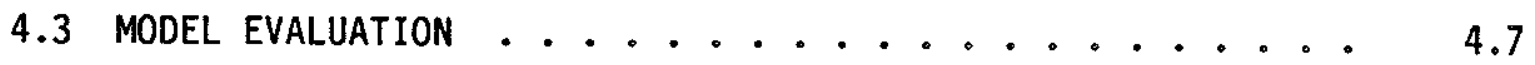

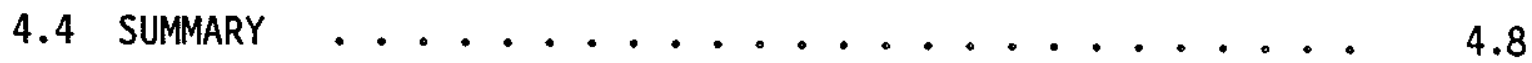

5.0 COMPUTER INVESTIGATIONS OF TANK MIXING USING A SINGLE,
CENTERED NONROTATING JET MODEL

5.1 OBJECTIVES .............................. 5.1

5.2 ANALYSIS ........................... 5.1

5.2 .1 Background ................ 5.1

5.2 .2 Approach ................... 5.6

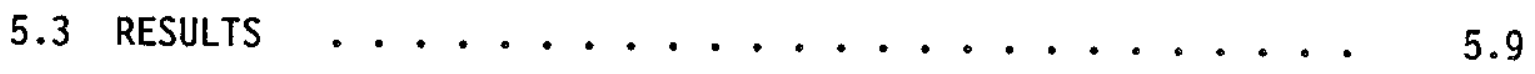

5.3 .1 flow Fields .................... 5.9

5.3 .2 Particle Tracking ............ 5.32

5.4 Limitations ............................. 5.41

6.0 SCOPING EXPERIMENTS ......................... 6.1

6.1 EXPERIMENT OBJECTIVES ....................... 6.3

6.2 TEST APPROACH .......................... 6.4

6.2.1 Prototype Facility and Waste Characteristics ... 6.4 
6.2.2 Prototype Design Basis . . . . . . . . 6.5

6.2 .3 Simulant Development and Verification ...... 6.7

6.2 .4 Mode1 .................... 6.9

6.2 .5 Scoping Experiment Design .......... 6.9

6.3 EQUIPMENT DESCRIPTION ....................... 6.13

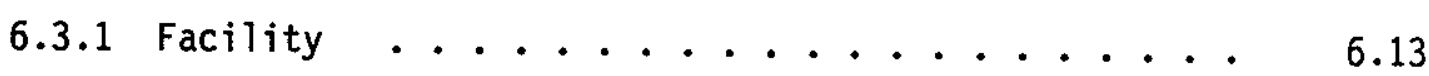

$6.3 .1 .11 / 12$-Scale Equipment $\ldots . . . . .6 .13$

6.3.1.2 Simulant Makeup and Transfer ..... 6.15

6.3.2 Instrumentation ............... 6.17

6.4 DATA ANALYSIS APPROACH ................ 6.20

6.4 .1 Process Measurements ........... 6.21

6.4.2 Simulant Property Measurements ....... 6.21

6.4.3 Statistical Analys is Requirements for Concentration

Measurements ............

6.4.3.1 Standard Deviation of Replicate Samples and Analyses .............. 6.21

6.4.3.2 Probability of Erroneous Conclusions .. 6.22

6.4.3.3 Desired Detectable Differences .... 6.23

6.4.3.4 Number of Samples per Location or Slurry
Combination ........................ 6.23

6.5 RESULTS ............................ 6.25

6.5.1 Simulant Characterization ......... 6.26

6.5 .2 Statistical Analysis of Concentration Data .... 6.27

6.5.3 Effects of Uniformity Test Parameters ...... 6.28

6.5.4 Full-Scale Operation Predictions ....... 6.28

6.5.5 Conclusions and Recommendations ........ 6.29

6.6 Limitations .......................... 6.30 
7.0 NUMERICAL MODEL DEVELOPMENT FOR TANK MIXING ANALYSIS $\ldots . . .7 .1$

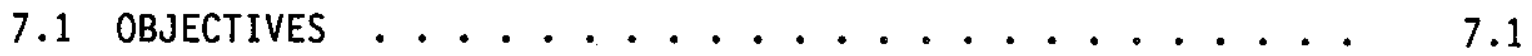

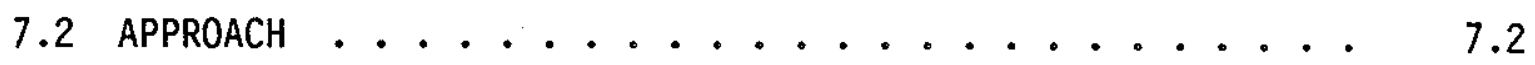

7.2.1 Preliminary Qualification towards Rotating Jet

Simulation ................. 7.2

7.2.2 1/12-Scale Experiment Simulations . . . . . 7.4

7.2.3 Single Pump Full-Scale Prototype Simulation . . . 7.5

7.2.4 Multiple Pump Simulation ......... 7.5

7.3 PRESENTATION OF RESULTS . . . . . . . . . . 7.6

7.4 CONSIDERATIONS FOR THE LONG TERM .............. 7.10

8.0 TANK SLURRY UNIFORMITY DEFINITION AND RETRIEVAL EXPERIMENTS $\cdots \quad 8.1$

8.1 EXPERIMENT OBJECTIVES $\ldots \ldots \ldots . \ldots . \ldots . \ldots . \ldots$

8.2 TEST APPROACH ........................ 8.2

8.2.1 Modeling Slurry Uniformity at 1/6-Scale ..... 8.3

8.2.2 Defining Experiment Design ........ 8.3

8.2.3 Waste Retrieval Experiments . . . . . . 8.10

8.3 RESULTS ............................. 8.14

8.3.1 Effects of Uniformity Test Parameters and Tank
Slurry Retrieval Experiments ....... 8.15

8.3.2 Full-Scale Operation Predictions ...... 8.17

8.3.3 Conclusions and Recommendations ....... 8.17

8.4 Limitations . . . . . . . . . . . . . . . 8.19

9.0 REAL-TIME MEASUREMENT OF SLURRY CONCENTRATION . . . . . . 9.1

REFERENCES ............................. 10.1

APPENDIX - METHOD FOR ESTIMATING SOLIDS DENSITY . . . . . . A.1 


\section{FIGURES}

1.1 Double-Shell Tank Waste Treatment, Storage, and Disposal Paths .

1.2 Double-Shell Tank Waste Retrieval Equipment . . . . . . . . 1.3

1.3 Double-Shell Tank Mixer Pump Riser Configurations . . . . . 1.4

3.1 Correlation of Mixing Times for a Propeller in an Unbaffled Vessel........................... 3.5

3.2 Correlation of Mixing Time for Turbines in Baffled Vessels . . 3.7

3.3 Correlation of Dimensionless Blend Time Versus Reynolds Number ......................... . . . 3.9

3.4 Flow Patterns in Propeller-Stirred Vessels . . . . . . . . 3.11

3.5 Jet Mixing of Liquids in Vessels . . . . . . . . . . 3.13

3.6 Effect of Liquid Density Difference on Jet Velocity for Mixing Liquids......................

3.7 Intensity of Agitation a) Unstable Fillets are on Vessel Bottom, b) Particles Swept off of Vessel Bottom, c) Solids are Homogeneously Distributed ..................

3.8 Anticipated Trend in Uniformity as a Function of Froude and Reynolds Numbers at Constant Gravitational Settling Number...

3.9 Comparison of Froude Number and Reynolds Number Regions of Interest in Prototype and 1/12-Scale Model ..........

3.10 TEMPEST Genealogy . . . . . . . . . . . . . .

4.1 Investigation of Flow Chart Slurry Uniformity Within Tanks . . 4.2

5.1 TEMPEST Computational Grid . . . . . . . . . . . 5.5

5.2 Velocity Vectors on a Vertical Plane at $\theta=2^{\circ}$. . . . . . 5.10

5.3 Velocity Vectors on a Vertical Plane at $\Theta=10.4^{\circ}$. . . . 5.11

5.4 Velocity Vectors on a Vertical Plane at $\Theta=22.05^{\circ}$. . . . 5.12 
5.5 Velocity Vectors on a Vertical Plane at $\Theta=39.15^{\circ}$. . . . 5.13

5.6 Velocity Vectors on a Vertical Plane at $\theta=60.6^{\circ}$. . . . . 5.14

5.7 Velocity Vectors on a Vertical Plane at $\Theta=74.3^{\circ}$. . . . . 5.15

5.8 Velocity Vectors on a Vertical Plane at $\Theta=84^{\circ}$. . . . . 5.16

5.9 Velocity Vectors on a Horizontal Plane at $z / H=0.006^{\circ}$. . . 5.17

5.10 Velocity Vectors on a Horizontal Plane at $z / H=0.033^{\circ}$. . . 5.18

5.11 Velocity Vectors on a Horizontal Plane at $z / H=0.069^{\circ}$. . . 5.19

5.12 Velocity Vectors on a Horizontal Plane at $\mathrm{z} / \mathrm{H}=0.126^{\circ}$. . . 5.20

5.13 Velocity Vectors on a Horizontal Plane at $\mathrm{z} / \mathrm{H}=0.223^{\circ}$. . . 5.21

5.14 Velocity Vectors on a Horizontal Plane at $\mathrm{z} / \mathrm{H}=0.387^{\circ}$. . . 5.22

5.15 Velocity Vectors on a Horizontal Plane at $z / H=0.644^{\circ} \ldots .23$

5.16 Velocity Vectors on a Horizontal Plane at $z / H=0.857^{\circ}$. . . 5.24

5.17 Velocity Vectors on a Horizontal Plane at $z / H=0.979^{\circ}$. . . 5.25

5.18 Comparison of Computed Results (dark lines) with the Experimental and Theoretical Results of Bamberger, Bates, and Waters (1990) (open symbols) for Axial Velocity Profiles along the Vertical Jet Centerline at $\sim_{25}$ Nozzle Diameters Downstream from the Jet Exit ...............

5.19 Comparison of Computed Results with the Experimental and Theoretical Results of Bamberger, Bates, and Waters (1990) for Axial Velocity Profiles along the Vertical Jet Centerline at $\sim 41$ Nozzle Diameters Downstream from the Jet Exit . . . . .

5.20 Comparison of Computed Results with the Experimental and Theoretical Results of Bamberger, Bates, and Waters (1990) for Axial Velocity Profiles along the Vertical Jet Centerline at $\sim 57$ Nozzle Diameters Downstream from the Jet Exit .....

5.21 Comparison of Computed Results with the Experimental and Theoretical Results of Bamberger, Bates, and Waters (1990) for Axial Velocity Profiles along the Vertical Jet Centerline at 66 Nozzle Diameters Downstream from the Jet Exit 
5.22 Comparison of Computed Results with the Experimental and Theoretical Results of Bamberger, Bates, and Waters (1990) for Axial Velocity Profiles along the Horizontal Jet Centerline at 25 Nozzle Diameters Downstream from the Jet Exit

5.23 Comparison of Computed Results with the Experimental and Theoretical Results of Bamberger, Bates, and Waters (1990) for Axial Velocity Profiles along the Horizontal Jet Centerline at $\sim 41$ Nozzle Diameters Downstream from the Jet Exit ..........................

5.24 Comparison of Computed Results with the Experimental and Theoretical Results of Bamberger, Bates, and Waters (1990) for Axial Velocity Profiles along the Horizontal Jet Centerline at $\sim 57$ Nozzle Diameters Downstream from the Jet Exit

5.25 Comparison of Computed Results with the Experimental and Theoretical Results of Bamberger, Bates, and Waters (1990) for Axial Velocity Profiles along the Horizontal Jet Centerline at $\sim 66$ Nozzle Diameters Downstream from the Jet Exit

5.26 Particle Density "Bin" Plot Computational Grid . . . . . . 5.37

5.27 Particle Density "Bin" Plots for Case 2 . . . . . . . . 5.38

5.28 Particle Density "Bin" Plots for Case 3 . . . . . . . . . 5.39

5.29 Particle Density "Bin" Plots for Case 4 . . . . . . . . 5.40

6.1 Logic Diagram for Experimental Plan . . . . . . . . . . 6.2

6.2 Test Facility Schematic Diagram . . . . . . . . . . . 6.14

$6.31 / 12-S c a l e$ Double-Shell Tank Model . . . . . . . . . 6.15

6.4 Slurry Mixing Pump Configuration . . . . . . . . . . 6.16

6.5 Proposed Concentration "Grab Sample" Measurement Locations • • 6.18

6.6 Schematic of Bottle-and-Rod Tank Sampler . . . . . . . . 6.19

6.7 Example of Expected Linear Correlation of $\Delta C / C$ versus $G s \quad$. $\quad 6.30$ 
7.1 Example of Boundary Fitted Grid ............ . 7.7

7.2 Example of TEMPEST Volume Fraction Contours . . . . . . 7.8

7.3 Example of TEMPEST Horizontal Concentration Profile . . . . 7.9

7.4 Example of TEMPEST Transient Concentrations Variable Viscosity
with Enhanced Settling Velocity . . . . . . . . .

8.1 Variation of Gravitational Settling Number with Froude Number . 8.8

8.2 Typical Concentration Profiles as a Function of Height . . . 8.11

8.3 Optimum Retrieval Location as a Function of Inhomogeneity . . 8.12

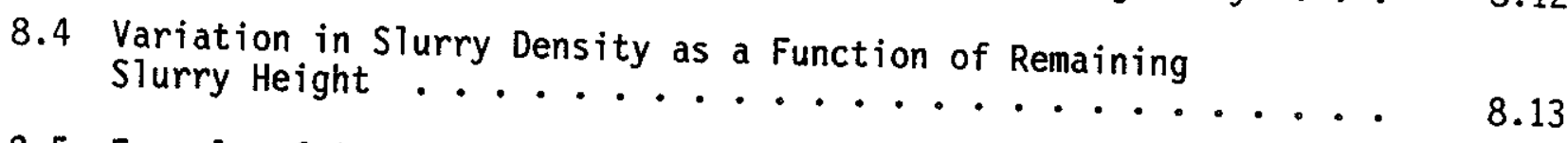

8.5 Example of Concentration versus Height Plot for Waste Retrieval

8.6 Example of Correlation of $\triangle \mathrm{C} / \mathrm{C}$ versus Gs 8.18

8.7 Example of $\Delta C / C$ versus $G s \ldots \ldots . \ldots .18$

8.7 Example of Correlation of $\Delta \mathrm{C} / \mathrm{C}$ versus $\mathrm{Fr} \ldots \ldots . \ldots$ 


\section{TABLES}

1.1 Waste Types ... . . . . . . . . . . . . 1.2

1.2 Prototype Waste Tank Dimensions .............. 1.5

1.3 Tank Contents and Usage .................... 1.5

3.1 Comparison of Prototype and Model Settling Times ....... 3.42

3.2 Waste Property Summary ................ 3.44

3.3 Comparison of Table Top Experiment with Prototype ...... 3.56

4.1 Strategy Activities ................ 4.3

5.1 Prototype Parameter Range .................... 5.6

5.2 TEMPEST Simulation Parameters .................... 5.8

6.1 Prototype Tank and Waste Retrieval System Dimensions .... 6.5

6.2 Physical Waste Properties Data Summary ......... 6.6

6.3 Particle Size Distribution by Waste Type ........ 6.6

6.4 Pi Parameters ........................ 6.7

6.5 Prototype Properties .................. 6.8

6.6 Scoping Experiment Parameter Set, Based on Prototype .... 6.9

$6.71 / 12$-Scale Model Configuration ............ 6.10

6.8 Scoping Experiment Parameter Set, Based on Model ..... 6.11

6.9 Property Value Range to Model Process at 1/12-Scale ..... 6.11

6.10 Test Matrix Example ... . . . . . . . . 6.12

6.11 Instrumentation .................... 6.17

6.12 Anticipated Physical Properties of Simulants ....... 6.26

6.13 Estimates of Inhomogeneity from Concentration Measurements . . 6.29 
8.1 1/6-Scale Model Configuration ........... 8.4

8.2 Defining Experiment Parameter Set, Based on Model . . . . 8.5

8.3 Property Value Range to Model Process at 1/6-Scale ..... 8.5

8.4 Target Properties for Simulants to be Used in 1/6-Scale Tests . 8.7

8.5 Tests to Determine the Effect of Tank Slurry Level and Number of Pumps in the 1/6-Scale Defining Experiment . . . 8.9

8.6 Estimates of the Degree of Inhomogeneity from Concentration Measurements for One Pump Configuration and Tank Component

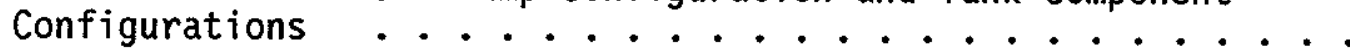

8.7 Estimates of Inhomogeneity from Waste Retrieval Experiments for Various Mixer Pump Configurations and One Tank Component

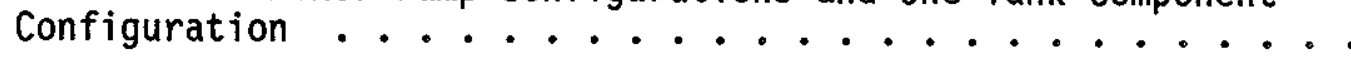




\section{NOMENCLATURE}

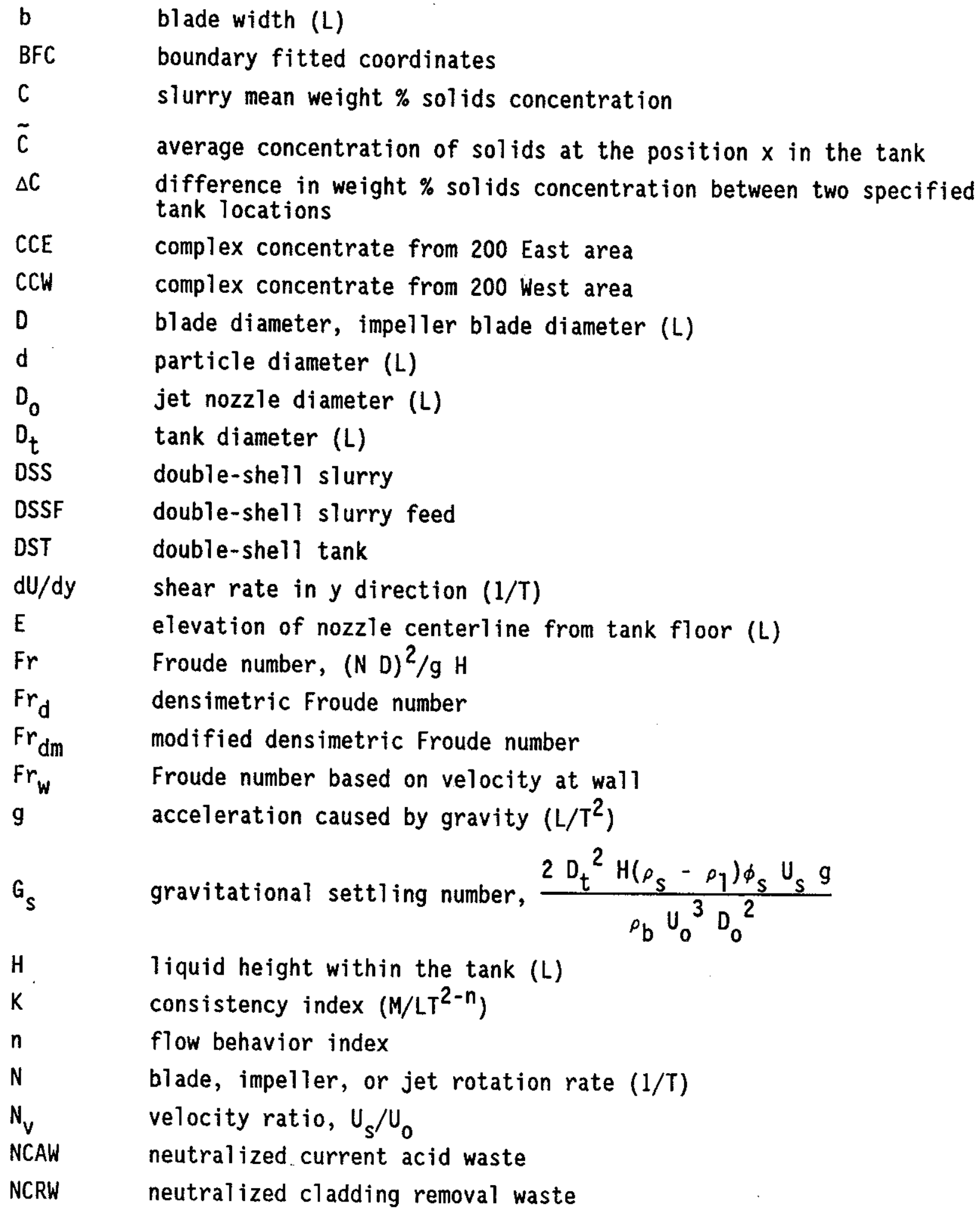




\begin{tabular}{|c|c|}
\hline $\mathrm{p}$ & propeller width (L) \\
\hline PFPW & plutonium finishing plant waste \\
\hline Q & volumetric discharge for an impeller or jet mixer $\left(\mathrm{L}^{3} / \mathrm{T}\right)$ \\
\hline $\operatorname{Re}_{b}$ & blade Reynolds number \\
\hline $\operatorname{Re}_{c}$ & critical Reynolds number denoting transition to turbulence \\
\hline $\operatorname{Re}_{j}$ & impeller Reynolds number \\
\hline $\operatorname{Re}_{j}$ & jet Reynolds number \\
\hline $\operatorname{Re}_{\mathrm{p}}$ & propeller Reynolds number \\
\hline s & $\begin{array}{l}\text { ratio of solids density to bulk density }\left(\rho_{\mathrm{s}} / \rho_{\mathrm{b}}\right) \text {, or ratio of solids } \\
\text { density to liquid density }\left(\rho_{\mathrm{s}} / \rho_{1}\right)\end{array}$ \\
\hline $\mathrm{T}_{\mathrm{m}}$ & mixing time $(T)$ \\
\hline$t_{s}$ & $\begin{array}{l}\text { time required for single particle to settle from top of liquid to } \\
\text { bottom of tank }(T)\end{array}$ \\
\hline$U_{0}$ & jet exit velocity $(L / T)$ \\
\hline$U_{s}$ & particle unhindered settling velocity $(L / T)$ \\
\hline $\begin{array}{l}U_{W} \\
v^{\prime}\end{array}$ & $\begin{array}{l}\text { jet velocity at the tank wall }(L / T) \\
\text { tank volume }\left(L^{3}\right)\end{array}$ \\
\hline $\overrightarrow{\mathrm{x}}$ & coordinate (position vector) of a location in tank (L) \\
\hline $\mathrm{x}$ & scale factor \\
\hline
\end{tabular}

\section{Greek Letters}

$\begin{array}{ll}\mu & \text { fluid viscosity }(M / L T) \\ \mu_{\mathrm{a}} & \text { apparent viscosity }(M / L T) \\ \mu_{\mathrm{b}} & \text { slurry viscosity }(M / L T) \\ \eta_{\mathrm{rh}} & \text { rotation number, based on liquid height } \\ \eta_{\mathrm{rj}} & \text { rotation number, based on jet diameter } \\ \rho & \text { fluid density }\left(M / \mathrm{L}^{3}\right) \\ \Delta \rho & \text { fluid density difference }\left(M / \mathrm{L}^{3}\right) \\ \rho_{\mathrm{b}} & \text { mean mixture density, slurry bulk density }\left(M / \mathrm{L}^{3}\right) \\ \tilde{\rho}_{\mathrm{b}} & \text { local average density as a function of location in the } \operatorname{tank}\left(M / \mathrm{L}^{3}\right) \\ \Delta \rho_{\mathrm{b}} & \text { variation in mixture density from tank top to bottom }\left(M / \mathrm{L}^{3}\right) \\ \rho_{\mathrm{infinity}} & \text { mean density of fluid outside jet }\left(M / \mathrm{L}^{3}\right) \\ \rho_{\mathrm{b}, j} & \text { bulk density of the jet } \\ \rho_{\mathrm{b}, \infty} & \text { bulk density of the mixture just outside the jet }\end{array}$




\begin{tabular}{|c|c|}
\hline${ }^{\rho_{C}}$ & centrifuged solids density $\left(M / L^{3}\right)$ \\
\hline$\rho_{\mathrm{j}}$ & jet density $\left(M / L^{3}\right)$ \\
\hline$\rho 1$ & liquid density $\left(M / L^{3}\right)$ \\
\hline$\rho_{\mathrm{m}}$ & mean mixture density $\left(M / L^{3}\right)$ \\
\hline$\Delta \rho_{m}$ & $\begin{array}{l}\text { variation in density of solids in the mixture from tank top to } \\
\text { bottom }\left(M / L^{3}\right)\end{array}$ \\
\hline${ }^{\rho_{S}}$ & particle or solids density $\left(M / L^{3}\right)$ \\
\hline$\tau$ & shear stress $\left(M / L T^{2}\right)$ \\
\hline$\tau_{y}$ & slurry yield stress $\left(M / L T^{2}\right)$ \\
\hline$\theta$ & dimensionless mixing time \\
\hline${ }^{\theta} \mathrm{FG}$ & dimensionless mixing time defined by Fox and Gex \\
\hline$\theta_{m}$ & modified dimensionless mixing time \\
\hline$\phi$ & $\begin{array}{l}\text { inclination of jet from hoirzontal plane (degrees), mean volume } \\
\text { concentration of solids in the mixture }\end{array}$ \\
\hline$\Delta \phi$ & $\begin{array}{l}\text { variation in volume concentration of solids in the mixture from } \\
\text { tank top to bottom }\end{array}$ \\
\hline$v$ & kinematic viscosity $\left(L^{2} / T\right)$ \\
\hline
\end{tabular}


E: 


\subsection{INTRODUCTION}

\subsection{BACKGROUND}

Double-shell tanks (DSTs) at Hanford are used to store liquid and sludge wastes (transuranic, high-level, and low-level). Prior to being solidified for permanent storage, liquid and sludge waste in double-shell tanks will be retrieved and transferred to existing or new pretreatment facilities. Retrieval technology applicable to the various double-shell tank wastes must be clefined, developed, and demonstrated. These wastes will be processed into immobile waste forms suitable for disposal. A flow diagram of the proposed treatment strategies is displayed in Figure 1.1. Double-shell tank wastes originate from various sources including the single-shell tanks, the canyon reprocessing facility, analytical laboratories, and the decontamination operations. The evaporator facility is used to reduce waste volume. Doubleshell tank wastes are processed in the waste pretreatment facility where they are separated into high-level and low-level waste fractions and returned to double-shell tanks. The low-level waste fraction is processed in the grout treatment facility; the high-level waste fraction is to be processed in the Hanford Waste Vitrification Plant.

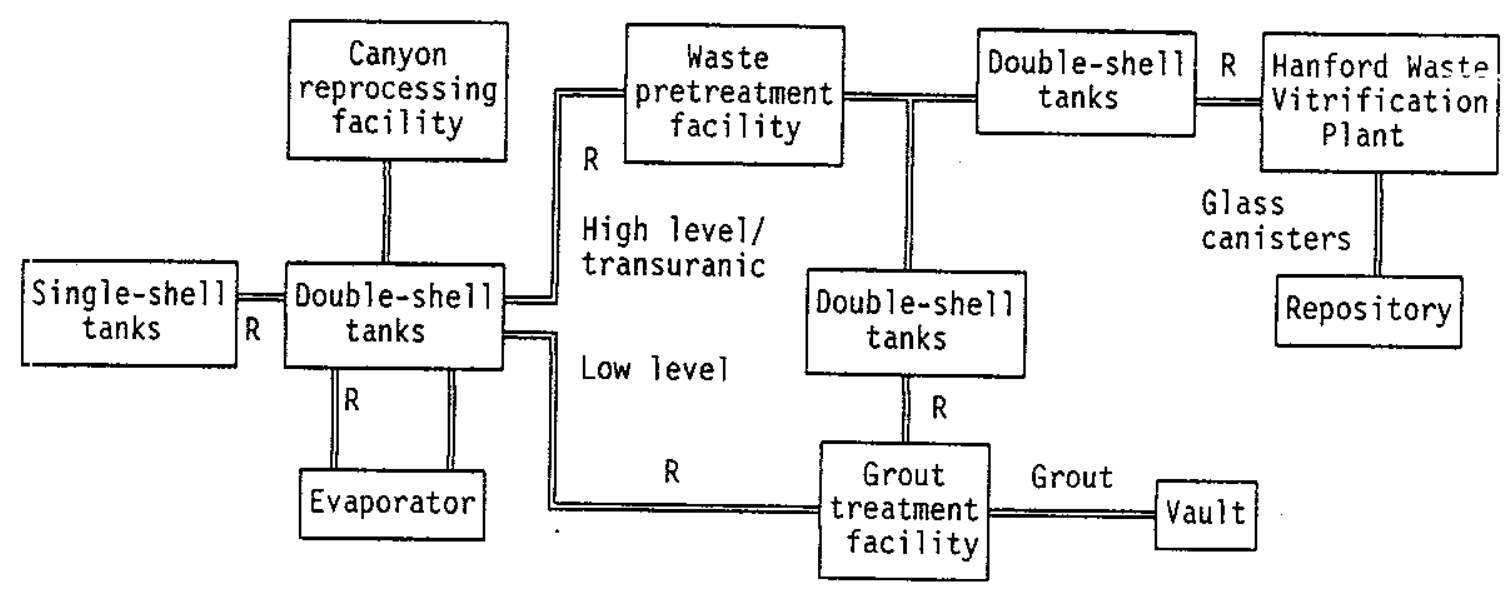

$R$ : Waste mobilization and retrieval system required to perform this waste transfer

FIGURE 1.1 Double-Shell Tank Waste Treatment, Storage, and Disposal Paths 
The waste treatment strategies can only be performed successfully by ensuring that the slurry feed streams removed from the tank are uniform in concentration. The feed streams consist of seven types of low-level and highlevel waste, listed in Table 1.1. For waste retrieval, the tanks can be configured as displayed in Figure 1.2 using mixing pumps to resuspend the tank contents and to maintain a uniform suspension throughout the tank and using a centrally located retrieval pump to transfer slurry out of the DST. Other tank configurations using one to four mixing pumps are illustrated in Figure 1.3. Typical tank dimensions are listed in Table 1.2. Individual tank usage and contents vary; this information is summarized in Table 1.3.

Mixing pumps will be installed in the double-shell tanks to mobilize and suspend settled sludge as a first step toward retrieving the tank contents. The mixer pumps have high volume, horizontally directed jets that impact and mobilize the sludge and mix it into a slurry. The mixing pumps will also be used to maintain the solids in suspension during slurry removal. These two processes, mobilization and suspension, involve different mechanisms for which the scaling relationships differ. Fow, Scott, Whyatt, and Ruecker(a) investigated mobilization of the settled solids analytically and conducted pilotscale experiments in FY87. Operating conditions for prototype mixer pumps

TABLE 1.1. Waste Types

Waste Definitions and Designations

NCAW Neutralized current acid waste

NCRW Neutralized cladding removal waste

PFPW Plutonium finishing plant waste

CCE Complex concentrate from 200E area

CCW Complex concentrate from 200W area

DSS Double-shell slurry

DSSF Double-shell slurry feed

(a) 1987 draft report. Pacific Northwest Laboratory, Richland, Washington. 


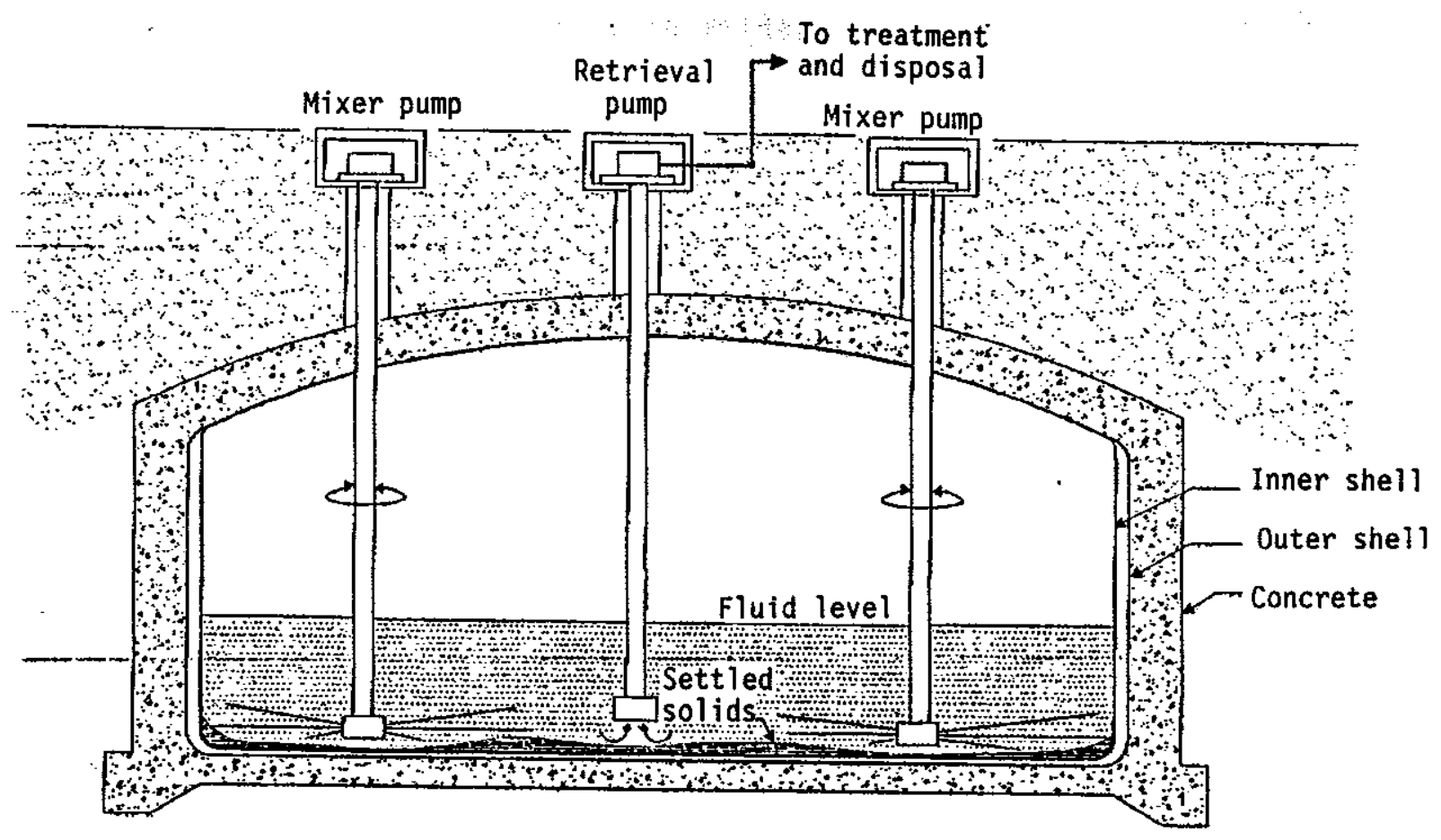

FIGURE 1.2. Double-Shell Tank Waste Retrieval Equipment

were developed based on these investigations. Limited analyses to date have addressed solids suspension in the tanks. Heath(a) summarized potentially important slurry suspension mechanisms without ranking them by importance.

\subsection{OBJECTIVE OF TANK UNIFORMITY INVESTIGATION}

The purpose of the studies to investigate slurry uniformity in waste tanks is to define mixing pump operating limits that will ensure an adequately uniform feed waste stream during waste retrieval from the tanks. The waste stream becomes the process feed for the waste pretreatment and/or immoljilization processes. It is anticipated that these processes will impose strict limits to the waste concentration and composition in the feed stream thereby imposing requirements on the mixing pump operating conditions within the double-shell waste storage tanks. This document presents a strategy for the development of operating criteria that will address the maintenance of solids in suspension. The strategy methodology is balanced to include

(a) 1988 draft report. Pacific Northwest Laboratory, Richland, Washington. 
Mixer Pump Riser Configurations for:
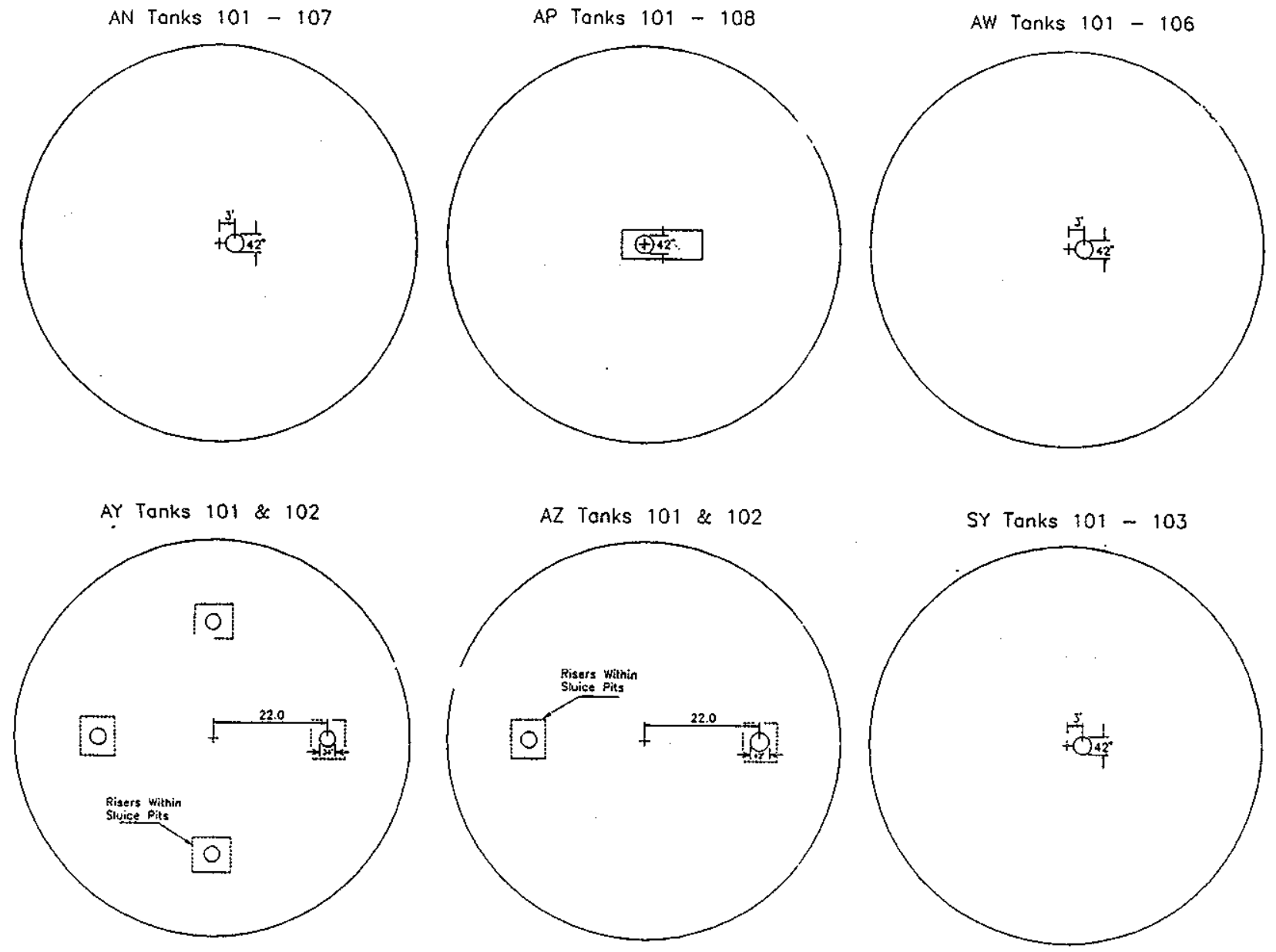

FIGURE 1.3. Double-She11 Tank Mixer Pump Riser Configurations

analytical, computational, and experimental research investigations. A critical path, based on the most probable outcome of the prior steps, is outlined. Decision points and rational for making the decisions are included with these analyses. Using this information, the Westinghouse Hanford Company will develop their mixing pump and retrieval pump operating strategies to ensure that a uniform feed process can be provided. This feed will need to remain uniform while tank equipment is operated to reduce pump and equipment energy consumption and to reduce the potential for tank shell erosion.

The purpose of this research is to provide correlations to predict mixing pump operating conditions required to maintain a uniform suspension of 
TABLE 1.2. Prototype Waste Tank Dimensions

Dianeter

Tank Geometry

Distance, pump centerline to tank wall

$22.9 \mathrm{~m}(75 \mathrm{ft})$

Fluid depth

$11.4 \mathrm{~m}(37.5 \mathrm{ft})$

Final

Initial

Mixing Pump Dimensions

Nozz:le diameter

$0.15 \mathrm{~m}$ (6 in.)

Distance, tank bottom to nozzle centerline

0.30 to $0.46 \mathrm{~m}$ (12 or $18 \mathrm{in.}$ )

Distance, pump centerline to nozzle discharge

Distance, tank floor to pump intake

$0.44 \mathrm{~m}$ (17.5 in.)

Jet Properties

$U_{0} D_{0}$

$2.73 \mathrm{~m}^{2} / \mathrm{s}\left(29.4 \mathrm{ft}^{2} / \mathrm{s}\right)$

$U_{0} D_{0}$ operating range

$25 \%$ to $100 \%$

Discharge angle from vertical

TABLE 1.3. Tank Contents and Usage

Tank Designation

AN 101, 103, 106

AN 102 and 107

AP 102 and 104

AP 103

AW 101

AW 102

AW 103 and 105

AW 104

AW 106

AY 101

AZ 101 and 102

SY 101 and 103

SY 102
Usage and/or Contents

Double-shell slurry

Complex concentrate from 200 East

Grout feed tanks

Double-shell slurry

Double-shell slurry

Double-she11 slurry feed, evaporator feed tank

Neutralized cladding removal waste

Dilute receiver

Evaporator slurry receiver tank transient

Complex concentrate from $200 E$ area

Neutralized current acid waste

Complex concentrate from $200 \mathrm{~W}$ area

Plutonium finishing plant 
solids in double-shell tanks after sludge mobilization. These correlations will be accomplished through analytical, computational, and experimental investigations with the following objectives:

- prioritize dimensionless variables governing slurry uniformity in tanks

- develop correlations to describe the mixing process in the prototype waste tank

- determine the number of mixing pumps and operating conditions $\left(\% U_{0} D_{0}\right)$ required for the continuous, steady-state operation while maintaining a uniform slurry composition within the tank.

The research scope includes five activities:

- analyzing the effects of scale upon mixing parameters using a nonrotating jet model (see Section 5.0)

- experimentally ranking the dimensionless variables affecting mixing (see Section 6.0)

- developing the computational model based on experimental results (see Section 7.0)

- experimentally varying the parameters of importance to provide data to develop correlations to describe slurry uniformity within tanks (see Section 8.0)

- developing real-time measurement techniques to characterize uniformity within the scaled experiments (see Section 9).

The details of each activity are described in the remainder of this report.

\subsection{TEST STRATEGY PLAN ORGANIZATION}

The test strategy is organized to present the results of this analysis; it is also organized as if it were the final report resulting from the analyses, computer modeling, and experimentation outlined in Section 1.2. This combined presentation fulfills two separate goals. First, it structures the strategy to present a logical concise argument for each evaluation step and postulates anticipated results. Second, it provides predictions of analytically derived results and correlations in the predicted final report format. This method of presentation will enable Westinghouse Hanford Company 
to evaluate the type of information received and to assess information usefulness according to Westinghouse Hanford's process applications.

The strategy plan includes two computational activities, two experimental activities, and one instrumentation developmental activity. Anticipated conclusions and recommendations resulting from these activities are listed in Section 2.0. In Section 3.0, background data from previous activities at Hanford and from the literature are analyzed. These data are used to rank the dimensionless groups that describe particulate suspension and settling mechanisms prevalent in the waste tanks. In Section 4.0 , the test strategy outline is presented. Following the outline, in Sections 5.0 through 9.0, each of the five activities is defined including analysis objective, equipment description, test approach, data analysis approach, and projected results and limitations. In Section 5.0, the results of the TEMPEST code simulation of slurry mixing within tanks based on a centered, nonrotating jet are presented. In Section 6.0, the scaled scoping experiments are described. In Section 7.0, the methodology of TEMPEST modeling of slurry mixing within tanks based on the rotating jet model and further code applications are outlined. In Section 8.0, the scaled, defining experiments are outlined. In Section 9.0, realtime measurement techniques applicable to quantifying slurry uniformity within tanks are described. 



\subsection{CONCLUSIONS AND RECOMMENDATIONS}

This document presents an analysis of the mechanisms influencing slurry mixing within double-shell tanks. A research program to characterize slurry mixing in the tanks is proposed. The research outlined presents a combined experimental/computational approach to produce correlations to describe slurry concentration profiles in the tank (and therefore slurry uniformity) as a function of mixer pump operating conditions. Conclusions from the analytical and nonrotating mixer pump computational investigations and recommendations for additional modeling efforts and for scoping, defining, and retrieval experiments are listed in Section 2.1. Anticipated experimental results from the scoping and defining tests are listed in Section 2.2.

\subsection{CONCLUSIONS}

The results of the analytical investigation presented in Section 3.0 indicate that

- Froude number ( $\mathrm{Fr}$ ), Reynolds number (Re), and tank geometry affect mixing behavior significantly in mechanically agitated systems (Section 3.1 .1 ) as well as in jet mixed systems (Section 3.1.2). The qualitative difference in mixing time between jet and mechanically mixed systems is that transition to turbulence occurs at a lower Reynolds number when jet mixers are used (Section 3.1.3).

- The jet mixing experiments conducted in tank 241-AP-102 exhibited the effect of a neutrally buoyant jet that travelled to the top surface of the liquid in the tank. The solids concentration in the tank was low and did not affect the mean jet density (Section 3.1 .2 ). Based on this experiment, the effect of density gradients on mixing behavior is not known and its importance cannot be discounted (Section 3.4.1).

- Particle settling velocity is the critical physical parameter dictating the degree of suspension attained in a solids suspension design; other parameters such as particle diameter, particle Reynolds number, and solids density affect resuspension only by their influence on the particle settling velocity (Section 3.1.3). The gravitational settling number (GS) will be used to describe this effect. 
- Solids concentration affects the transition to turbulence, the absolute level of kinetic energy in flow of slurries through pipes, and is expected to affect other types of flows similarly; therefore, experiments should be conducted at concentrations similar to those in the waste tanks (Section 3.2).

- In the prototype, the jet Reynolds number is in the turbulent range; therefore, changes in Reynolds number are not expected to influence prototype mixing behavior because scaled experiments should match Reynolds number regime by being fully turbulent. The Froude number may affect mixing at all nozzle exit velocities. Because stratification may occur at low Froude numbers, scaled experiments should match the prototype Froude number range (Section 3.2).

- Review of physical and rheological waste characterization data indicates that double-shell tank slurries exhibit both Newtonian and non-Newtonian rheologies. Experimental investigations should first characterize jet mixing for Newtonian slurries to provide a baseline for future non-Newtonian investigations as required (Section 3.3).

- Qualitative table top experiments investigating the effects of buoyancy upon a horizontal near-floor jet impacting a vertical wall indicated that a neutrally buoyant jet rises readily, but that a dense liquid jet or a jet with an immiscible phase, both with velocity similar to the neutrally buoyant jet, do not. If the slurry in the waste tank is stratified, the possibility of density effects cannot be ruled out (Section 3.4.2).

Computational modeling of the velocity flow fields in the prototype and 1/12-scale model using the TEMPEST computer code (Section 5.0) indicate that

- The TEMPEST model of the near-floor jet agrees well with the experimental data taken by Bamberger, Bates, and Waters (1990). The main features of the flow (jet development, transition from free jet to wall jet, and spreading of the jet along the impinged tank wal1) are adequately resolved in the simulations to provide a reasonable picture of the large-scale mixing process occurring in the double-shell tank.

- Particle tracking was used in the model to investigate the potential for particle settling in the 1/12-scale simulations of fluid motion in the tank; trends in the analyses indicate that the distribution moved toward homogeneity of tank contents as mixing time increased for the conditions simulated.

- TEMPEST models of the flow field in the prototype and at $1 / 12$-scale show good agreement. 
A strategy to define prototype operating conditions, operating range to provide a uniform concentration slurry in the tank, and a homogeneous process feed when the slurry is retrieved is outlined in Section 4.0. The strategy plan recommendation is to conduct a balanced analytical, computational, and experimental program to provide correlations to describe slurry uniformity in waste tanks over the range of proposed operating conditions.

The computational effort should include the development of capabilities to

- model a simple rotating, particulate laden, dual-jet mixing pump centered in the waste tank

- model multiple, rotating, particulate laden, dual-jet mixing pumps not centered in the waste tank

- guide the design of scoping, designing, and retrieval test matrixes

- develop a QA Level II code based on successful completion of producing results compatible with the data from the scaled experiments.

As a result of the analytical investigations and the nonrotating jet computer modeling, scaled experiments should be conducted to investigate slurry homogeneity and retrieval. The experiments include

- $1 / 12$-scale scoping experiments to investigate the effects of the dimensionless groups

- 1/6-scale defining experiments to investigate correlation nonlinearities over the projected range of operating parameters and tank component configurations

- retrieval experiments to compare retrieval homogeneity with slurry homogeneity within the tank

- based on the results of the Newtonian retrieval experiments, nonNewtonian experiments may be recommended.

A demonstration of an ultrasonic receiver transmitter pair showed that the system has the potential to detect variations in slurry concentration. An ultrasonic real-time measurement system should be developed to provide continuous measurement of slurry concentration as a function of location and elevation in the tank. 


\subsection{RECOMMENDATIONS (a)}

The following results are anticipated from the scoping experiments:

- Gravitational settling number and Froude number will both affect slurry uniformity within the waste tank; jet Reynolds number in the fully turbulent regime will not.

- Homogeneity will not be achieved under all operating conditions.

- Defining experiments will be required at a larger scale than the scoping experiments.

- Linear correlations will be developed describing the effect of concentration deviation from uniformity $(\Delta C / C)$ versus jet flow parameter $\left(U_{0} D_{0}\right)$ as a function of the dependent variables investigated.

The following results are anticipated from the defining experiments:

- Nonlinear correlations will be developed describing the effect of concentration deviation from uniformity $(\Delta C / C)$ versus jet flow parameter $\left(U_{0} D_{0}\right)$ as a function of the dependent parameters investigated.

- Correlations describing prototype performance will be developed from the scoping and defining experimental data.

The following results are anticipated from the retrieval experiments:

- When the retrieval line is positioned below the tank midpoint, slurry homogeneity is not necessarily required to provide a homogeneous retrieval stream.

- When a variable height retrieval line is positioned near the top of the liquid, slurry homogeneity within the tank will be required to provide a homogeneous retrieval stream.

- Correspondence between slurry homogeneity within the tank and slurry homogeneity within the retrieval line will be developed.

- Depending whether slurry uniformity within the tank and slurry uniformity in the retrieval line are achieved, an acceptable prototype operating range may be recommended based on prototype configuration and operating conditions.

(a) This document is a strategy plan. The results presented in Section 2.2 Recommendations are those predicted analytically prior to conducting the actual experiments. 


\subsection{REVIEW OF MIXING LITERATURE}

Maintaining a solid suspension in a slurry in a vessel requires some degree of agitation. Current plans call for the use of jet mixer pumps to mix and resuspend undissolved solids in the double-shell tanks. The background information describing slurry suspension is presented in five sections: 1) the mixing of liquid/liquid mixtures (Section 3.1),2) the dimensional analysis of factors that affect waste uniformity in the tanks (Section 3.2), 3) review of double-shell tank waste physical property data (Section 3.3), 4) review of experimental data (Section 3.4), and 5) the TEMPEST (Trent and Eyler 1989) computer code, used to model waste mixing in the tanks.

\subsection{MIXING OF LIQUID/LIQUID MIXTURES}

When two miscible fluids, such as fresh water and saltwater, are placed in a tank, the concentration of a particular constituent, such as salt, will vary spatially. Stirring the liquids will reduce the differences in concentration until the concentration in all parts of the tank approaches some constant level. The time required to reduce the maximum concentration differences to some arbitrarily defined level depends on the flow pattern induced by the stirrer. The required time is also affected by the velocity at which the waste in the tank is stirred, the tank geometry, and the fluid properties.

Stirring in a vessel may be accomplished in a variety of ways. Mechanical agitators are the most common industrial means of stirring two fluids. However, stirring may also be accomplished by injecting high velocity fluid into the vessel using a jet mixer. Literature describing the factors affecting mechanical mixing is much more common than that describing jet mixing because the former has more widespread application in industry. Much of the terminology used to describe mixing using mechanical agitators is commonly associated with jet mixing. An important quantity that is defined in the mixing literature is the "mixing time" ( $\mathrm{Tm})$, which is defined as the time required for an inhomogeneity introduced into a tank to be destroyed. Most authors use this term to describe mixing that occurs after a steady-state flow pattern has been achieved; it will be used in this sense here. 


\subsubsection{Parameters That Affect Mixing in Mechanically Agitated Systems}

The major purpose to be achieved during the mixing problem studied here is to achieve and maintain a uniform degree of mixing. Mixing time is expected to relate to both problems. Mixing time describes how quickly a portion of the tank in which slurry concentration differs from the average concentration in the tank can be mixed to return to the average tank concentration. Mixing time relates directly to the period required to go from an unsteady distribution in the tank to the final steady-state distribution and gives an indication of how much time is required to achieve the uitimate degree of uniformity. Mixing time is also expected to be related to the level of mixing achieved. During solids mixing, there will be a balance between the rate at which solids settle and create regions of excess concentration and the rate at which batches of concentrated fluid can be mixed with the rest of the tank. When the time required to mix nonuniform regions is large compared to the time during which these periods form, large degrees of nonuniformity are expected to exist in the tank. In contrast, when the mixing time is small compared to the time required for nonuniformity to be achieved, small degrees of nonuniformity are achieved. Factors that are known to affect mixing time in miscible fluids will be discussed here.

The mixing time required to reduce waste inhomogeneities in the tank using mechanical agitators has been experimentally determined in a number of studies, including those by Van de Vusse (1962), Kramers et. a1. (1953), Norwood and Metzner (1960), Marr (1959), and Fox and Gex (1956). Most studies focused on the time required to reduce concentration differences in a tank to some arbitrarily small value. This time is referred to as the mixing time and will be denoted by $T_{m}$ in this discussion. The results of these experiments are consistent and illustrate that the dimensionless mixing time in a tank is strongly affected by the Reynolds number when flow is laminar, but that dimensionless mixing time is unaffected by the Reynolds number in the turbulent-flow region. The experiments also indicate that the densimetric Froude number, which is the ratio of kinetic energy to gravitational potential energy, is also found to be important; the Froude number appears in the correlations proposed by Van de Vusse (1962), Norwood and Metzner (1960), and Fox and Gex (1956). 
The dimensionless parameters governing mixing time in mechanically agitated vessels are expected to affect mixing achieved using jet mixers. Because the tolerances on the concentration differences vary from experiment to experiment, the predictions for mixing time must be compared on a qualitative rather than quantitative basis.

The dimensionless time used to correlate the data varies throughout the literature. Results here will be stated in terms of the following dimensionless time, which commonly appears in the literature:

$$
\theta=\frac{T_{m} Q}{V}
$$
where $Q=\underset{(L / T)}{\text { volumetric discharge rate for either an impeller or a jet mixer }}$

$$
\begin{aligned}
T_{m} & =\text { mixing time }(T) \\
V & =\text { tank volume }\left(L^{3}\right) \\
\theta & =\text { dimensionless mixing time. }
\end{aligned}
$$

Dimensionless mixing time is sometimes written in terms of the blade dimensions and rate of rotation as

$$
\theta=\frac{T_{m} N D^{2} b}{V}
$$

where $N=$ blade rotation rate $(1 / T)$

$D=b l$ ade diameter $(L)$

$b=b 7$ ade width $(L)$.

For a propeller, the blade width may be replaced by an equivalent propeller width, $p$. 
For jet mixing data, dimensionless mixing time may be expressed in terms of the velocity of the fluid leaving a jet as

$$
\theta=\left(\frac{T_{m} U_{0}}{H}\right)\left(\frac{D_{0}}{D_{t}}\right)^{2}
$$

where $U_{0}=$ jet exit velocity $(L / T)$

$$
\begin{aligned}
H & =\text { liquid height within the tank }(L) \\
D_{0} & =\text { jet nozzle diameter }(L) \\
D_{t} & =\text { tank diameter }(L) .
\end{aligned}
$$

Van de Vusse (1962) measured the time required to mix two liquids of different densities that were initially stratified in the tank. A correlation to predict the mixing time was developed using the following dimensionless parameters:

the impeller Reynolds number, $\mathrm{Re}_{\boldsymbol{i}}$

$$
\operatorname{Re}_{i}=\frac{\rho_{1} D^{2} N}{\mu}
$$

where $\mathrm{N}=$ impeller rotation rate $(1 / T)$

$$
\begin{aligned}
D & =\text { impeller blade diameter }(L) \\
\rho_{1} & =\text { density of mixed liquids }\left(M / L^{3}\right) \\
\mu & =\text { fluid viscosity }(M / L T) .
\end{aligned}
$$

and the densimetric Froude number, $F r_{d}$, based on the liquid height, $H$, and the density difference between the two fluids, $\Delta \rho$,

$$
F r_{d}=\frac{\rho_{1} N^{2} D^{2}}{\Delta \rho g H}
$$


where $\Delta \rho=$ the difference between the density of the two layers of liquids $\left(M / L^{3}\right)$

$$
g=\text { the acceleration caused by gravity }\left(L / T^{2}\right) \text {. }
$$

Typical results for mixing times obtained by Van de Vusse (1962) are displayed in Figure 3.1 .

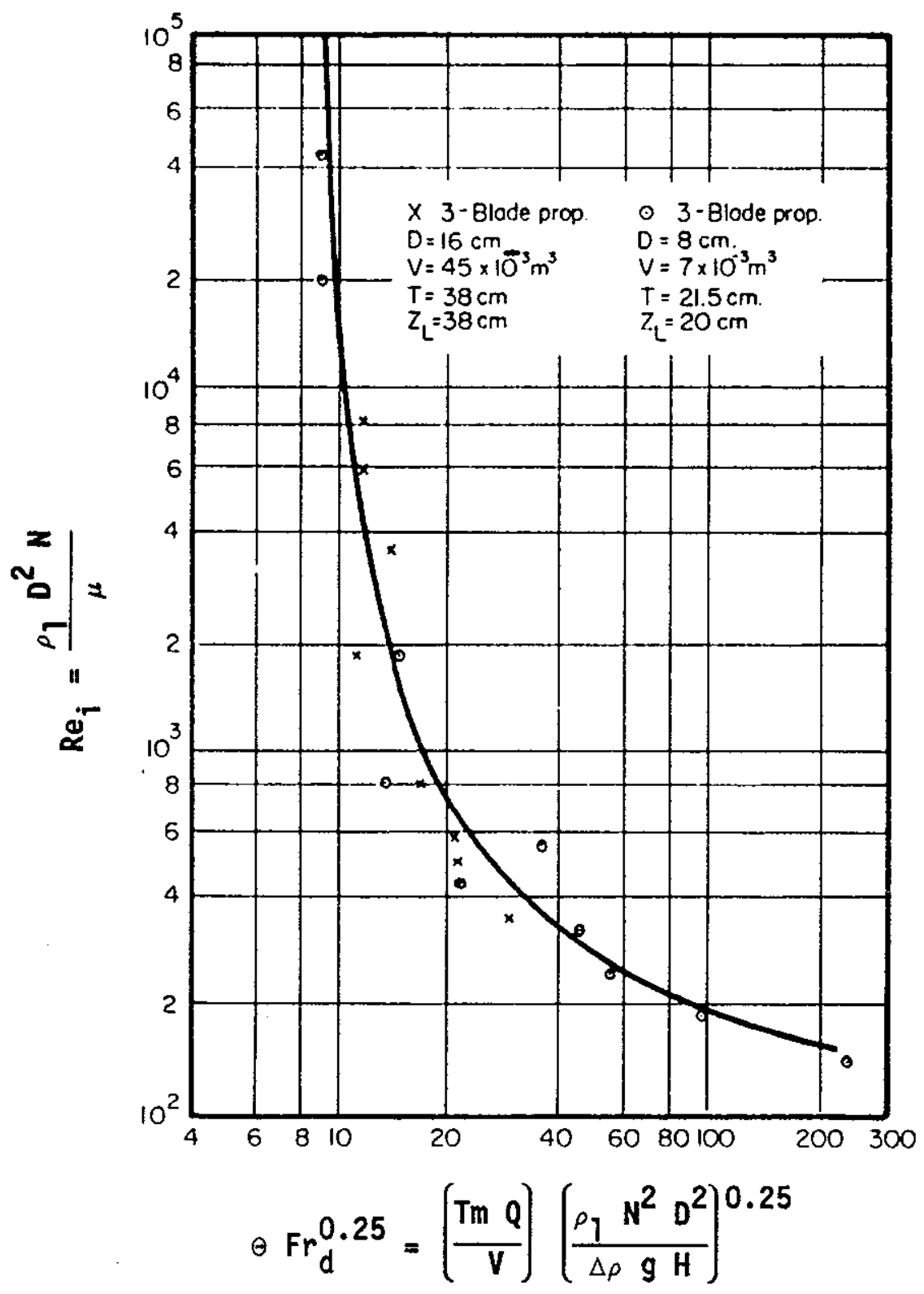

FIGURE 3.1. Correlation of Mixing Times for a Propeller in an Unbaffled Vessel (Van de Vusse 1955) 
Dimensionless mixing time decreases with increasing Reynolds numbers and decreases with densimetric Froude numbers. The impeller Reynolds number, $\mathrm{Re}_{\mathfrak{i}}$, can have a significant effect on the mixing time at low Reynolds numbers. However, this effect becomes less important at high Reynolds numbers. Van de Vusse (1962) suggested that the effect of the Reynolds number is negligible at impeller Reynolds numbers $\left(\operatorname{Re}_{j}\right)$ greater than 100,000 , where the dimensionless mixing time is a function of the Froude number only. Van de Vusse (1962) suggests that mixing time at Reynolds numbers greater than 100,000 may be predicted using the following equation.

$$
\theta=\frac{T_{m} Q}{V}=9 \mathrm{Fr}_{\mathrm{d}}
$$

Thus, at high Reynolds numbers, mixing time decreases monotonically with the densimetric Froude number. At low Reynolds numbers, both the Reynolds number and the densimetric Froude number affect dimensionless mixing time.

Norwood and Metzner (1960) studied mixing of constant density fluids in baffled vessels using turbine agitators. Each turbine had six flat blades where $b / D=1 / 5$. The correlation for mixing time obtained by Norwood and Metzner is displayed in Figure 3.2. A modified dimensionless mixing time, $\theta_{\mathfrak{m}}$, as defined by Norwood and Metzner and used in Figure 3.2, is

$$
\theta_{m}=\left(\frac{N T_{m} D^{2}}{D_{t}{ }^{2}}\right)\left(\frac{N^{2} D^{2}}{g H}\right)^{-1 / 6}\left(\frac{D}{H}\right)^{1 / 6}\left(\frac{D_{t}}{H}\right)^{1 / 2}
$$

This may be written as

$$
\theta_{m}=\theta(F r)^{-1 / 6}\left[\begin{array}{l}
H \\
\bar{b}
\end{array}\right) \cdot\left(\frac{D_{t}}{H}\right)^{1 / 2}\left(\frac{D}{H}\right)^{1 / 6}
$$




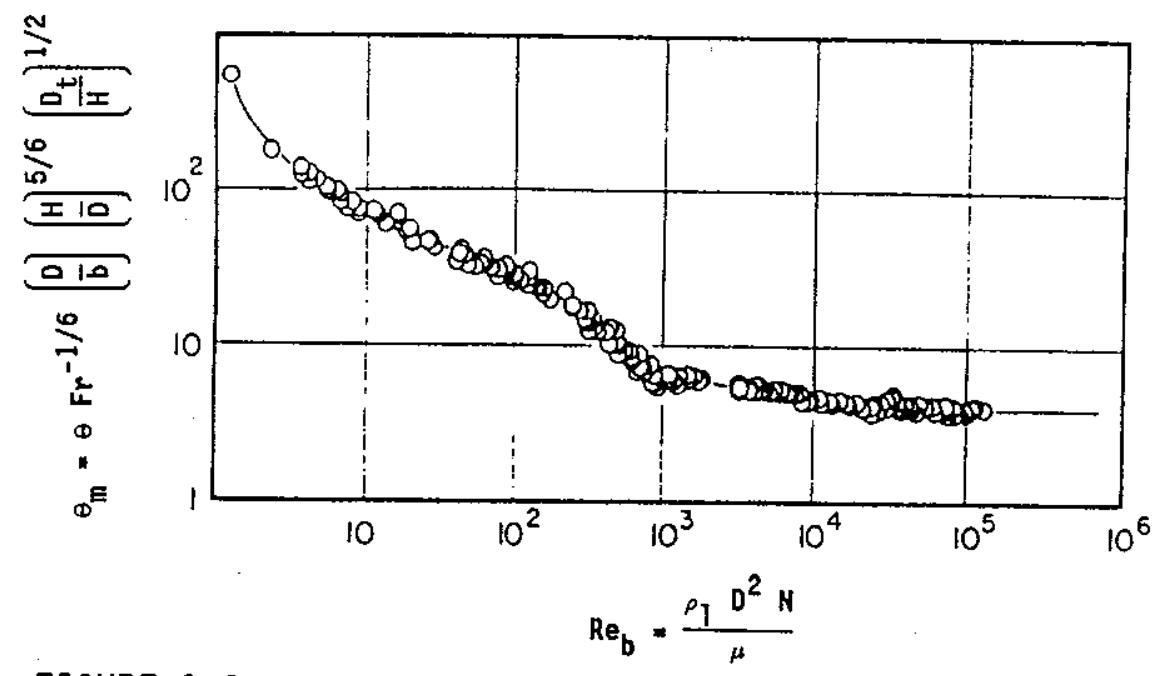

FIGURE 3.2. Correlation of Mixing Time for Turbines in Baffled Vessels (Norwood and Metzner 1960)

where the Froude number, $\mathrm{Fr}$, is defined as

$$
\mathrm{Fr}=\frac{(\mathrm{ND})^{2}}{\mathrm{gH}}
$$

Consequently, Norwood and Metzner's modified mixing time, $\theta_{m}$, is the procluct of the dimensionless mixing time defined in Equation (3.8), a Froude number, $\left[\mathrm{N}^{2} \mathrm{D}^{2} / \mathrm{g} \mathrm{H}\right]$, based on the depth of the tank contents, and aspect ratios describing the tank geometry.

Norwood and Metzner's modified mixing time, $\theta_{\mathrm{m}}$, decreases with increasing Reynolds number. Dimensionless mixing time, $\theta$, decreases with increasing Reyriolds numbers, increases with increasing Froude numbers, and is seen to vary' with Reynolds numbers below a blade Reynolds number $\left(\operatorname{Re}_{b}\right)$ of 1000 . The effect of the Reynolds number is unimportant above $R e=1000$. The graph presented by Norwood and Metzner (1960) suggests that at $\operatorname{Re}_{b}>10,000$, the mixing time, $\theta$, varies as

$$
\theta=N T_{m} \cdot\left(\frac{D}{D_{t}^{2}}\right)^{2}-F r^{1 / 6}
$$


Results similar to those found by Norwood and Metzner (1960) were reported by Fox and Gex (1956); Fox and Gex also report that the dimensionless mixing time in constant density fluids increases slightly with the Froude number. In contrast, Van de Vusse (1962) reports that dimensionless mixing time decreases with the densimetric Froude numbers. The differences between the results reported by Norwood and Metzner (1960) and those reported by Van de Vusse (1962) may be largely a function of the density differences in the fluid. Van de Vusse studied the mixing of fluids with different densities, while both Fox and Gex (1956) and Norwood and Metzner (1960) studied the mixing of fluids with identical densities. The results of Van de Vusse suggest that when density gradients are present, mixing time decreases with an increasing densimetric Froude number.

In all cases reported, increasing blade speed decreases dimensionless mixing time. However, Van de Vusse's (1962) results suggest that in a given tank increasing blade speed by a factor of $N$ will reduce mixing time by a factor of $N^{3 / 2}$. The results of Norwood and Metzner (1960) suggest that a comparable increase in the blade speed will decrease mixing times by a factor of $\mathrm{N}^{2 / 3}$.

The effect of both the Froude number and Reynolds number can be justified physically. The Froude number describes the offsetting tendency of jet buoyancy and kinetic energy on the mixing achieved in a vessel and is consistently found to affect the mixing time in agitated vessels. However, the quantitative effect of varying the Froude number appears to depend on the density difference between the fluids. When the mixing jet is more dense than the surrounding fluid, dimensionless mixing time decreases with an increasing densimetric Froude number $\left(F r_{d}\right)$. Where the jet is neutrally buoyant, the mixing time increases with an increasing Froude number.

The Reynolds number describes the degree of turbulence achieved in the tank. The effect of the Reynolds number on the mixing time in the tanks is discussed qualitatively by Dickey and Fenic (1976) and illustrated in

Figure 3.3. At low Reynolds numbers, viscosity has a significant influence on the flow field in the tank, and flow is laminar. Mixing time in agitated vessels is found to vary inversely with the rate of agitator rotation so the 


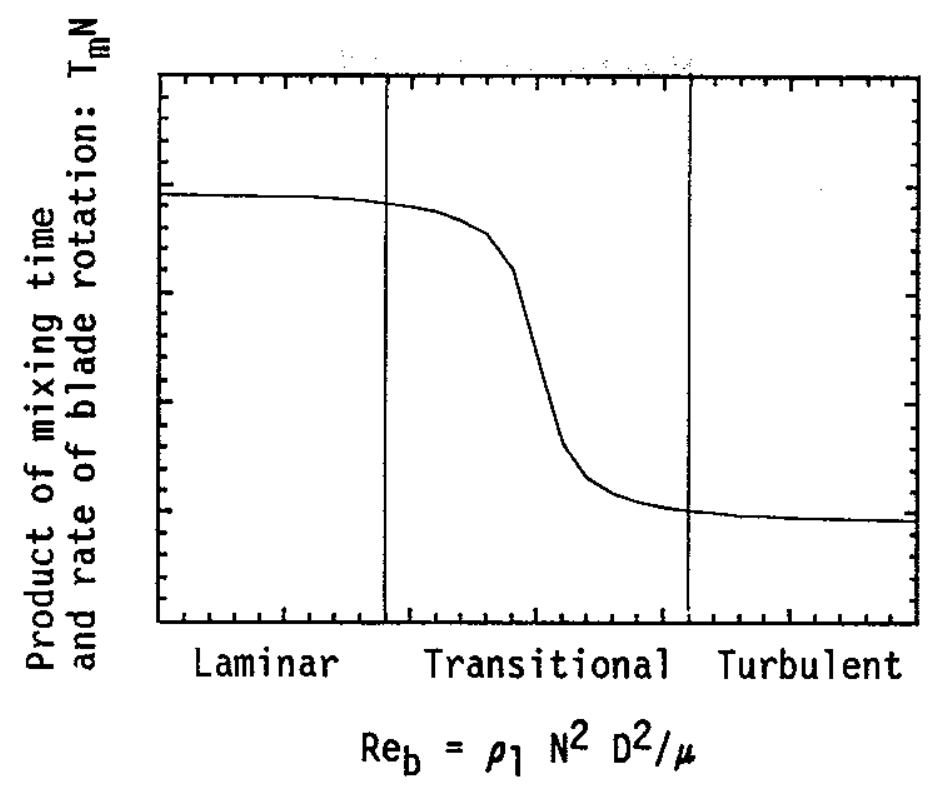

FIGURE 3.3. Correlation of Dimensionless Blend Time Versus Reynolds Number (Dickey and Fenic 1976)

procluct of mixing time and rate of rotation is a constant in the laminar region of Figure 3.3. As the Reynolds number increases, the flow becomes turbulent, and mixing times diminish more rapidly. When flow is fully turbulent, mixing time is once again directly proportional to the rate of rotation of the agitator vane, but the proportionality constant in the turbulent region is much smaller than that in the laminar region. This decrease in proportionality constant leads to much smaller mixing times in the turbulent region, and should lead to more efficient mixing.

The combination of the transitional and turbulent regions described by Dickey and Fenic appear qualitatively similar to the data obtained by Norwood and Metzner (1960) and that of Fox and Gex (1956). However, their discussions do not include tank geometry effects or Froude number effects. In addition, Dickey and Fenic's discussion does not suggest numerical values for the transitional Reynolds number. It is also worth noting the low Reynolds number region in Figure 3.3 in which mixing time is unaffected by Reynolds number. Although this region is described by Dickey and Fenic (1976), the region does not appear in any of the experimental results reported by Norwood and Metzner (1960), Fox and Gex (1956), or Van de Vusse (1962). In their results, Reynolds number affects mixing time even in the laminar region. 
In mechanically agitated systems, the transition from laminar flow to turbulent flow depends on the blade Reynolds number $\left(\operatorname{Re}_{b}\right)$. Dickey and Fenic (1976) suggest that fully laminar flow occurs below $\operatorname{Re}_{b}=20$, while fully turbulent flow occurs above $\operatorname{Re}_{b}=10,000$. The exact location of the transition depends on the vessel geometry and blade type and cannot be predicted with precision. In the results reported by Fox and Gex (1956), there is a transition in the mixing behavior attributed to transition from laminar flow to turbulent flow at a Reynolds number $\left(\operatorname{Re}_{b}\right)$ near 10,000 . The data of Norwood and Metzner (1960) illustrate a change in the mixing behavior near a Reynolds number $\left(\operatorname{Re}_{b}\right)$ of 1200 . Because the critical Reynolds number $\left(R_{c}\right)$ for transition from laminar flow to turbulent flow varies widely in mechanically agitated vessels, it might vary in jet mixing as well. However, it is possible that the critical Reynolds number will be more constant in jet mixing because the variations seen in propeller mixing may be caused by propellor geometry.

The effect of liquid depth on mixing patterns in propeller-stirred vessels was studied by Marr and Johnson (1963). The aspect ratio of the tank was found to have a distinct effect on the flow pattern in the tank and hence mixing. Shallow tanks were found to exhibit a downward flow below the propellers and a recirculating upward flow near the tank walls. Tall tanks exhibited two recirculating zones, one in the lower and one in the upper portion of the tank. The aspect ratio at which the recirculating region first occurs appears to be affected somewhat by the ratio of the propeller to tank diameters. Typical flow patterns are displayed in Figure 3.4.

The existence of qualitatively dissimilar flow patterns was found to have an effect on mixing time. The aspect ratio at which the upper recirculating zone first appeared was observed to be correlated with breaks in the correlation-predicted mixing time.

The qualitative change in the fluid circulation pattern observed by Marr and Johnson is significant in terms of selecting an appropriate prototype design; it suggests that tank geometry can have an important influence on flow patterns, which, in turn, affect mixing times. Consequently, geometric similarity appears to be important when performing scaled mixing experiments in tanks. 


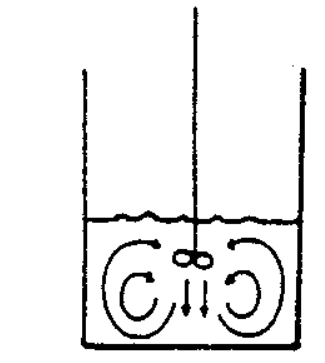

SMALL PROPELLER IN TANK WTH LOW HOLDUP

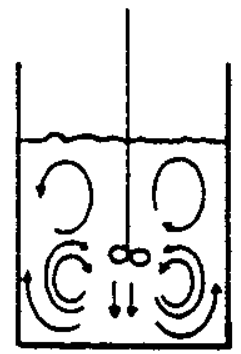

INTERMEOIATE HOLOUP

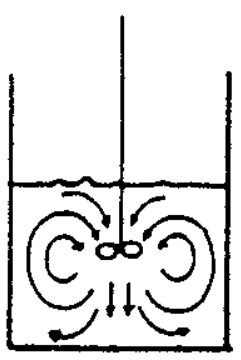

SMALL PROPELLER IN TANK WITH INTERMEDIATE HOLDUP

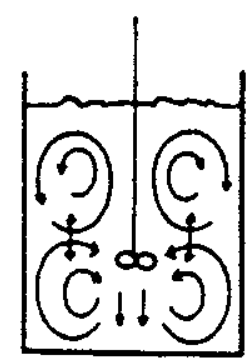

EXCESSIVE HOLOUP

FIGURE 3.4. Flow Patterns in Propeller-Stirred Vessels (Uht and Gray 1966)

Thus the Froude number, Reynolds number, and tank geometry a11 appear to affect mixing behavior significantly. If possible, all three should be matched when performing scaled tests to study mixing behavior in tanks.

\subsubsection{Jet Mixing of Liquid/Liquid and Single-Phase Fluids}

Studies of fluid mixing using jet mixing pumps have been performed by Fox and Gex (1956) and Fosset and Prosser (1951). Both experiments reported on factiors affecting the mixing time in vessels.

The time required to mix a constant density fluid injected with a jet mixe:r was studied by Fox and Gex (1956). The specific jet mixer design was not described. Tests were performed using $0.30-\mathrm{m}(1-\mathrm{ft})$ and $1.5-\mathrm{m}(5-\mathrm{ft})$ diameter tanks; one case was performed using a 4.3-m (14-ft) diameter tank. Jet Reynolds numbers $\left(\operatorname{Re}_{j}\right)$ ranged between 200 and 100,000. 
Fox and Gex (1956) report that dimensionless mixing time was influenced by jet Reynolds number $\left(\operatorname{Re}_{j}\right)$. At a jet Reynolds number less than 2000 , flow was laminar, and mixing time was predicted using the relation

$$
\theta=\frac{T_{m} U_{0} D_{0}^{2}}{H D_{t}^{2}} \sim\left(\frac{F r}{R e_{j}^{8}}\right]^{1 / 6}\left(\frac{D_{0}}{D_{t}}\right)^{4 / 3}\left(\frac{D_{t}}{H}\right)^{1 / 3}
$$

where jet Reynolds number $\left(R_{j}\right)$ was defined as

$$
\operatorname{Re}_{j}=\frac{\rho U_{0} D_{0}}{\mu}
$$

At jet Reynolds numbers greater than 2000 , flow was turbulent and mixing time obeyed the relation

$$
\theta=\frac{T_{m} U_{0} D_{0}^{2}}{H D_{t}^{2}}-\left(\frac{F r}{R e}\right)^{1 / 6}\left(\frac{D_{0}}{D_{t}}\right)^{4 / 3}\left(\frac{D_{t}}{H}\right)^{1 / 3}
$$

The Froude number was found to affect the mixing time in both the laminar and turbulent flow regimes. The results obtained by Fox and Gex (1956) are illustrated graphically in Figure 3.5. Fox and Gex report that the jet location had no measurable effect on mixing time. Details of experiments where jet location was varied were not reported.

The results obtained by Fox and Gex (1956) are qualitatively similar to the results found for mixing using mechanical agitators. Once again, the Reynolds number is seen to have an important influence at low Reynolds numbers; the effect is small but non-negligible at the higher Reynolds numbers. In addition, the dimensionless mixing time for fluids with no differences in density was found to increase with an increasing Froude number (Fox and Gex 1956). This finding is similar to the results reported by Norwood and Metzner (1960) using mechanical agitators. 


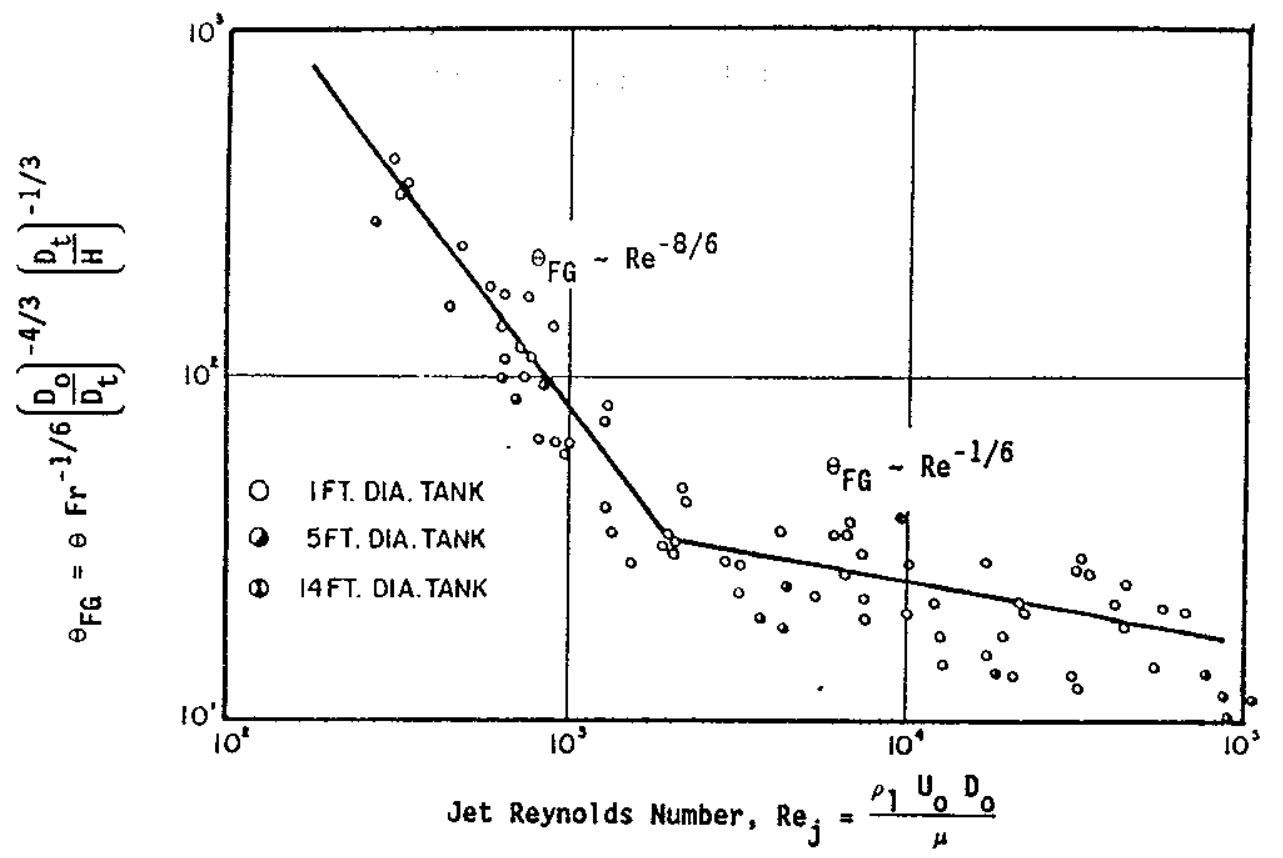

FIGURE 3.5. Jet Mixing of Liquids in Vessels (Fox and Gex 1956)

Fox and Gex (1956) report qualitatively similar results using propellers to achieve mixing. The primary difference between the two cases was in the magnitude of the transitional Reynolds number. A sharp transition in the mixing time correlation was observed at a Reynolds number $\left(\operatorname{Re}_{j}\right)$ of 2000 when mixing was achieved using jet mixers, while turbulent behavior was observed at $\mathrm{Re}_{\mathrm{p}}$ of 10,000 when mixing was achieved using propellers. This sharp transition was attributed to the onset of turbulent motion in the tank and suggests that turbulence occurs at lower Reynolds numbers using jet mixers than when using propeller mixers. However, specific features of the jet mixer and tank design could affect the transition from laminar flow to turbulent flow in different regions of the tank, consequently, it is not certain that the Reynolds number, at which there is a sharp transition in mixing behavior, would occur at $\mathrm{Re}=2000$ in all jet mixer designs.

It is not surprising that the jet Reynolds number has a strong influence on mixing behavior. The jet Reynolds number has been observed to have a strong effect on the characteristics of a free jet. Free jets have been observed to be turbulent at Reynolds numbers above $\operatorname{Re}=1500$; viscosity is expected to prevent jet turbulence at lower Reynolds numbers (Albertson et al. 
1950). At much greater Reynolds numbers, the characteristics of the jet are expected to be independent of the Reynolds number; at this point, the jets are referred to as "fully turbulent", and the fluid profiles are expected to be similar to one another. It is likely that the transition in the mixing behavior observed by Fox and Gex is related to the initial transition from laminar flow to turbulent flow of the jet because it occurs at a jet Reynolds number near the transition to turbulence.

Jet mixing in large tanks was studied by Fosset and Prosser (1951). Measurements were performed using 25 different tanks with diameters between $4.6 \mathrm{~m}(15 \mathrm{ft})$ and $44 \mathrm{~m}(144 \mathrm{ft})$. Tank heights ranged from $4.6 \mathrm{~m}(15 \mathrm{ft})$ to $11 \mathrm{~m}(35 \mathrm{ft})$. An aqueous solution of sodium carbonate $\left(\mathrm{NaCO}_{3}\right)$ with a density greater than that of water was injected into the tank. The time required to mix a high-density fluid introduced into the tank using the jet mixer was determined by measuring the electrical conductivity of the solution in the tank.

The initial experimental study reported by Fosset and Prosser was designed to study the effect of the Reynolds number on the mixing time; 15 cases were measured. However, dimensionless mixing time was found to be independent of the Reynolds number. The major finding of the initial study was that mixing behavior was strongly influenced by gravitational factors, and that the densimetric Froude number, $\mathrm{Fr}_{\mathrm{d}}$, was the most important parameter affecting dimensionless mixing times.

A second study was designed to report the effect of the densimetric Froude number on jet motion. Fosset defines a modified densimetric Froude number as

$$
F r_{d m}=\frac{\rho U_{0}^{2} \sin ^{2}\left(\phi+5^{\circ}\right)}{\Delta \rho g H}
$$

where $\phi=$ inclination of the jet from the horizontal plane (degrees) (e.g., $\phi=0^{\circ}$ for a horizontal jet).

At low densimetric Froude numbers, the jet was unable to rise to the top of the tank, and the fluid in the tank stratified. The number of jet diameters 
that the jet rises as a function of the density ratio and the modified Froude number $\left(\mathrm{Fr}_{\mathrm{dm}}\right)$ is plotted in Figure 3.6 from Fossett and Prosser (1951). At low Froude numbers, the jet is seen to rise only a few jet diameters above the injection point.

The tank Froude number achieved during resuspension in the prototype cannot be known a priori because the density of the fluid emitted from the jet depends on the degree of mixing achieved in the tank. However, the Froude number may be estimated by assuming some value for the relative density of the mixture emitted by the jet. Slurry near the jet inlet located in the lower reglon of the tank might be expected to be slightly more concentrated than in the upper regions. Consequently, the jet fluid may be slightly more dense than the surrounding fluid. Because the jet will be taking up liquid from the

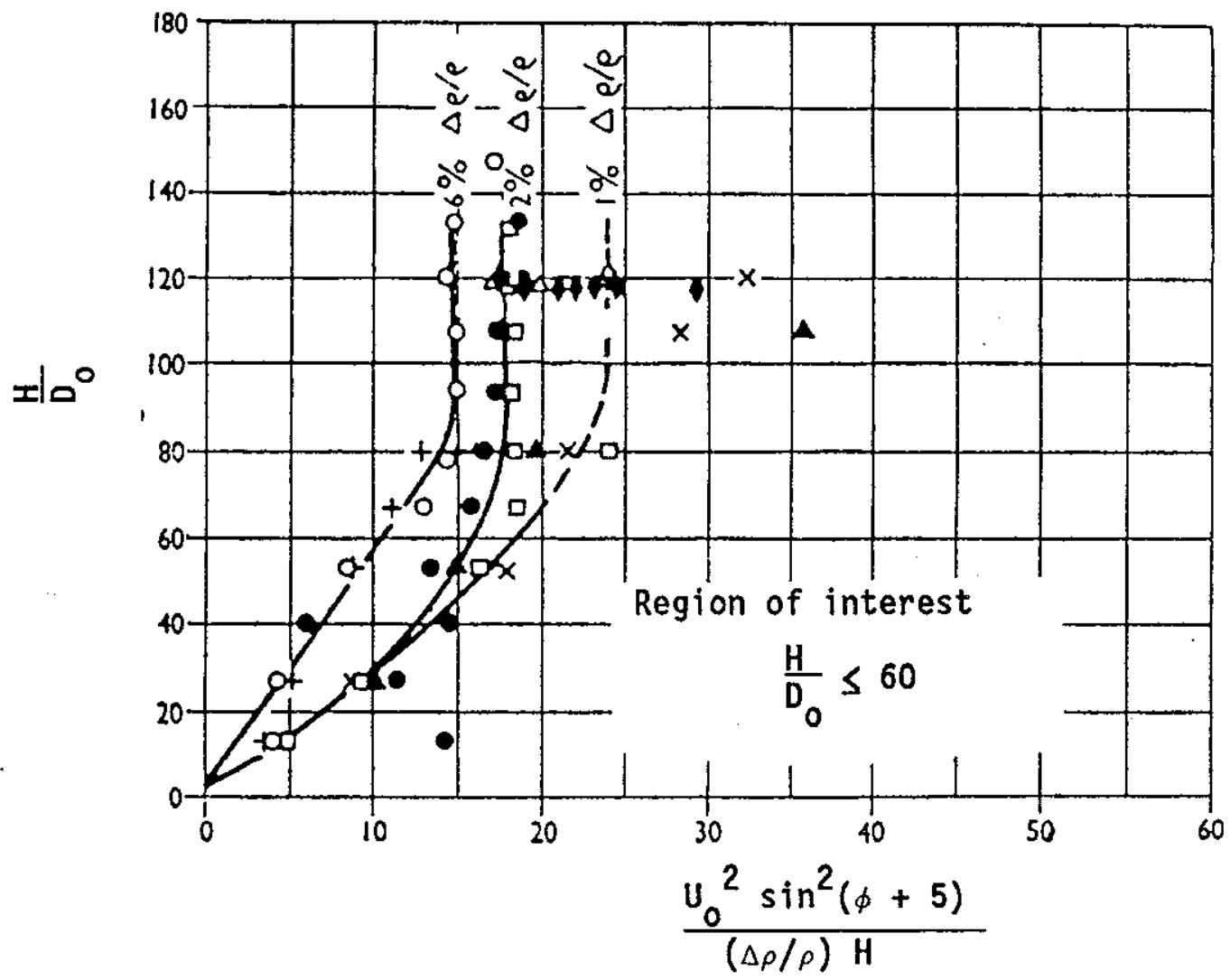

FIGURE 3.6. Effect of Liquid Density Difference on Jet Velocity for Mixing Liquids (Fosset and Prosser 1951) 
lower region of the tank, it is possible that the jet fluid density will exceed the mean fluid density. Assuming that the jet density exceeds the tank mixture density by $1 \%$, stratification in a $9.1-\mathrm{m}$-high (30-ft-high) tank using a $0.15-m$ (6-in.) diameter nozzle will occur if the jet is unable to rise at least 60 nozzle diameters. Fosset and Prosser's results indicate that a densimetric Froude number of 17 is required to allow a free horizontal jet with an excess density of $1 \%$ to rise to this leve1. A Froude number of 17 could be achieved by injecting fluid at $64.6 \mathrm{~m} / \mathrm{s}(212 \mathrm{ft} / \mathrm{s})$, which is significantly greater in magnitude than the current design velocity of $18 \mathrm{~m} / \mathrm{s}$ $(59 \mathrm{ft} / \mathrm{s})$ based on a $U_{0} D_{0}$ of $2.73 \mathrm{~m}^{2} / \mathrm{s}\left(29.4 \mathrm{ft}^{2} / \mathrm{s}\right)$. Impact of the jet stream with the wall is expected to increase the distance a jet can rise in the tank; however, calculations based on Fosset and Prosser's results suggest that the effect of density on the jet motion could be important especially if $\Delta \rho / \rho$ is large.

Preliminary experiments to mix tank waste were performed in double-shell tank No. 241-AP-102. In this experiment, limestone was added to a solution of sodium hydroxide in water and used as a slurry simulant. The bulk solids loading that would have been achieved in this experiment if all solids had been suspended was $1.2 \%$ by weight. (a) Analysis indicated that approximately $10 \%$ of these solids were suspended in the tank during operation, (b) thus on average the slurry contained approximately $0.1 \%$ solids by weight. None of the reported concentration measurements exceeded $0.2 \%$ solids by weight. Based on these measurements, it is estimated that the jet density never exceeded the fluid density by more than $0.2 \%$ during this test. Because uniform mixing appears to have been achieved away from the settled limestone bed, it is likely that the jet was neutrally buoyant; therefore, the jet would be expected to travel to the top of the tank, as was observed in the test in tank No. 241-AP-102. Thus, the test results from tank No. 241-AP-102 do not contradict the findings of Fosset and Prosser because the solids concentration in tank No. 241-AP-102 was not large enough to affect the mean jet density.

\footnotetext{
(a) Analytical data for double-shell tank No. 241-AP-102 samples taken from October 19 through 24, 1987.

(b) Operability test report for the in-tank mixer pump.
} 


\subsubsection{Summary of Factors Affecting Mixing in Liquid/Liquid and Single-Phase}

Dimensionless mixing time in liquid/liquid and single-phase fluids is found to be affected by the Reynolds number, Froude number, and by the aspect ratios describing the tank geometry. The dimensionless parameters found to affect mixing using either of the jet mixers or mechanical agitators were similar to one another. The primary difference between the mixing time achieved using jet mixers and the level of mixing achieved using agitators was that: the transition to turbulence occurred at a lower Reynolds number when jet mixers were used. All dimensionless parameters that affect mixing of singlephase fluids were expected to affect solids suspension in solid/liquid mixing. In addition, the dimensionless parameters that affect solids suspension using mechanical agitators are expected to be identical to those that affect solids suspension using jet mixers.

\subsubsection{Mixing in Solid/Liquid Suspensions}

Neither the Froude number nor the Reynolds number fully characterize the problem posed by the need to maintain suspension of solids. Suspension of solids in an agitated vessel is a complex phenomenon, particularly when the fluid motion is turbulent. The motion of individual particles, and consequeritly the degree of suspension in the vessel, is affected by the fluid motion, the ability of the particles to respond to fluid motions, and by the relative importance of gravitational effects. Unfortunately, the dimensionless parameters governing the suspension of solids are not well understood. However, some understanding of the factors affecting solids suspension may be achieved by examining the types of suspension maintainable.

Different degrees of solids suspension may be maintained using either jet mixers or mechanical agitators. A scale of agitation is defined by Gates, Morton, and Fondy (1976) as the level of motion required to maintain a particular degree of suspension in a tank. Scale levels 1 and 2 are defined as motions that are sufficient to produce some movement of all solids in the tank. However, motion is not sufficient to lead to suspension; moving fillets of solids may form on the tank bottom. Agitation at this scale is illustrated 
in Figure 3.7a. Scale levels 3 through 5 are sufficient to suspend all particles off the tank bottom, and to provide uniformity in the lower onethird of the tank. This type of suspension is illustrated in Figure $3.7 \mathrm{~b}$. Finally, scale levels 6 through 10 represent uniform suspensions in which the tank contents are not stratified. A scale of 6 .ensures concentration uniformity of $95 \%$ throughout the tank, while an agitation scale of 10 ensures concentration uniformity of $98 \%$.

The degree of concentration uniformity that must be achieved in the tank to ensure that the difference in mixture density at the top and bottom of the tank varies by less than $1 \%$ can be obtained by evaluating the relation:

$$
\frac{\Delta \phi}{\phi}=\frac{\Delta \rho_{\mathrm{b}}[(s-1) \phi-1]}{\rho_{\mathrm{b}}[s-1] \phi}
$$

where $\phi=$ mean volume concentration of solids in the mixture

$\Delta \phi=$ variation in volume concentration of solids in the mixture from tank top to bottom
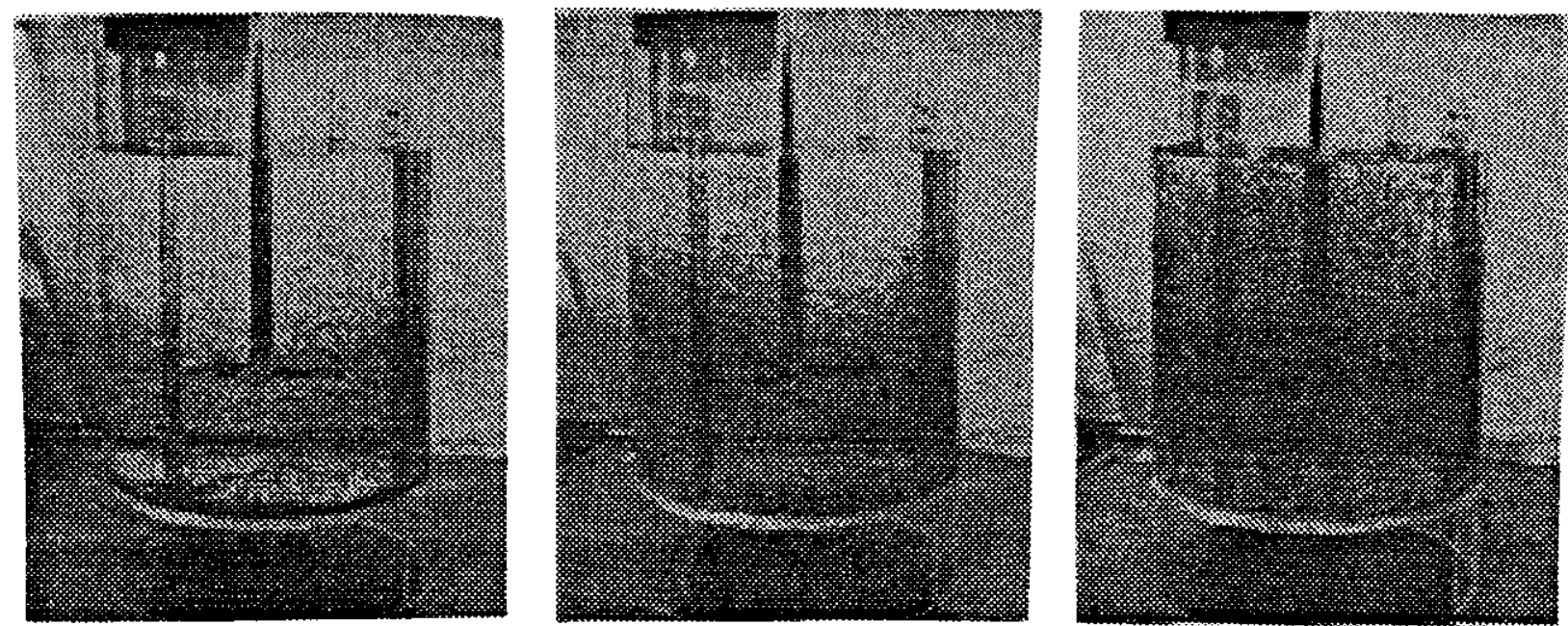

a) Scale of agitation $=1$ b) Scale of agitation $=3$ c) Scale of agitation $=9$

FIGURE 3.7. Intensity of Agitation a) Unstable Fillets are on Vessel Bottom, b) Particles Swept off of Vessel Bottom, c) Solids are Homogeneously Distributed (Gates, Morton, and Fondy 1976) 
$s=$ ratio of solids density to liquid density $\left(\rho_{S} / \rho_{1}\right)$

$\rho_{b}=$ mean mixture density $\left(M / L^{3}\right)$

$\Delta \rho_{\mathrm{b}}=$ variation in mixture density from tank top to bottom $\left(M / \mathrm{L}^{3}\right)$.

Thus, if the mean solids concentration is $15 \%$ and the ratio of the solids to liquid density is 2.5 and if the nonuniformity in solids concentration must be 1 imited to $94 \%$, then it is necessary to 1 imit the differences in mixture density to $1 \%$. This could be maintained with a "scale of agitation" of 6 .

The physical mechanisms involved in achieving the degree of uniformity shown Figure 3.7 are discussed briefly by Gates, Morton, and Fondy (1976). They note that in the two stratified cases, the particles are set in motion by large-scale fluid motions only. More uniform mixing requires a greater degree of small-scale motion, which is expected only when the tank motion is turbiulent.

A method for predicting the degree of agitation required to produce a particular scale of mixing using mechanical agitators is described in Gates, Morton, and Fondy (1976). Unfortunately, the design method is dimensionally inhomogeneous; this inhomogeneity is certain to introduce difficulties caused by scale-up. In addition, the dimensional inhomogeneity renders application to jet mixing impossible, even in a qualitative sense. However, the design method suggested by Gates, Morton, and Fondy indicates that the particle settling velocity is the critical physical parameter dictating the degree of suspension attained in a solids suspension design, and that other parameters such as particle diameter, particle Reynolds number, and solids density affect the resuspension problem only through their influence on the particle settling velocity.

\subsection{DIMENSIONAL ANALYSIS OF FACTORS AFFECTING SLURRY UNIFORMITY}

The physical processes governing slurry mixing in tanks complex and do not lend themselves readily to exact analytical treatment. As a result, accurate predictions of prototype behavior require some degree of experimentation. Dimensional analysis is an important analytical tool that can be used to reduce the number of experiments required and also used to provide a basis for the interpretation and presentation of the experimental 
results. This section will begin with a general discussion of similarity. Dimensional analysis will then be used to obtain a set of dimensionless numbers that characterize the steady-state slurry mixing problem. The time required to achieve steady-state will be considered at the end of this section.

The concept of similarity underlies much of the experimental work in the field of fluid mechanics; use of similarity allows information obtained in one set of experiments to be used to predict behavior under apparently different conditions, provided that the conditions are similar in terms of important geometric, dynamic, and kinematic features. Thus, for example, mixing behavior in a prototype can be predicted on the basis of similar scaled experiments in a model of the prototype.

Methods to determine the requirements to ensure similarity between scaled experiments and prototypes exist, and may be applied to any problem. All methods involve the use of dimensional analysis, which produces a set of dimensionless parameters that may be used to characterize the physical process. Because the dimensionless parameters produced using dimensional analysis are not unique, physical understanding of the process under consideration must be used to select physically meaningful dimensionless parameters.

The first requirement for similarity between a scaled experiment and the prototype is that of geometric similarity. Geometric similarity exists when all points on the scaled model have a one-to-one correspondence to points in the prototype. For example, geometric similarity requires that both the prototype and the scale model tank have identical shapes. That is, if the prototype tank is a cylindrical tank with a particular aspect ratio, the scaled tank must also be cylindrical and have the same aspect ratio. In addition, complete similarity requires that all components (e.g., the pump, the air-lift circulators, and other tank components) in the two tanks be located in the same relative positions. If these requirements are not met, the prototype and experiment will not be geometrically similar. The importance of maintaining geometric similarity is not known a priori. 
Exact similarity between the model and the prototype also requires that the kinematic conditions and dynamic processes in the tank be identical. Kinematic similarity requires all fluid streamlines and particle pathlines to have a one-to-one correspondence in the prototype and model. Dynamic similarity requires that all external and internal forces applied to the model correspond to forces applied to the prototype. In addition, these forces must be properly scaled. This task appears daunting because fluid streamlines and particle pathlines and some of the internal forces are dependent parameters. Fortunately, imposing similarity on all independent parameters ensures similarity of all dependent parameters.

In practice, kinematic and dynamic similarity of geometrically similar flows may be ensured by the use of dimensional analysis, which requires listing all the relevant dimensional parameters that are important to the problem. In the steady-state problem, the relevant dimensional parameters are thought to be:

- Geometric parameters

$$
\begin{aligned}
D_{0} & =\text { jet nozzle diameter }(L) \\
D_{t} & =\text { tank diameter }(L) \\
E & =\text { elevation of nozzle centerline from tank floor }(L) \\
H & =\text { liquid height in tank }(L) \\
N & =\text { rate of rotation of jet }(1 / T) .
\end{aligned}
$$

- Slurry and particle properties

$$
\begin{aligned}
C= & \text { slurry mean weight } \% \text { solids concentration } \\
\Delta C= & \text { difference in weight \% solids concentration in two } \\
& \text { specified locations in the tank. (This is the dependent } \\
& \text { variable of interest.) } \\
\mu_{b}= & \text { slurry viscosity }(\mathrm{M} / \mathrm{LT}) \\
\rho_{\mathrm{b}}= & \text { slurry bulk density }\left(\mathrm{M} / \mathrm{L}^{3}\right) \\
\rho_{\mathrm{S}}= & \text { particle (solids) density }\left(\mathrm{M} / \mathrm{L}^{3}\right) .
\end{aligned}
$$

- Dynamic properties

$$
\begin{aligned}
g & =\text { acceleration caused by gravity }\left(L / T^{2}\right) \\
U_{0} & =\text { jet exit velocity }(L / T) \\
U_{S} & =\text { particle unhindered settling velocity }(L / T) .
\end{aligned}
$$


Judgement was exercised in the selection of these properties: first is the decision not to include the surface tension of the slurry because surface tension effects are expected to be small; second is the selection of the particle settling velocity $\left(U_{S}\right)$ rather than the particle diameter (d). In a sense, there is no difference between choosing settling velocity or particle diameter because it may be shown that for given values of the slurry and solids densities, slurry viscosity, and acceleration caused by gravity, the particle settling velocity and diameter are not independent parameters. Rather, specifying the diameter automatically determines the settling velocity, and vice versa. However, selection of particle settling velocity produces more physically meaningful dimensionless groups.

Other physical features of interest that might have been incorporated into a dimensional model for resuspension include

- jet expansion angle

- hindered particle settling velocity

- fluid turbulent kinetic energy at any location in the tank.

The magnitude of each of these parameters can be shown to be dependent on the 11 independent parameters selected for use in the dimensional analysis to be performed. For example, fluid turbulent kinetic energy in a single-phase fluid is expected to be a strong function of the jet velocity and the jet Reynolds number. Particle concentration has been shown to increase critical Reynolds number for transition to turbulence in slurry flows as well as the absolute turbulence intensity in turbulent slurry flows (Gore and Crowe 1990). Thus, in the slurry suspension problem, the absolute concentration of particles may also affect the turbulent kinetic energy. However, all three of these effects on the turbulent kinetic energy may be properly modeled in a scaled experiment by selecting appropriate values for the independent parameters described above.

The expansion angle of a free jet and the ability of a jet to entrain fluid both affect the mixing phenomena in the tank. Both of these quantities are dependent variables within the context of the suspension problem under consideration. 
Finally the actual, or hindered, settling velocity that will be achieved in the tank is expected to depend strongly on

- unhindered settling velocity

- degree of fluid turbulence

- volumetric concentration of particles in the slurry.

Becaluse the degree of fluid turbulence and volumetric concentration of particles will vary throughout the tank, the hindered particle settling velocity will not be constant everywhere in the tank. However, if a correctly scaled unhindered particle settling velocity is used for testing and the level of turbulence in the tank and slurry concentration are appropriately scaled, thell the hindered settling velocity is expected to be correctly scaled.

The Buckingham $\mathrm{Pi}$ theorem may be applied to show that the slurry unitormity mixing problem may be completely described using a set of 10 dimensionless parameters, which are often referred to as $\pi$ parameters. The set of $10 \pi$ parameters determined using dimensional analysis are not unique, mearing that there is more than one correct set of dimensional groups that may be used to describe the problem. The theory of similarity ensures that, no matter which set of 10 dimensionless groups incorporating all 13 of the dimensional parameters listed above is selected, if 9 of these 10 groups are matched in an experiment, then the tenth will automatically match. Thus, the goal is to obtain nine useful algebraically independent parameters that do not contain the dependent parameter $\Delta C$, and one dependent parameter that contains $\Delta C$.

The most trivial of the dimensionless parameters are the mean weight $\%$ solids concentration, $C$, and the difference in the solids concentration, $\Delta C$. These are already dimensionless. It is preferable to express the nonuniformity in the solids concentration, $\Delta C$, as a fraction of full-scale. Thus, the first $\pi$ group selected will be the dependent variable of interest to this problem.

$$
\pi_{1}=\frac{\Delta C}{C}
$$


The second $\pi$ group selected will be solids concentration

$$
\pi_{2}=\mathrm{C}
$$

The solids concentration has been shown to have an effect on the transition to turbulence and on the absolute level of turbulent kinetic energy in the flow of slurries through pipes (Gore and Crowe 1990). Consequently, the solids concentration is expected to affect transition to turbulence and the degree of fluid turbulence in other flows as well. Because the qualitative and quantitative effect of varying the solids concentration is not known, it is recommended that tests be performed at concentrations comparable to those that occur in the tank.

The next dimensionless parameters that will be obtained are a set of dimensionless parameters describing the tank geometry. While there appear to be numerous possible ratios of $D_{0}, D_{t}, E$, and $H$ that could be used to form dimensionless groups, it may be shown that there are exactly three linearly independent geometric parameters. Thus, it is sufficient to select three independent groups. The parameters chosen are:

$$
\begin{aligned}
& \pi_{3}=\mathrm{D}_{0} / \mathrm{H} \\
& \pi_{4}=\mathrm{D}_{\mathrm{t}} / \mathrm{H} \\
& \pi_{5}=\mathrm{E} / \mathrm{H}
\end{aligned}
$$

Clearly, alternate parameters such as $D_{0} / D_{t}$ or other combinations of $E$ with $D_{0}$ or $D_{t}$ could have been chosen. However, these parameters may be obtained by taking ratios of currently defined groups; thus, they are not linearly independent of the parameters selected. Thus, the fact that the parameters used to describe the geometry are not unique (in the sense that different sets could be chosen) has no real significance.

Geometric similarity requires that $\pi_{3}, \pi_{4}$, and $\pi_{5}$ in the scaled model match the values in the prototype. In addition, the entire tank must be a scaled model of the prototype. This means that a number of other geometric 
ratios must also match in the scaled model and the prototype. These include, for example, any geometric ratios describing the placement of the tank components such as air-lift circulators, radiation dry wells, the steam coil and others, and the ratio of the distance between the nozzle exit and the flocir.

There are currently four different tank designs; these tanks contain from one to four pumps. It is expected that the mixing behavior will be governed by similar dynamic dimensionless parameters in all cases; however, different correlations will be required to predict mixing in the various tanks. That is to say, a scaled experiment in a model tank that matches the one-pump geometry prototype is expected to predict mixing in the one-pump prototype only; however, the important dimensionless parameters describing the dynamics of mixing are expected to be similar in all tanks.

The ratio of the two densities will be selected as the sixth parameter:

$$
\pi_{6}=\rho_{\mathrm{s}} / \rho_{\mathrm{b}}
$$

The magnitude of the density ratio, $\pi_{6}$ is not expected to affect mixing behavior directly, and it appears that this variable may be manipulated to allcw other parameters to match. Justification for matching the density ratio when performing scaled experiments will be discussed later in this section.

It is now convenient to select $\pi$ groups that are related to parameters discussed in the literature. The seventh $\pi$ group will be chosen to be the Reynolds number based on the velocity of the jet at the nozzle, the jet diameter, and the bulk density of the fluid.

$$
\pi_{7}=\operatorname{Re}_{j}=\frac{\rho_{\mathrm{b}} U_{0} D_{0}}{\mu}
$$

Fox and Gex (1956) suggest that the jet Reynolds number, $R e_{j}$, affects mixing in tanks of single-phase mixtures. Thus, it is likely that this quantity also affects solids suspension. In a general flow, the Reynolds number affects the stability of the flow and affects the turbulence structure. Consequently, the advantage of selecting the Reynolds number over some other dimensionless 
parameter is that this parameter has some physical significance. However, it is possible that the degree of mixing achieved will become independent of the Reynolds number in the futly turbulent range.

The eighth $\pi$ group selected will be a Froude number:

$$
\pi_{8}=F r=\frac{U_{0}^{2}}{g H}
$$

It is possible to show that the Froude number can have an important influence on the flow pattern that is achieved when a free surface boundary condition exists in a flow. When the Froude number is large, the surface level will be perturbed by the fluid motion. This surface perturbation is sometimes vigorous and can affect the actual circulation pattern achieved in the tank. Thus, the degree of mixing might be expected to be affected by the Froude number. Fosset and Prosser (1951) suggested that the contents of mixing tanks will stratify at low values of a modified densimetric Froude number ( $\mathrm{Fr}_{\mathrm{dm}}$ ). (The exact definition of the Froude number used by Fosset and Prosser was described in Section 3.1.2. It cannot be applied directly here because the density difference between the fluid leaving the jet and the slurry in the tank is a dependent variable in a slurry mixing problem.)

A more physically justifiable Froude number to characterize the jet motion is the densimetric Froude number

$$
F r_{d}=\frac{\rho_{b, j} U_{0}^{2}}{\left(\rho_{b, j}-\rho_{b, \infty}\right) g H}
$$

where $\rho_{\mathrm{b}, j}=$ bulk density of the jet

$\rho_{b, \infty}=$ bulk density of the mixture just outside the jet.

It is also possible to define a Froude number based on the velocity of the jet at the wall. The velocity of the jet at the wall is expected to be a function of the nozzle velocity, the distance traveled, and the ratio of the elevation of the jet to the jet nozzle diameter, E/D. In the case where one mixer pump 
is $p l a c e d$ in the center of the tank, the distance traveled would be one-half of the tank diameter. The ratio of the jet velocity at the wall to its velocity at the nozzle is expected to vary as

$$
\frac{U_{w}}{U_{0}}=\left(\frac{2 D_{0}}{D_{t}}\right) f\left(\frac{E}{D_{0}}\right)
$$

where $U_{W}$ is the velocity of the jet at the wall and $f\left(E / D_{0}\right)$ is a function of unknown form. In general, the function $f\left(E / D_{0}\right)$ will match in geometrically similar experiments in which the ratio $E / D_{0}$ matches.

The Froude number based on the wall velocity is defined as

$$
F r_{w}=\frac{U_{w}^{2}}{g H}
$$

and can be shown to be related to the Froude number based on the nozzle velocity by the relation

$$
\frac{F r_{w}}{F r}=\left[\begin{array}{ll}
4 D_{0} & f\left(\frac{E}{D_{t}}\right.
\end{array}\right]^{2}
$$

The quantity on the right-hand side of the equation is a function of geometry only' and would match in any two geometrically similar experiments. Thus, selection of either Froude number is arbitrary because they are not independent.

The goal of this study is to develop an experimental test plan in which the concentration profiles in the scaled model are similar to those in the prototype. That is, if scaling is properly performed, the concentration ratios at both scales should match or:

$$
\left.\left.\frac{\vec{C}\left(\vec{x} / D_{0}\right)}{C}\right)_{\text {model }}=\frac{\tilde{C}\left(\vec{x} / D_{0}\right)}{C}\right)_{\text {prototype }}
$$


where $\tilde{C}=$ average concentration of solids at the position $x$ in the tank

$C=$ average concentration of solids in the entire tank

$\rightarrow$

$x=$ the coordinate of a location in the tank (L)

$D_{0}=$ jet nozzle diameter $(L)$.

In order for the jet development to be similar in both the scaled model and the prototype, the densimetric Froude number $\left(F r_{d}\right)$ must match at each point along the jet trajectory. Because the jet concentration changes as it entrains more particles, this may only be accomplished if the bulk slurry density $\left(\rho_{\mathrm{b}, \mathrm{m}}\right)$ in the scaled model has a one-to-one correspondence with the bulk slurry density in the prototype $\left(\rho_{\mathrm{b}, \mathrm{p}}\right)$. That is, the densimetric Froude number will match only if the bulk density profiles are similar or if the following relation is true everywhere in the tank.

$$
\left.\left.\frac{\tilde{\rho}_{\mathrm{b}}\left(\overrightarrow{\mathrm{x}} / \mathrm{D}_{0}\right)}{\rho_{\mathrm{b}}}\right)_{\text {model }}=\frac{{\tilde{\rho_{\mathrm{b}}}}_{\mathrm{b}}\left(\overrightarrow{\mathrm{x}} / \mathrm{D}_{0}\right)}{\rho_{\mathrm{b}}}\right)_{\text {prototype }}
$$

where $\tilde{\rho}_{\mathrm{b}}\left(\vec{x} / D_{0}\right)=$ local value of bulk slurry density and $\rho_{\mathrm{b}}=$ average slurry density in the tank as a whole. In general, the following relationship can be used

$$
\rho_{\mathrm{b}}=\frac{\int_{V} \tilde{\rho}_{\mathrm{b}}\left(\vec{x} / \mathrm{D}_{0}\right) \mathrm{dV}}{V}
$$

where $V=$ tank volume and integration is performed over the tank volume.

If the slurry concentration in the tank were uniform, the local value of the slurry density would match the average density of the tank as a whole

$$
\tilde{\rho}_{\mathrm{b}}\left(\overrightarrow{\mathrm{x}} / \mathrm{D}_{0}\right)=\rho_{\mathrm{b}}
$$


everywhere in the tank. The density and concentration may be related using

$$
\rho_{\mathrm{b}}=\frac{\rho_{\eta} \rho_{\mathrm{S}}}{\rho_{\mathrm{s}}(1-\mathrm{C})+\rho_{1} \mathrm{C}}
$$

where $\rho_{\mathrm{b}}=$ bulk density $\left(M / L^{3}\right)$

$\rho_{1}=1$ iquid density $\left(M / L^{3}\right)$

$\rho_{S}=$ solids density $\left(M / L^{3}\right)$

$C=$ average weight $\%$ solids concentration in tank.

So the ratio of the local slurry density $\tilde{C}$ at a particular location in the tank, $x$, to the average density in the tank is:

$$
\frac{\tilde{\rho}_{b}(x)}{\rho_{b}}=\frac{\rho_{s}(1-C)+\rho_{1} c}{\rho_{s}[1-\tilde{C}(x)]+\rho_{7} \tilde{C}(x)}=\frac{s(1-c)+c}{s[1-\tilde{C}(x)]+\tilde{C}(x)}
$$

where $\tilde{c}(x)=$ local average concentration at a position in the tank

$$
\begin{aligned}
\tilde{\rho_{b}}(x)= & \text { local average density as a function of the location in } \\
& \text { the tank } \\
s & =\rho_{s} / \rho_{1}=\text { ratio of the solids density to the liquid density. }
\end{aligned}
$$

The relationship between density and concentration is nonlinear. Consequeritly, it is not possible to simultaneously match the spatial distribution of the solids concentration, the mean solids concentration in the tank (C) and the mean slurry density distribution without also matching the specific density ratio $(s)$. While the specific density ratio does not have a direct influence on the dynamics of jet mixing, this ratio must match in both the prototype and the scaled experiment if the relative importance of gravity and momentum are to scale properly at every point in the tank. Thus, matching the Frocde number defined in $\pi_{8}$ and the specific density ratio (s) is the only manner in which the more physically meaningful densimetric Froude number may be matched everywhere in the tank. 
A parameter that describes the solids settling behavior may be obtained by including the particle unhindered settling velocity $\left(U_{S}\right)$. There are a number of possible "correct" choices for this parameter. Selection from the numerous possible parameters is arbitrary; however, it is preferable to select a parameter that has some physical significance. There are two parameters that have physical significance: the first parameter is the ratio of the particle settling velocity to the velocity of the jet at the nozzle $\left(U_{S} / U_{0}\right)$, the second parameter is the ratio of the power supplied by the jet to the rate at which the gravitational field does work to draw particles down to the lower regions of the tank. This quantity will be referred to as the gravitational settling number or Gs.

$$
G s=\frac{2 D_{t}^{2} H\left(\rho_{s}-\rho_{1}\right) \phi_{s} U_{s} g}{\rho_{b} U_{0}^{3} D_{0}^{2}}
$$

Here $\phi$ is the volume fraction of solids in the slurry and may be determined as a function of the weight $\%$ solids concentration using

$$
\phi_{\mathrm{S}}=\frac{\rho_{\mathrm{b}} \mathrm{C}}{\rho_{\mathrm{S}}}
$$

The velocity ratio $\left(U_{S} / U_{0}\right)$ can be shown to be related to the ratio of the "mixing" time $\left(T_{m}\right)$ to the time required for individual particles to settle from the top to the bottom of the tank $\left(t_{s}\right)$. The mixing time in a tank was defined as the time required to break up an inhomogeneity introduced into the tank. Dimensionless mixing time was defined in Equation (3.3) as

$$
\theta=\left[\frac{T_{m} U_{0}}{H}\right) \cdot\left(\frac{D_{0}}{D_{t}}\right)^{2}
$$

and was found to be a function of the Reynolds number, Froude number, and the tank geometry. 
The time for a single particle to settle in the tank when the concentration is low is

$$
t_{s}=\frac{H}{U_{S}}
$$

where $t_{s}=$ time required for a single particle to settle from the top of liquid to the bottom of the tank.

Thus, for a given jet Reynolds number, Froude number, and tank geometry, the ratio of these two times varies as

$$
\frac{T_{m}}{t_{s}}=\frac{\theta D_{t}^{2} U_{s}}{D_{0}^{2} U_{0}}=\frac{\theta D_{t}^{2} N_{v}}{D_{0}^{2}}
$$

where $N_{v}=$ the velocity ratio $\left(U_{s} / U_{0}\right)$.

In the limit where this ratio approaches infinity, the jet will be unable to keep particles in suspension because particles will settle rapidly. When this ratio is small, suspension may be possible.

In contrast, the gravitational settling number describes a limiting phenomenon. Lifting particles against the pull of gravity into the upper regions of the tank requires that work be supplied to the tank. The maximum rate at which the jet may perform work to lift the particles is limited by the rate at which it supplies energy to the tank. The gravitational field is simultaneously doing work to draw the particles down. When the gravitational settling number (Gs) is very large, the gravitational effects are expected to be important, and the tank contents may be expected to stratify.

In fact, the choice of either the velocity ratio $\left(N_{v}\right)$ or the gravitational settling number (Gs) is arbitrary because the two are related by the relation:

$$
G s=\frac{2(s-1)}{F r} \phi\left(\frac{D_{t}}{D_{0}}\right)^{2} \frac{U_{s}}{U_{0}}=\frac{2(s-1) \phi}{F r}\left(\frac{D_{t}}{D_{0}}\right)^{2} N_{v}
$$


Thus, the two parameters may not be specified independently once the Froude number, tank geometry, solids concentration, and the relative density of the solids and slurry are specified.

Thus, the gravitational settling parameter (Gs) is selected as the ninth $\pi$ group in this experiment. No differences in the generality of the results is expected based on selecting this parameter rather than the velocity ratio $\left(\mathrm{N}_{\mathrm{v}}\right)$.

The ninth $\pi$ group is defined

$$
\pi_{g}=G s=\frac{2 D_{t}{ }^{2} H\left(\rho_{s}-\rho_{\eta}\right) \phi_{s} U_{s} g}{\rho_{b} U_{0}{ }^{3} D_{0}{ }^{2}}
$$

Finally a parameter must be selected to describe the effect of jet rotation. Kinematic similarity, for jet development may be ensured by specifying the final $\pi$ group to be

$$
{ }^{\eta} r j=\frac{N D_{0}}{U_{0}}
$$

where $N$ equals jet rate of rotation $(1 / T)$. This parameter will be referred to as the rotation number $\left(\eta_{r j}\right)$ based on jet diameter.

An alternative parameter describes the ratio between the time required for the jet to return to a particular location and the time required for particles to settle. This is

$$
\eta_{r h}=N t_{s}=\frac{N H}{U_{s}}
$$

This parameter will be referred to as the rotation number based on tank height. When testing is done in geometrically similar tanks with identical velocity ratios $\left(N_{v}\right)$, the selection of the two parameters is arbitrary. 
Because the rate of jet rotation is slow in this problem, it is expected that the jet rotation will not have a strong effect on jet development. In contrast, the time allowed for settling may be significant. For this reason, the tenth $\pi$ parameter will be selected to be

$$
\pi_{10}=\eta_{\text {rh }}=\frac{N H}{U_{S}}
$$

The theory of similarity ensures that the difference in concentration between the bottom and the top of both the prototype and the scaled model will obey some functional relation of the form:

$$
\frac{\Delta C}{C}=f\left(C, s, D_{0} / H, D_{t} / H, E / H, F r, R e, G s, \eta_{r h}\right)
$$

The form of this relation cannot be obtained using dimensional analysis but must be obtained either through analytical treatment of the problem or through experimentation. However, similarity dictates that if the all nine dimensional parameters on the right-hand side of the functional relation are identical in the two cases, the concentration difference will also be identical. This would be true even if a different set of dimensionless parameters had been selected to characterize the problem.

In principle, the information required to predict the behavior in the prototype may be obtained by performing experiments at any scale, provided that all nine of the independent parameters in the prototype are matched in the scaled experiment. The difficulty, in practice, is that it is not always possible to match all parameters simultaneously in both scales. This is the case in the problem of interest where eight of the nine independent parameters may be conveniently matched in both of the experiments.

The difficulty in matching all parameters arises because very low viscosity fluids are not available; this lack of low viscosity simulant makes it impossible to match both the Froude and the Reynolds numbers simultaneousiy in some scaled experiments. Both the Froude number and Reynolds number have been shown to affect mixing time. Matching the Froude number and Reynolds 
numbers simultaneously using an experiment performed at smaller scale than the prototype requires the use of a lower viscosity fluid and a lower speed jet. This may be shown as follows.

Assume that all geometric features in the scaled model are reduced by a scale factor $X$, that is:

$$
X=\frac{D_{t, m}}{D_{t, p}}=\frac{H_{m}}{H_{p}}=\frac{D_{0, m}}{D_{0, p}}
$$

where the $m$ subscript denotes evaluation in the scaled experiment and $p$ in the prototype.

The scaled velocity in the model tank may be determined by matching the Froude number. That is

$$
\left.\frac{U_{0}^{2}}{g H}\right]_{\text {model }}=\left.\frac{U_{0}^{2}}{g H}\right|_{\text {prototype }}
$$

Because $H_{m} / H_{p}=X$, this imposes the relationship on the velocities:

$$
\frac{U_{m}}{U_{p}}=\sqrt{\frac{H_{m}}{H_{p}}}=\sqrt{x}
$$

The viscosity requirement for scaled experiments may be found by imposing the Reynolds number criterion:

$$
\operatorname{Re}_{\mathrm{m}}=\operatorname{Re}_{\mathrm{p}}
$$

which results for kinematic viscosity, $\nu$

$$
\frac{\nu_{m}}{\nu_{p}}=\frac{U_{0, m} D_{0, m}}{U_{0, p} D_{0, p}}
$$


where $\nu_{\mathrm{m}}=\mu_{\mathrm{m}} / \rho_{\mathrm{b}, \mathrm{m}}$ and $\nu_{\mathrm{p}}=\mu_{\mathrm{p}} / \rho_{\mathrm{b}, \mathrm{p}}$ are the effective kinematic viscosities in the scaled model and the prototype.

Substituting the relationships between the the scale $(X)$ velocities and noz:le diameter results in:

$$
\frac{\nu_{m}}{\nu_{p}}=\left(\frac{D_{0, m}}{D_{0, p}}\right)^{3 / 2}=x^{3 / 2}
$$

In firinciple, both Froude and Reynolds numbers may be matched in scaled experiments. However, obtaining fluids of sufficiently low viscosity is often impassible. The proposed experimental plan suggests that the slurry simulants used have densities similar to those expected to exist in the prototype. Absolute viscosities of the double-shell tank slurries are expected to be as low as $0.002 \mathrm{~Pa}-\mathrm{s}(2 \mathrm{cP})$ and as high as $0.05 \mathrm{~Pa}-\mathrm{s}(50 \mathrm{cP})$. The upper viscosity is only expected to be exhibited by extremely concentrated slurries, while the lower viscosity is expected to be observed in dilute slurries. Simultaneously matching the jet Reynolds number and the tank Froude number ach eved using the $0.002 \mathrm{~Pa}-\mathrm{s}(2 \mathrm{cP})$ fluid in the prototype tank requires that test:s be performed using a $5 \times 10^{-5} \mathrm{~Pa}-\mathrm{s}(0.05 \mathrm{cP})$ fluid in a $1 / 12$-scale tank. This viscosity is much lower than that exhibited by most fluids. [For reference, water at $20^{\circ} \mathrm{C}$ has a viscosity of $\left.0.001 \mathrm{~Pa}-\mathrm{s}(1.0 \mathrm{cP}).\right]$ The 0.0 : $\mathrm{Pa}-\mathrm{s}(50 \mathrm{cP})$ fluid behavior could be matched using a fluid with a viscosity of $0.0012 \mathrm{~Pa}-\mathrm{s}(1.2 \mathrm{cP})$ in a $1 / 12$-scale simulation. Fluids with viscosities of $0.0012 \mathrm{~Pa}-\mathrm{s}(1.2 \mathrm{cP})$ do exist; however, it is deemed unlikely that: a moderately concentrated slurry with this viscosity could be manufactured. As a result of the lack of sufficiently low viscosity slurries, either the Reynolds number or the Froude number, but not both, may be matched in a 1/12-scale experiment.

As a result of the difficulties that arise in attempting to match all dimensionless parameters, it is important to identify which parameters will have: the smallest effect on the degree of uniformity achieved in the tank. This may be done by 1) determining which parameters have a negligible effect in related problems discussed in the literature and 2) performing prototype testing to determine the relative importance of different parameters. 
The literature suggests that the parameters affecting mixing times for miscible fluids are Froude number ( $\mathrm{Fr}$ ), Reynolds number (Re), and tank geometry. The effect of geometry is noticeable, but has not been quantified. Consequently, it is recommended that geometric similarity be maintained. The effect of Froude number on mixing times has been shown to be important when density differences exist. If the densimetric jet Froude number $\left(F r_{d}\right)$ is low, the tank contents will stratify. It is not possible to know a priori whether the jet Froude number will have a significant effect on mixing during operation of the prototype because the magnitude of the density differences in the tank are not known. Estimates based on Fosset and Prosser's (1951) results indicate that the Froude number may have an effect. If testing in a scaled model is to produce useful results, the experiments must be performed in a Froude number range where the tendency to stratify is equivalent to that expected in the prototype tank. This restriction requires that the Froude number in the scaled model match that in the prototype.

Currently the literature suggests that the jet Reynolds number has an important effect on mixing times when $R_{j}<2000$; at larger Reynolds numbers mixing times are not strongly affected by the jet Reynolds number. If the effect on the degree of uniformity achieved is similar to the effect on mixing time, the degree of uniformity achieved as a function of Froude and Reynolds numbers when the gravitational settling number is held constant might be expected to vary, as illustrated in Figure 3.8. In the laminar range, the degree of inhomogeneity $(\Delta C / C)$ achieved in the tank decreases with increasing Froude or Reynolds number. However, in the turbulent range, the Reynolds number no longer has an effect. Consequently, it appears that it is not necessary to match the Reynolds number exactly if the actual Reynolds numbers used in testing are much greater than 2000. However, testing should still be done in the turbulent range. The Reynolds number range that will occur in the waste tanks has been investigated. The design of the jet mixers allows them to be operated at speeds as $10 \mathrm{w}$ as $25 \%$ of full speed $\left(0.25 \mathrm{U}_{0} \mathrm{D}_{0}\right)$. The current design of the mixer nozzle diameter will be $0.15 \mathrm{~m}(6 \mathrm{in.})$ and the full-speed velocity will correspond to a $U_{0} D_{0}$ of $2.73 \mathrm{~m}^{2} / \mathrm{s}\left(29.4 \mathrm{ft}^{2} / \mathrm{s}\right)$. It is assumed that the maximum velocity achieved using these jets does not depend on the fluid properties. The range of Reynolds numbers and Froude numbers 


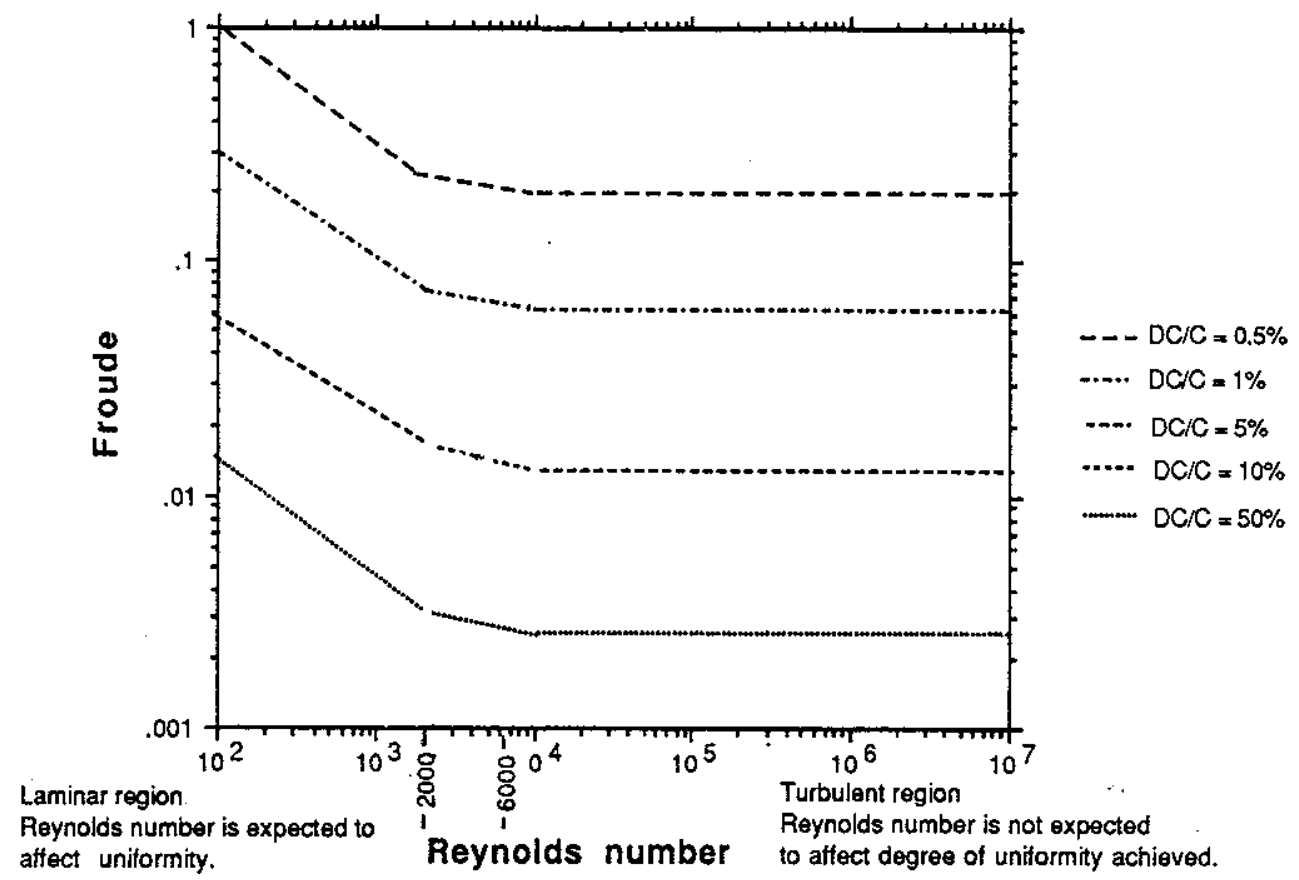

FIGURE 3.8. Anticipated Trend in Uniformity as a Function of Froude and Reynolds Numbers at Constant Gravitational Settling Number

proposed for use in the solids resuspension task is shown in Figure 3.9. When the tank is filled with a fluid of a known viscosity and density, varying the jet velocity affects both the Froude and Reynolds number. The rightmost solid diaconal line represents the locus of operation when a fluid with a specific gravity of 1.25 and a viscosity of $0.002 \mathrm{~Pa}-\mathrm{s}(2 \mathrm{cP})$ is being mixed in the prototype tank. The operating line when a fluid with similar density but with viscosity of $0.05 \mathrm{~Pa}-\mathrm{s}(50 \mathrm{CP}$ ) is mixed falls to the left of the $0.002 \mathrm{~Pa}-\mathrm{s}$ (2 cP) line. The upper solid horizontal line denotes the Froude number that will be achieved when the jet mixers are operated at full speed. The lower solid horizontal line represents the Froude number at $25 \%$ of full speed. The parallelepiped formed by these four lines represents the Reynolds number and Froude number region of interest. In addition, the Froude number corresponding to $15 \%$ of ful1-speed operation in the prototype is shown by a 


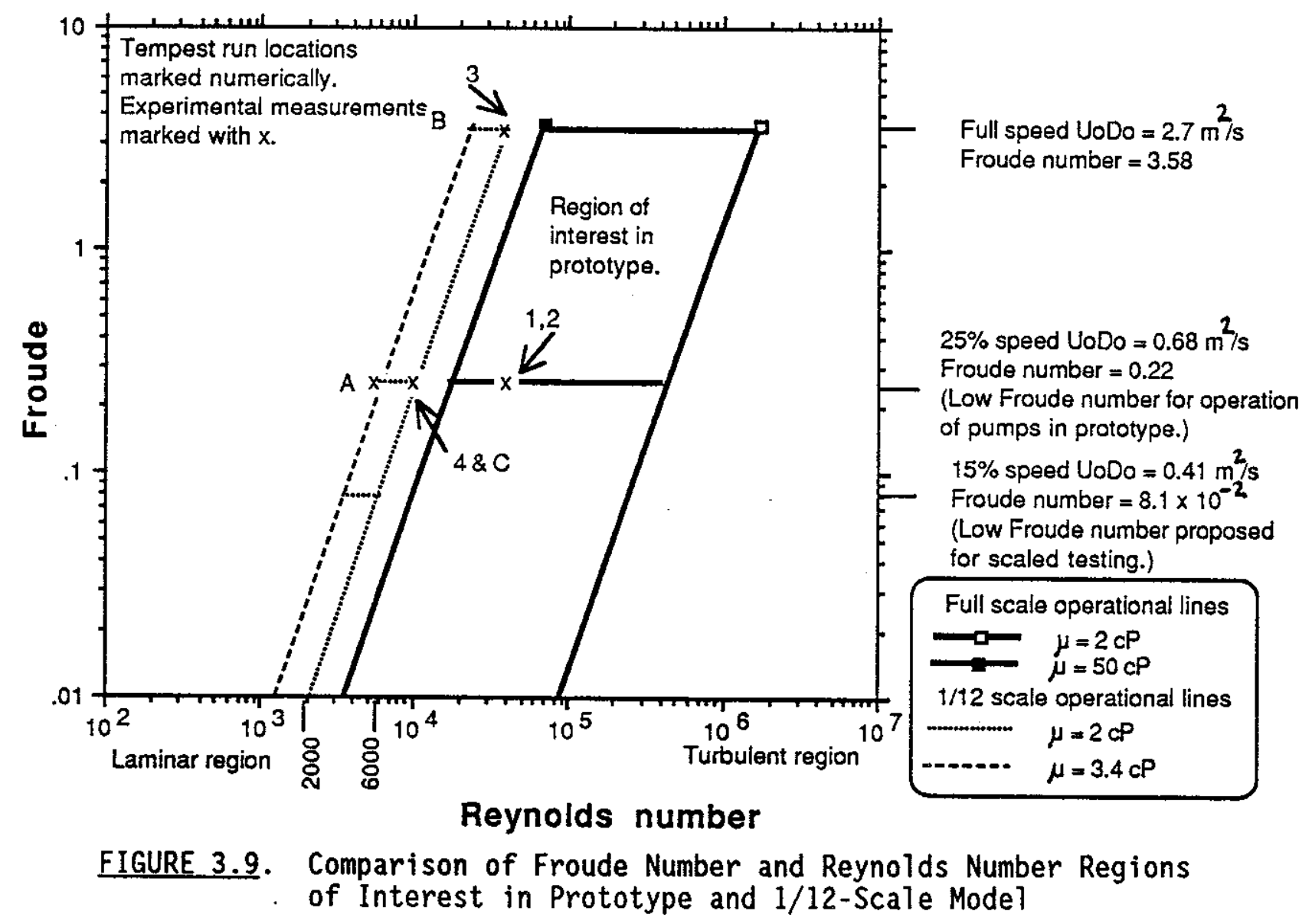

thin solid line. This thin solid line corresponds to the lower region of interest experimentally. Testing at a lower speed than anticipated during operation will provide a margin of safety for any correlations developed during testing.

The minimum Reynolds number at which the jet may be operated in the prototype is $10^{4}$, which is sufficiently above critical value of 2000 observed by Fox and Gex (1956) to ensure that mixing in the prototype will be turbulent. Thus, the changes in the Reynolds number are not expected to have an important influence in the mixing behavior observed in the prototype.

However, the Froude number may affect the mixing at all nozzle exit velocities. In addition, the results of Fosset and Prosser (1951) suggest that stratification may occur at low densimetric Froude numbers, while scaling suggests that the nondensimetric Froude numbers will affect the degree of surface rippling that occurs at the upper surface and can affect mixing by 
affecting the flow pattern achieved in the tank. It is extremely important that tests be conducted at the Froude numbers achieved in the prototype tank to assess the possibility of stratification at the small scale. Running tests at frototype Reynolds numbers in the small scale would result in large Froude numbers; in this case, stratification might not be observed in the scaled model even though it would occur in the prototype.

A parallelepiped is drawn to show the region to be studied in a proposed 1/12-scale experiment. The region is bounded by the same Froude numbers and by the operational lines describing the Froude number/Reynolds number variation achieved in the scaled model using $0.002 \mathrm{~Pa}-\mathrm{s}(2 \mathrm{cP})$ and $3.4 \times 10^{-3} \mathrm{~Pa}-\mathrm{s}$ (3.4 CP) fluids. The lower fluid viscosity value is selected to represent an achievable low value of viscosity in a simulated slurry and to ensure that the degree of surface deformation is comparable to that which would occur in the prototype. Matching the nondensimetric Froude number is important when the achieved Froude numbers are on the order of one or greater. When the achieved Froude numbers are less than one, the surface will not deform and the effect of the Froude number will be less important. In the case of interest here, the Froude number falls between 3.6 and 0.08 at full and $15 \%$ speed, respectively. Consequently, some surface rippling is expected in the fullspeed case and it is expected that the magnitude of the densimetric Froude number will affect the mixing process. In addition, the magnitude of the densimetric Froude number is expected to affect the jet motion. It is proposed that both be matched in this experiment. Matching both can be accomplished using only one solids to supernate density ratio because the density ratio does not vary widely in the actual waste tanks. The higher viscosity fluid is selected to allow the Froude number to equal that achieved in the prototype when the jet operates at $25 \%$ of full speed to be matched while maintaining a fully turbulent flow. Fox and Gex (1956) suggest that transition to turbulence occurs at a Reynolds number of 2000 . However, most mixing studies indicate that some Reynolds number effects may be noticeable near transition. In addition, specific design features for the jet may affect the critical Reynolds number. Matching the Reynolds number regime is considered critical. In the proposed plan, all tests are at Reynolds numbers of 6000 or greater, which is expected to ensure turbuient flow. 
It is possible to match all other dimensional parameters. Consequently it is recommended that testing be performed at values of the specific density $(\mathrm{s})$, concentration (C), Froude number $(\mathrm{Fr})$, gravitational settling number (Gs), and rotation number $\left(\eta_{r h}\right)$, which match those that occur in the prototype tank. Matching both specific density and Froude number will ensure that the densimetric Froude number is also matched. It is thought that experiments performed in this parameter range will provide data that is relevant to predictions of mixing in the prototype tank.

The time required to reach steady-state operation has not yet been addressed. In general, concentration distribution achieved during steadystate is of the greatest concern in this problem because a solids distribution must be maintained for a period of time. However, during prototype operation, the mixing pump jets will operate at full speed during resuspension efforts. The $p l a n$ then calls for reducing the velocity of the jets and maintaining suspension at a lower pump speed. Consequently, the degree of mixing is expected to decrease from a well mixed state to a less well mixed state over a period of time. Eventually, steady-state operation will be achieved. Because the jet rotates, the steady-state operating condition may have periodic fluctuations in concentration and velocity, which are imposed by the jet.

During testing, slurry simulant will be pumped from the make-up tank to the scale model tanks. It is anticipated that the initial condition for the slurry will be well mixed. As time progresses, the solids concentration will approach a steady-state value. During steady-state operation, periodic time variations imposed by the jet will still exist; however, no steady trends over time in either concentration or flow patterns will be observed.

It is essential that the flow pattern at steady-state be realized. Consequently, the jet pump must be maintained at the target speed for a sufficiently long time to allow steady-state operation. There are a number of factors affecting the time required to achieve steady-state because both the velocity field and the concentration profile must achieve steady-state behavior. Because there is feedback between the two fields, both will achieve the steady-state condition simultaneously. However, the scaling can be 
considered separately with the understanding that steady-state behavior is achieved only after the time period required for both fields to become steady.

The velocity field near the jet opening is expected to approach steadystatie over a time period (T), which varies as

$$
T_{s 1}=C\left(D_{0} / U_{0}\right)
$$

wher'e $C$ is a constant of unknown magnitude but which is of order one so that no time variations that are not related to jet rotation will be evident after some: number of mutitples of the ratio $D_{0} / U_{0}$.

Far from the jet, the velocity field will approach steady-state at a slower rate because the jet takes longer to penetrate all regions of the flow. In this region, the velocity profile in a single-phase fluid appraoches steady-state over a time period, which varies as

$$
T_{s 2}=C\left(L / U_{0}\right)
$$

where $L$ is the distance from the jet nozzle and $C$ is a constant of unknown magr itude.

The rate at which the density distribution approaches steady-state is more complicated because it is affected by

1. the rate at which solids are transported by mean motions of the fluid

2. the rate at which solids are transported by diffusive motions induced by the existance of eddies

3. the rate at which particles settle out from the flow.

When the initial distribution is uniform and solids are completely mixed, the time scale for achieving steady-state would be expected to vary as

$$
T_{s 3}=C\left(H / U_{s}\right)
$$


so that the concentration would be expected to approach its steady-state after some multiple of the ratio $\mathrm{H} / \mathrm{U}_{\mathrm{S}}$, which is the time required for individual particles to settle from the top to the bottom of the tank.

The longest time estimate to achieve steady-state is the third time scale $\left(T_{s 3}\right)$. This time scale can be used to estimate the time required to achieve steady-state in the prototype during testing. The actual times required to reach steady-state are shown in Table 3.1. The transient period in the prototype will be approximately 9 hours when $100-\mu \mathrm{m}$ diameter particles settle in a fluid with a viscosity of $21 \times 10^{-3} \mathrm{~Pa}-\mathrm{s}(21 \mathrm{cP}$ ) and 800 hours ( 33 days) when $10-\mu \mathrm{m}$ diameter particles settle in a fluid of the same viscosity. The transient period would be shorter for less viscous fluids. In the scaled mode1, the longest transient period will be 42 hours, which will occur when 5- $\mu \mathrm{m}$ diameter particles settle in the simulant with a viscosity of $3.4 \times 10^{-3} \mathrm{~Pa}-\mathrm{s}$ ( $3.4 \mathrm{cP}$ ).

TABLE 3.1. Comparison of Prototype and Model Settling Times

\begin{tabular}{|c|c|c|c|c|c|}
\hline & $\begin{array}{l}\text { Fluid } \\
\text { Height, } H\end{array}$ & $\underset{\mu}{\operatorname{Viscosity}}$ & $\begin{array}{l}\text { Particle } \\
\text { Diameter, } \\
\text { d. } \\
\end{array}$ & $\begin{array}{c}\text { Settling } \\
\text { Velocity, } \\
\text { Us }\end{array}$ & $\begin{array}{l}H / U_{S}, \\
\text { hours }\end{array}$ \\
\hline Prototype & $\begin{array}{c}9.1 \mathrm{~m} \\
(30 \mathrm{ft})\end{array}$ & $\begin{array}{c}21 \times 10^{-3} \mathrm{~Pa}-\mathrm{s} \\
(21 \mathrm{cP})\end{array}$ & $100 \mu \mathrm{m}$ & $3 \times 10^{-4} \mathrm{~m} / \mathrm{s}$ & 8 \\
\hline Prototype & $\begin{array}{c}9.1 \mathrm{~m} \\
(30 \mathrm{ft})\end{array}$ & $\begin{array}{c}21 \times 10^{-3} \mathrm{~Pa}-\mathrm{s} \\
(21 \mathrm{cP})\end{array}$ & $10 \mu \mathrm{m}$ & $3 \times 10^{-6} \mathrm{~m} / \mathrm{s}$ & \\
\hline 1/12-scale & $\begin{array}{c}0.76 \mathrm{~m} \\
(30 \mathrm{in} .)\end{array}$ & $\begin{array}{c}3.4 \times 10^{-3} \mathrm{~Pa}-\mathrm{s} \\
(3.4 \mathrm{cP})\end{array}$ & $20 \mu \mathrm{m}$ & $8.0 \times 10^{-5} \mathrm{~m} / \mathrm{s}$ & 2.6 \\
\hline $1 / 12$-scale & $\begin{array}{c}0.76 \mathrm{~m} \\
(30 \mathrm{in.})\end{array}$ & $\begin{array}{c}3.4 \times 10^{-3} \mathrm{~Pa}-\mathrm{S} \\
(3.4 \mathrm{CP})\end{array}$ & $5 \mu \mathrm{m}$ & $5.0 \times 10^{-6} \mathrm{~m} / \mathrm{s}$ & 42 \\
\hline $1 / 12$-scale & $\begin{array}{c}0.76 \mathrm{~m} \\
(30 \mathrm{in.})\end{array}$ & $\begin{array}{c}2.0 \times 10^{-3} \mathrm{~Pa}-\mathrm{S} \\
(2 \mathrm{CP})\end{array}$ & $20 \mu \mathrm{m}$ & $1.4 \times 10^{-4} \mathrm{~m} / \mathrm{s}$ & 1.6 \\
\hline 1/12-scale & $\begin{array}{c}0.76 \mathrm{~m} \\
(30 \text { in. })\end{array}$ & $\begin{array}{c}2.0 \times 10^{-3} \mathrm{~Pa}-\mathrm{s} \\
(2 \mathrm{cP})\end{array}$ & $5 \mu \mathrm{m}$ & $8.5 \times 10^{-6} \mathrm{~m} / \mathrm{s}$ & 25 \\
\hline
\end{tabular}


The length of the transient period is important both in the prototype and the scaled experiment. In the prototype, the length of the transient is extremely long. Consequently, if the pumps are turned down or fail, there will be a large period of time before the particles settle completely out of the liquid. This is particularly true for small particles that may take a montih to settle.

In the scaled experiment, where the goal is to determine the degree of mixing achieved during steady-state, the transient time is important because it clictates the length of time that the pumps must operate before steadystate may be expected to be achieved. During testing using the larger $20-\mu \mathrm{m}$ particles, the transient will be approximately 2-1/2 hours. In contrast, the trarisient period when 5- $\mu \mathrm{m}$ particles are used is approximately 42 hours. Consequently, the pumps must operate at least $1-1 / 2$ days prior to measuring the concentration profile when $5-\mu \mathrm{m}$ particles are used.

\subsection{WASTE CHARACTERISTICS}

The characteristics of wastes contained in double-shell tanks have been investigated, and are presented here. This information was used to determine the ranges in which the dimensionless parameters governing mixing will fall during suspension efforts using the current mixer pump design.

\subsubsection{Double-Shell Tank Slurries}

Characteristics of double-shell slurries have been obtained from core samples reported in a number of draft reports and letters. The mean slurry density, the density of the centrifuged solids in the slurry, the supernatant density, the weight \% of solids, and both the mean diameter and volume mean diameter taken from available reports are summarized in Table 3.2; values reported for simulated waste slurries are also included in this table. Omitted entries indicate that the value for the corresponding property was not reported.

Bulk densities are found to range from $1100 \mathrm{~kg} / \mathrm{m}^{3}\left(1.1 \mathrm{~g} / \mathrm{cm}^{3}\right)$ for a slurry composed of $30 \%$ washed solids from tank $101-\mathrm{AZ}$ to $1800 \mathrm{~kg} / \mathrm{m}^{3}$ $\left(1.8 \mathrm{~g} / \mathrm{cm}^{3}\right)$ for undiluted core samples drawn from tank 103-AN. The samples 


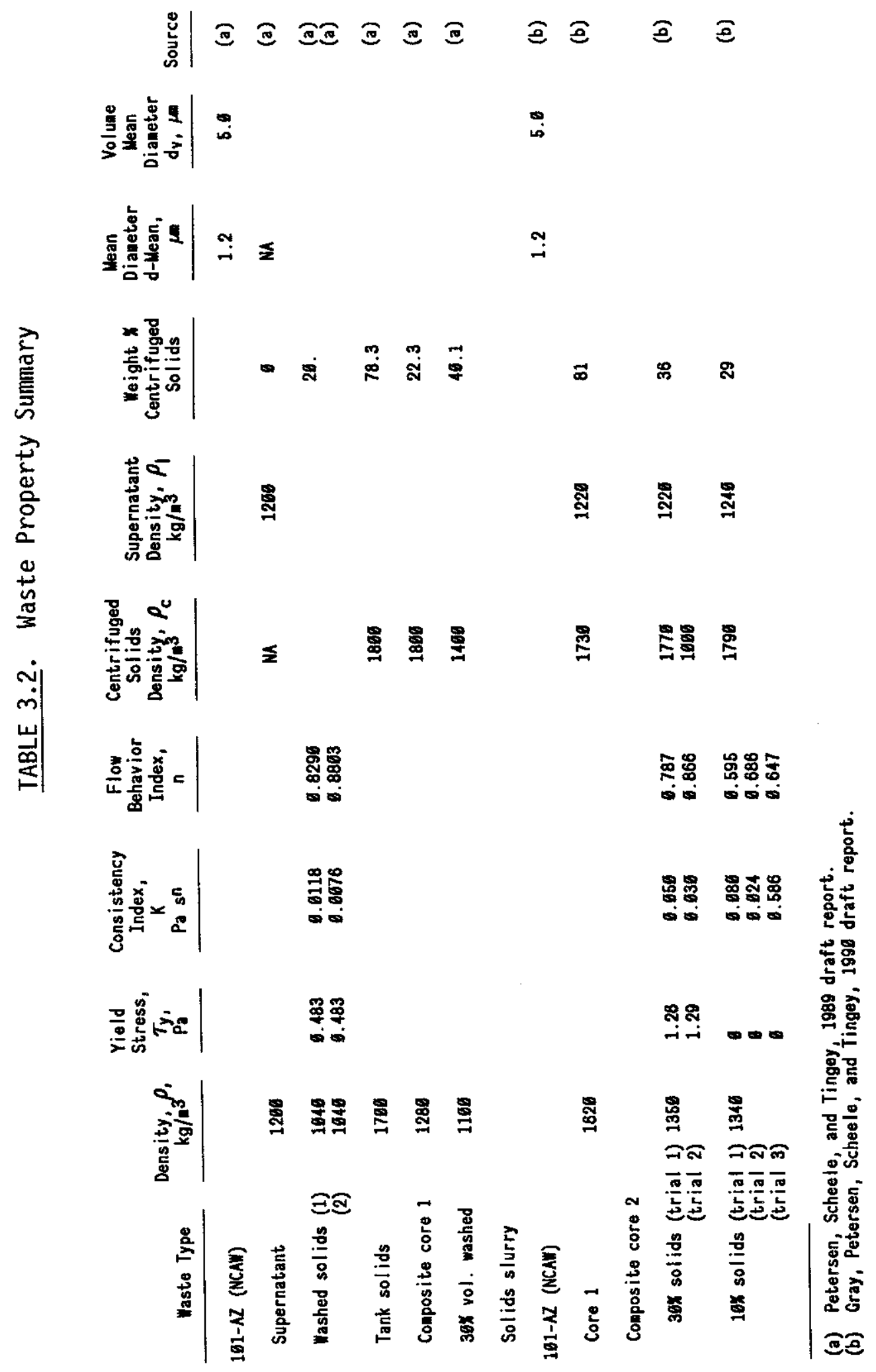




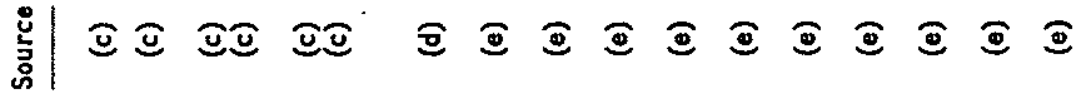

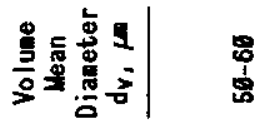

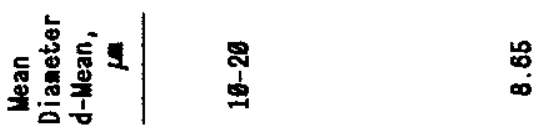

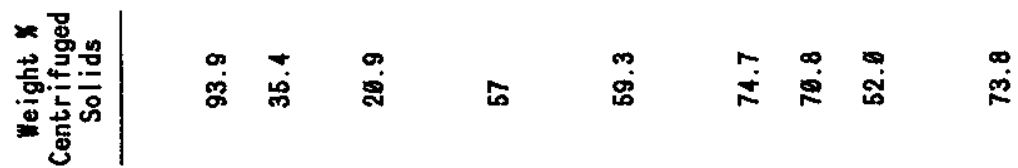

$$
\begin{aligned}
& \text { 당 } \\
& \text { 嵌| } \\
& \stackrel{9}{9} \\
& \text { 害高旁旁 }
\end{aligned}
$$

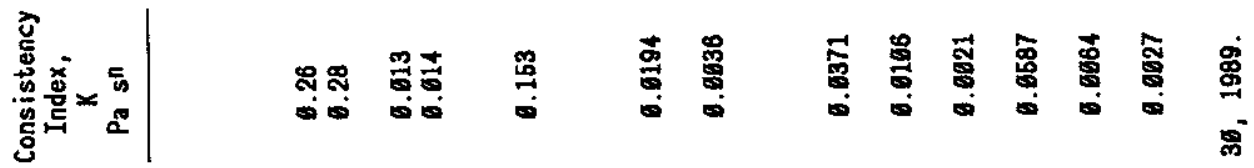

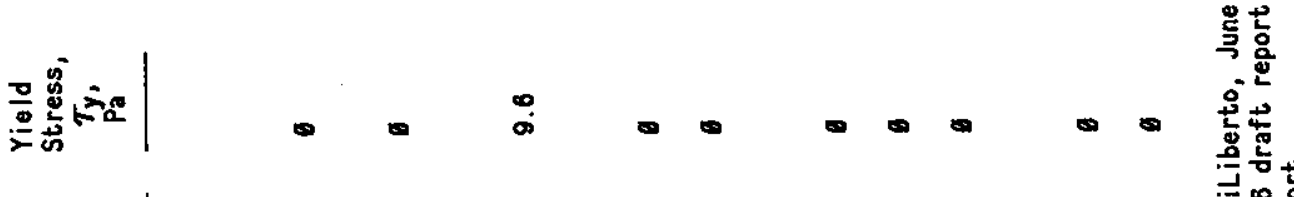

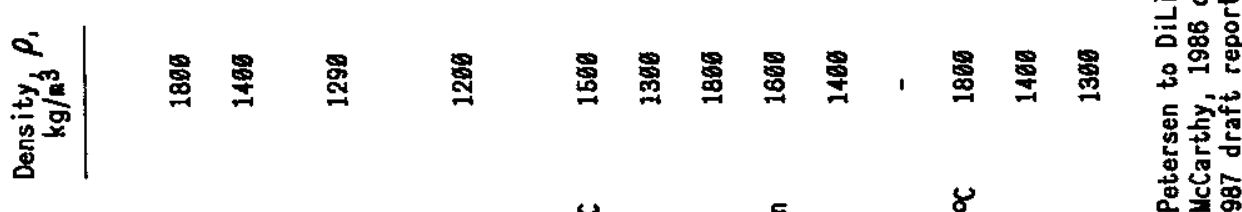

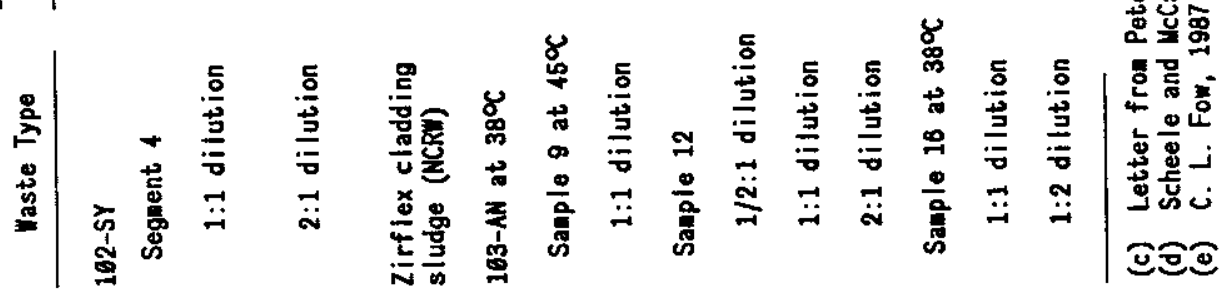




$$
\begin{aligned}
& \text { 岇| }
\end{aligned}
$$

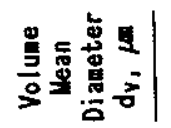

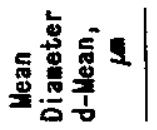

$$
\begin{aligned}
& \text { 焉事 } \\
& \text { 茟 }
\end{aligned}
$$

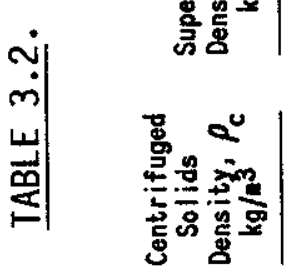

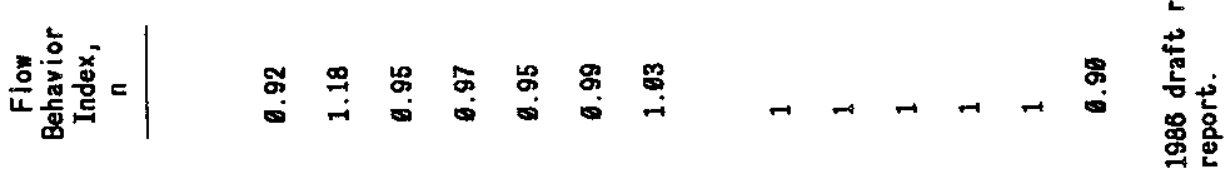

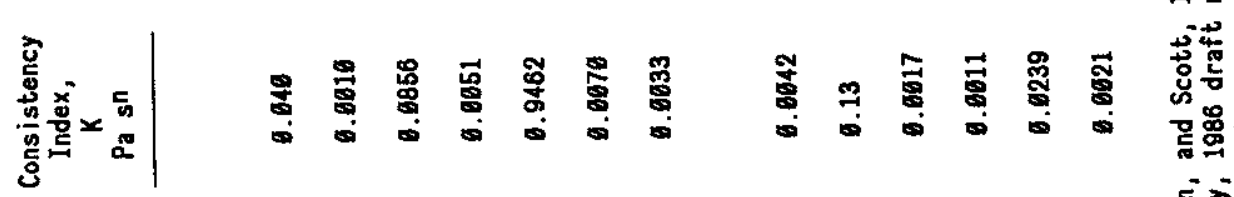

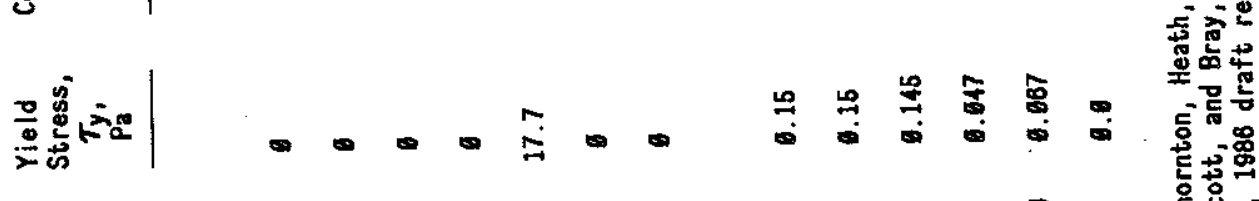

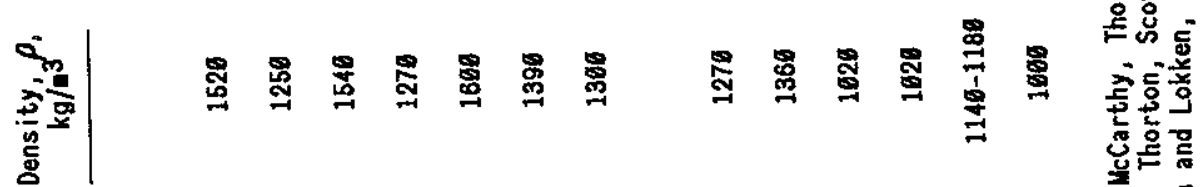

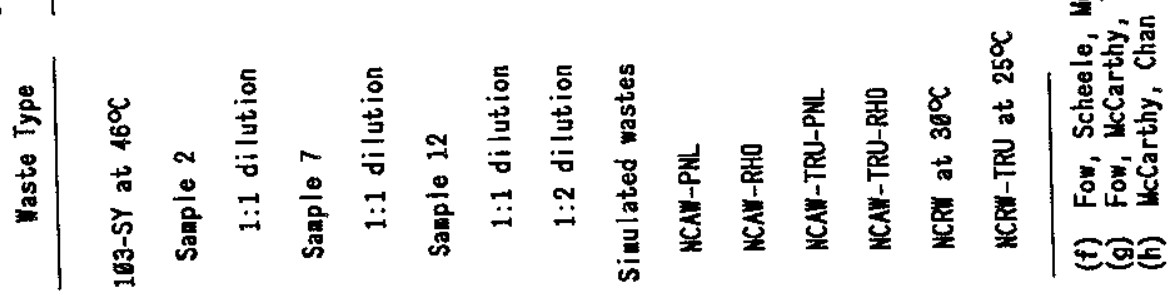


fron tank 103 -AN contain approximately $75 \%$ solids by weight; this high weight $\%$ solids suggests that these are samples taken from a region occupied by setiled solids. In general, samples with high densities correspond to those contiaining large quantities of solids.

The bulk density of the centrifuged solids is reported to range from $1350 \mathrm{~kg} / \mathrm{m}^{3}\left(1.35 \mathrm{~g} / \mathrm{cm}^{3}\right)$ (reported for wastes from Zirflex cladding) to 1800 $\mathrm{kg} / \mathrm{ml}^{3}\left(1.8 \mathrm{~g} / \mathrm{cm}^{3}\right)$ (reported for wastes from tank $\left.101-\mathrm{AZ}\right)$. The solids density for the samples from tank 103-AN, which has the largest reported bulk slurry density, are not reported.

The bulk density of centrifuged solids is determined by measuring the mass of a volume of solids that has been centrifuged to remove as much liquid as piossible. Centrifuging results in high packing fractions, (i.e., minimal voiclage). However, solids packing fractions of one that correspond to $100 \%$ of a vcilume being occupied by solids are not possible. Consequently, the actual volume occupied by solids is less than the apparent volume as measured in the centrifuge. The additional volume measured is occupied by air or water. As a result, the density of the centrifuged solids is expected to be less than the actual density of individual solid particles in the waste. The density of the individual solid particles is expected to be close to $2500 \mathrm{~kg} / \mathrm{m}^{3}\left(2.5 \mathrm{~g} / \mathrm{cm}^{3}\right)$.

The density of the supernatant is reported to $\mathrm{fall}$ between $1079 \mathrm{~kg} / \mathrm{m}^{3}$ $\left(1.079 \mathrm{~g} / \mathrm{cm}^{3}\right)$ for the supernatant from Zirflex cladding wastes and $1240 \mathrm{~kg} / \mathrm{m}^{3}$ $\left(1.24 \mathrm{~g} / \mathrm{cm}^{3}\right)$, which corresponds to the density of supernatant from a sample from tank 101-AZ. Because water is the major liquid added to the tank, the supernatant density is not expected to fall below $1000 \mathrm{~kg} / \mathrm{m}^{3}\left(1.0 \mathrm{~g} / \mathrm{cm}^{3}\right)$.

The settled solids are vigorously agitated prior to particle size measurement to ensure that there is no particle agglomeration. The equivalent population mean diameter of the solids in the waste ranges from $1.2 \mu \mathrm{m}$ to $20 \mu \mathrm{m}$. The reported values of the volume mean diameter are larger than the equivalent population mean diameter and fall between $5 \mu \mathrm{m}$ and $60 \mu \mathrm{m}$. Effective particles diameters during resuspension may be larger if solids agglomerate to form larger particles. It is not certain that the method of solid resuspension used in the waste tanks will produce an equivalent degree of agitation and produce particle sizes in the reported range. It is expected 
that any agglomerated solids that pass through the pump will be separated into individual solids. The ratio of the tank volume to the volume flow rate of slurry through the pump gives an order of magnitude estimate of the amount of time required for the entire tank contents to pass through the pump. This time is on the order of 3 hours when a pump with a $0.15-\mathrm{m}(6-i n$.$) diameter$ nozzle operates with an exit velocity speed of $17.9 \mathrm{~m} / \mathrm{s}(58.8 \mathrm{ft} / \mathrm{s})$. The probability that solids will reagglomerate is not known.

Parameters describing slurry rheology are also shown in Table 3.2. The shear stress, $r$, during flow of a yield pseudoplastic fluid can be described using the equation:

$$
\tau=\tau_{y}+k\left(\frac{d U}{d y}\right)^{n}
$$

where

$$
\begin{aligned}
\tau & =\text { shear stress }\left(M / L T^{2}\right) \\
\tau_{y} & =\text { slurry yield stress }\left(M / L T^{2}\right) \\
K & =\text { consistency index }\left(M / L T^{2-n}\right) \\
d U / d y & =\text { shear rate in } y \text { direction }(1 / T) \\
n & =\text { flow behavior index. }
\end{aligned}
$$

This equation is sometimes written in the form of an apparent viscosity, $\mu_{a}$ :

$$
\mu_{a}=\frac{\tau}{\left(\frac{d U}{d y}\right)}=\frac{\tau_{y}+K\left(\frac{d U}{d y}\right)^{n}}{\left(\frac{d U}{d y}\right)}
$$

The most extensive characterizations of waste rheology are provided in the reports of analysis of core samples taken from tank 101-AZ reported by Gray, Petersen, Scheele and Tingey(a); tank 103-AN, reported by Fow ${ }^{(b)}$; and tank 103-SY reported by Fow, Scheele, McCarthy, Thorton, Heath and Scott. (c)

(a) 1990 Draft Report. Pacific Northwest Laboratory, Richland, Washington.

(b) 1987 Draft Report. Pacific Northwest Laboratory, Richland, Washington.

(c) 1986 Draft Report. Pacific Northwest Laboratory, Richland, Washington. 
Undiluted waste from tank 101-AZ contained $81 \%$ solids by weight. The supirnatant and solids in this waste were separated and recombined to form more dilute waste types. The waste from the second core sample from tank 101-AZ containing $30 \%$ solids was yield pseudoplastic and exhibited a yield stress; the waste containing $10 \%$ solids was pseudoplastic but did not exhibit a yield stress. Petersen, Scheele and Tingey (a) report the slurry that contiained $20 \%$ washed solids from the first core sample from tank 101-AZ was also yield pseudoplastic. In addition, a figure in their report illustrating the stress-strain curve for the supernatant from tank 101-AZ suggests that the supernatant was also non-Newtonian, and may have been yield pseudoplastic; however, the yield stress of the supernatant was not reported. Analyses of wast:e samples 9 and 12 from tank 103-AN were Newtonian; sample 16 from tank 103.AN was non-Newtonian, but became Newtonian after dilution.

The lowest reported viscosity for a nominally Newtonian slurry is $0.001 \mathrm{~Pa}-\mathrm{S}$ (1 cP), which was reported by Fow, Scheele, McCarthy, Thorton, Heatih and Scott(b) for a sample 1:1 dilution of sample 2 from tank 103-SY. The highest viscosity is $0.086 \mathrm{~Pa}-\mathrm{s}(86 \mathrm{CP})$, which was reported for undiluted sluclge from sample 7 from tank 103-SY; after dilution the viscosity of this sample fell to $0.005 \mathrm{~Pa}-\mathrm{S}(5 \mathrm{cP})$. The solids concentrations of these two slurries were not reported. The viscosity of all slurries decreased on difution, which suggests that slurry viscosity increases with concentration.

It is expected that mixing behavior in the non-Newtonian slurries will differ somewhat from behavior observed in the Newtonian slurries. The effect of ron-Newtonian behavior on mixing behavior is difficult to quantify. In general, the existence of a fluid yield stress, $\tau_{y}$, is important relative to the consistency index, $K$, in regions where the fluid strain rate is low; the existence of a yield stress is less important in regions were the strain rate is high. During suspension efforts, the fluid strain rate will be low in regions far from the jet axis; in this region, the existence of a yield stress is likely to cause the particle settling velocity to decrease, which would impede settling. Unfortunately, the increased apparent viscosity $\left(\mu_{\mathrm{a}}\right)$ in this

(a) 1989 Draft Report. Pacific Northwest Laboratory, Richland, Washington. (b) 1986 Draft Report. Pacific Northwest Laboratory, Richland, Washington. 
region may also enhance the dissipation of turbulent kinetic energy. This dissipation could lead to greater settling in the region far from the nozzle exit because turbulent fluctuations aid particle suspension. The fluid strain rate is largest near the jet exit; thus, it is likely that the yield stress will have a smaller effect on jet development than on the behavior observed far from the tank.

It is difficult to make a general statement describing the rheology of the double-shell tank wastes. Some wastes are Newtonian; some are nonNewtonian. Some exhibit yield stresses; some do not exhibit yield stresses. Consequently, the mixing behavior must be predicted for a large variety of waste rheologies. Currently, mixing behavior in non-Newtonian slurries is poorly understood. It would be useful to determine which factors affect mixing in Newtonian slurries both because a number of waste slurries are Newtonian, and because an understanding of the mixing process in Newtonian fluids would serve as a baseline for understanding the behavior in nonNewtonian slurries.

\subsection{REVIEW OF TESTING}

Tests of phenomena related to the solids suspension are discussed in this section. In the Section 3.4.1 a study in which the feasibility of the jet mixer suspension system was investigated is discussed; this study was conducted by Rockwell Hanford Operations. The information gained from this experiment was evaluated to determine whether it could be applied to the current solids suspension study. In Section 3.4.2 the results of a small table top experiment that illustrates the effects of density differences on jet motion in a qualitative manner are presented.

\subsubsection{Tests Conducted in Tank TK-102-AP}

Preliminary tests to determine the feasibility of using mixer pumps to resuspend settled solids were performed by Rockwell in October of 1987; the results of this study were reported by V. L. Hunter (a). Tests were conducted using a mixture of water, sodium hydroxide, limestone solids, a sodium sulfate

(a) 1988 Draft Report. Westinghouse Hanford Company, Richland, Washington. 
solution, and disodium fluorescein dye. Data describing the suspended solids concentration in this test were examined and used to evaluate two unresolved questions about the important mechanisms governing suspension of solids in tanlis. These questions were 1) whether the test in tank 102-AP had already shovin that uniform mixing of settling solids could be achieved using fullspeed jets in a full-scale tank and 2) whether or not the changes in the jet density caused by nonuniformity in the solids concentration could affect the jet development by preventing it from rising. Unfortunately, little information could be obtained from this test because the solids concentration usecl was extremely low, and the actual accuracy of the concentration measurement was not reported. In addition, the size and settling velocity of the solids were not reported.

The test plan indicates that 1) in August, in preparation for the test, sodium hydroxide and water were added simultaneously through riser 1 (this shol:ld have resulted in a uniform sodium hydroxide mixture); 2) in october, crushed limestone was added through three risers; and 3) sodium sulfate and disodium fluorescein were then added in sequence through risers 1 and 22 , respectively. It is expected that the addition of crushed limestone would have eliminated any concentration gradients that may have existed in the sodium hydroxide solution, but that the sodium sulfate and disodium flucrescein would not have mixed with the sodium hydroxide solution during addition. The initial concentration of sodium sulfate, disodium fluorescence dye, and suspended solids were measured at risers 1, 16, and 22 at three tank elevations, which were referred to as top, middle, and bottom in the report.

The initial measurement indicated that the fluorescein dye was concentrated near riser 22, where it had been added; the two measurements taken from sample bottles near the bottom of riser 22 indicated concentrations of $1.058 \mathrm{~kg} / \mathrm{m}^{3}$ and $0.670 \mathrm{~kg} / \mathrm{m}^{3}$. The fluorescence concentration at the bottom of the riser was approximately $0.57 \mathrm{~kg} / \mathrm{m}^{3}$; the concentration at the two other risers did not exceed $0.15 \mathrm{~kg} / \mathrm{m}^{3}$. The sulfate concentrations ranged from 0.0089 molar near the top of risers 22 and 16 and 0.01 molar near the bottom at all three risers. Solids concentration at the beginning of testing ranged between $0 \%$ and $0.003 \%$ by weight; low concentrations of solids were expected at the beginning of testing because the solids rested on the bottom of the tank. 
Mixing was then initiated by activating the pump; the concentration of solids, sulfate, and fluorescein dye were measured at the sample locations to determine the time required to achieve uniform mixing. Once mixed, the concentrations of the dissolved chemicals are expected to remain uniform even in the absence of agitation. However, the solids can settle and require some agitation to remain uniformly distributed. The ability of the jets to maintain suspension of solids in the tank could be determined by measuring the solids concentration distribution in the tank during vigorous agitation.

Douglas ${ }^{(a)}$ reports that during vigorous agitation, the average concentration of suspended solids in the tank was found to be approximately $0.1 \%$ by weight. Had all solids in the tank been suspended, the solids concentration would have been $1.2 \%$, thus only $10 \%$ of the total solids added to the tank were suspended. (In comparison, it is unlikely that the solids concentration in double-shell tank wastes is as $10 \mathrm{w}$ as $1.2 \%$ by weight.) Measurements of solids concentration in core samples taken from tanks indicates that the solids concentration by weight \% ranges from $22 \%$ reported by Petersen, Scheele, and Tingey ${ }^{(b)}$ for a core sample from tank 101-AZ to $93.9 \%$ reported by Petersen $(c)$ for a core sample from tank 102-AZ. While it is likely that the core samples significantiy overrepresent the amount of solids in well-mixed wastes, it seems unlikely that the wastes contain less than $10 \%$ total solids. Thus, the test in tank 102-AP was conducted using wastes at much lower insoluble solids concentrations than expected in real wastes.

Nonuniformity in the solids concentration above the settled bed could not be detected during testing in tank 102-AP; the solids concentration was reported to be uniform on this basis. The concentration data indicate that the nonuniformity in the concentration was less than the resolution of the measurement method. Hunter reports that the procedure used to measure solids concentration allowed cross-contamination of samples. In addition, it was possible for solids to be lost when the samples were transferred from the grab bottle to the sample bottle; the magnitude of the errors introduced in this

(a) Westinghouse Internal Memo November 30, 1987.

(b) 1989 Draft Report. Pacific Northwest Laboratory, Richland, Washington.

(c) Correspondence to A. D. DiLiberto/L. M. Sasaki from M. E. Peterson dated February 16, 1990. 
manner was not quantified. As a result, it is not possible to state the level of resolution achieved during testing, or to state with precision what degree of uniformity was achieved.

Nevertheless, it does appear that the solids which were suspended were uniformly distributed in the liquid. However, it is a matter of great concern that on 1 y $10 \%$ of the solids in the tank were suspended at all. The data indicate that most of the solids were not suspended but remained on the tank floor. The videotape of the experiment shows that the region directly below the Jump intake was completely cleared, but that solids had collected near the tank wall. This distribution of solids suggests that the agitation provided by tie mixer pump was not sufficient to lift most of the particles off the tank floor. It is possible that the jet lifted particles in the vicinity of the jet intake, but that the fluid motion far from the jet was not sufficient to maintain suspension. Particles were then deposited near the wall.

It is important to note that only $10 \%$ of the solids in tank 102 -AP were remo'red when liquid was pumped from the tank; $90 \%$ of the solids remained in the tank ${ }^{(a)}$. The results from the test in tank 102-AP indicate that there is cause for concern regarding resuspension if the solids used in tank 102-AP are equivalent in size to those contained in double-shell tank wastes. The size distribution of the crushed limestone was not provided by Hunter (a), and thus, it is not possible to state whether the jet used in that test would be capable of miantaining suspension of the actual wastes contained in the double-shell tank:s.

The videotape of the mixing process shows that the mixing jet was able to reach the top of the tank without difficulty. It was suggested that the ability of the jet to reach the upper surface in the tests performed in tank $102-A P$ indicated that buoyancy effects could not be important during suspension of double-shel1 tank wastes. However, a liquid containing $0.1 \%$ solicls by weight, such as that used in tank 102-AP, is not expected to exhibit large: spatial density variations even if the solids are highly stratified. It appears highly unlikely that the mixture density of the jet in tank 102-AP differed from the mean liquid density by more than $0.1 \%$. The fact that no

(a) Westinghouse Internal Memo November 30, 1987. 
density effects were observed in this test does not imply that density effects are not possible when wastes containing significantly more solids are mixed. Thus, the importance of density gradients on mixing behavior in the waste suspension problem is not known, and cannot be ruled out on the basis of the experiment in tank 102-AP.

\subsubsection{Table Top Experiments on Froude Number Effect}

Table top experiments were performed to demonstrate a number of qualitative physical mechanisms that are expected to affect the mixing process in tanks. A pair of experiments were performed to show the difference between the motion of a neutrally-buoyant single-phase jet and a negatively-buoyant single-phase jet. A third experiment was performed to show the similarity between a dense single-phase jet and a negatively-buoyant solid/liquid jet. All experiments used ordinary equipment and the results were expected to be qualitative in nature.

In the first experiment, the reservoir was filled with tap water to which food coloring had been added. A $3.2 \times 10^{-3} \mathrm{~m}(1 / 8-i n$.) ID plastic tube with an attached glass elbow was used to syphon water from the reservoir into a pan filled with tap water. When the reservoir was elevated above the glass pan, water flowed and created a fluid jet. Fluid in the jet traveled to the wall and climbed the wall until the jet met the upper free surface. The velocity of the jet was varied during the test by changing the elevation of the reservoir; the jet was able to climb the wall at all elevations. The maximum reservoir elevation was approximately $0.9 \mathrm{~m}(3 \mathrm{ft})$.

In the second experiment, the reservoir was filled with a saturated saltwater solution that had a specific gravity of approximate 1.2 to which food coloring had been added; the pan was filled with tap water. Before reaching the wall, jet development was qualitatively similar to that seen in the first experiment. However, the jet was unable to climb the wall, even when the maximum head (reservoir height) was supplied. Instead the jet reversed direction and fluid flowed horizontally towards the opposite wall. The jet velocity, which was approximately $0.6 \mathrm{~m} / \mathrm{s}(2 \mathrm{ft} / \mathrm{s})$ was sufficient to allow fluid to reach the back wall of the tank and change direction again. Raising the elevation of the reservoir was found to allow the jet to climb the 
wall slightly, but a reservoir elevation of $0.76 \mathrm{~m}(2.5 \mathrm{ft})$ did not provide sufficient head to allow the jet to reach the free surface. The second experiment was repeated using saltwater with specific gravity of 1.05 . The results were similar; once again it was not possible to apply sufficient head to $a$ llow the jet to reach the free surface.

The goal of the experiment was to illustrate qualitative mechanisms that may affect the degree of mixing achieved in the tank. Approximate values of the Reynolds and Froude numbers for the test case were determined in a later test. The flow rate through the tube was determined by measuring the time required for the level of water in a reservoir to drop $0.025 \mathrm{~m}(1 \mathrm{in.})$. The reservoir was approximately circular with a diameter of $0.070 \mathrm{~m}(2-3 / 4 \mathrm{in.})$ the diameter of the reservoir was measured using a ruler. Time was measured using a wristwatch. The inside diameter of the plastic tube was reported to be $3.2 \times 10^{-3} \mathrm{~m}(1 / 8 \mathrm{in}$.$) ; this was confirmed using a ruler. The reservoir$ was elevated $0.9 \mathrm{~m}(3 \mathrm{ft})$ above the level of the pan and the time required for the top surface of the water to travel $0.025 \mathrm{~m}$ ( 1 in.) was determined to be $19.53 \mathrm{~s}$. The test was repeated and the time was determined to be $19.59 \mathrm{~s}$. Variation in velocity during actual demonstrations is expected to have occurred as a result of variations in reservoir height above the table. Consequently, all velocity values listed here are approximate.

The Froude and densimetric Froude numbers achieved during this test are listed in Table 3.3. These values assume that the velocity achieved during testing was not affected by the concentration of the saltwater and was approximately equal to the value measured in the water experiment. The Froude number achieved in al1 three experiments was 0.64 ; however, the densimetric Froude number, which governs the buoyancy effect, achieved for the fresh water jet was infinite. The densimetric Froude number for the saturated jet and dilute jet were approximately 4 and 13 , respectively. The Froude numbers to be achieved in the prototype of full speed and at one-quarter speed are 3.6 and 0.22 , respectively. The densimetric Froude numbers to be achieved cannot be known a priori. However, densimetric Froude numbers of 13 would be achieved if the density difference $(\Delta \rho)$ between the jet and the fluid were $27 \%$ when the jet operates at full speed and $\Delta \rho$ was $1.7 \%$ if the jet operates at 
TABLE 3.3. Comparison of Table Top Experiment with Prototype

\begin{tabular}{|c|c|c|c|c|c|c|c|}
\hline & $\begin{array}{c}\text { Jet Exit } \\
\text { Velocity } \\
U_{\mathrm{m} / \mathrm{s}}(\mathrm{ft} / \mathrm{s})\end{array}$ & $\begin{array}{c}\text { Tank } \\
\text { Height } \\
H, \\
m(\text { in. })\end{array}$ & $\begin{array}{c}\text { Nozzle } \\
\text { Oiameter } \\
\text { Dó } \\
\text { m(in.) }\end{array}$ & $\begin{array}{l}\text { Fluid } \\
\text { Densiţ̧y. } \\
\text { kg/m }\end{array}$ & $\begin{array}{l}\text { Density } \\
\text { Difference, } \\
\Delta \rho / \rho, \%\end{array}$ & $\begin{array}{l}\text { Froude } \\
\text { Number }\end{array}$ & $\begin{array}{l}\text { Densimetric } \\
\text { Froude Number } \\
\rho_{j} U_{o}^{2} / \Delta \rho g H\end{array}$ \\
\hline \multicolumn{8}{|l|}{ Table top scale } \\
\hline Fresh water & $\begin{array}{r}0.61 \\
(2)\end{array}$ & $\begin{array}{l}0.64 \\
(2.5)\end{array}$ & $\begin{array}{c}3.2 \times 10^{-3} \\
(1 / 8)\end{array}$ & 1000 & 0 & $6.4 \times 10^{-1}$ & $\infty$ \\
\hline Saturated saltwater & $\begin{array}{r}0.61 \\
(2)\end{array}$ & $\begin{array}{l}0.64 \\
(2.5)\end{array}$ & $\begin{array}{c}3.2 \times 10^{-3} \\
(1 / 8)\end{array}$ & 1200 & 16 & $6.4 \times 10^{-1}$ & 4 \\
\hline Dilute saltwater & $\begin{array}{r}0.61 \\
(2)\end{array}$ & $\begin{array}{l}0.64 \\
(2.5)\end{array}$ & $\begin{array}{r}3.2 \times 10^{-3} \\
(1 / 8)\end{array}$ & 1050 & 5 & $6.4 \times 10^{-1}$ & 13 \\
\hline \multicolumn{8}{|l|}{ Full-scale } \\
\hline full speed, $\Delta p=27 \%$ & $\begin{array}{c}17.9 \\
(58.8)\end{array}$ & $\begin{array}{c}9.1 \\
(360)\end{array}$ & $\begin{array}{r}0.15 \\
(6)\end{array}$ & 1000 & 27 & 3.6 & 13 \\
\hline $\begin{array}{l}\text { One-quarter speed. } \\
\Delta \rho / \rho=1.7 \%\end{array}$ & $\begin{array}{c}4.48 \\
(14.7)\end{array}$ & $\begin{array}{l}9.1 \\
(360)\end{array}$ & $\begin{array}{r}0.15 \\
(6)\end{array}$ & 1000 & 1.7 & $2.2 \times 10^{-1}$ & 13 \\
\hline
\end{tabular}

one-quarter speed. Because gravitational effects at Froude numbers as high as 13 were observed in the lab, this suggests that gravitational effects may be noticeable at full-scale.

A third experiment was performed using a mixture of sifted garden soil and water to form the jet. In this experiment, the jet was observed to reach the wall and turn around in a manner similar to that observed for the saltwater jet. The "mud" jet was not able to reach the free surface.

The three experiments performed illustrated qualitative effects on jet motion that arise as a result of fluid density differences. Fosset and Prosser (1951) had shown that the excess density could prevent a negatively buoyant free jet from rising to the top of the tank. It had been argued that the effect of buoyancy would be unimportant when a wall jet rose as a result of impact with the wall. Comparison of the motion of a neutrally buoyant jet and that of a dense jet illustrate that the effect of density differences is qualitatively similar; while a neutraliy buoyant jet rises readily, a dense jet with similar velocity does not. The third experiment, in which the mean jet density was caused by the addition of an immiscible phase (i.e., garden soil), the jet acted in a manner similar to the dense saltwater jet. This 
illustrated that the effect of the density difference on a two-phase jet will be similar to that seen in a single-phase jet.

It should be noted that the effects discussed here are qualitative, and that the importance of the density effect in solids suspension in the tank is not known. Density differences will arise in the tank only if the solids concentration is sufficiently high to affect the mean slurry density and if the solids are not uniformly suspended in the fluid. Petersen(a) reports that the first core sample from tank 101 -AZ contained $22.3 \%$ solids by weight. Gray, Petersen, Scheele and Tingey(b) report that the second core sample contained $81 \%$ solids by weight. A solids concentration of $22 \%$ would be sufficient to affect the mean spatial density of the fluid. If the tank contents were stratified, this could lead to some mean density gradients in the tank. Consequently, the possibility that qualitative effects similar to those seen in the table top experiments cannot be ruled out. Uniformity testing should be designed in a manner that would allow these effects to be observed if they occur in the tanks. This means that testing should be performed at Froude numbers that are equivalent to the Froude numbers observed in the tank. Testing at higher Froude numbers would tend to minimize the effects of density gradients and could produce overly optimistic predictions of the level of mixing that will be achieved in the tank.

\subsection{DESCRIPTION OF TEMPEST COMPUTER MODEL}

Numerical simulation of governing transport equations for fluid flow, heat transfer, and species constituent transport has become more common place in the analysis of complex engineered systems. Pacific Northwest Laboratory has been actively involved in this area for over 15 years. As a part of that involvement, the TEMPEST computer code as described by Trent and Eyler (1989) has followed an extensive and complex path to its present state (Figure 3.10). The code has evolved into a sophisticated, yet complex, analysis tool that has rather broad application to a wide variety of flow systems.

(a) 1989 Draft Report. Pacific Northwest Laboratory, Richland, Washington. (b) 1990 Draft Report. Pacific Northwest Laboratory, Richland, Washington. 
TEMPEST is based on numerical solution of finite volume approximated equations that govern momentum, energy, and mass transport of species. It is a transient, three-dimensional analysis tool that uses proven numerical schemes, yet requires knowledgeable application by the user.

Two primary TEMPEST development paths have been followed; both 1 ink back to a U. S. Department of Energy developed version, LMOD3, first released in 1983. The present day $\mathbf{N} 32$ version has followed the standard coordinate (Cartesian, cylindrical), explicit numerics route. The TX series has expanded to include boundary fitted coordinates, a semi-implicit numerical scheme for momentum transport, and numerous improvements in physics applications. Both versions of the code have been widely applied, but the N32 version is better documented. Presently, the TX version of the code is being consolidated to account for specialized application developments of recent years.

Early use of TEMPEST in waste tank analys is was reported by Eyler (1983) and 01 iver and Eyler. (a) These analyses were initial evaluations examining the ability of the code to compute physics of interest in the waste tanks subject to air-lift circulator operation. In this early work, capability to treat concentration dependent viscosity and settling solids was developed. These capabilities are required for the current analysis; however, the capabilities must be retested because the logic has not been exercised recently. Additionally, in the IX code version (the version planned for use in the uniformity analysis) other features are present that are (or may be) required. These features include the capability to model non-Newtonian (power 1aw) fluids, moving boundaries, and presentation of extensively enhanced graphics. Enhanced graphics are of utmost importance to evaluate computed results in large, complex systems.

Numerical solution of governing transport equations provides a means of coupling an extensive set of interacting phenomena. Subject to the limitations of the numerical approach and solution schemes, such a coupling can provide insights into effects that are difficult or impossible to measure.

(a) 1983 Draft Report. Pacific Northwest Laboratory, Richland, Washington. 


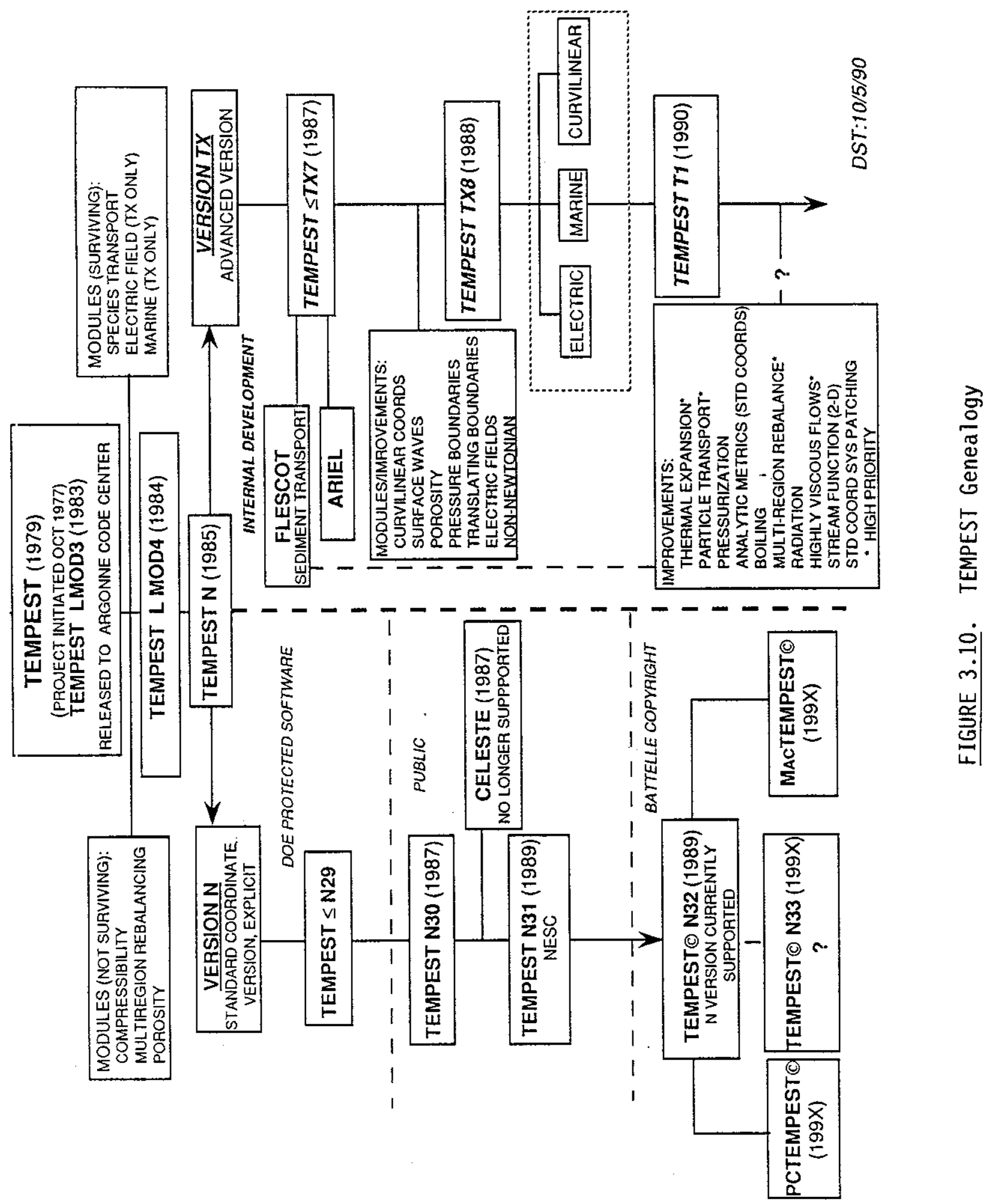


Analysis can be done on a fully coupled and integrated basis, or separate effects can be investigated to determine sensitivities. It is necessary in the long term, however, to ascertain the accuracy and validity of each complex application by relating the numerical predictions to measured experimental data for the purpose of qualifying and/or validating the numerical simulation tool. 


\subsection{OUTLINE OF STRATEGY}

A phased experimental and computational analysis program is proposed to analyze mixing phenomena of slurries in waste tanks. A flow chart outlining the strategy of the slurry uniformity investigation is presented in Figure 4.1. In the flow chart, each step is numbered. The justification for the steps and the anticipated results are described in this section.

A literature survey to identify theory and analyze experiments addressing issues similar to the problem of uniformity of slurry concentration within tanks was conducted and is summarized, see Section 3.1 [Step (1)]. Although similar experiments focusing on mechanical and jet mixing have been conducted, none of the experiments were of the scale or geometry of the double-shell tanks (see Section 3.4). The results of the literature and experiment review (Step 1) led to the recommendation of phased experimental and computational analyses to further investigate the phenomena of slurry mixing within tanks, Step (2).

From the literature and physics of the problem, dimensionless groups describing jet mixing were prioritized. In order of decreasing influence, the dimensionless groups are listed as gravitational settling number (Gs), Froude number ( $F r)$, and Reynolds number (Re). These groups, as well as the other dependent and independent variables of interest, are described in Section 3.0. The results of this activity (Step 2) led to defining the prototype operating range and the corresponding experimental region of interest.

To analyze mixing in tanks and associated slurry uniformity, a combination of allalytical, computational, and experimental tasks are identified and linked through an investigation strategy [Step (3b)]. The major components of the strat:egy are listed in Table 4.1 .

\subsection{COMPUTATIONAL MODELING}

Computational modeling is proposed to accomplish several objectives that fall into two basic categories: short term and long term. In the short-term cateşory, objectives include performing sufficient analysis and numerical 


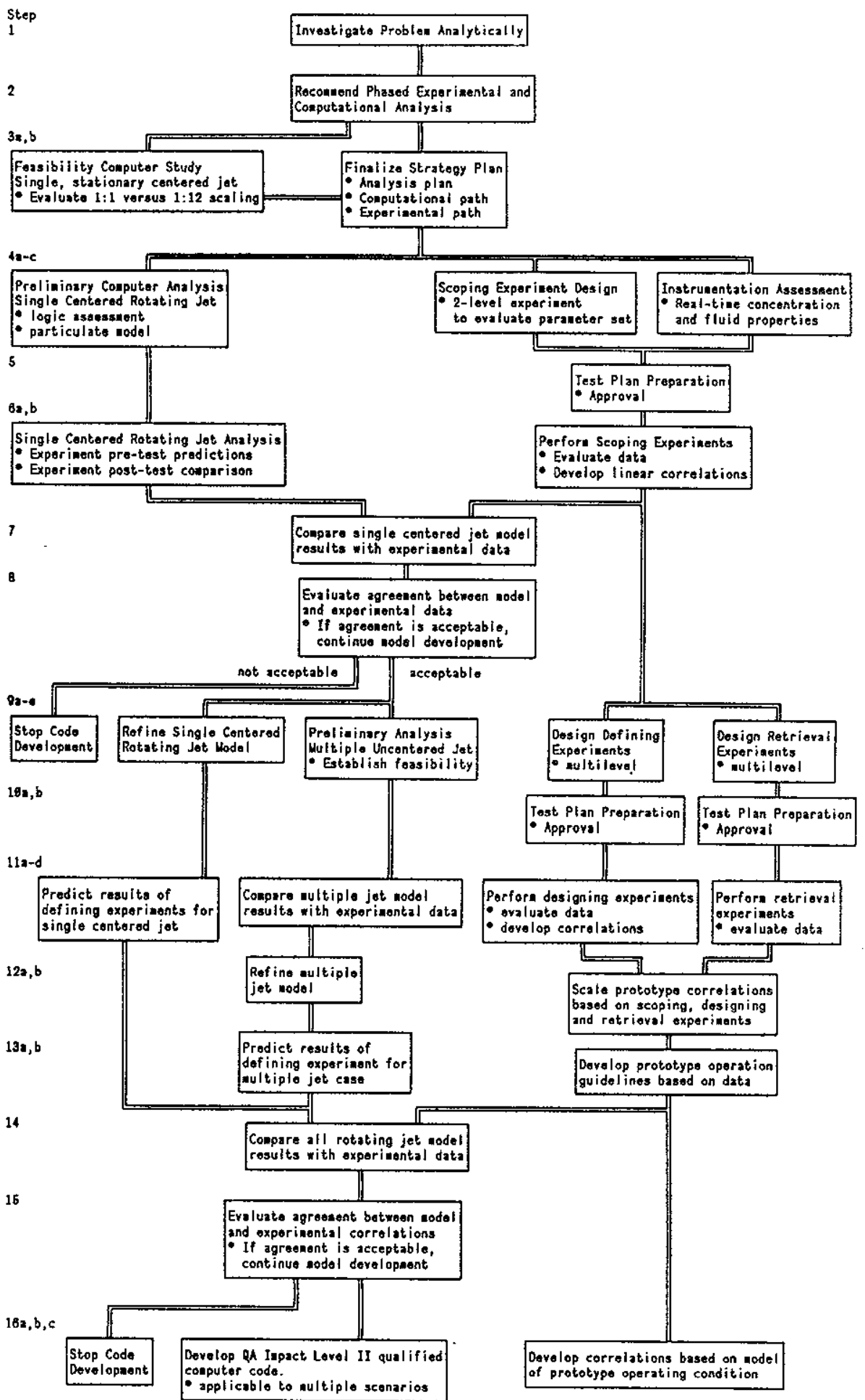

FIGURE 4.1. Investigation of Flow Chart Slurry Uniformity Within Tanks 


\section{TABLE 4.1. Strategy Activities}

\begin{tabular}{|c|c|}
\hline Analysis Activities & Step \\
\hline \multicolumn{2}{|l|}{ Compare } \\
\hline $\begin{array}{l}\text { - experimental data and } \\
\text { code predictions }\end{array}$ & $\begin{array}{l}7,8 \\
14,15,16 \mathrm{~b}\end{array}$ \\
\hline Computational Activities & Step \\
\hline \multicolumn{2}{|l|}{ Develop model } \\
\hline - nonrotating jet & $4 a$ \\
\hline - single rotating jet & $6 a, 9 b, 11 a$ \\
\hline - multiple rotating jet & $9 c, 11 b, 12 a, 13 a$ \\
\hline Validate model & $16 \mathrm{~b}$ \\
\hline Experimental Activities & Step \\
\hline \multicolumn{2}{|l|}{ Develop instrumentation } \\
\hline $\begin{array}{l}\text { - real-time method to } \\
\text { measure concentration }\end{array}$ & $4 c$ \\
\hline \multicolumn{2}{|l|}{ Uniformity experiments } \\
\hline - scoping studies & $4 b, 5,6 b$ \\
\hline - defining studies & $9 d, 10 a, 11 c$ \\
\hline Retrieval experiments & $9 e, 10 b, 11 d$ \\
\hline Develop correlations & $6 b, 12 b, 16 b$ \\
\hline $\begin{array}{l}\text { Provide recommendations } \\
\text { for prototype operation }\end{array}$ & $13 b$ \\
\hline
\end{tabular}

testing to allow making qualified decisions to direct the approach for the numerical simulation analysis. These objectives include

- evaluating the applicability of 1/12-scale scoping experiments by comparing results of flow simulations between prototype and scaled geometries based on a nonrotating jet model [Step (3a)]

- performing preliminary investigations of uncoupled, settling particle transport to evaluate coding logic and modeling approaches [Step (3a)]

- investigating modeling approaches incorporating jet rotational motion [Step (4a)]

- providing "blind" predictions of planned uniformity $1 / 12$-scale scoping experiments [Step (4a and $6 a)$ ]. 
Each of these computational modeling objectives provides support for qualifying the TEMPEST code as an analysis tool for use in investigating mixing phenomena in double-shell tanks. Once preliminary analysis is conducted with the code and data become available from the scaled experiments; a means exists for confirming computational capability.

Agreement and/or disagreement between numerical computations and the scaled experimental results will be examined closely. Decision points [Steps 8 and 15] in the strategy plan are included that will allow the continuance/cessation of numerical simulation as an analysis path. Assuming that the agreement is satisfactory, performing numerical simulation at prototype conditions provides a means of obtaining cost-effective insight into the coupled effects of mixing, jets, and solids settling in double-shell tanks. It is imperative, however, that sufficient initial qualification and analys is be done to understand what the numerical simulation is doing and that sufficient investigation of the comparison of computed results and measured data in the scaled experiments be done to understand the results of both.

Subsequently, it will be necessary to plan for further requirements. Long-term objectives include

- evaluating, qualifying, and validating the TEMPEST code for use under higher QA-level analysis [Step (16b)]

- extending analysis capabilities to other tank configurations through development and implementation of models for more advanced physics [Step $(6 a, 9 b, 9 c, 11 a, 11 b, 12 a, 13 a, 14)]$.

The decision points shown in the strategy plan [Steps 8 and 15] allow for reevaluating the direction of longer-term objectives.

\subsubsection{Model Evaluation}

The results of the scaled scoping experiments will be compared to the results of the preliminary numerical simulation [Step (4a and $6 a)$ ]. It is planned that at least one "blind" (meaning simulating the experiment as planned, prior to performing the experiment) calculation will be performed without jet rotation and without solids settling and that one "blind" calculation will be performed with jet rotation and with solids settling. 
The "blind" calculations are to be compared to measured data. Measured data from the planned scaled experiments will be sparse relative to the complete fluid and particulate flow field results of the numerical simulations. Thus, careful evaluation of the predictions and measurements must be done to best determine the level of agreement and/or disagreement so that competent decisions to recommend continuance of numerical and/or experimental aspects of the program can be made at appropriate times. It would be best to also perform a post-experiment simulation [Step (6a)], if important parameters such as fluid properties, jet rotation speed and jet velocity vary from the originally proposed values.

Once preliminary confirmation of agreement levels is made, numerical simulation of other scaled experiments will be necessary. At a minimum, numerical simulation of the three lower extremes of the experimental region of interest in the scaled experiments is needed (see Figure 3.9). These are corners of the region of interest: 1) Point A--low Reynolds number (Re)/low Froude number $(\mathrm{Fr}), 2$ ) Point B--low Re/high $\mathrm{Fr}$, and 3) Point C--high Re/low $\mathrm{Fr}$. In addition, it may be necessary to simulate dependencies of particle settling velocity (particle size). These cases are performed in addition to the numerical simulations already performed and marked as 1, 2, 3, and 4 on Figure 3.9. The results of cases 1 thorugh 4 are discussed in Section 5.0.

\section{1.:. Model Validation}

Validation of the numerical simulation modeling approach will be necessary to confirm the ability of TEMPEST to correctly compute the expected physics. The clata from the scaled experiments will be the initial data upon which conclusions of validity will be made. However, it is recognized that data from the planned experiments will be sparse meaning few specific sites are sampled, and that further validation may be necessary to satisfy long-term objectives of an analysis tool qualified to Impact Level II(a) [Step (13a)].

\subsubsection{Computational Prediction of Full-Scale Operation}

With successful completion of the comparison of numerical and experimental results performed at $1 / 12$-scale, the numerical analysis tool and the modeling

(a) Procedures for Quality Assurance Program. PNL-MA-70, Vol. 1. Pacific Northwest Laboratory, Richland, Washington. 
approaches defined in attaining that comparison would be used to predict ful1scale operation. At a minimum, scaling the numerical simulations to fullscale at the same three corners (Points A, B, and C, Figure 3.9) as in the earlier 1/12-scale region of interest would be necessary to ascertain the limits. Further, assuming that sufficient uniformity is attained or not attained at the corners of the prototype region of interest, the model could be used to determine the lowest limits of operation at which sufficient mixing (uniformity) is present.

\subsection{EXPERIMENTS}

Two sets of experiments, scoping experiments and defining experiments, are proposed to provide required data to develop correlations of slurry homogeneity within tanks over the range of mixer pump operation. Because the solids concentration in the tank may vary with time or process conditions during mixing with jets, it is desirable to observe the concentration fluctuations. Methods to measure average concentration as a function of time will be investigated to select the appropriate method [Step (4c)]. An appropriate real-time measurement system will be specified.

\subsubsection{Scoping Experiments}

Scoping experiments at 1/12-scale [Steps (4b and 6b)] are proposed to exercise the parameters of interest over an appropriately scaled range, to model mixing in the prototype. The scoping experiments will define whether the prioritization of dimensionless groups is correct [Step (1)].

The 1/12-scale facility is deemed adequate to perform scoping experiments. The 1/12-scale facility was constructed explicitly to model a double-shell tank including mixing pumps and air-lift circulator arrays and has been used to investigate sludge resuspension by Fow, Scott, Whyatt, and Ruecker(a).

\subsubsection{Defining Experiments}

Based on results of the scoping experiments, a second set of experiments will be recommended to quantify the functional relation between the parameters of interest [Step (9d and 11c)]. The test matrix will be expanded to permit

(a) 1987 Draft Report. Pacific Northwest Laboratory, Richland, Washington. 
evaluation of nonlinearities within the relations and will provide data to develop correlations. In addition, if uniform mixing is achieved for every case tested in the 1/12-scale scoping study, no further testing will be recommended. With uniformity, this recommendation can be made because greater unitormity is expected in the prototype than in the $1 / 12$-scale model tests.

The current analysis and inability to match all dimensionless parameters at the 1/12-scale(a), as discussed in Section 3.2, prompts the recommendation to conduct defining experiments at a larger scale (e.g., in the range from 1/6-scale to 1/3-scale). However, the time delay and increased cost required to clevelop a larger scale facility must be addressed in addition to the quality of cata when final recommendations are made whether to proceed with additional testing at 1/12-scale or at a larger scale.

\subsubsection{Retrieval Experiments}

To further quantify the role of slurry homogeneity required to provide an invariant slurry feed for disposal processes, retrieval experiments are proposed [Step (9d and 11d)]. The objectives of these experiments are to determine the concentration variation produced when slurry is retrieved. These data can be compared to data of slurry mixing in tanks to determine what mixer pump settings are required for a uniform concentration feed [Step (12b)]. Using data from both data sets, an acceptable prototype operating range can be specified [Step (13b)].

\subsection{MODEL EVALUATION}

The results of the scoping experiments will be compared with the results predicted computationally with and without jet rotation. These comparisons will be used to evaluate the TEMPEST code's ability to predict mixing phenomena. Recommendations will be made at this time as to whether or not code comparisons should continue. It is currently anticipated that additional code work will be recommended.

(a) In the scoping study performed in a $1 / 12-s c a l e$ model, experiments are limited to a turbulent jet Reynolds number regime, which limits operation to speeds corresponding to $25 \%$ to $100 \% \mathrm{U}_{0} \mathrm{D}_{\mathrm{O}}$ for the prototype. This corresponds to the range of interest for actual operation of the prototype. 
Based on 1/12- and larger-scale data, correlations will be developed to predict tank slurry uniformity as a function of mixer pump operating conditions (e.g., the percentage of design $U_{0} D_{0}$ ).

\subsection{SUMMARY}

A brief description of the anticipated path to be followed through the Slurry Uniformity Investigation flow chart (Figure 4.1) has been provided. The path is anticipated based on the analyses presented in this strategy plan; results from any step could change the preferred course. Additional details of the computational and experimental activities are provided in Sections 5.0 through 9.0. 


\subsection{COMPUTER INVESTIGATIONS OF TANK MIXING USING A SINGLE, CENTERED NONROTATING JET MODEL}

The TEMPEST computer code (Trent and Eyler 1989) can be used to model a stalionary jet that is centered in a tank. This orientation is similar to the single, centered mixing pump configuration proposed by Westinghouse Hanford Company to maintain a uniform concentration of slurry in some waste tanks. The TEMPEST computer code was used to evaluate the feasibility of proposing scaled experiments to be conducted in a 1/12-scale model of a double-shell tank. The computer modeling was conducted using a cylindrical coordinate-based grid and problem symmetry to model the flow velocity profiles that exist during tank mixing with a stationary jet. The results of this analysis are presented in this section. Section 5.1 lists the research objectives. Sections 5.2 . and 5.3 describe the approach and results, and Section 5.4 summarizes the limitations of the analysis.

\subsection{OBJECTIVES}

The preliminary numerical modeling effort was conducted to quantify the effects of geometry and Froude number scaling on the ability of the mixer pumf to maintain uniformity of the tank contents. Four computer simulations were performed using the TEMPEST computer code to determine flow characteristics for the waste tanks for various fluid properties and nozzle exit conditions. The objectives of these simulations were to evaluate the effects of scaling between the model and the prototype. Some simulations were conducted by arbitrarily selecting fluid properties to match all dimensionless groups simultaneously. The validity of scaled experiments was evaluated by matching 1/12-scale and prototype conditions using realistic fluid properties.

\subsection{ANALYSIS}

\subsubsection{Background}

The TEMPEST computer program was designed for use in analys is of fluid and thermal systems. The program is described in detail in Trent and Eyler (198.). For the purpose of these simulations, the mass, momentum, and spe- 
cies conservation equations are represented in finite difference form in TEMPEST. Simulation of turbulent flow fields is accommodated with the inclusion of a $k-\epsilon$ (a) turbulence model. The fluid is assumed to be incompressible. Transport of numerous species may be included in the computation.

The TEMPEST simulations are intended to produce steady-state flow field results. To obtain steady-state flow fields in TEMPEST, the simulations progress in time from some assumed initial condition until the changes in the flow field are insignificant over a time interval roughly approximating the characteristic time scale of the flow. For the tank uniformity cases in this study, this time scale would correspond to the "turn-over" time--i.e., the time required for a fluid element leaving the mixer pump to travel around the tank and return to the vicinity of the mixer pump suction. Typically, a flow field image is visually inspected as an initial assessment of the convergence to steady state. In addition, a few selected points may be considered in detail to compare the change in fluid velocity at these points. For the present simulations, however, a more extensive assessment algorithm was developed.

In this algorithm, the statistics generated from two measures of error are considered. In a point-by-point comparison of two vector fields, the vector from one field may differ from its counterpart both in direction and magnitude. To quantify the deviation in direction, the cosine of the angle between the vectors is calculated with the following algorithm:

$$
\operatorname{Cos}[\theta(\vec{x})]=\frac{\vec{u}(\vec{x}, t+T) \cdot \vec{u}(\vec{x}, t)}{|\vec{u}(\vec{x}, t+T)||\vec{u}(\vec{x}, t)|}
$$

This algorithm compares the velocities at the same point in the flow field, $\vec{x}$, for two representations of the flow field: one at time $t$ and one at time $t+T$. If the two fields agree exactly, the angle $\theta$ will be zero at all points

(a) " $k$ " represents turbulent kinetic energy and " $\epsilon$ " represents the dissipation of turbulent kinetic energy. In this model, $k$ and $\epsilon$ are used to determine the effective turbulent viscosity. 
in the flow field. Therefore, the values of $\operatorname{Cos}(\theta)$ would be one at all points in the flow field.

To quantify the deviation in magnitude, the following algorithm is used:

$$
\epsilon_{|\vec{u}|}(\vec{x})=\frac{|\vec{u}(\vec{x}, t+T)-\vec{u}(\vec{x}, t)|}{\left|\begin{array}{l}
\vec{u}_{\text {nozzle }} \mid \\
\mid
\end{array}\right|}
$$

Thi:s algorithm compares the difference in velocity magnitude at a common point in the flow field at two different times. The difference is normalized by the magnitude of the fluid velocity as it exits the pump nozzle. If the flow is not changing with time, the difference will be zero at each point in the flow field.

Applying these algorithms to two representations of the same flow field (one: at time $t$ and one at a later time $t+T$ ) produces two sets of information regarding the convergence of the solution to steady state. As mentioned, a steaidy-state comparison would result in a value of one for the orientation measure and zero for the magnitude measure at each point in the flow field. In $a$. numerical simulation that advances in time approaching a steady-state concition this will rarely be the case. Therefore, to assess the approach to convergence, the statistics generated from these algorithms are used. The two sets of data comprised by the pointwise deviations in vector orientation and magnitude each represent a distribution. When the statistics from these distributions indicate that the deviations are within acceptable ranges, the solutions are assumed to have converged to steady state. Typically, one might consider the mean, standard deviation, and range of the distributions as key statistical quantities for the assessment.

This approach was employed for the four TEMPEST simulations described herein. For all four cases, the statistics from the distribution of deviations in vector orientation produced means of greater than 0.985 (better than $1.5 \%$ error in the average), with standard deviations less than 0.073 and a range of 2 (essentially -1 to +1 ). Ideally, the standard deviation should be very close to zero and the range should be very close to +1 . That these values are markedly different than these ideal values is, in large part, 
because of the sensitivity of the computation of $\operatorname{Cos}(\theta)$ when the magnitude of the two vectors is quite small. Any misalignment of these two vectors is greatly amplified by their small magnitude. The statistics from the distribution of magnitude deviations produced mean errors of less than $1 \%$, with standard deviations of less than 0.002 and maximum deviations of less than $3 \%$. Based on these quantitative assessments, it was deemed that, for the intended purpose, the solutions had converged.

Figure 5.1 illustrates the computational grid used in these TEMPEST simulations. Just over 4000 nodes were used to represent the fluid domain in the tanks for each of the four cases considered. For the 1/12-scale cases, the node sizes in the radial and vertical directions were reduced by a factor of 12. Only one-quarter of the tank was modeled in each case. Symmetry boundary conditions were invoked along the $\theta=0^{\circ}$ and $90^{\circ}$ rays. Solid, noslip boundary conditions were invoked to represent the walls of the tank. The upper surface of the fluid domain $[\mathrm{H}=9.1 \mathrm{~m}(30 \mathrm{ft})$ for Case 1 and $H=0.76 \mathrm{~m}(2.5 \mathrm{ft})$ for Cases 2, 3, and 4] was modeled as a slip surface--that is, the velocity component normal to this upper surface was forced to zero in the computation. The pump was assumed to be centered azimuthally on the $\theta=0^{\circ}$ axis and radially on the tank centerline, $R=0 \mathrm{ft}$. The pump diameter is $1.1 \mathrm{~m}$ (42 in.) and was modeled as a momentum source in the TEMPEST simulations. Consequently, the fluid velocity corresponding to the exit velocity of the pump was imposed at $R=0.53 \mathrm{~m}$ (21 in.) over the first two azimuthal nodes of the model. Thus, the mixer pump exit velocity was imposed at $R=0.53 \mathrm{~m}(21 \mathrm{in}$.$) oriented along the rays corresponding to \theta=2^{\circ}$ and $\theta$ $=6^{\circ}$. The suction side of the pump was not explicitly modeled in these simulations.

This representation of the tank and its contents is sufficient to capture the overall features of the flow field, although the details of pump jet development and the wall boundary layers are not well represented with this node configuration. To resolve these features in TEMPEST would require a level of node development and corresponding computer run times beyond that required for this preliminary assessment. Despite this restriction, much can be learned from these simulations about the large-scale fluid motion in the tanks. 


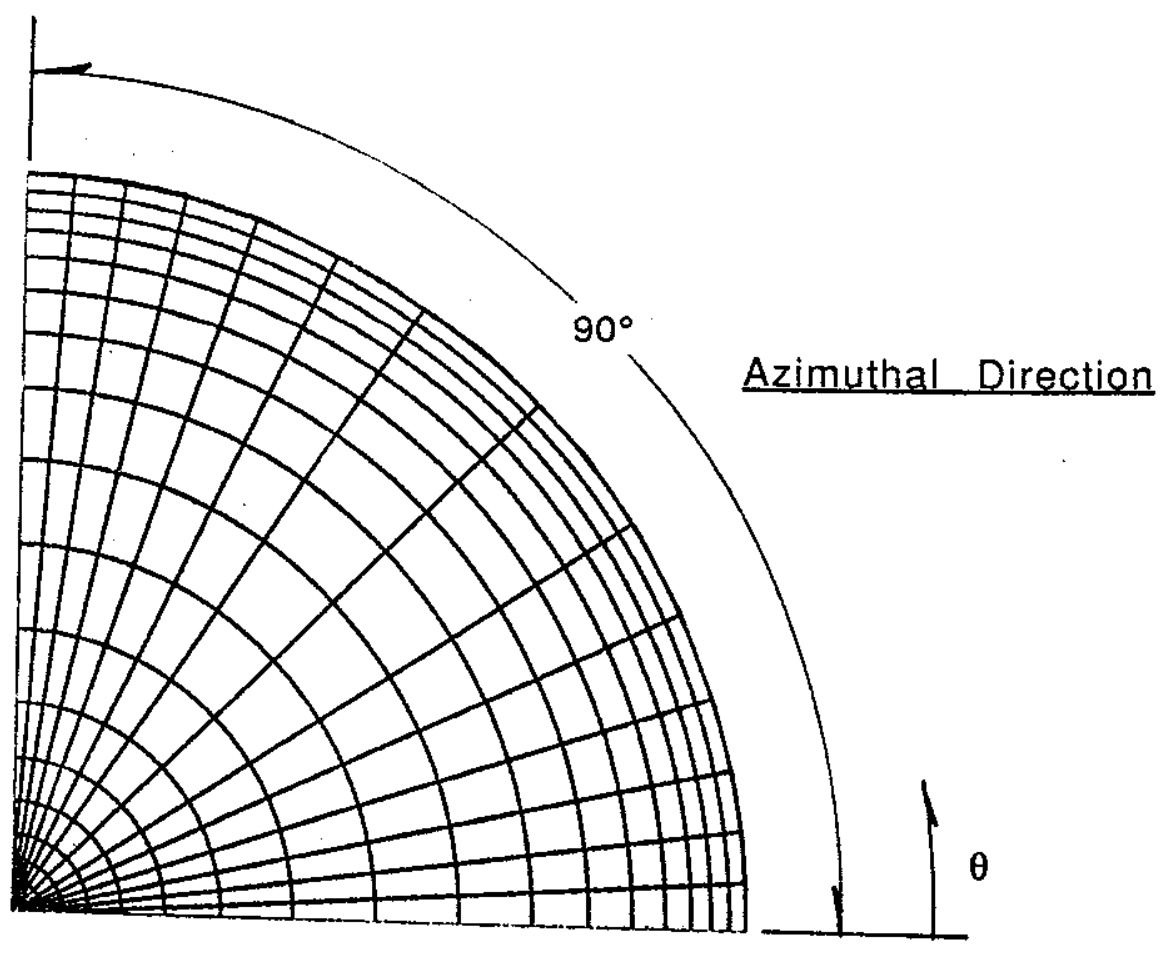

a) Horizontal Planes

\section{Radial Direction}

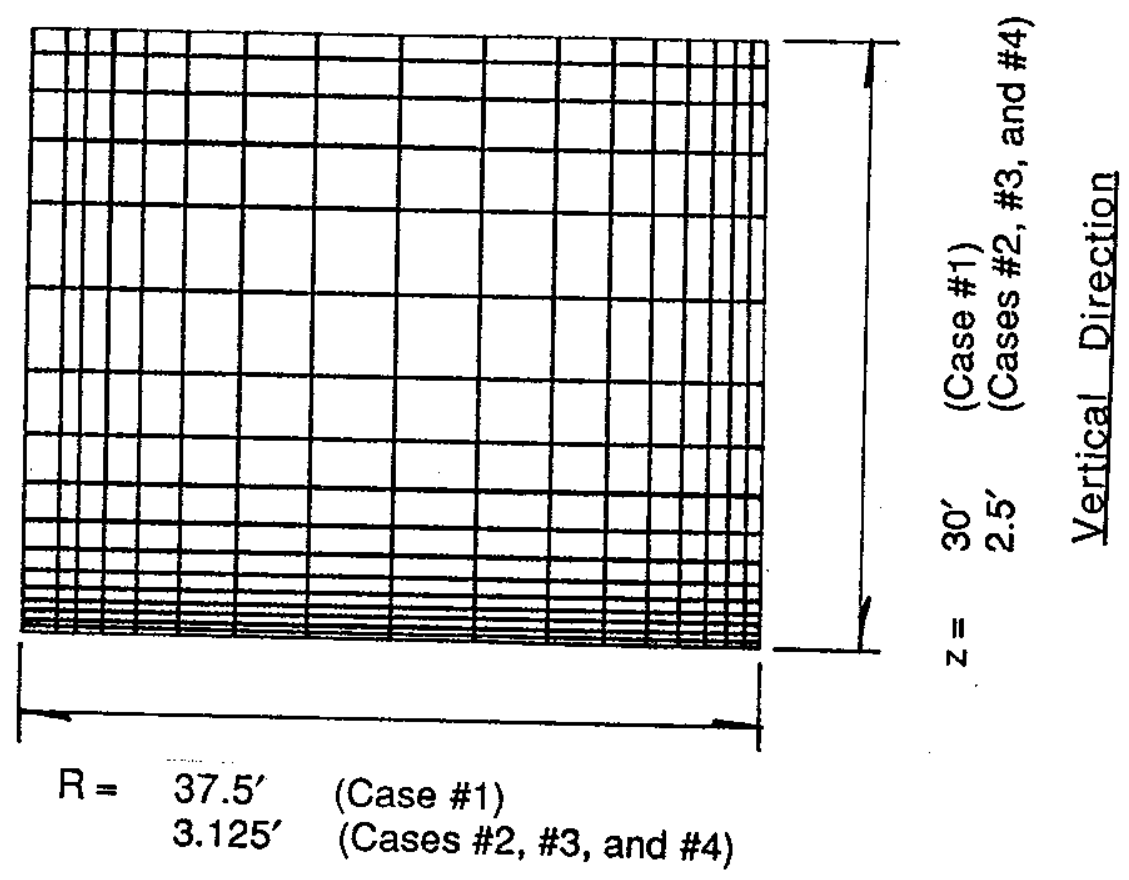

b) Vertical Planes

FIGURE 5.1. TEMPEST Computational Grid 


\subsubsection{Approach}

The simulations were made for the prototype and 1/12-scale conditions assuming one stationary mixer pump (centered in the tank) and no other internal tank components or obstructions to flow. One simulation modeled the fullscale tank geometry, while the other three simulations modeled the geometry of the 1/12-scale test apparatus. Fox and Gex (1956) indicate that for jet mixing, the homogeneity of the tank contents is only modestly dependent upon the jet Reynolds number $\left(R_{j}\right)$ when it is above a critical value of $\sim_{2000}$. The anticipated range of operating conditions for the prototype-scale tank uniformity study is well above this value (Table 5.1).

On the other hand, Fossett et al. (1949) indicates that the ability to mix the contents of a tank is a strong function of the densimetric Froude number [Equation (3.5)] for small values of the Froude number. Unlike the experiments of Fossett et al., the density of the fluid leaving the mixer pump in the waste tanks for this work is not a controlled parameter--it depends upon the uniformity of the tank contents. Therefore, the Froude number used herein depends only on the mixer pump jet exit velocity, $U_{0}$, and the tank fluid depth, H. With this definition of Froude number [Equation (3.9)], the Froude number range in the prototype is $0.22 \leq \mathrm{Fr} \leq 3.58$.

Consequently, two 1/12-scale simulations were performed at identical Reynolds numbers but at two different Froude numbers to assess the dependence upon Froude number; with the Reynolds number matching that of the full-scale case. For the 1/12-scale cases, all geometrical parameters were scaled linearly to $1 / 12$ that of the full-scale conditions. Thus, the tank diameter, fluid height, and pump inlet and outlet diameters were scaled down

TABLE 5.1. Prototype Parameter Range

Parameter
Pump operation
$U_{0} D_{0}$
Jet Reynolds number
Viscosity

$\frac{\text { Range }}{25 \% U_{0} D_{0} \text { to } 100 \% U_{O} D_{O}}$
0.410 to $2.73 \mathrm{~m}^{2} / \mathrm{s}(4.41$ to $29.4 \mathrm{ft} 2 / \mathrm{s})$
104 to 106
0.002 to $0.05 \mathrm{~Pa}-\mathrm{s}(2$ to $50 \mathrm{cP})$


appropriately. The jet velocity at the pump outlet was adjusted to obtain the desired Froude number. Similarly, the bulk fluid viscosity was adjusted to obtain the described Reynolds number. The bulk fluid density was not altered in the 1/12-scale tests so that the same specific gravity and mass frastion of the particulate relative to the bulk fluid could be maintained. The $U_{O} D_{0}$ combination chosen for the full-scale numerical simulation corresponds to the $25 \%$ operating condition for the pump. This is the estimated, reasonable lower-bound operating condition. It is expected that operating the pump at the $25 \%$ level will sustain the tank in a well-mixed state while reducing the power input and pump heat load to the tank contents (relative to the full-power operating condition).

In Table 5.2, the values of each of the dimensionless parameters for the four TEMPEST cases considered are listed. Case 1 corresponds to the simulation of the full-scale apparatus. Case 2 corresponds to the 1/12-scale appiratus with jet exit velocity $\left(U_{0}\right)$ and fluid viscosity $(\mu)$ adjusted to achieve the Reynolds and Froude numbers prescribed in Case 1. Therefore, compraring the results obtained from Case 2 with those of Case 1 indicates only' the effect of geometric scaling because all the dimensionless groups of interest are scaled appropriately. Case 3 represents the 1/12-scale apparatus witr: the bulk fluid viscosity $(\mu)$ set to that which will be used in the $1 / 12$ scale experiments $[0.002 \mathrm{~Pa}-\mathrm{S}(2 \mathrm{cP})]$. Jet exit velocity $\left(U_{0}\right)$ was adjusted for this case to obtain the full-scale Reynolds number with $U_{0} D_{0}$ of $25 \%$. The Froude number that results from this combination of parameters equals that expected for the full-scale apparatus. Thus, comparing the results of case 3 with those of Case 2 will enable an assessment of the effects of varying Froude number. Case 4 represents another potential experimental condition in the 1/12-scale apparatus with Froude number equal to Case 2 but the Reynolds number is reduced to 25\% of Case 2. Comparing the effects of Case 2 with Case 4 will provide information on the effects of varying only Reynolds number.

Each simulation was performed assuming a single mixer pump assembly. The mixer pump has two diametrically opposed, horizontal jets. In the prototype experimental configurations, the mixer pumps will either be 
TABLE 5.2. TEMPEST Simulation Parameters

\begin{tabular}{|c|c|c|c|c|}
\hline \multirow[b]{2}{*}{ Parameter } & \multicolumn{4}{|c|}{ Case } \\
\hline & 1 & 2 & 3 & 4 \\
\hline Scale & 1 & $1 / 12$ & $1 / 12$ & $1 / 12$ \\
\hline Reynolds number, Re & $4.1 \times 10^{4}$ & $4.1 \times 10^{4}$ & $4.1 \times 10^{4}$ & $1 \times 10^{4}$ \\
\hline Froude number, $\mathrm{Fr}$ & 0.22 & 0.22 & 3.58 & 0.22 \\
\hline Tank diameter, $D_{t}, m(f t)$ & $\begin{array}{l}23 \\
(75)\end{array}$ & $\begin{array}{l}1.91 \\
(6.25)\end{array}$ & $\begin{array}{l}1.91 \\
(6.25)\end{array}$ & $\begin{array}{l}1.91 \\
(6.25)\end{array}$ \\
\hline Fluid height, $H, m(f t)$ & $\begin{array}{l}9.1 \\
(30)\end{array}$ & $\begin{array}{l}0.76 \\
(2.5)\end{array}$ & $\begin{array}{l}0.76 \\
(2.5)\end{array}$ & $\begin{array}{l}0.76 \\
(2.5)\end{array}$ \\
\hline Pump outlet diameter, $D_{0}, m$ (in.) & $\begin{array}{l}0.15 \\
(6)\end{array}$ & $\begin{array}{l}0.01 \\
(0.5)\end{array}$ & $\begin{array}{l}0.01 \\
(0.5)\end{array}$ & $\begin{array}{l}0.01 \\
(0.5)\end{array}$ \\
\hline$U_{0} D_{0}, m^{2} / \mathrm{s}\left(\mathrm{ft}^{2} / \mathrm{s}\right)$ & $\begin{array}{l}0.68 \\
(7.29)\end{array}$ & $\begin{array}{l}0.017 \\
(0.18)\end{array}$ & $\begin{array}{l}0.066 \\
(0.71)\end{array}$ & $\begin{array}{l}0.017 \\
(0.18)\end{array}$ \\
\hline$U_{0}, \mathrm{~m} / \mathrm{s}(\mathrm{ft} / \mathrm{s})$ & $\begin{array}{l}4.44 \\
(14.57)\end{array}$ & $\begin{array}{l}1.28 \\
(4.21)\end{array}$ & $\begin{array}{l}5.17 \\
(16.97)\end{array}$ & $\begin{array}{l}1.28 \\
(4.21)\end{array}$ \\
\hline Percent of full-scale $U_{0} D_{0}$ & 25 & 0.6 & 2.4 & 0.6 \\
\hline Power-to-volume ratio $\left(\mathrm{W} / \mathrm{m}^{3}\right)$ & 0.27 & 0.08 & 5.04 & 0.08 \\
\hline Bulk fluid density $\left(\mathrm{kg} / \mathrm{m}^{3}\right)$ & 1250 & 1250 & 1250 & 1250 \\
\hline Bulk fluid viscosity, $\mathrm{Pa}-\mathrm{s}, \quad(\mathrm{cP})$ & $\begin{array}{l}2.1 \times 10^{-4} \\
(0.21)\end{array}$ & $\begin{array}{l}4.8 \times 10^{-4} \\
(0.48)\end{array}$ & $\begin{array}{l}0.002 \\
(2.0)\end{array}$ & $\begin{array}{l}0.002 \\
(2.0)\end{array}$ \\
\hline Particle diameter $(\mu \mathrm{m})$ & 100 & 8 & 17 & 17 \\
\hline Particle density $\left(\mathrm{kg} / \mathrm{m}^{3}\right)$ & 2500 & 2500 & 2500 & 2500 \\
\hline Particle mass fraction (Wt\%) & 25 & 25 & 25 & 25 \\
\hline $\begin{array}{l}\text { oscillated through } 180^{\circ} \text { at } 1 \mathrm{rpm} \\
\text { computer simulations considered h } \\
\text { preliminary simulations were inter } \\
\text { into the experimental program witl } \\
\text { requirement, combined with the vel }\end{array}$ & $\begin{array}{l}\text { rotated } c \\
\text { in did NO } \\
\text { to expl } \\
\text { existin }\end{array}$ & $\begin{array}{l}\text { tinuously } \\
\text { model this } \\
\text { e trends } \\
\text { computer }\end{array}$ & $\begin{array}{l}0.1 \text { rpm. } \\
\text { ump motior } \\
\text { provide } \\
\text { l. This }\end{array}$ & $\begin{array}{l}\text { The } \\
\text { These } \\
\text { sight }\end{array}$ \\
\hline
\end{tabular}


modifications are required), increases the justification of the approach described. Moreover, Rajaratnam (1976) indicates that, at these low pump rotiation rates and relatively high jet speeds (at the pump outlet) for the first half of the jet's travel toward the tank walls, the resulting axial velocity will not differ significantly from that which would be realized in the stationary jet case. For axial positions beyond $\sim 30$ jet diameters, Rajiratnam (1976) indicates that there will be a substantial deviation in the axicl velocity of the jet for the rotating case when compared with the stationary jet. However, in this region the effect from the tank walls will sigrificantly influence the development of jet velocity profile, regardless of the pump rotation rate. The conditions described in Rajaratnam (1976) do not address these boundary condition effects.

\subsection{RESULTS}

Tank uniformity assessments for each of the four cases considered were performed in two parts. In the first part, the steady-state flow field was comfuted using the TEMPEST computer code. The tank geometry, mixer pump exit jet velocity, and fluid properties were modeled in these simulations. In the seccnd part, the computed flow fields were used to assess slurry uniformity.

\subsubsection{Flow Fields}

Plots of the velocity vector fields are provided in Figures 5.2 through 5.17 for each of the four cases considered. Each figure provides the flow fields realized on a particular plane of the simulation. To orient the reader, the relative location of these planes is indicated by the small figure in the center of each page. For example, Figure 5.2 illustrates the velocity vector fields realized on the vertical plane coincident with the $\theta=2^{\circ}$ ray. This ray is highlighted in the central plot in this figure. The nodal velocity vectors presented in each plot frame have been scaled on the maximum velocity for that frame. Consequently, when comparing the relative magnitude of the flow velocities between cases, the maximum fluid velocity must be considered. The maximum fluid speed for each plot frame is indicated (in $\mathrm{ft} / \mathrm{s}$ ) near the right border of each figure. 

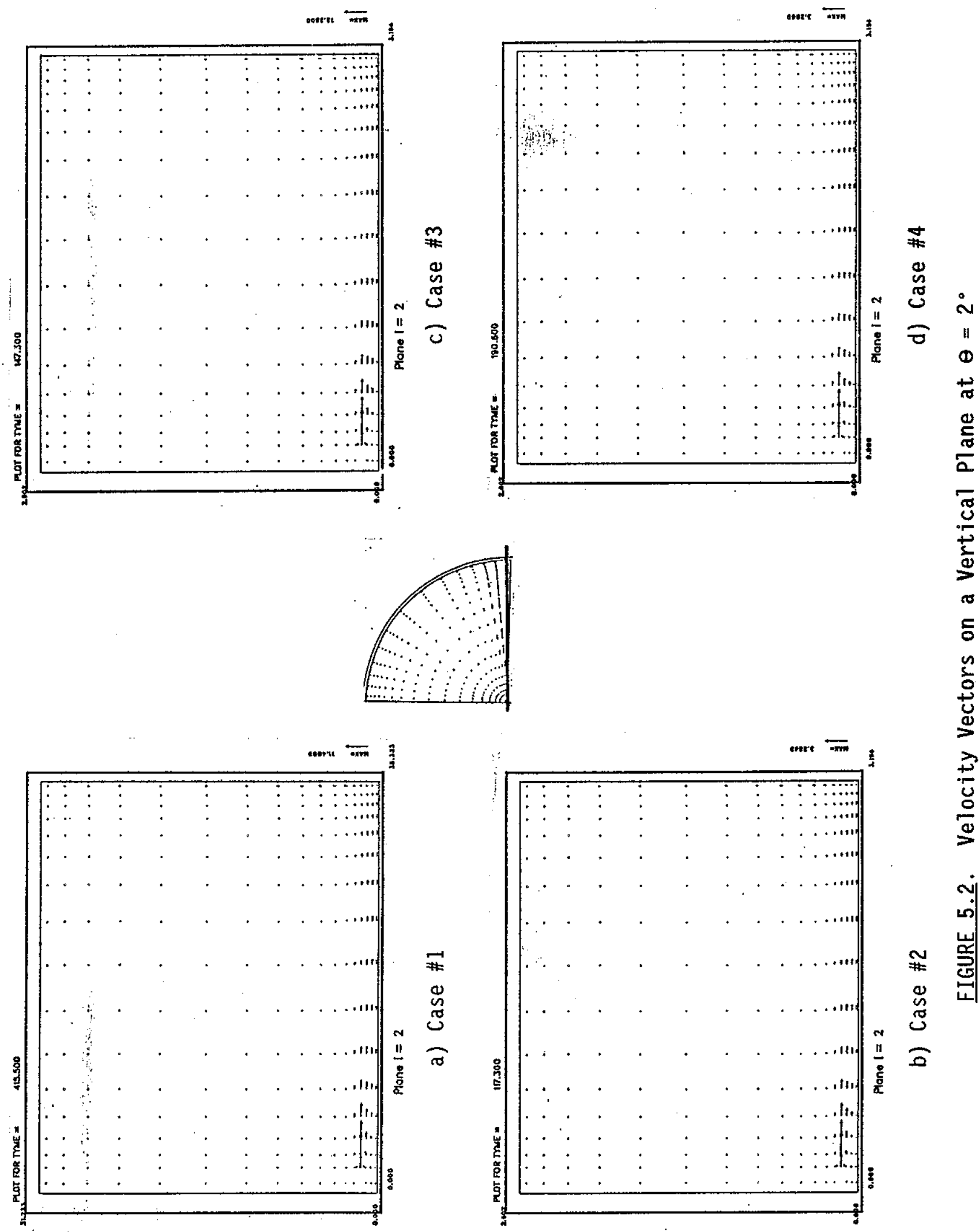

矛 

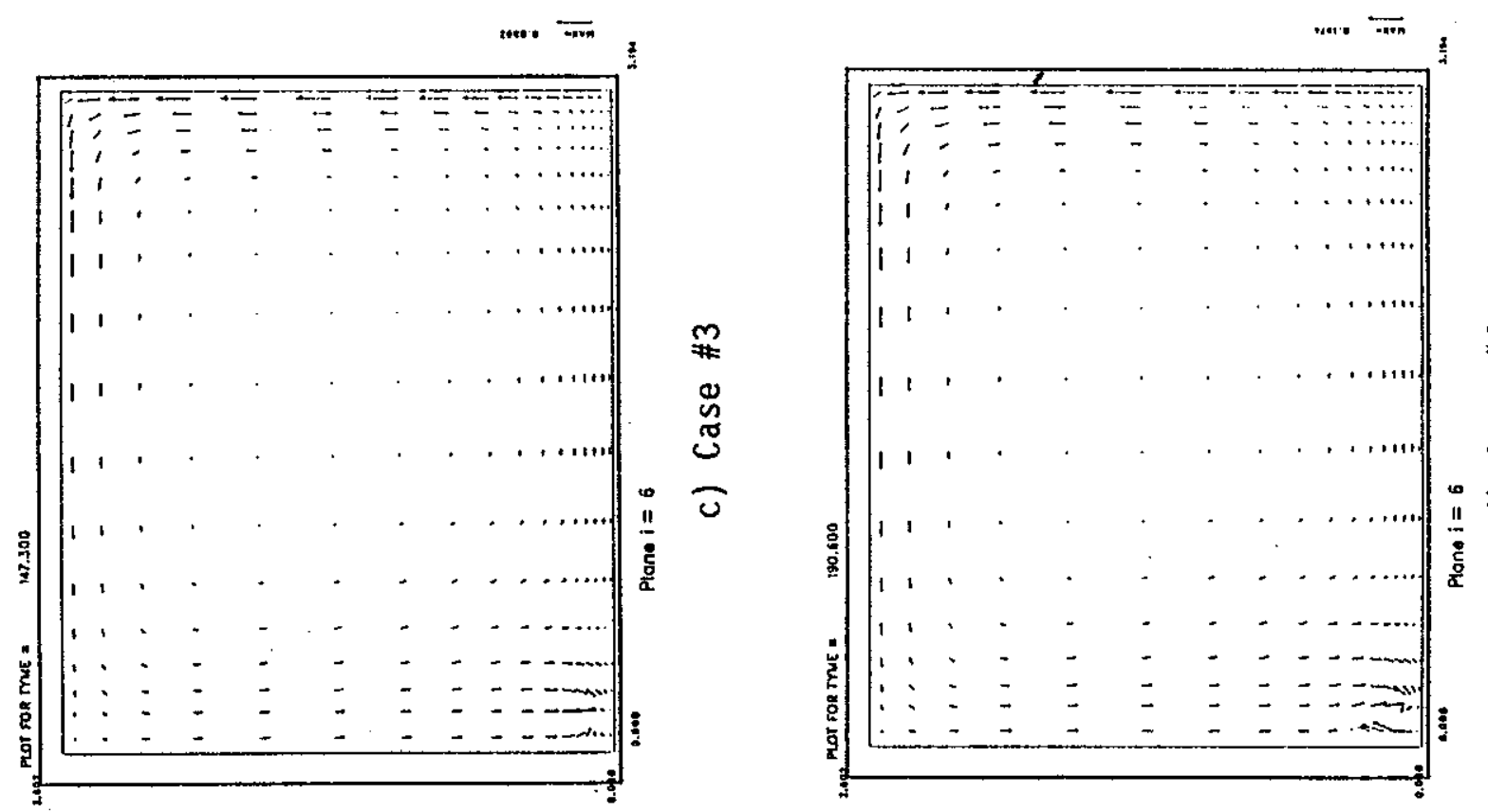

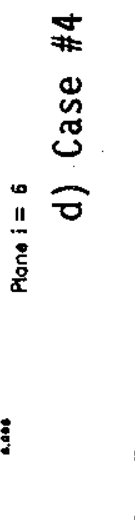

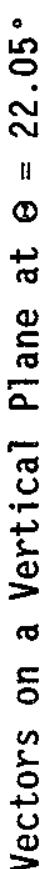
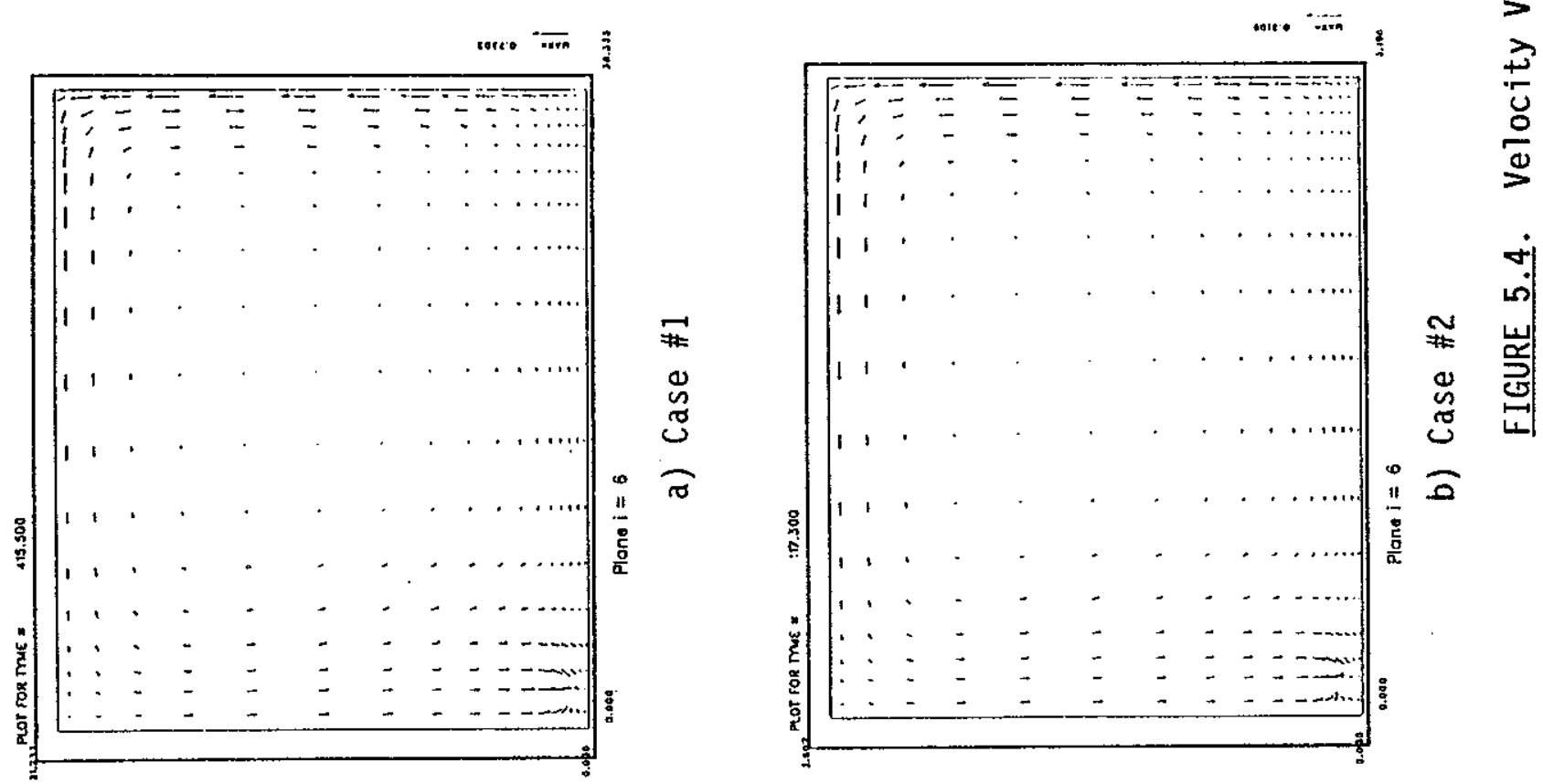

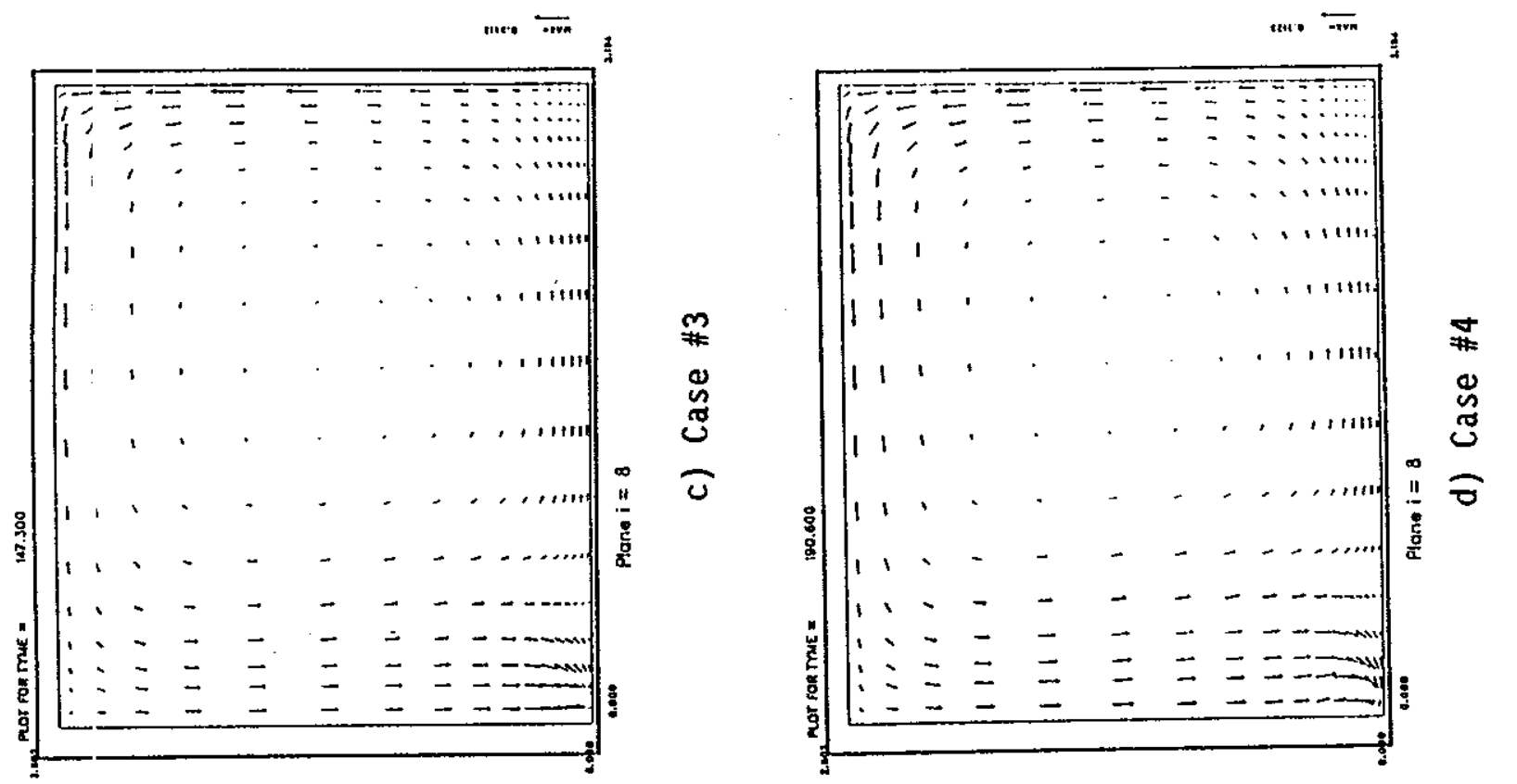

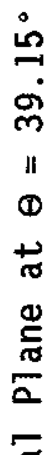

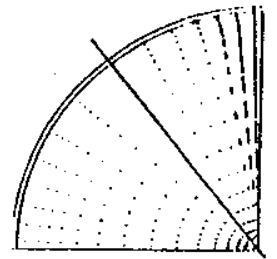

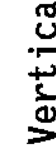
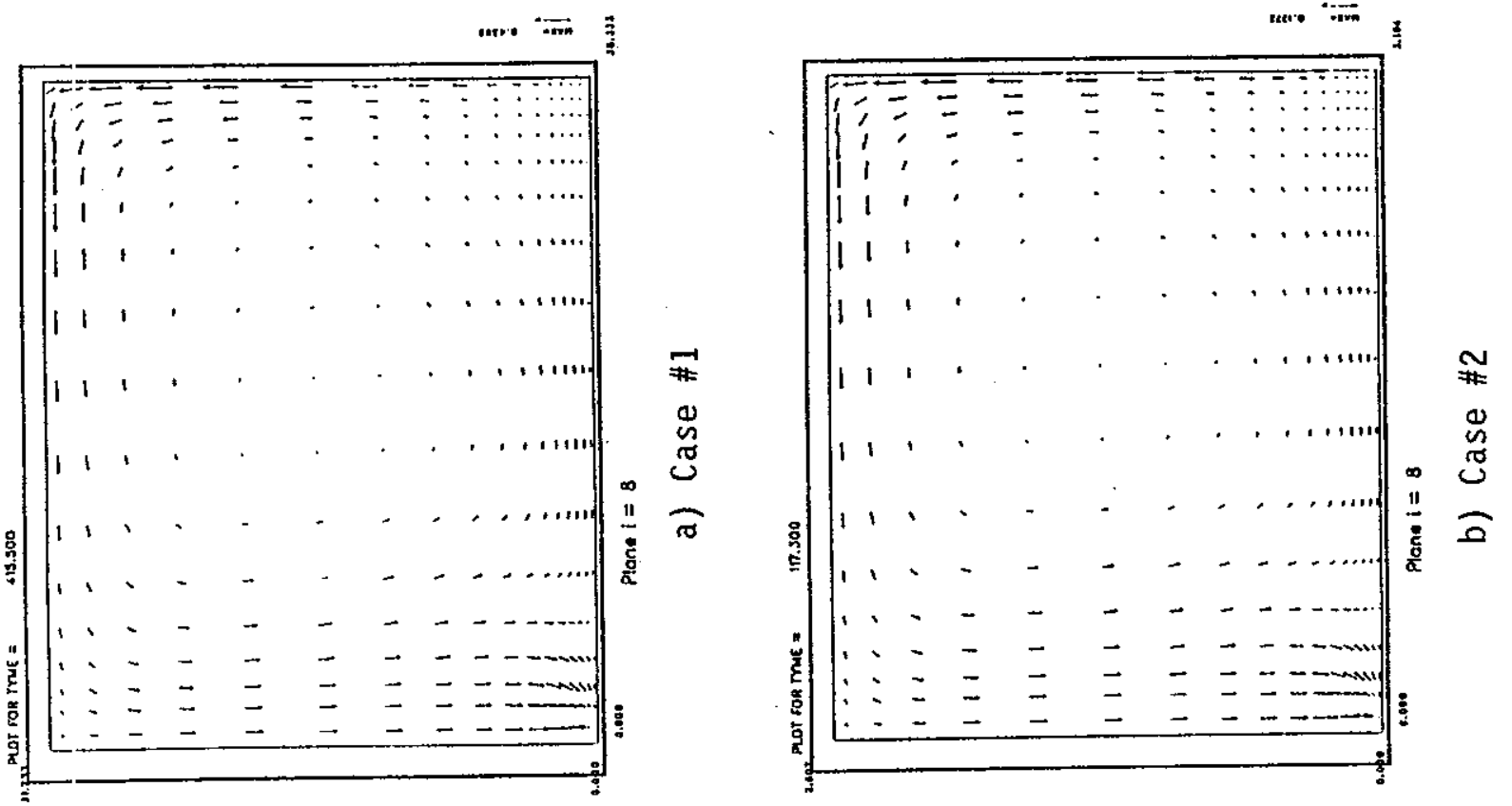

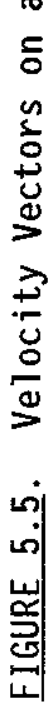



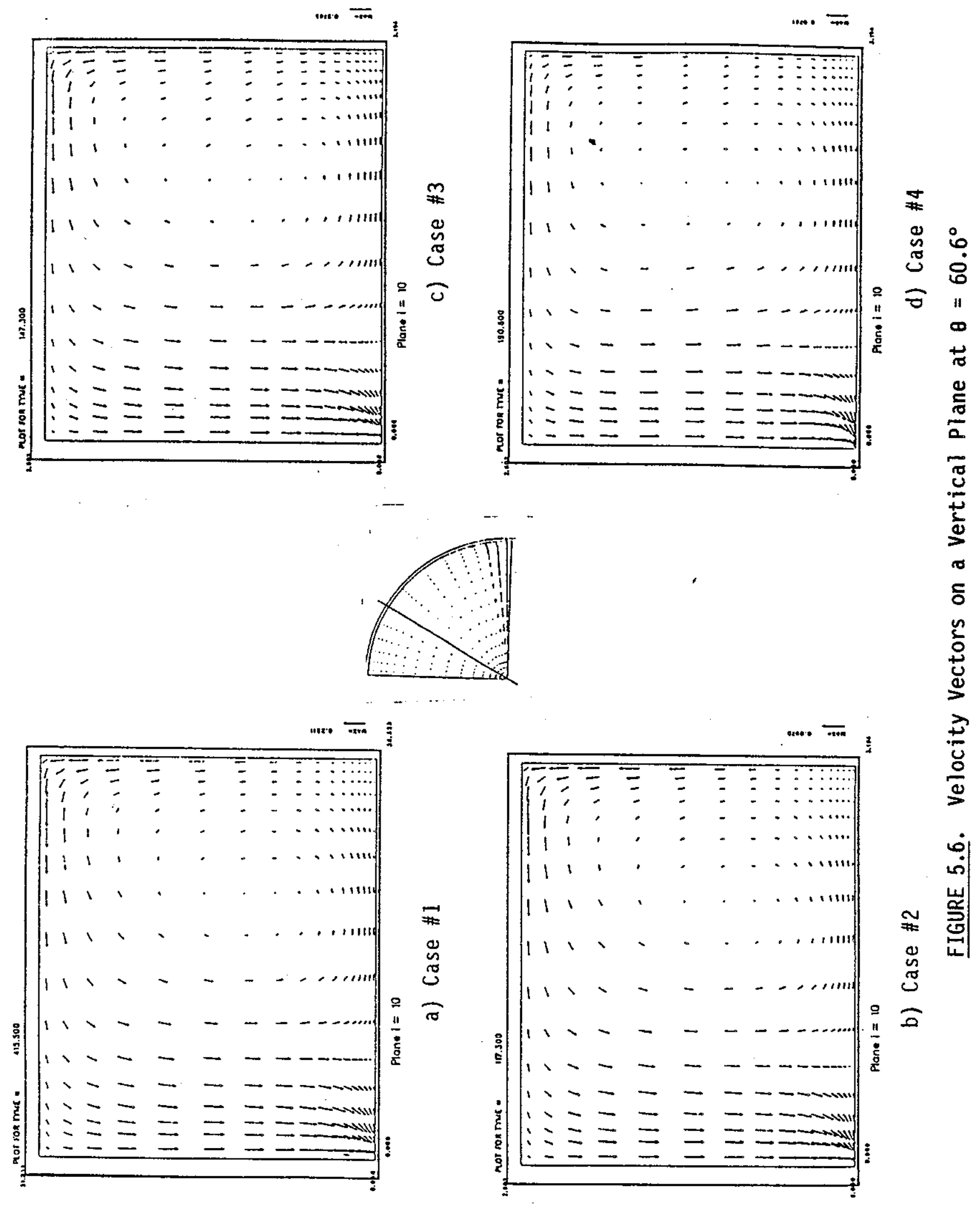

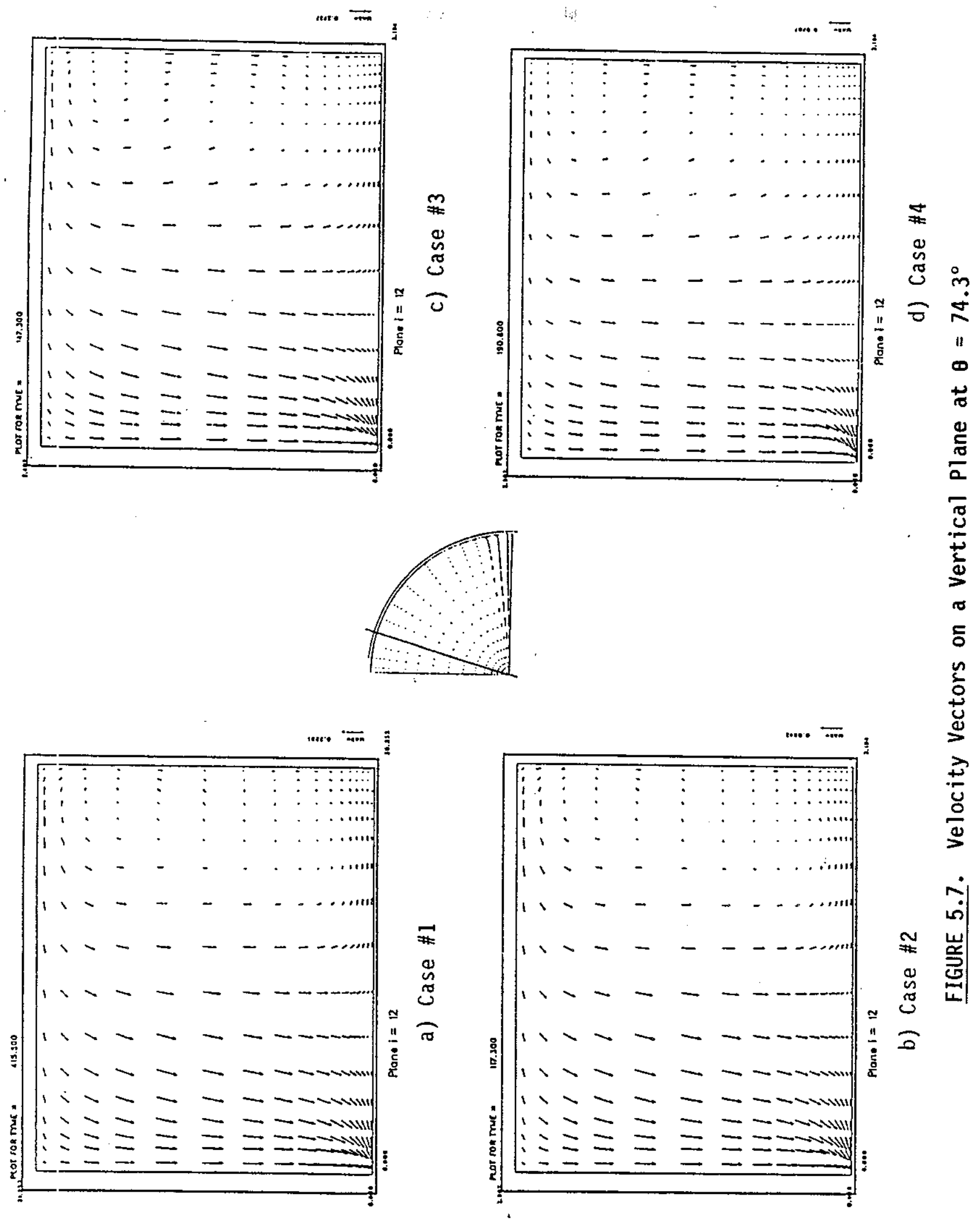

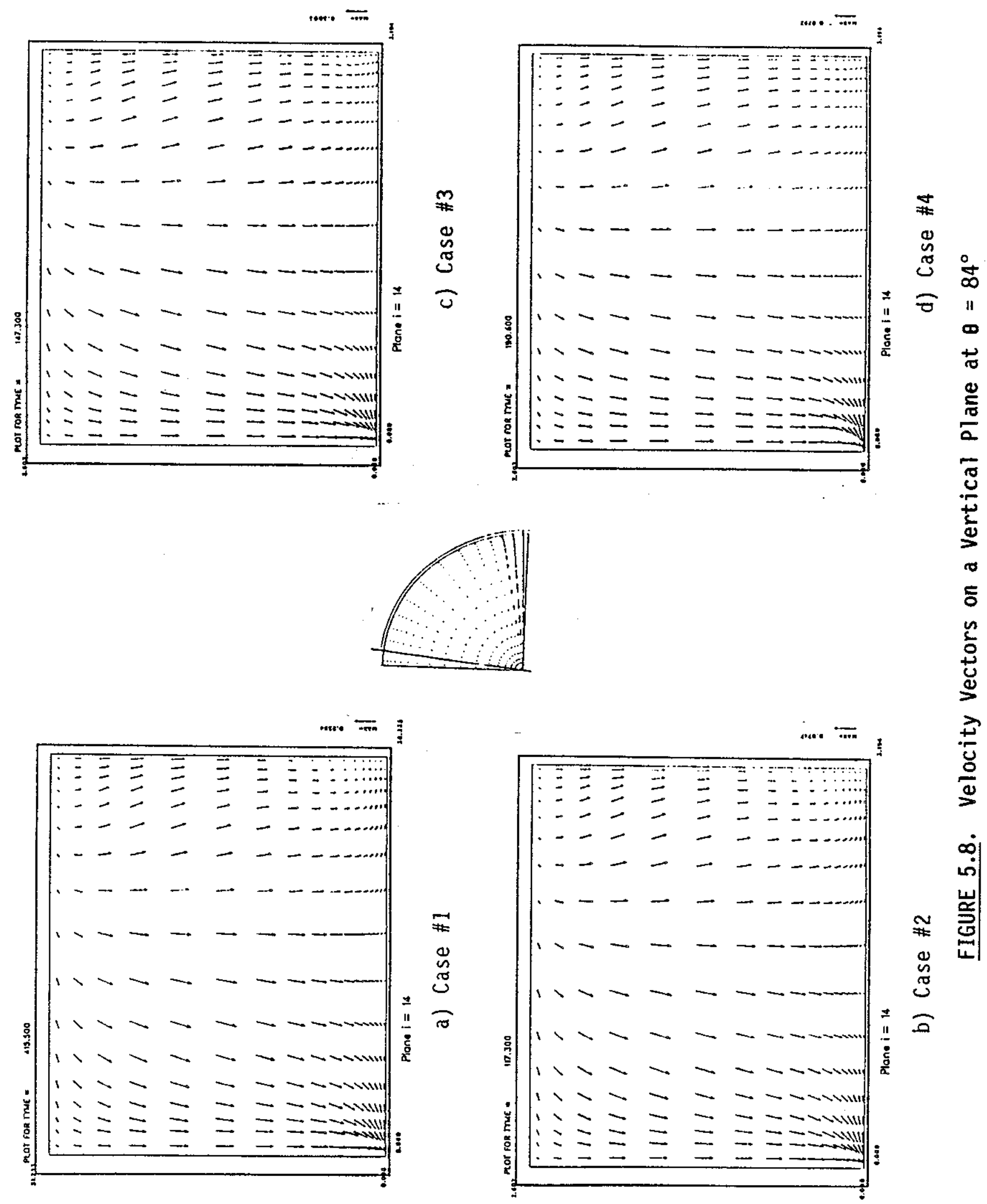

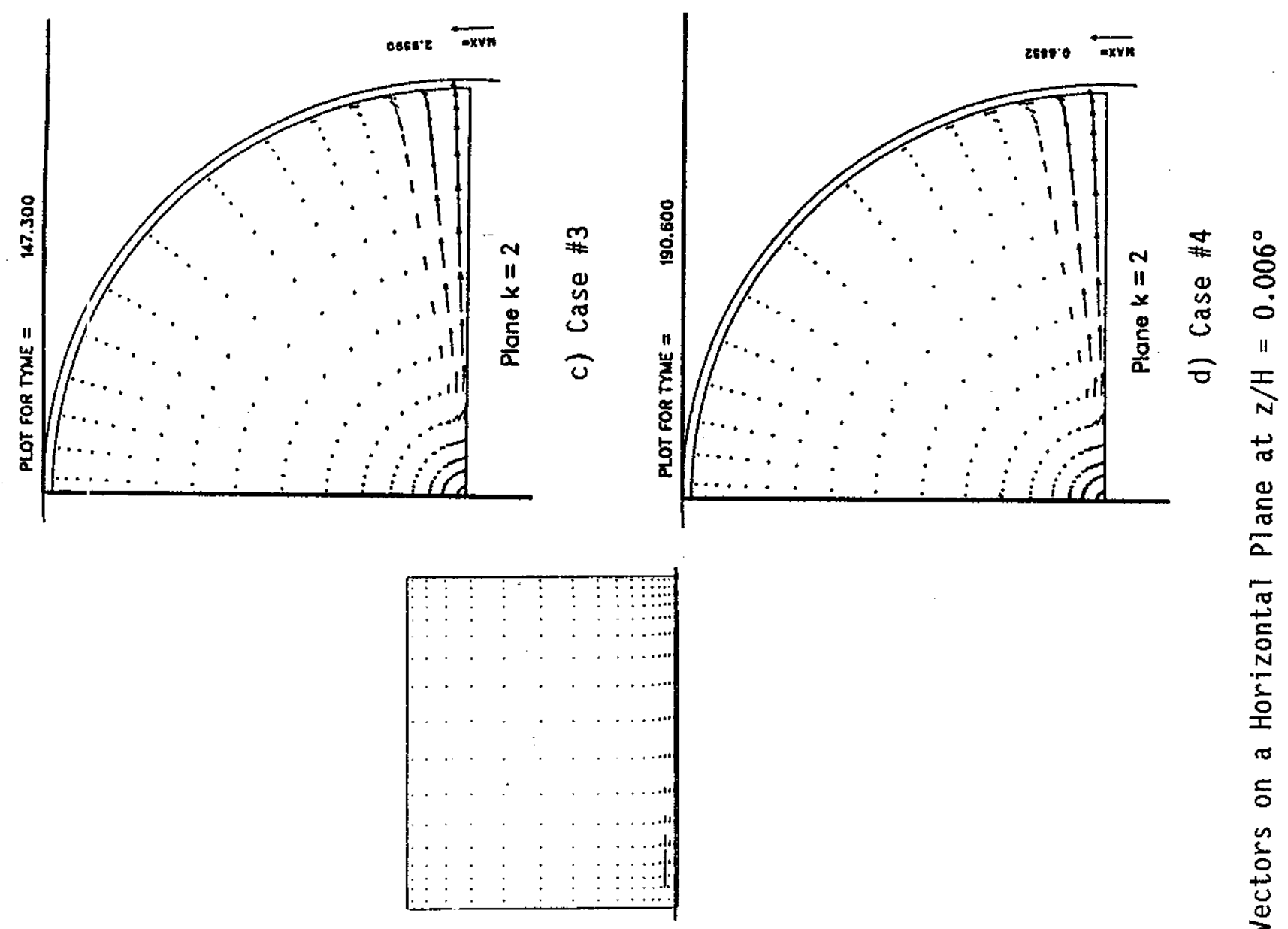

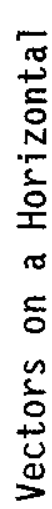
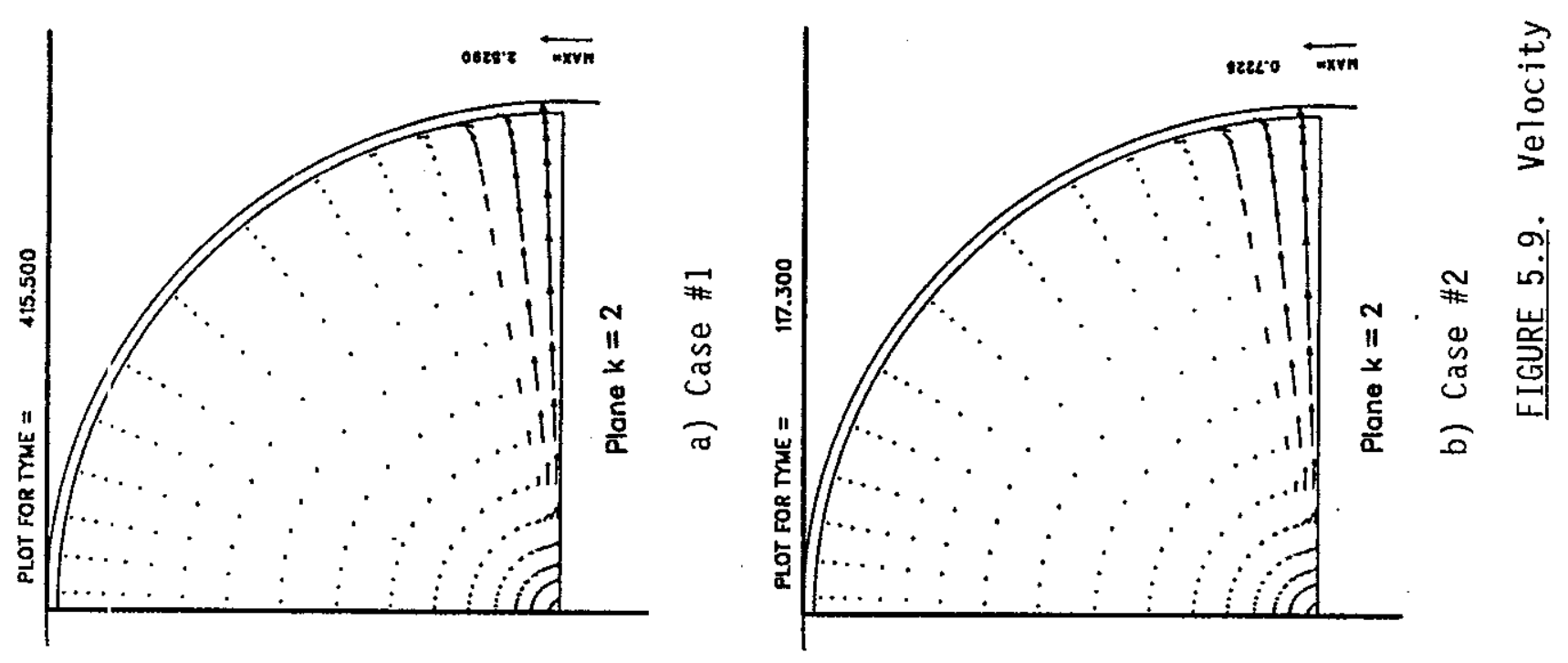

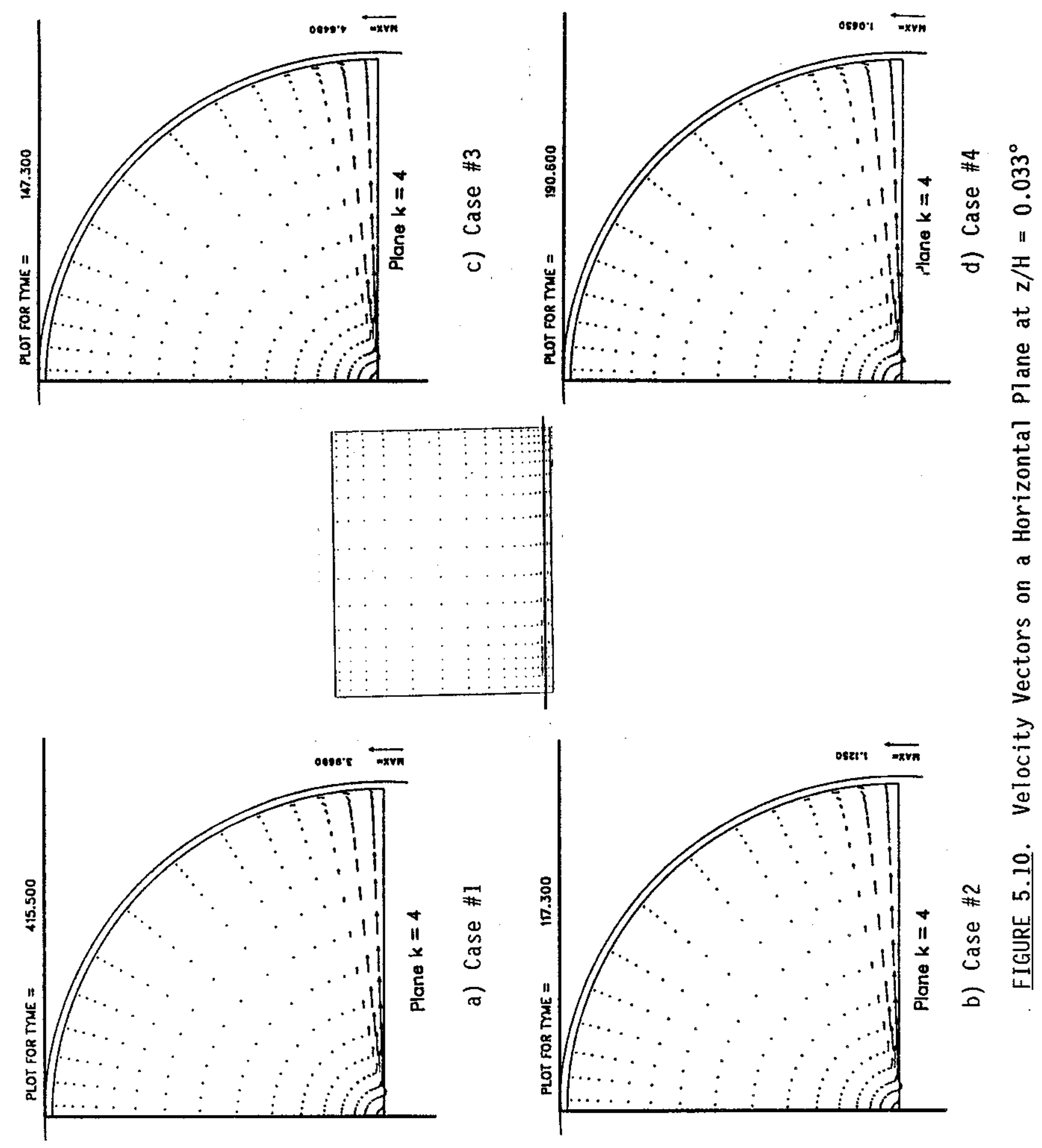

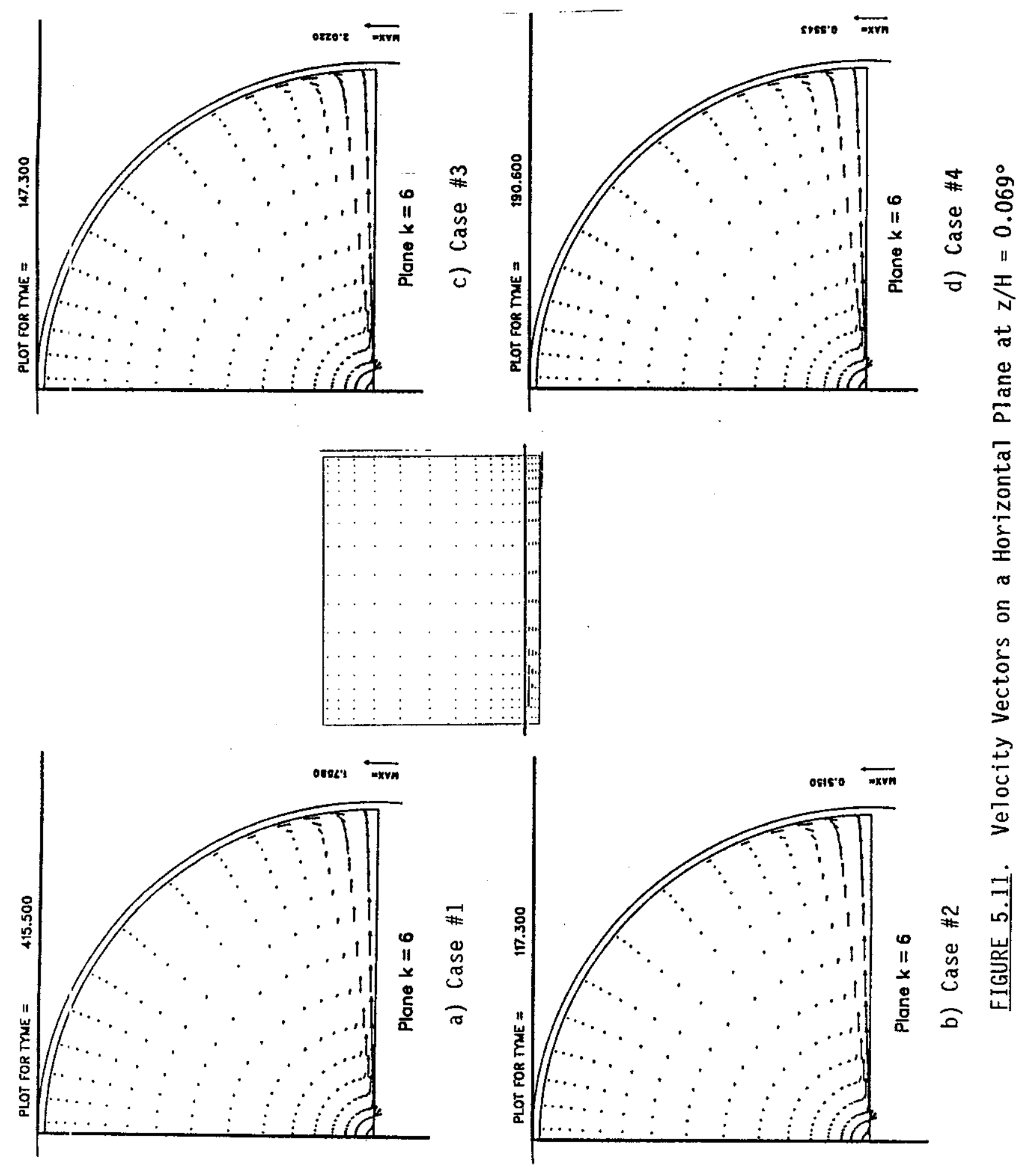

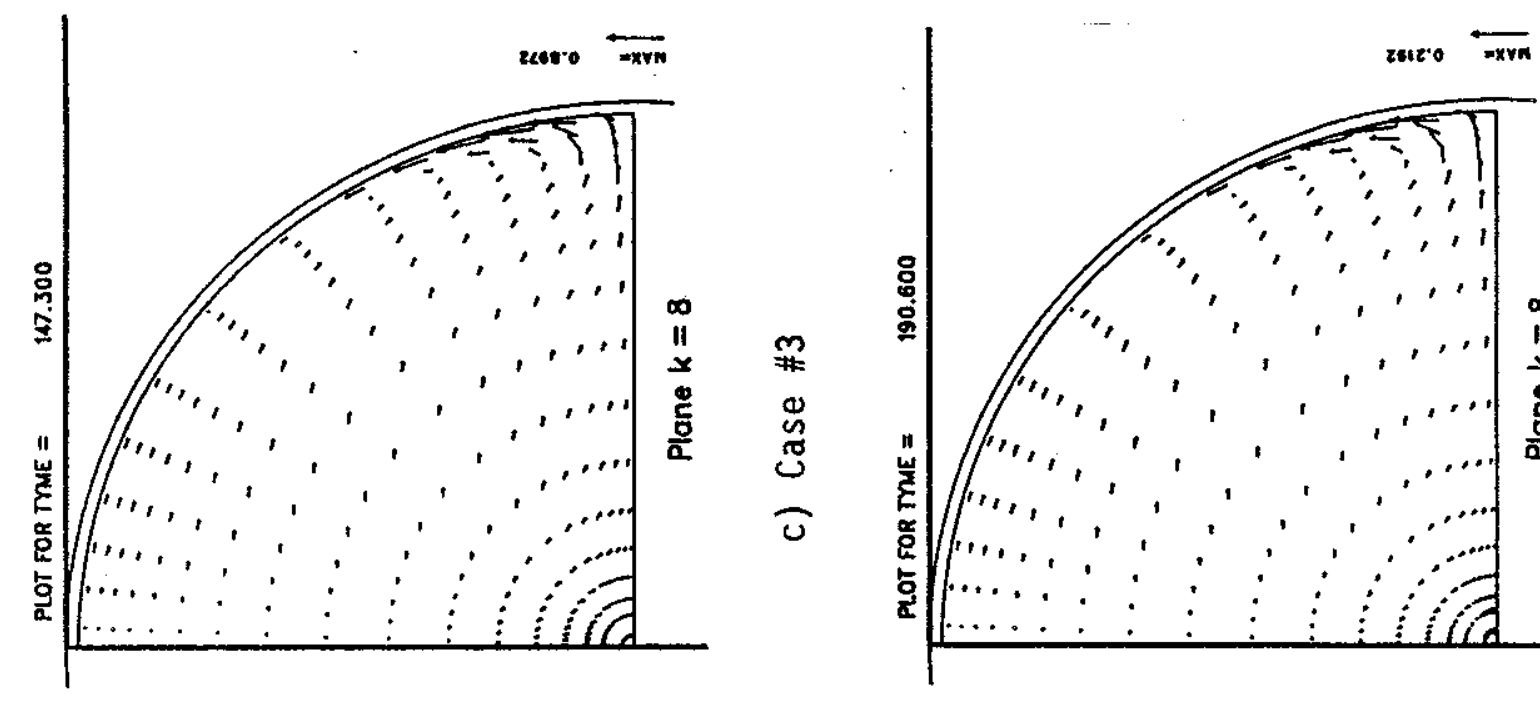

$\frac{1}{13}$

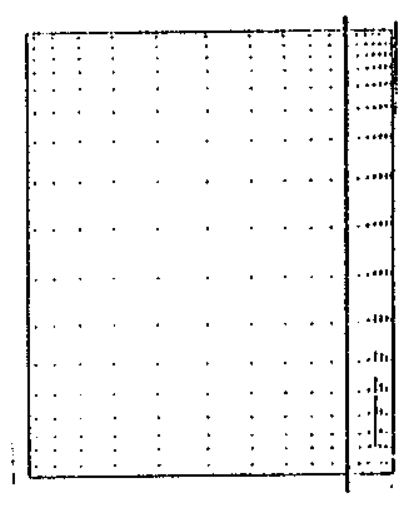

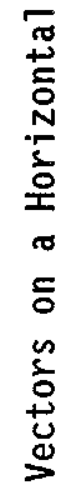
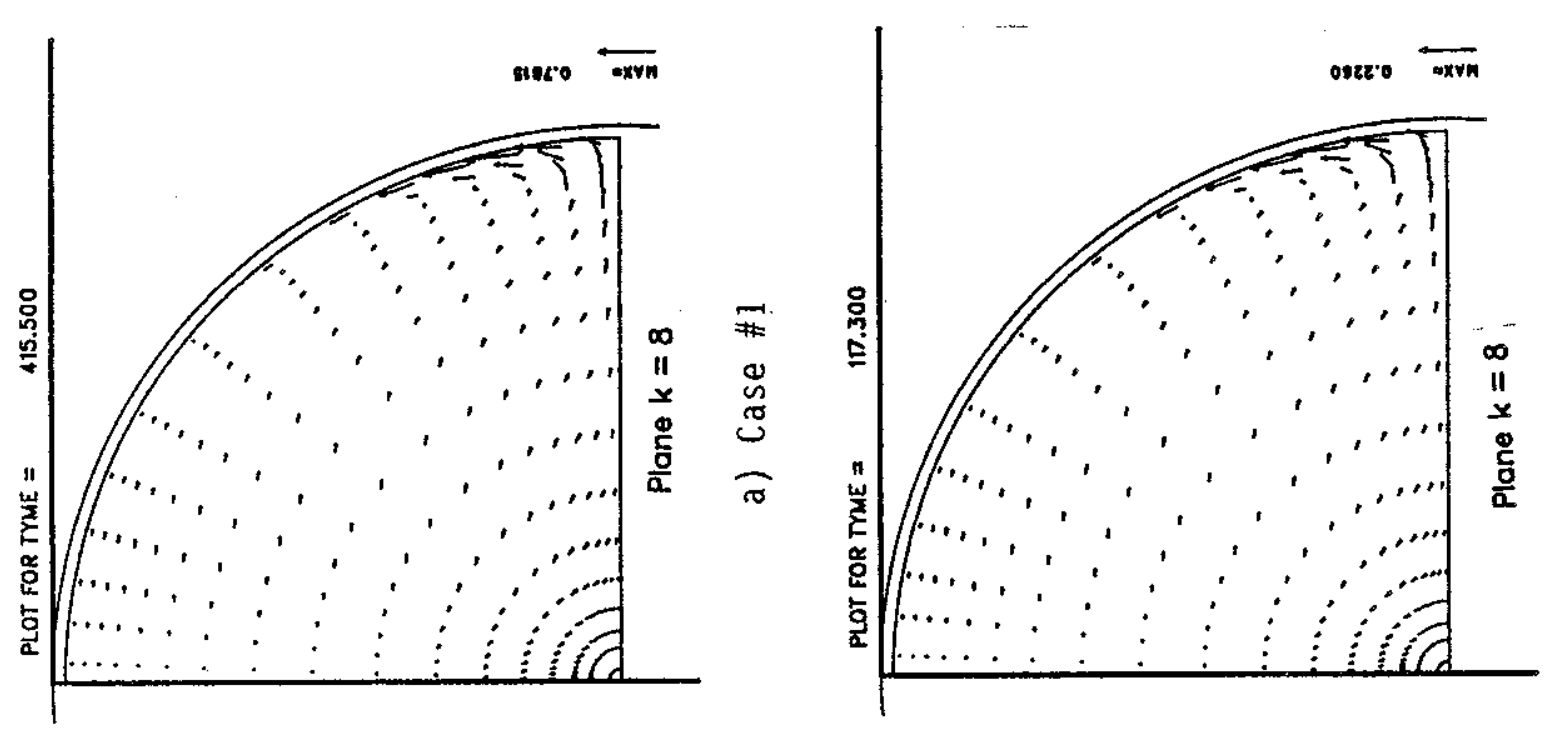

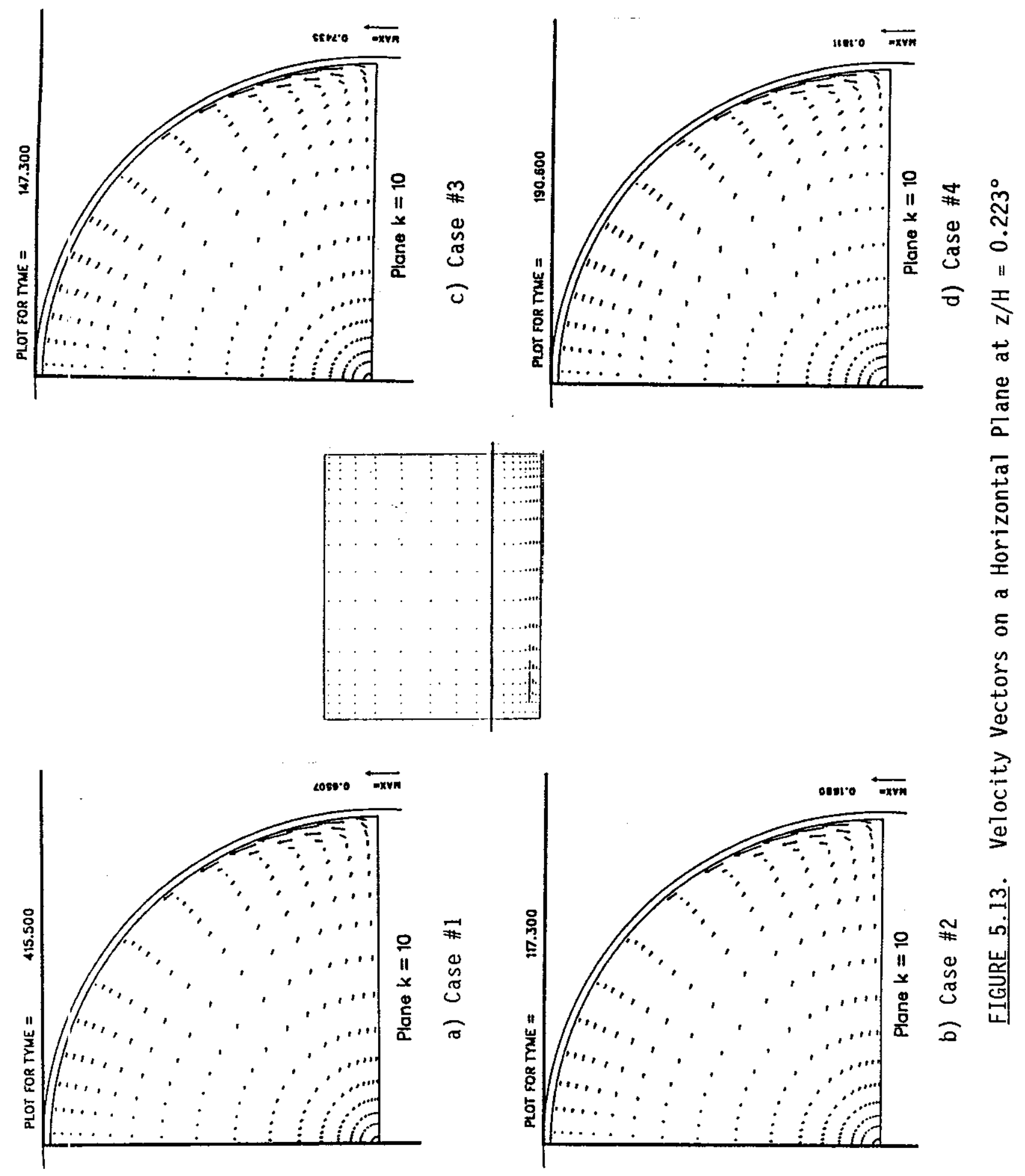

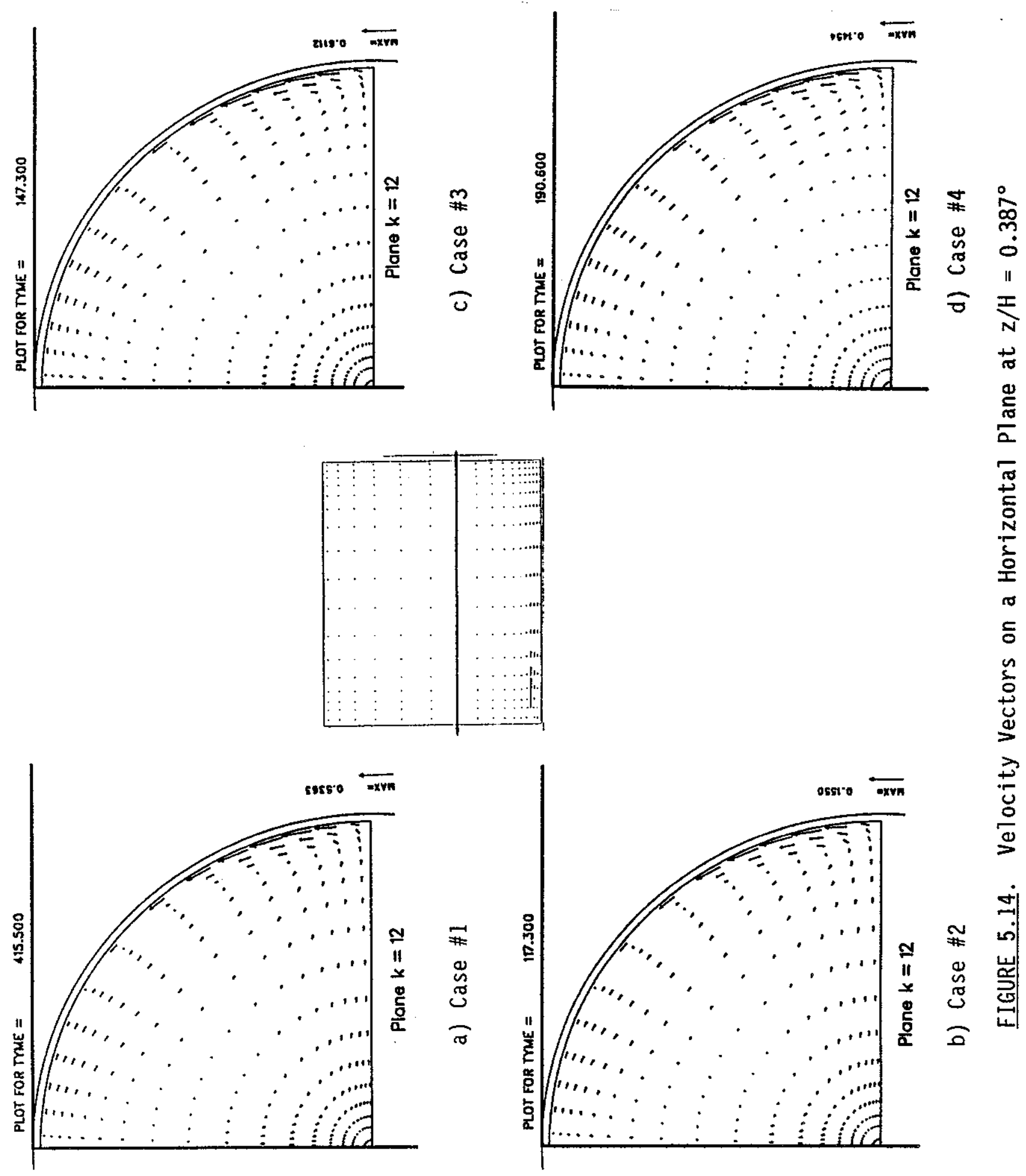

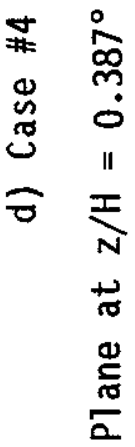



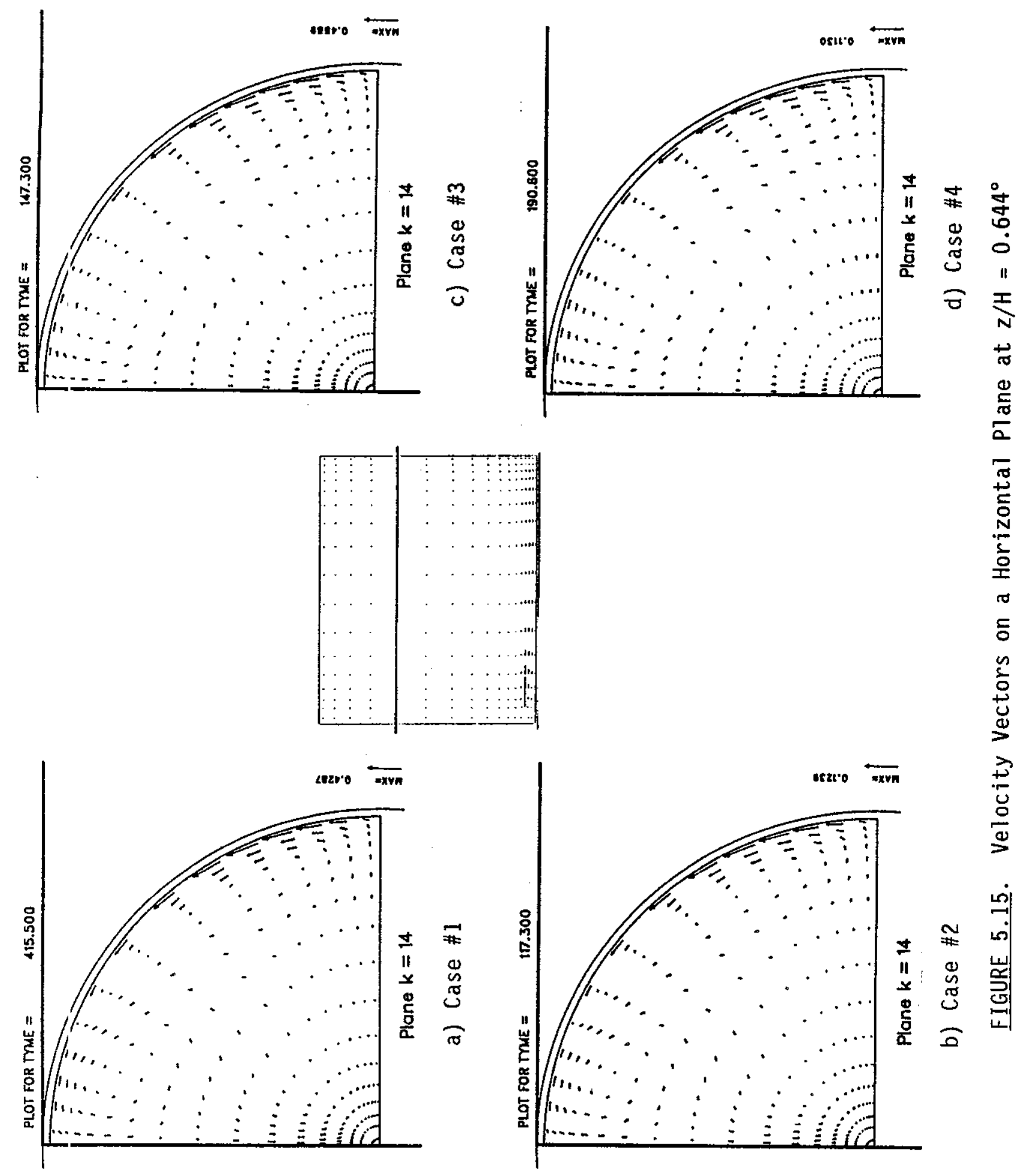

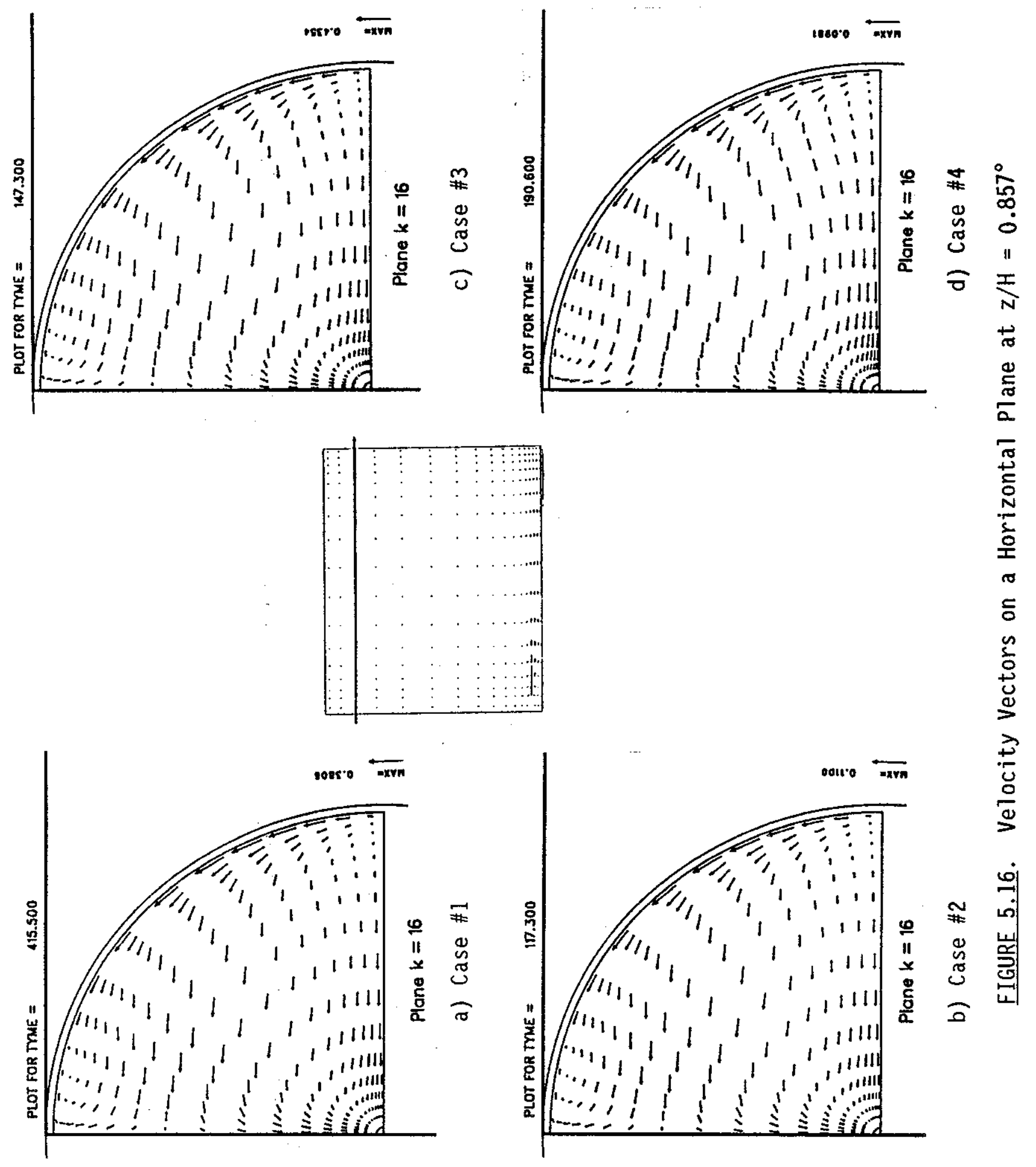

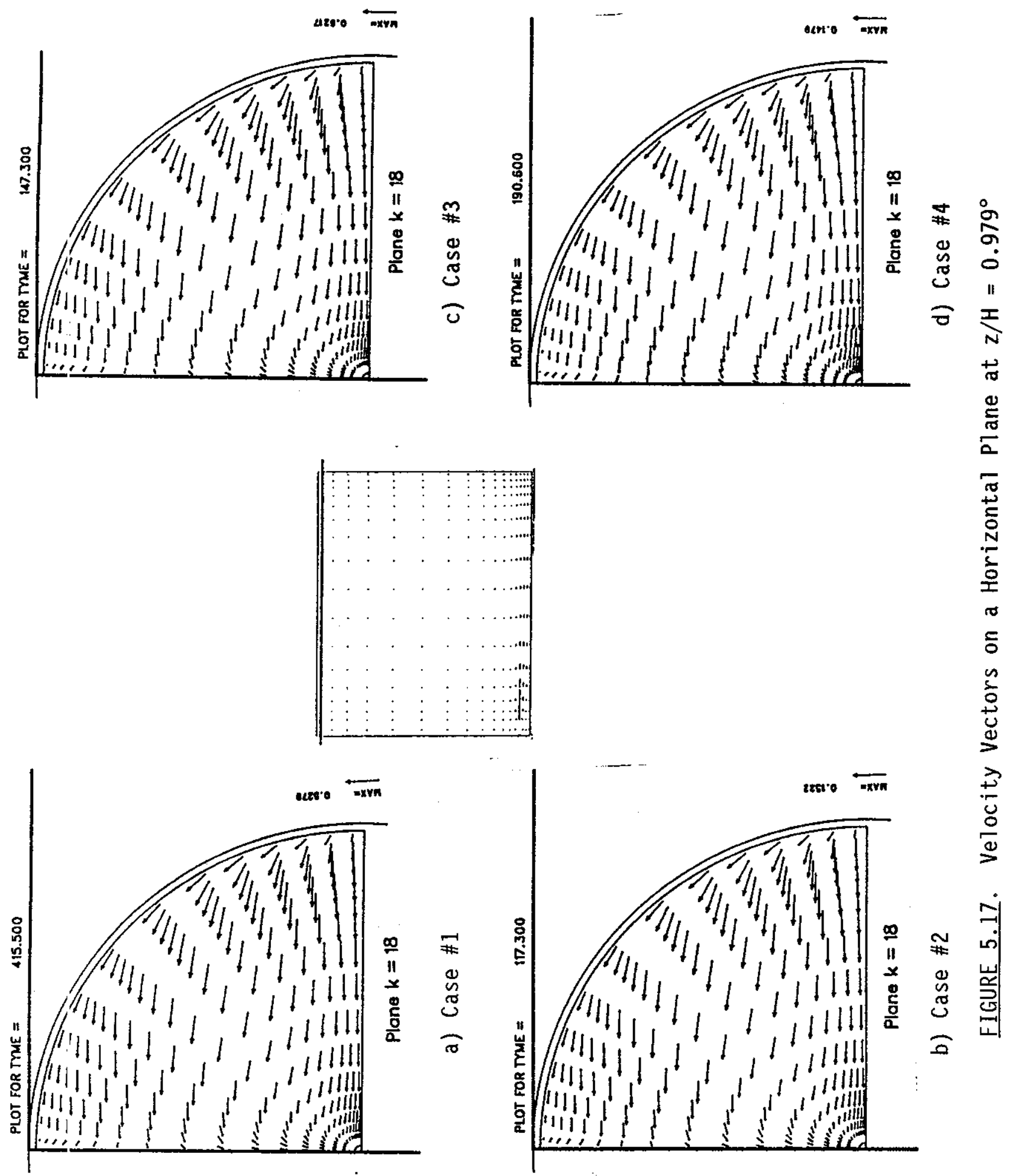
Overall, the flow field features are very similar for each of the four cases considered. The differences occur primarily in the near field regions (i.e., close to the mixer pump exit) of the domain and in the attachment region along the tank bottom. Each of the four cases results in a mixing "plume" that fills the tank. Aside from the large eddy that dominates the flow pattern in the tank, there exists a smaller eddy near the upper fluid surface in the vicinity of $\theta=84^{\circ}$. The presence of this structure is clearly illustrated in Figure 5.16. The reduced momentum flux and streamline curvature of the fluid in this region, together with the symmetry conditions at the $\theta=$ $90^{\circ}$ ray, all contribute to the formation of this smaller eddy.

Figures 5.2 through 5.8 illustrate the flow fields realized on vertical planes cut through the computational domain. The flow field in the vicinity of the mixer pump exit is illustrated in Figure 5.2. The effects of the tank floor on the development of the jet are illustrated in Figures 5.2 and 5.3 . As the fluid exits the pump it entrains fluid, thereby leading to the spread of the jet velocity profile. The presence of the tank floor restricts the downward spread of the jet, however. This near-wall effect on the jet is observed shortly downstream from the mixer pump exit. The jet also expands in the lateral direction. This is evident in the velocity vector plots for the horizontal planes of the computational domain (see Figures 5.9 through 5.11). These horizontal plane plots also clearly illustrate the effect of the tank wall on the spread of the jet. As the mixer pump effluent approaches the tank wall, it spreads out and runs along the wall in both the vertical and azimuthal directions. In the vicinity of the tank wall, the fluid washes up the walls of the tank until it reaches the top. This motion occurs in each of the four cases considered. In the upper regions of the tank, the fluid then makes its way back toward the central regions of the tank, whereupon it returns to the mixer pump and repeats the process.

The results of these computations are compared with those obtained in the experiments of Bamberger, Bates, and Waters (1990) for the 1/6-scale design condition with a jet Reynolds number of $1.87 \times 106, \operatorname{Re}=U 1$. The conditions of the Bamberger et a1. experiments are significantly different 
fron those simulated in Case 1, however. These differences should be considered when comparing the computed and experimental results. First, the fluid used in the Bamberger et al. experiments was water. The viscosity of the water was much lower than that modeled in Case $1\left(6.059 \times 10^{-4} \mathrm{~Pa}-\mathrm{s}\right.$, experimental, versus $0.021 \mathrm{~Pa}-\mathrm{s}$, in the full-scale computational configuration). In addition, while the distance of the jet centerline from the tank floor was properly scaled with the jet diameter, the jet was not centered in the tank. In the jet forces test facility the jet exit was located approximately $0.2 \mathrm{~m}$ ( 8 in.) from one wall of the tank but directed at the tank wall diametrically opposite the jet exit location. The tank-to-nozzle diameter ratio was significantly smaller in the Bamberger et al. experiment than in the Case 1 configuration. However, the distance from the nozzle exit to the portion of the tank wall upon which the jet impinges was significantly larger in the Bamberger et al. experiments (in terms of nozzle diameters) than for the Case 1 configuration (90 nozzle diameters versus 75 in the full-scale con:"iguration). The jet Reynolds number for the Bamberger et al. experiment was significantly higher than that of the Case 1 condition $(\sim 1.87 \times 106$ versus $4.1 \times 10^{4}$ for Case 1). Finally, the Froude number for the Bamberger et a1. experiment is much higher than for the Case 1 configuration (76 versus 0.22 for the full-scale configuration). These factors indicate that the fluid in the Bamberger et al. experiment was much more thoroughly agitated in the tank than was the fluid in the tank for Case 1. Despite these differences comprarisons of the computed results for Case 1 with data from the Bamberger et ill. experiments should provide some measure of the applicability of the TEMF'EST simulations.

Figures 5.18 through 5.25 illustrate several views of the jet velocity profile for the full-scale case (Case 1) at a number of locations downstream of the mixer pump jet exit. The computed results are indicated by the heavy lines and the heavy square and circular symbols. The experimental results of Bamberger et al. are indicated by the light square symbols without a line to join them. The thin solid line in these figures represents the velocity 


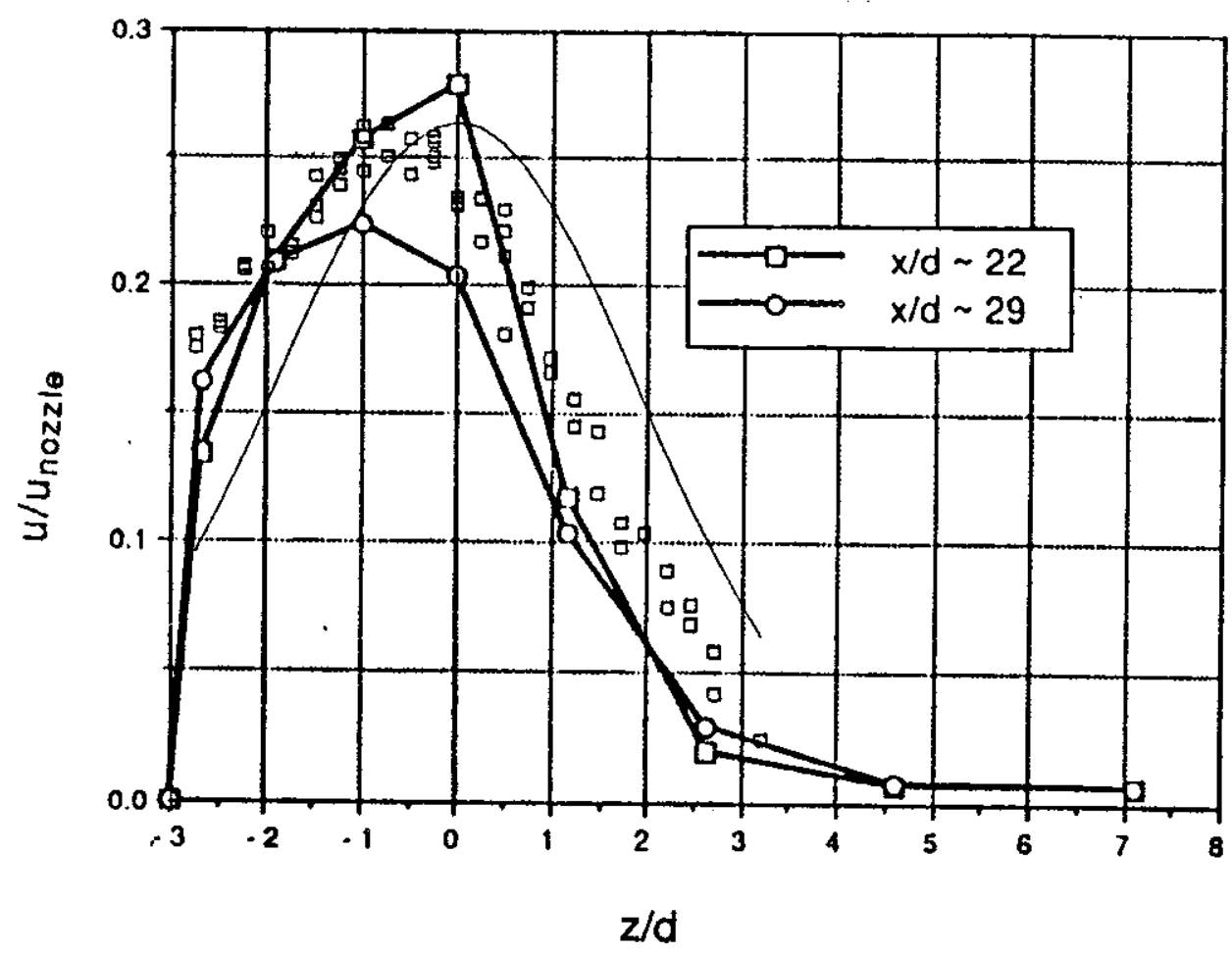

FIGURE 5.18. Comparison of Computed Results (dark lines) with the Experimental and Theoretical Results of Bamberger, Bates, and Waters (1990) (open symbols) for Axial Velocity Profiles along the Vertical Jet Centerline at $\sim 25$ Nozzle Diameters Downstream from the Jet Exit. The thin line is a reference profile for a round free jet in an infinite medium.

profile of a free jet described by Equation (5.3)(a) with a diffusion coefficient (K) equal to 6.5. This curve is provided for reference only because the free jet profile [Equation (5.3)] does not account for floor

(a) The axial and radial velocity profile of a free jet can be described using the following equation

$$
U_{r}=\frac{K U_{0} D_{0}}{x}\left[\exp -2 K^{2}\left(\frac{r}{x}\right)^{2}\right]
$$

which predicts the radial velocity distribution as a function of the nozzle $U_{0} D_{0}$ value, the distance from the nozzle $(x)$, and the distance from the jet centerline $(r)$. The Gaussian distribution functions that correlate the jet radial velocity profile involve the diffusion constant in the term, $2 \mathrm{~K} 2$. A high $\mathrm{K}$ value represents a velocity profile that peaks more in the center. A low $\mathrm{K}$ value represents a velocity profile that spreads more widely. 


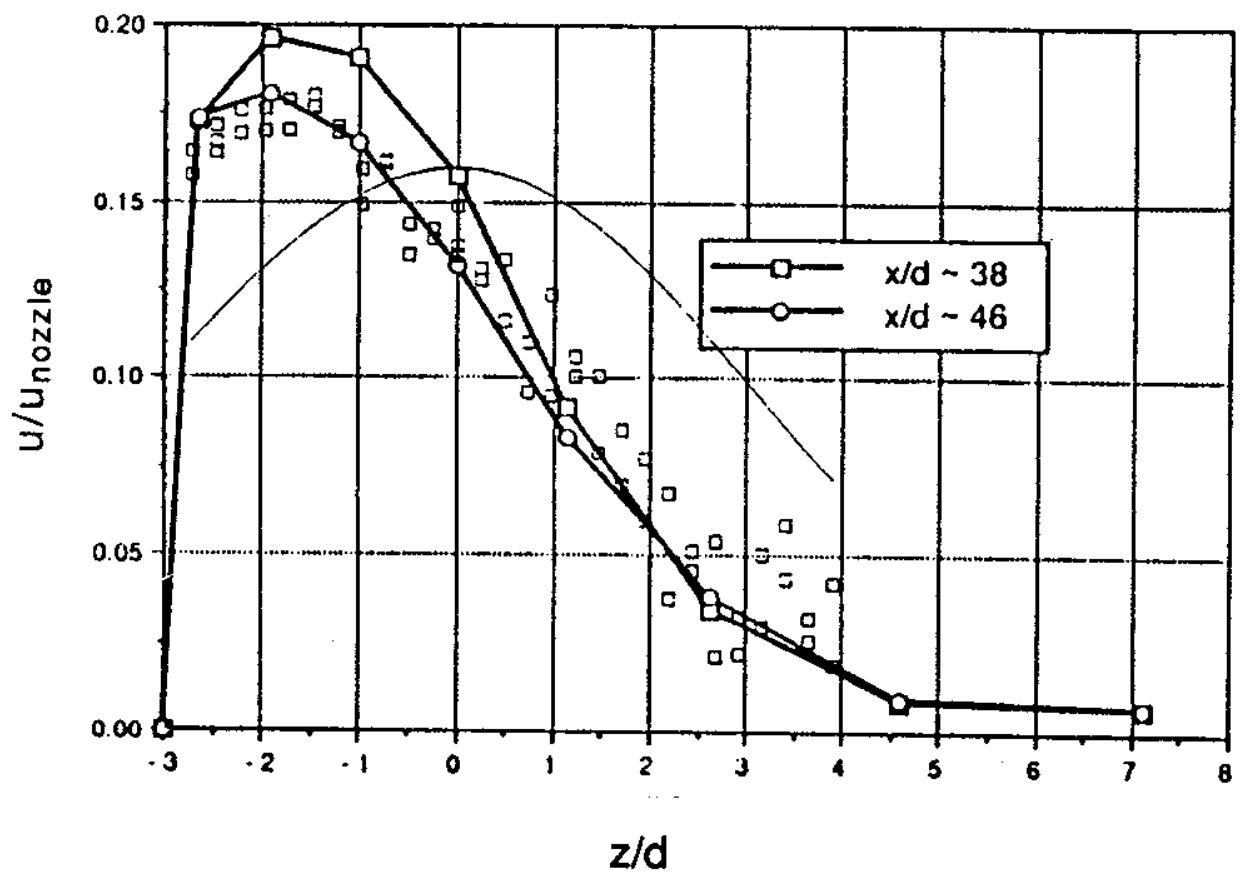

FIGURE 5.19. Comparison of Computed Results with the Experimental and Theoretical Results of Bamberger, Bates, and Waters (1990) for Axial Velocity Profiles along the Vertical Jet Centerline at $\sim 41$ Nozzle Diameters Downstream from the Jet Exit

effects present in the simulations and experiments. The abscissa on each of these figures represents the vertical distance from the jet centerline normalized based on the exit nozzle diameter $(z / D)$. The ordinate represents the local axial velocity component normalized on the mixer pump jet exit speed $\left[\sim 4 \mathrm{~g}_{i} \mathrm{~m} / \mathrm{s}(148 \mathrm{ft} / \mathrm{s})\right.$ in Bamberger, Bates, and Waters and $4.44 \mathrm{~m} / \mathrm{s}(14.57 \mathrm{ft} / \mathrm{s})$ in case 1]. The vertical spread of the jet is illustrated in Figures 5.18 through 5.21. The transition of free to near-wall jet is clear in these figures. The lateral spread of the jet is illustrated in Figures 5.22 through 5.25 .

The agreement between computation and experiment is encouraging, although some differences should be noted. The lower jet Reynolds number and higher fluid viscosity of the Case 1 configuration should produce a jet that is more diffuse than the jet in the Bamberger et al. experiment. Consequently, at a given $x / D$ location, the velocity profile for the computed results should exhibit a broader extent and lower peak than that for the corresponding 


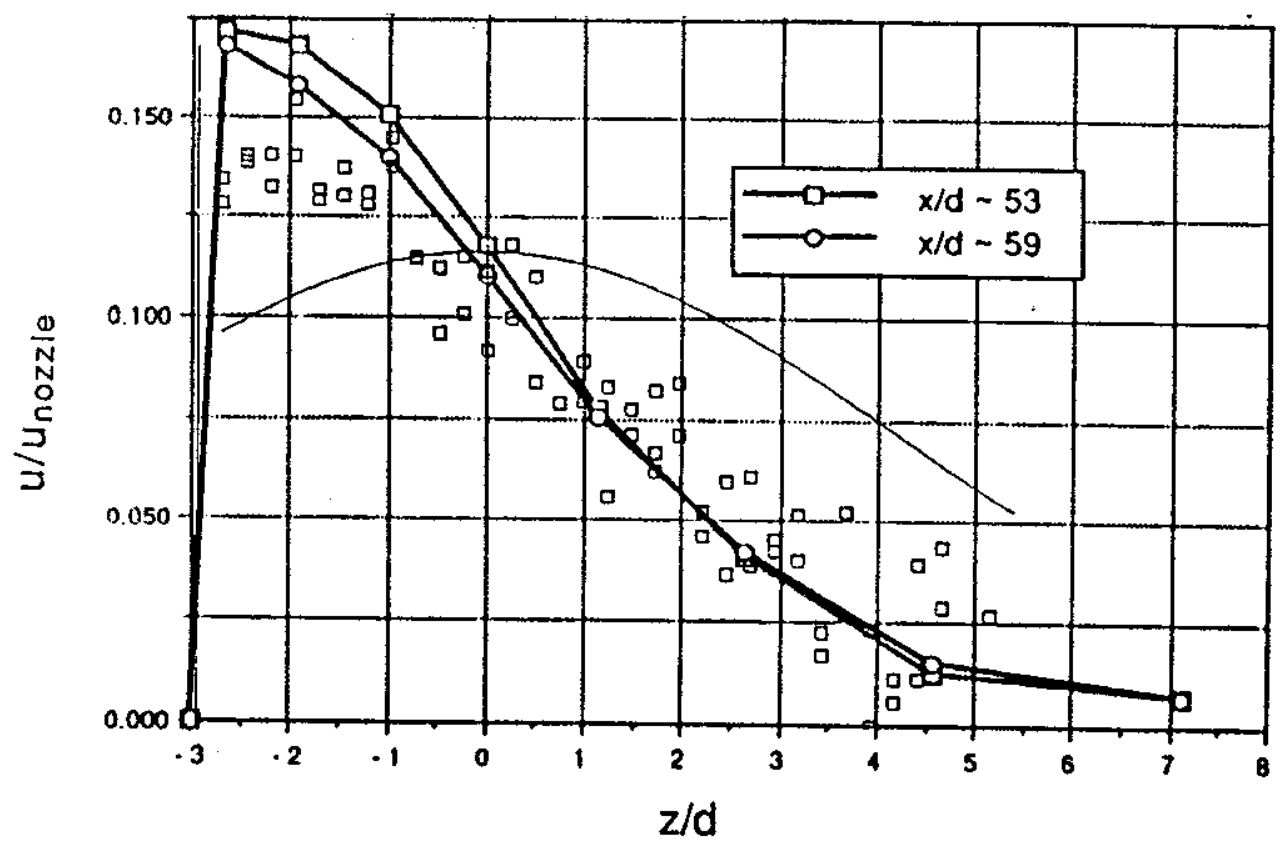

FIGURE 5.20. Comparison of Computed Results with the Experimental and Theoretical Results of Bamberger, Bates, and Waters (1990) for Axial Velocity Profiles along the Vertical Jet Centerline at $\sim 57$ Nozzle Diameters Downstream from the Jet Exit

Bamberger, Bates, and water (1990) results. This should be true for both the free and floor jet regimes of the flow field. As shown by Figures 5.18 through 5.21, it would appear that neither is the case. The overall vertical extent of the jet matches the Bamberger et al. data fairly well. The peak normalized fluid velocity in the free jet regime $(x / D \sim 25)$, Figure 5.18 is 0.25 for the Bamberger et al. results and ranges from 0.225 to 0.275 for the Case 1 simulated results.

At larger $x / D$ values, the theoretical result (thin solid line) presented in these figures does not agree well with either the computed or experimental data. This occurs because the theoretical result describes a free jet velocity profile, not a jet in the proximity of a floor. The Case 1 computed velocities in the near-floor region of the jet are consistently higher (at the same $x / D$, 41 to 66$)$ than that obtained from the Bamberger et al. experiment. The computed velocities near the floor may be higher because of a lack of resolution in the near-floor region of the simulation, or because the experiment exhibited more active overall tank motion. 


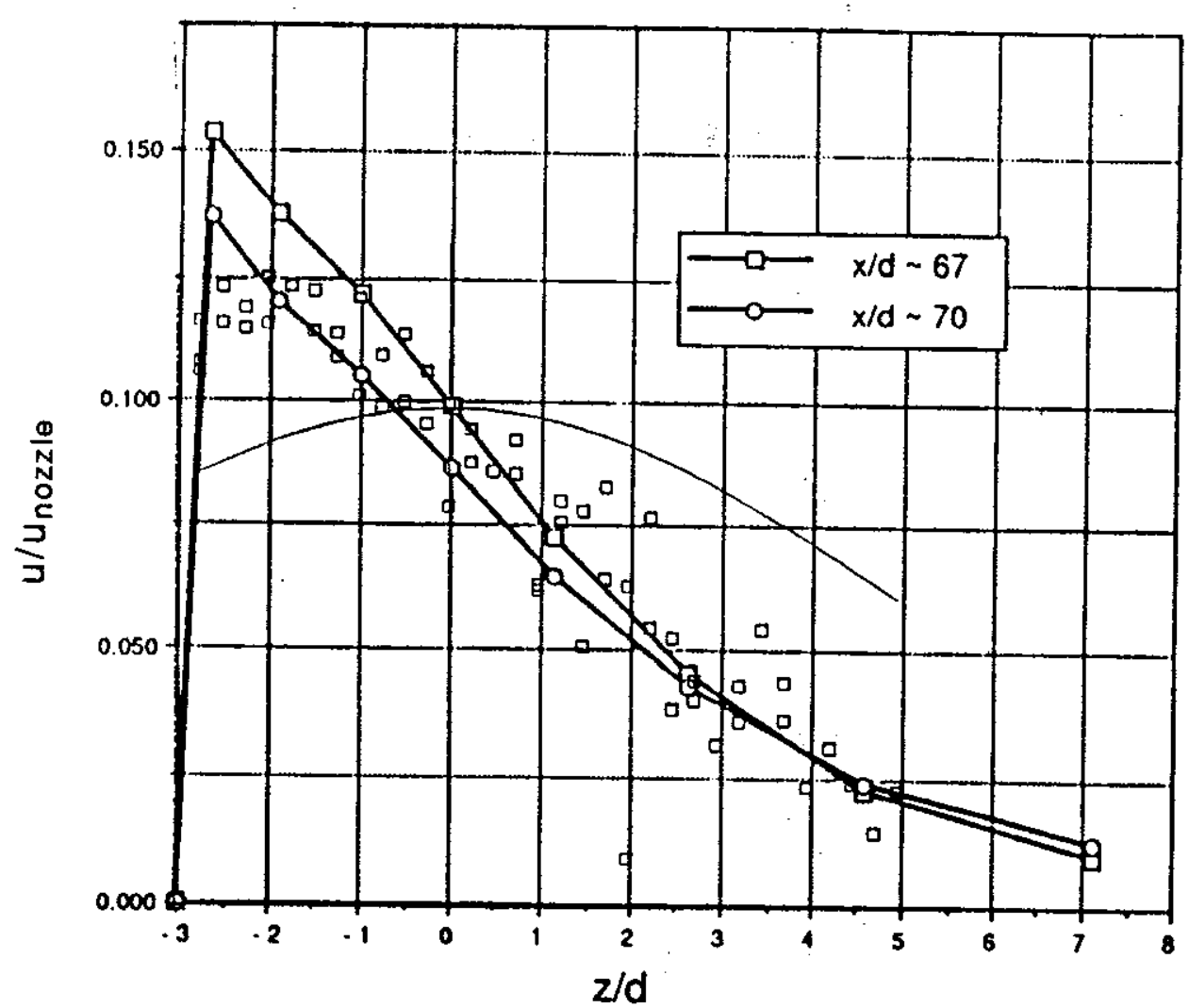

FIGURE 5.21. Comparison of Computed Results with the Experimental and Theoretical Results of Bamberger, Bates, and Waters (1990) for Axial Velocity Profiles along the Vertical Jet Centerline at 66 Nozzle Diameters Downstream from the Jet Exit

The lateral growth of the jet is illustrated in Figures 5.22 through 5.25. As with the vertical growth behavior of the jet described above, the peaks in the computed results are generaliy higher than for those experimental results. Again, this is somewhat surprising because the viscosity and Reynolds numbers would indicate that the simulated case should be more diffusive. The simulated jet does exhibit greater lateral spread than the experimental jet, however. The differences in the Froude numbers between the experiment and computation may offset the differences in Reynolds number and lead to reduced peak velccities in the developing regions of the jet.

All in all, the computational results exhibit features very similar to those obtained in the Bamberger et al. experiment. While there are some inconsistencies, it must be remembered that the Bamberger et al. experimental configuration was not the same configuration modeled in the Case 1 simulation. 


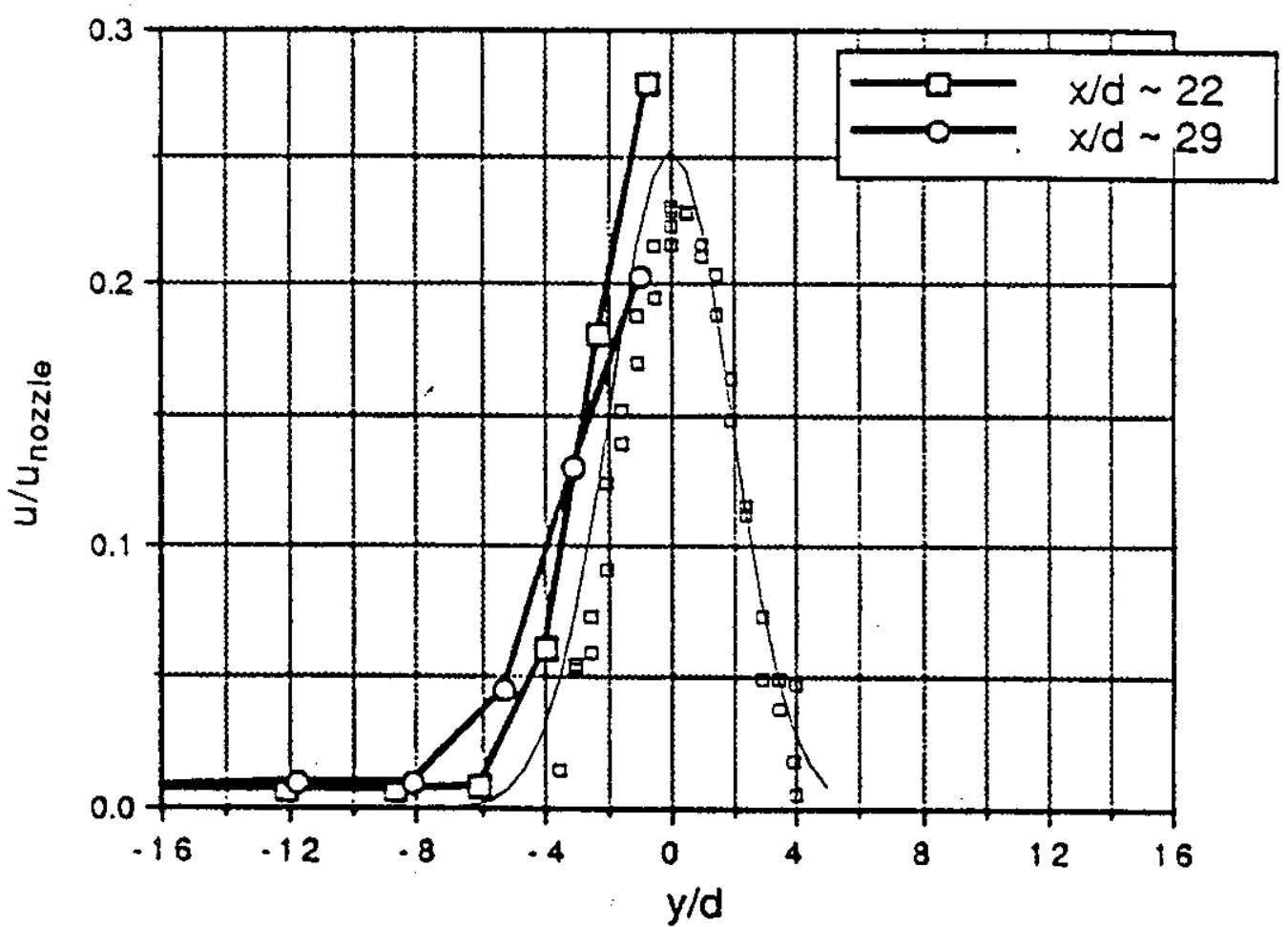

FIGURE 5.22. Comparison of Computed Results with the Experimental and Theoretical Results of Bamberger, Bates, and Waters (1990) for Axial Velocity Profiles along the Horizontal Jet Centerline at $\sim_{25}$ Nozzle Diameters Downstream from the Jet Exit

With this in mind, it would appear that the main features of the flow (i.e., the development of the jet, the transition from free to wall jet along the tank floor, and the spreading of the jet along the impinged tank side wall) are adequately resolved in the computational simulations to provide a reasonable picture of the large-scale mixing process occurring in the tank.

\subsubsection{Particle Tracking}

The computed flow fields have been used to assess tank slurry uniformity. There are two approaches to this assessment. Ideally, one would like to include the transport of a fluid species explicitly in the computation of the flow field. In this approach, the fluid density is coupled to the concentration of the fluid species. The effect of variable density on flow field development would be a direct output of the computation. An alternate approach 


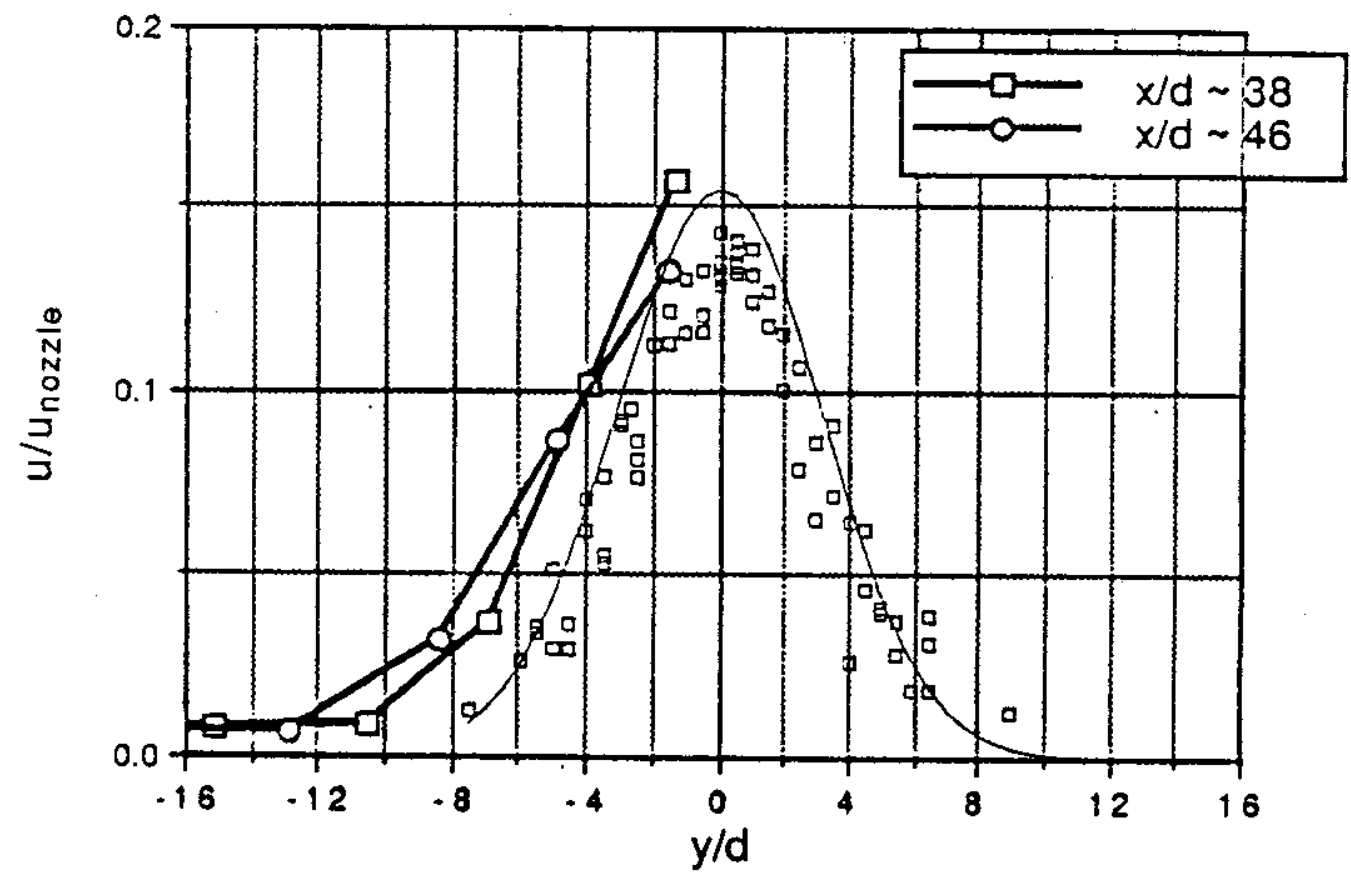

FIGURE 5.23. Comparison of Computed Results with the Experimental and Theoretical Results of Bamberger, Bates, and Waters (1990) for Axial Velocity Profiles along the Horizontal Jet Centerline at $\sim 41$ Nozzle Diameters Downstream from the Jet Exit

would be to compute the flow field as if the tank maintained a uniform mixture. Having generated this flow field, one could "sprinkle" the tank with a large number of particles of a particular size and specific gravity. This initial sprinkling would produce an effective particle density function (number of particles per unit volume in the tank) describing the contents of the tank. The motion of the particles can then be computed in a separate simulation. The particle dynamics account for both the fluid motion and the gravitational and drag effects on each particle. One could then assess the mixing behavior of the tank and pump arrangement by tracking the position of the particles. An efficient mixing process will tend to disperse the particles such that the volumetric concentration of particles (i.e., the particle density function) converges toward a constant value throughout the tank. 


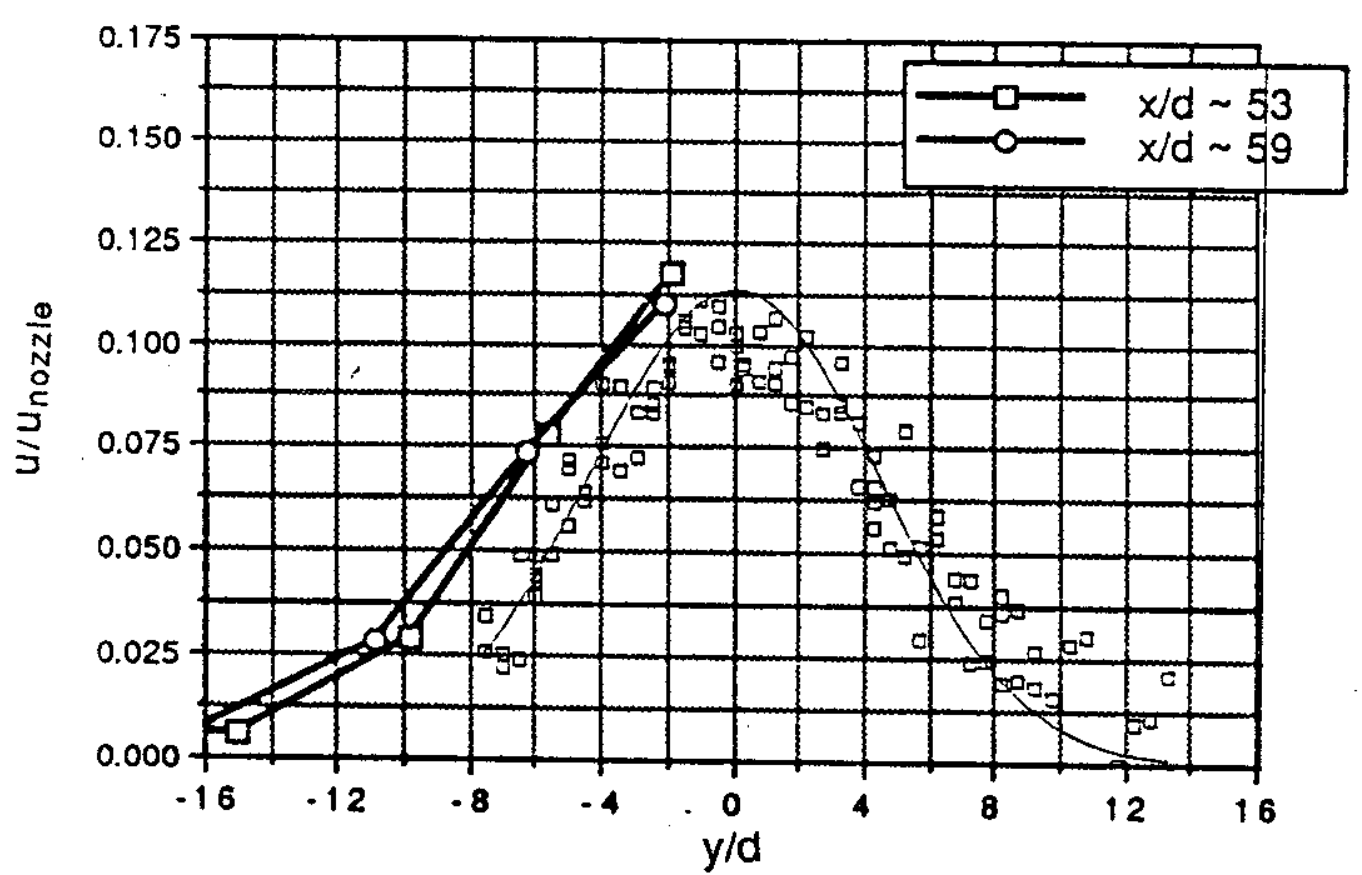

FIGURE 5.24. Comparison of Computed Results with the Experimental and Theoretical Results of Bamberger, Bates, and Waters (1990) for Axial Velocity Profiles along the Horizontal Jet Centerline at $\sim 57$ Nozzle Diameters Downstream from the Jet Exit

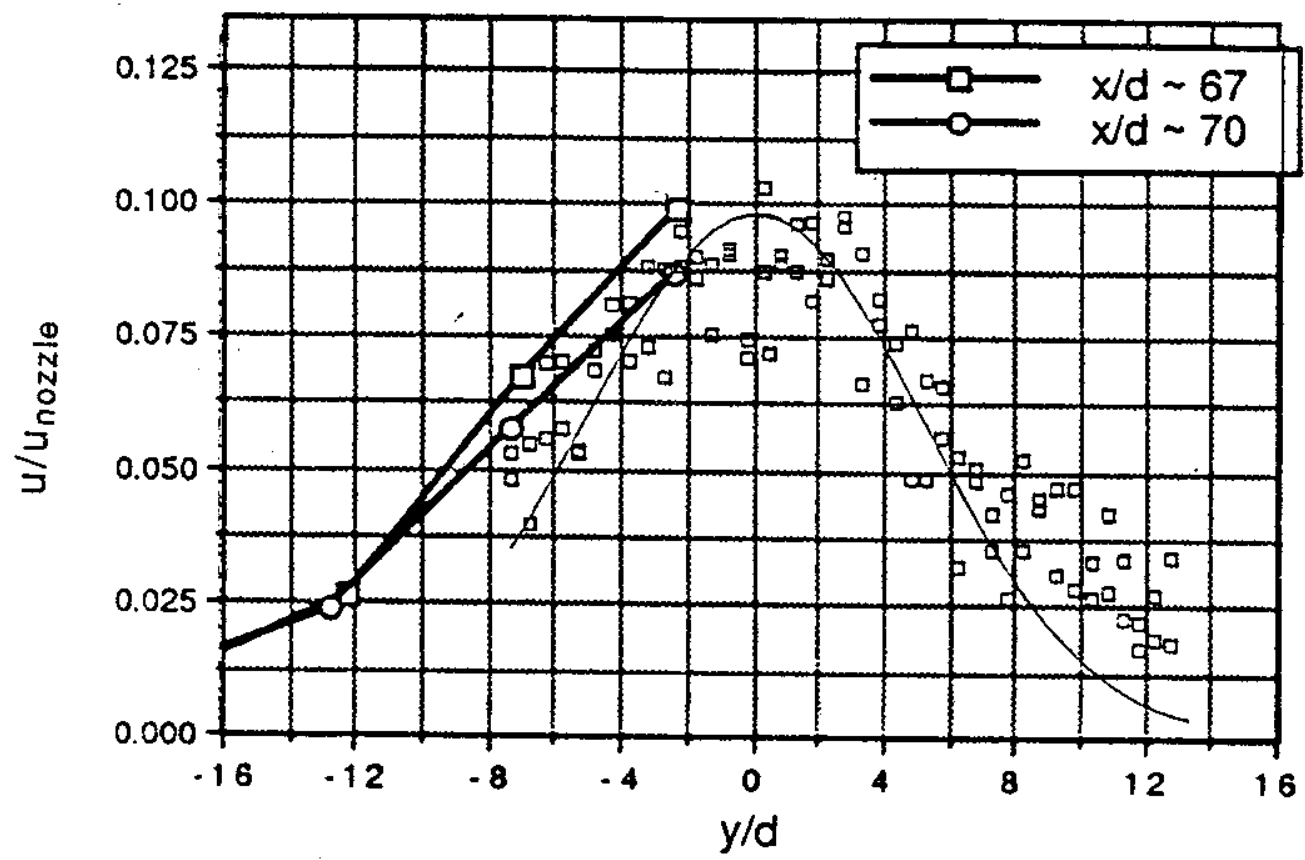

FIGURE 5.25. Comparison of Computed Results with the Experimental and Theoretical Results of Bamberger, Bates, and Waters (1990) for Axial Velocity Profiles along the Horizontal Jet Centerline at $\sim 66$ Nozzle Diameters Downstream from the Jet Exit 
There are reasons to choose either approach. In the first approach (in which the species concentration is an explicit part of the flow field computation) a substantial increase in computational requirements are incurred because of the coupling of the species field transport with the solution of the mass and momentum conservation equations for the fluid mixture. In the later approach, there is no allowance for feedback of concentration effects on the motion of the fluid. The computational requirements are significantly reduced, however. The coupling is not warranted if the particle tracking approach indicates that the tank/pump arrangement provides for efficient mixing.

The spectrum of particle sizes and specific gravities considered in these studies have Stokes velocities (settling velocities, $U_{S}$ ) well below the fluid

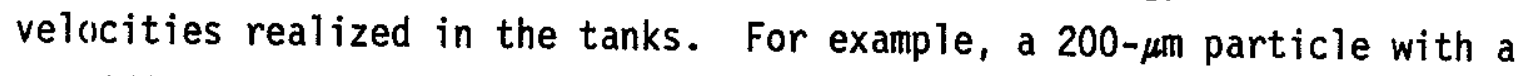
specific gravity of $0.0025 \mathrm{~Pa}-\mathrm{s}(2.5 \mathrm{cP})$ in a $0.021 \mathrm{~Pa}-\mathrm{s}(21 \mathrm{cP})$ fluid has a settling velocity of $0.001 \mathrm{~m} / \mathrm{s}(0.004 \mathrm{ft} / \mathrm{s})$. When this particle is exposed to a change in fluid velocity, it will accelerate (or decelerate) to $99 \%$ of that velcicity in $\sim 1.2 \times 10^{-3} \mathrm{~s}$. These settling velocities and response times are much less than the fluid velocities and recirculation time scales experienced in the tank. Therefore, one would conclude that if the tank was initially well mixed (a key assumption in this program), it will tend to stay well mixed.

of course, this line of reasoning requires several considerations. For example, the fluid velocities very near the wall will be on the order of the settling velocity of the particles. Consequently, particles near a wall will have an enhanced tendency to drop out. Additionally, no account is made for the increase in fluid viscosity as a result of this settling or its effect on the boundary layer thicknesses on the walls of the tank. These boundary layers represent regions of low flow and hence are potential particle drop-out sites. For these reasons the particle tracking approach was pursued to provide an assessment of the particle suspension in the simulated tank/pump configurations. 
The results obtained from this particle-tracking approach to tank uniformity assessment are illustrated in Figures 5.26 through 5.29. In Figure 5.26 a schematic is shown that indicates the manner in which the tank volume was discretized for this analysis. As indicated in this figure, only the 1/12-scale tank was modeled. The prototype case was not modeled because the increased volume of the full-scale tank would require substantially more particles to provide a meaningful population density; and the complexity of computation increases with the number of particles tracked. Therefore, simulating the full-scale tank case would require substantially more computational time. To provide an initial assessment of the validity of this particle-tracking approach, only the $1 / 12$-scale tank cases were modeled. The resolution in the vertical direction corresponds to that used in the flow field simulation. The resolution in the radial and azimuthal directions is somewhat coarser here than was used in the TEMPEST model of the tank. However, with this discretization, the tank is still divided into 1000 cells in which the density of particle loading is monitored. The simulation starts with an initially random sprinkling of $10^{4}$ particles over the fluid domain. The volume of the quarter-section of the tank is $0.543 \mathrm{~m}^{3}\left(19.17 \mathrm{ft}^{3}\right)$. Thus, if the particles were distributed uniformly, the particle number density would be approximately 15 particles/m3 (520 particles/ $\left./ \mathrm{ft}^{3}\right)$.

The results of these simulations are presented in the particle "bin" plots and statistics of Figures 5.27 through 5.29. In these figures, the particle number density is binned into increments spanning the range of densities realized in the tank. This abscissa represents the particle number density in each of these plots. The ordinate in these plots represents a count of the number of cells in the grid (refer to Figure 5.26) that have particle number densities falling within the range of a specific bin. The bin widths in each figure have been set to 500 . Thus, if the tank contents were perfectly uniform, all cells would have a particle number density of approximately 15 particles/m3 (520 particles/ft3) and the "bin" plot would have a bar one bin wide at an abscissal value of 520 and a height of 1020 (representing all of the cells in the "bin" computational grid). As the statistical information inset in each of these figures indicates, the initial 


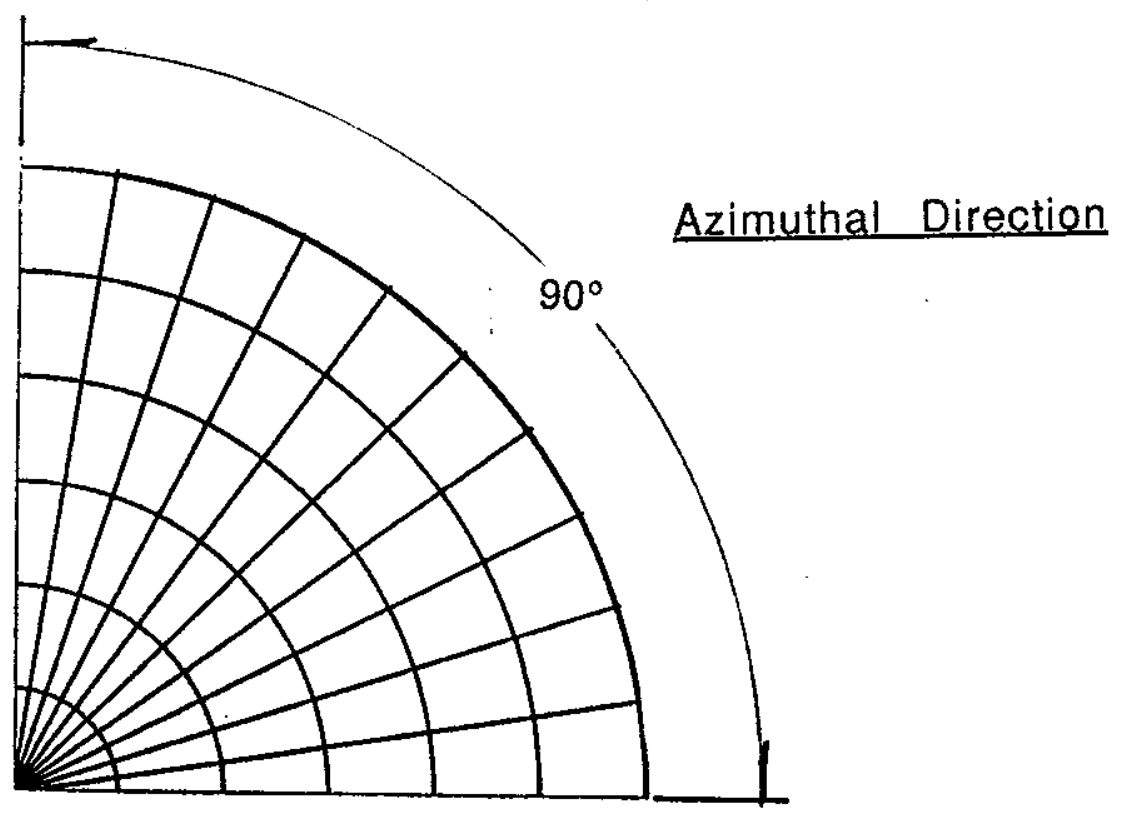

a) Horizontal Planes

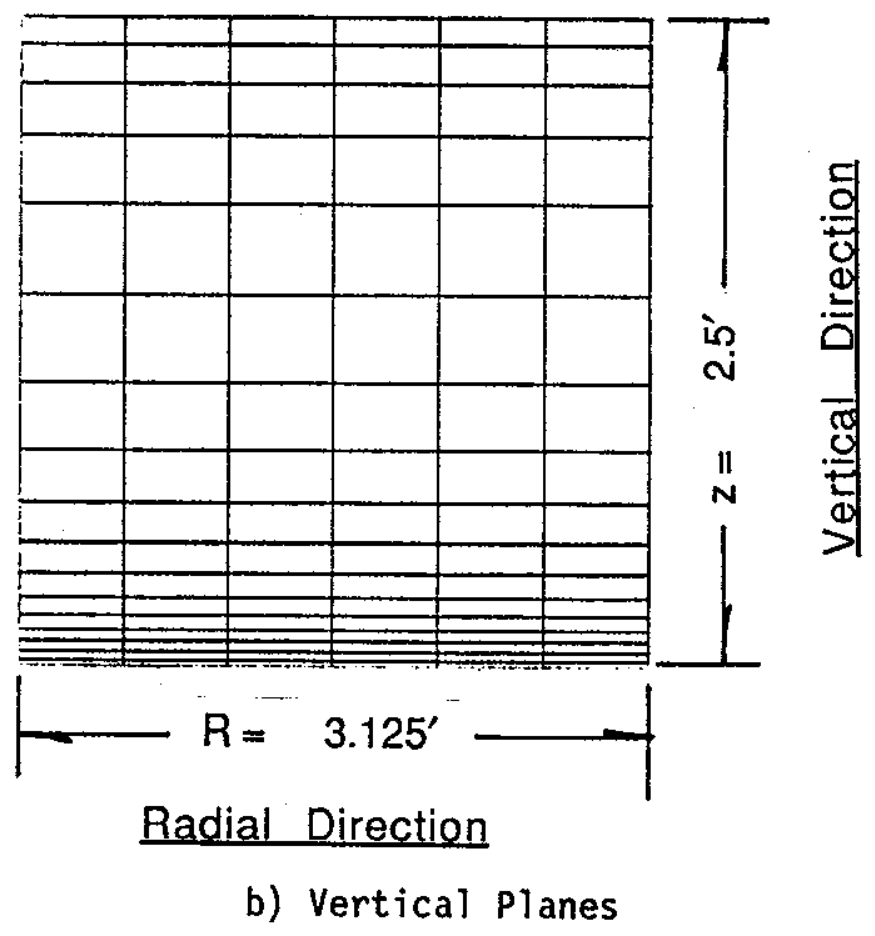

FIGURE 5.26. Particle Density "Bin" Plot Computational Grid 

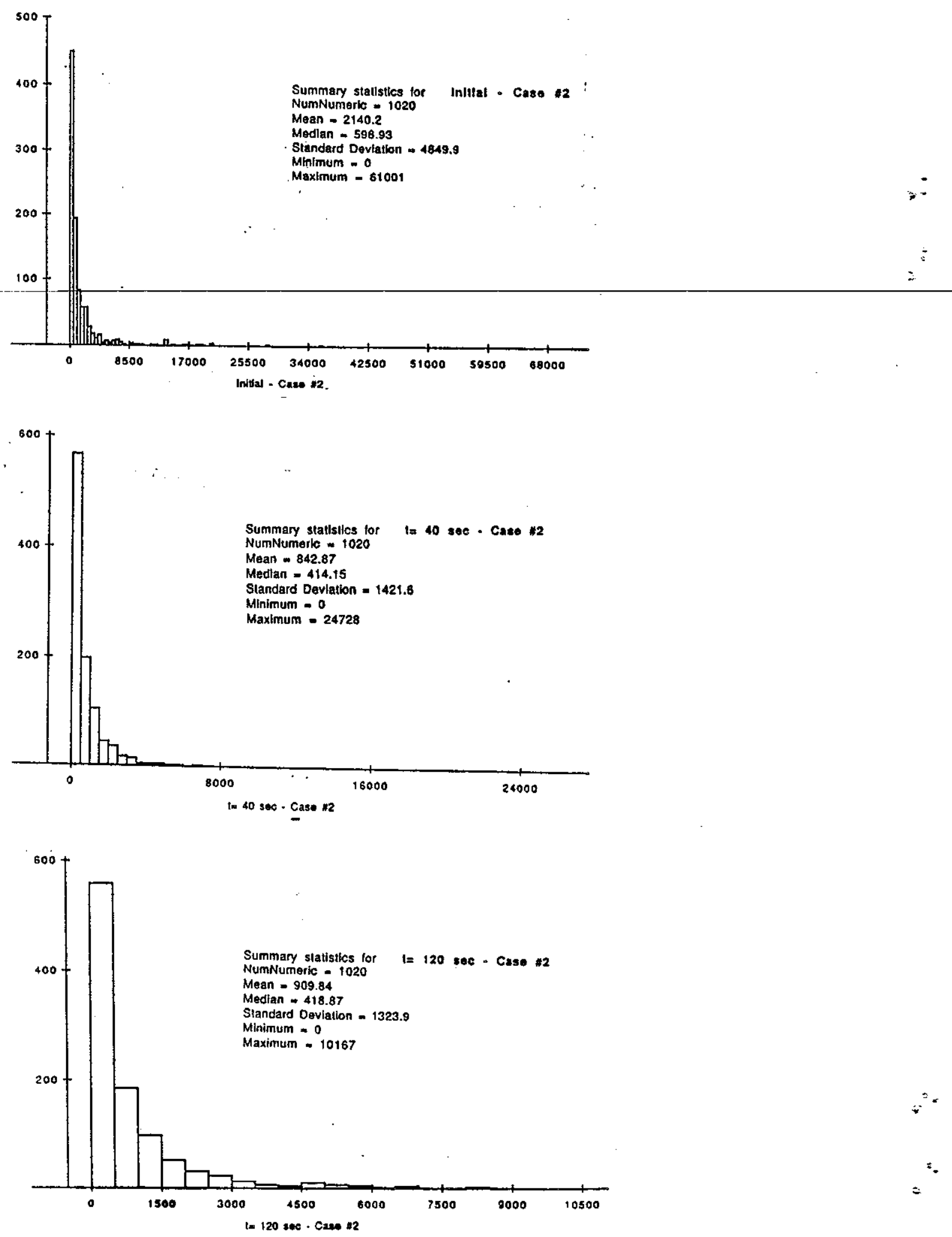

FIGURE 5.27. Particle Density "Bin" Plots for Case 2 

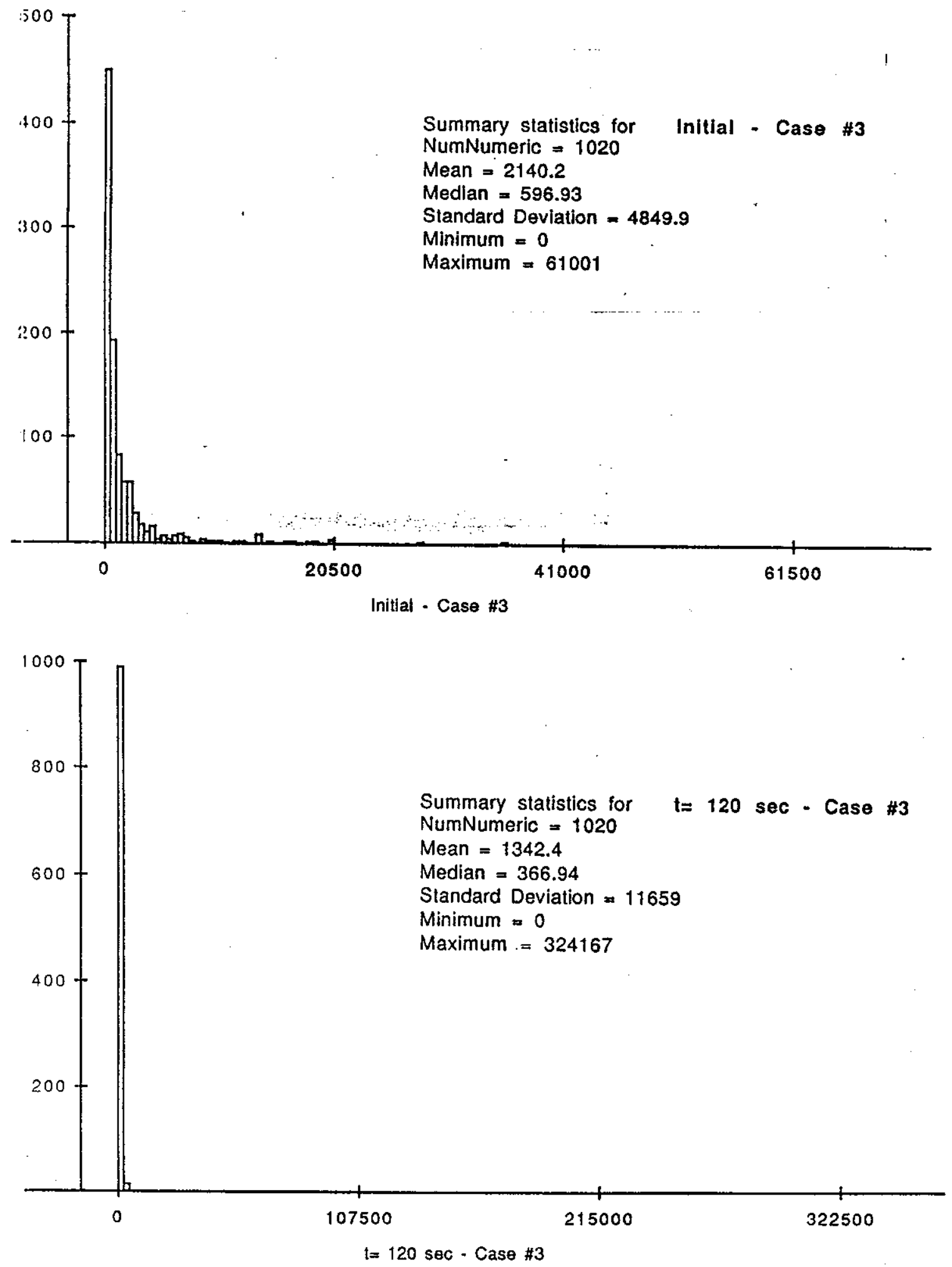

FIGURE 5.28. Particle Density "Bin" Plots for Case 3 

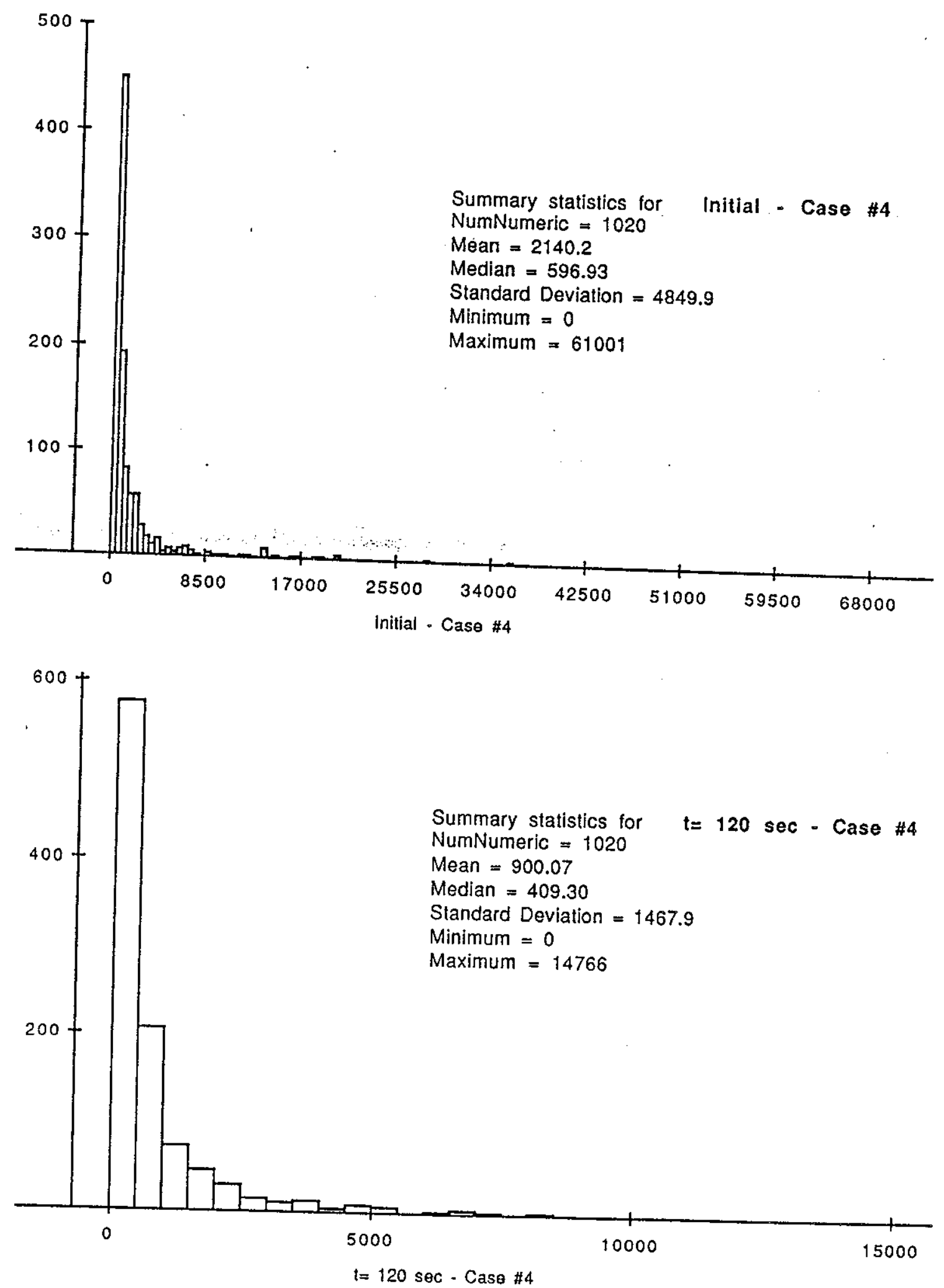

FIGURE 5.29. Particle Density "Bin" Plots for Case 426 
distributions are identical for each case. An average particle loading of 60 particles/m 3 (2140 particles $/ \mathrm{ft}^{3}$ ) was obtained with the random sprinkling algorithm for each case. The flow fields realized in each case were then used, together with the appropriate settling velocity for the particles modeled, to determine the distribution of particles at later times. For the Case 2 simulation, a particle size of $8 \mu \mathrm{m}$ was modeled. For Cases 3 and 4 , the particle size modeled was $17 \mu \mathrm{m}$. All three cases had particle densities of $2500 \mathrm{~kg} / \mathrm{m}^{3}$. Using the fluid viscosities appropriate for each case, the settling velocity for the particles in all three cases is essentially the samı, $9 \times 10^{-5} \mathrm{~m} / \mathrm{s} \cdot(0.0003 \mathrm{ft} / \mathrm{s})$.

Allowing the respective flow fields to redistribute the particles for a totial of $120 \mathrm{~s}$ results in the particle number density distribution plots illustrated in the bottom subplots of Figures 5.27 through 5.29. While the distributions have not achieved the desired uniformity, they do indicate a trend toward uniformity. The average particle number densities have moved toward the 15 particles $/ \mathrm{m}^{3}$ ( 520 particles/ft 3 ) value and, with the exception of the Case 3 results, the standard deviations and maximum concentrations have: lowered indicating a tightening in the range of the distribution. As mentioned, Case 3 indicates a departure from this trend. While the average concentration has dropped, the standard deviation and maximum concentrations has increased. This would indicate a collection of particles in a certain region of the flow field. Unfortunately, these data do not indicate the locition or extent of this collection region. However, this information is contained in the raw data and may be extracted with some additional effort.

\subsection{LIMITATIONS}

As indicated in the preceding section, the computational grid employed for the prediction of the tank flow fields was adequate to resolve the largerscale features of the flow patterns. The finer-scale motion associated with the entrainment of fluid in the jet and the formation of wall boundary layers in the tank are only marginally resolved in these simulations. Nevertheless, the computed results seem to match those anticipated experimentally and provide valuable insight as to the nature of the mixing plume present in the tanks. 
Moreover, they indicate that the mixer pump can involve the entire contents of the tank in the mixing process. The validity of this conclusion hinges upon the condition that there are no significant density gradients present in the tank, however.

These computational analyses assumed that the initial slurry composition was uniform. The second phase of the computational studies (described in Section 7.0) in this program will address cases with density gradients. The particle-tracking approach was chosen to study the potential for particle drop-out during the slurry maintenance process. The results presented in the preceding section tend to indicate that a trend toward uniformity exists. However, the results are somewhat inconclusive and should be explored further. As an aid to future assessment efforts, the time duration over which the particle drop-out phenomena is explored should be of sufficient duration to ensure that a particle has adequate time to fall-out of the flow field during the simulation. For the particle sizes, densities, and fluid viscosities of concern here, this will require a simulation of roughly 2 hours in the fullscale configuration and $\sim 45 \mathrm{~min}$ in the $1 / 12$-scale configurations. The results presented herein clearly do not extend over a sufficient period of time to provide substantive proof of tank uniformity. However, the trends indicated in the analyses performed indicate the desired move toward homogeneity of the contents in the tank. 


\subsection{SCOPING EXPERIMENTS}

Scoping experiments are proposed to investigate the effects of a number of jarameters that may influence tank slurry uniformity. In a scoping study, all applicable parameters are exercised at both high and low levels as is appropriate to span the range of prototype operating conditions currently proposed by Westinghouse Hanford Company. Because a 1/12-scale model of a wasi:e tank exists, the feasibility of performing the scoping experiments at this scale was investigated analytically and computationally. The analytical investigation of scaling, discussed in Section 3.2, indicates that although not all dimensionless groups can be matched simultaneously, the effect of limiting Reynolds numbers to the turbulent range would be adequate for conducting scoping experiments. In addition, it was found to be possible to exercise high and low values of Froude and gravitational settling numbers at any scale. In addition, the scoping experiments proposed here are designed to provide a conservative estimate of the uniformity that will be achieved in the prototype tanks. All relevant dimensionless parameters except the Reynolds number will be exercized in the range where the prototype will operate. The jet Reynolds number will be less than that at which the prototype jet is expected to operate. Consequently, if the Reynolds number has an effect, a greater degree of nonuniformity is expected in the 1/12-scale model than in the prototype. If Reynolds number has no effect, the degree of nonuniformity is expected to be identical in both tanks. As a result, if all tests conducted at $1 / 12$-scale with one mixer pump indicate that the mixing achieved in the tank is sufficient to maintain uniformity, this will indicate that uniformity will also be attained in the full-scale tank using one mixer pump operating at speeds as low as one-quarter of the current design full speed. Then, additional tests at a large scale would not be required unless the jet design or velocity were modified. The logic that would be followed at the end of $1 / 12$-scale testing is shown in Figure 6.1. However, it is not possible to simultaneously exercise high and low values of the Reynolds number, remain in the turbulent operational range, maintain geometric similarity, and operate at the appropriate Froude number at an arbitrary scale. This limitation is 


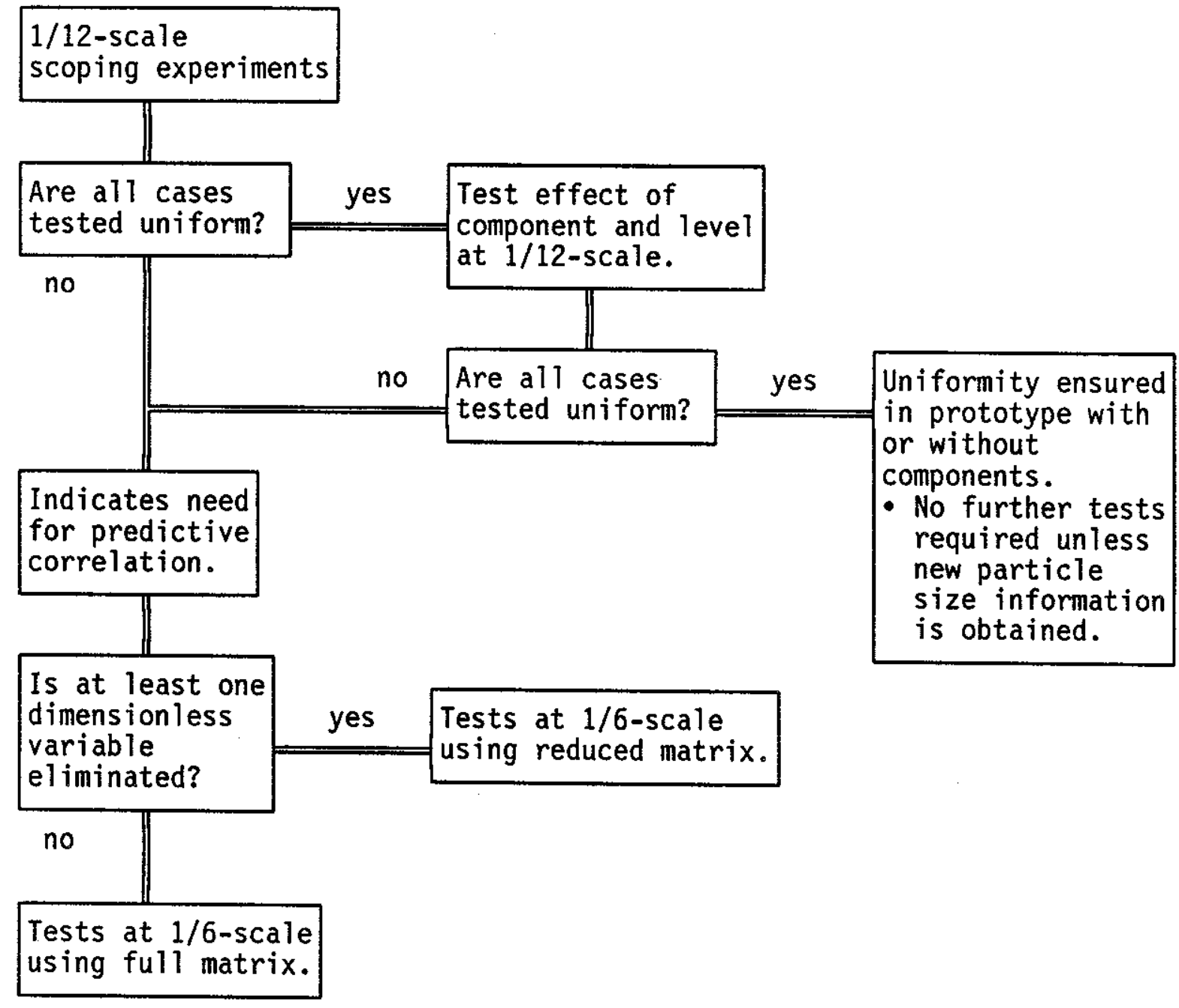

\section{FIGURE 6.1. Logic Diagram for Experimental Plan}

imposed by the viscosity of available simulants. Analysis indicates that it is possible to vary the Reynolds numbers by a factor of 1.7 in a $1 / 12$-scale tank while operating at Froude numbers equivalent to those achieved in the full-scale tank when the jet operates at full and quarter speed. This range allows both a high and low value of the Reynolds number to be achieved during testing using a 1/12-scale tank and is sufficient to allow the effect of 
Reynolds number on mixing to be detected. Tests at a smaller scale would not allow both a high and low Reynolds number value to be obtained and consequently would not allow the effect of the Reynolds number to be detected. Tests at a larger scale would allow a larger spread in the Reynolds number. Experiments at a larger scale are expected to require more lead time and to be more expensive because larger-scale facilities do not currently exist. In contrast, if nonuniformity is detected during the 1/12-scale experiments, defining experiments will be required at a larger scale to allow predictive correlations to se developed. The predictive experiments will provide a basis for design of the prototype system. In this case, the data from the 1/12-scale experiment will be used to determine which dimensionless variables govern the degree of uniformity achieved. This ranking may allow the number of tests run at a lariger scale to be reduced substantially and reduce costs.

The results of the computer analyses determined the appropriateness of 1/1:-scale experiments and are presented in Section 5.0. As a result, the scopjing experiments will be designed to be conducted at 1/12-scale. The scaled results can be used to predict mixing behavior in the prototype at full-scale. In the following subsections, the scoping experiment objectives, test approach, test: equipment, data analysis approach, anticipated results, and limitations are defined.

\subsection{EXPERIMENT OBJECTIVES}

The scoping experiment objectives are closely linked with the objectives of the TEMPEST computer modeling. These objectives are to

- confirm experimentally that dimensionless relationships [gravitationa] appropriate to describe slurry mixing in tanks

- rank dimensionless relationships that influence slurry mixing in tanks in order of decreasing importance

- provide linear (averages at high and low values) correlations based on scoping experiment results to describe the effects of dimensionless relationships and physical parameters 
- provide experimental data for TEMPEST code comparison

- provide direction for subsequent computational efforts to be determined from the agreement between the experimental and computational results

- provide direction for determining whether a 1/12-scale or larger scale is required to conduct the defining experimental efforts

- demonstrate the practicality of the technique.

\subsection{TEST APPROACH}

To provide background information for the 1/12-scale scoping experiments, the prototype waste tank and waste characteristics are summarized, and the prototype design bases are listed in Sections 6.2.1 and 6.2.2. Based on this prototype information, simulant development and verification are outlined in Section 6.2.3; the 1/12-scale model of the problem is presented in section $6.2 .4 ;$ and the scoping experiment design and test matrix are listed in Section 6.2 .5 .

\subsubsection{Prototype Facility and Waste Characteristics}

Double-shell tanks, with capacities of $3800 \mathrm{~m}^{3}\left(1 \times 10^{6} \mathrm{gal}\right)$, are used to store seven types of low level and high level waste at Hanford. Typical tank and waste retrieval system dimensions are listed in Table 6.1.

From process to process and tank to tank, the waste characteristics vary considerably. Waste characteristic data from core samples and from waste simulants are summarized in Table 3.1. The data in Table 3.1 were reviewed to provide the anticipated range of physical waste properties pertinent to modeling tank slurry uniformity; these properties are summarized in Table 6.2. Specific particle size distribution data for individual waste types are summarized in Table 6.3. The particle size distribution data are difficult to summarize because several particle size analyses techniques based on weight $\%$, volume $\%$, and geometric diameter were used. The mean diameters listed in Table 6.3 may be larger than the size data presented in Section 3.3; however, the particle diameter reference frames do differ between the two tables. 
TABLE 6.1. Prototype Tank and Waste Retrieval

System Dimensions

Tank Geometry

\begin{tabular}{|c|c|}
\hline & $23 \mathrm{~m}(75 \mathrm{ft})$ \\
\hline $\begin{array}{l}\text { Distance } \\
\text { Pump centerline to tank wall } \\
\text { Fluid depth }\end{array}$ & $11.4 \mathrm{~m}(37.5 \mathrm{ft})$ \\
\hline Final & $\leq 1.2 \mathrm{~m}(4 \mathrm{ft})$ \\
\hline Initial & $9.1 \mathrm{~m}(30 \mathrm{ft})$ \\
\hline \multicolumn{2}{|l|}{ Mixing Pump Dimensions } \\
\hline Nozzle diameter & $0.15 \mathrm{~m}$ (6 in.) \\
\hline $\begin{array}{l}\text { Distance } \\
\text { Tank bottom to nozzle centerline } \\
\text { Distance }\end{array}$ & $0.46 \mathrm{~m}$ (18 in.) \\
\hline $\begin{array}{l}\text { Distance } \\
\text { Pump centerline to nozzle discharge }\end{array}$ & $0.44 \mathrm{~m}$ (17.5 in.) \\
\hline $\begin{array}{l}\text { Distance } \\
\text { Tank floor to pump intake } \\
\qquad \text { Jet Properties } \\
\end{array}$ & $0.15 \mathrm{~m}(6 \mathrm{in.})$ \\
\hline$U_{0} D_{0}$ & $\mathrm{~m}^{2} / \mathrm{s}\left(29.4 \mathrm{ft}^{2} / \mathrm{s}\right)$ \\
\hline $\mathrm{U}_{0} D_{0}$ operating range & $25 \%$ to $100 \%$ \\
\hline Discharge angle from vertical & $90^{\circ}+3^{\circ},-0^{\circ}$ \\
\hline
\end{tabular}

\subsubsection{Prototype Design Basis}

To develop the scoping experiment test matrix, it is necessary to define all pertinent variables in terms of prototype quantities. Based on the Buckingham $\mathrm{Pi}$ analysis presented in Section 3.0, nine independent dimensionless parameters and one dependent parameter must be defined. These paraneters, summarized in Table 6.4., are composed of 12 properties that are defined in terms of prototype upper and lower bounds in Table 6.5. From the summaries provided in Table 6.5, the scoping experiment parameter range of high and low values is selected, and values are listed in Table 6.6. 


\section{TABLE 6.2. Physical Waste Properties Data Summary}

\begin{tabular}{|c|c|c|}
\hline Physical Property & \multirow[t]{2}{*}{ Anticipated Range } & \\
\hline \multicolumn{2}{|l|}{ Bulk properties } & \\
\hline Density, $\mathrm{kg} / \mathrm{m}^{3}$ & 1000 to 1500 & \\
\hline Viscosity, Pa-s (CP) & 0.001 to 0.05 ( 1 to 50$)$ & $\div$ \\
\hline Rheology & Newtonian & \\
\hline \multicolumn{2}{|l|}{ Supernate properties } & $=$ \\
\hline Density, $\mathrm{kg} / \mathrm{m}^{3}$ & 1000 to 1500 & \\
\hline \multirow{2}{*}{$\begin{aligned} \text { Viscosity, Pa-s }(\mathrm{CP}) \text { at } 25^{\circ} \mathrm{C} \\
\text { at } 50^{\circ} \mathrm{C}(\mathrm{a}, \mathrm{b})\end{aligned}$} & 0.006 to 0.01 (6 to 10$)$ & \\
\hline & 0.002 to 0.005 ( 2 to 5 ) & \\
\hline \multicolumn{3}{|l|}{ Solids properties } \\
\hline Density, $\mathrm{kg} / \mathrm{m}^{3}$ & 2500 & \\
\hline \multirow[t]{3}{*}{ Weight $\%$} & $20 \%$ to $25 \%$ in most tanks & \\
\hline & $\begin{array}{l}30 \% \text { to } 40 \% \text { in double-shell } \\
\text { tank slurry }\end{array}$ & \\
\hline & $\begin{array}{l}4 \% \text { to } 18 \% \text { in tank } 101-A Z \\
4 \% \text { to } 6 \% \text { is lowest range }\end{array}$ & \\
\hline
\end{tabular}

(a) Temperature in tank near $50^{\circ} \mathrm{C}$ during uniformity operations.

(b) Viscosity in tank $101-\mathrm{SY}$ varies from $0.02 \mathrm{~Pa}-\mathrm{s}(20 \mathrm{cP})$ at the top to $0.07 \mathrm{~Pa}-\mathrm{S}(70 \mathrm{cP})$ at the bottom.

TABLE 6.3. Particle Size Distribution by waste Type

\begin{tabular}{|c|c|}
\hline Waste Type & Particle Size Distribution \\
\hline \multirow[t]{2}{*}{ NCAW } & $\begin{array}{l}\text { By volume, mean diameter } 3.5 \mu \mathrm{m} \\
95 \%<9_{\mu \mathrm{m}}\end{array}$ \\
\hline & $\begin{array}{l}\text { By population, mean diameter } 1.6 \mu \mathrm{m} \\
95 \%<4 \mu \mathrm{m}\end{array}$ \\
\hline NCRW & $\begin{array}{l}\text { Geometric mean diameter } 8.5 \mu \mathrm{m} \\
\text { Range } 2 \text { to } 47 \mu \mathrm{m}\end{array}$ \\
\hline $\mathrm{CCW}$ & $\begin{array}{l}\text { By population, median diameter } 15 \mu \mathrm{m} \\
\text { By weight, median diameter } 54 \text { to } 115 \mu \mathrm{m}\end{array}$ \\
\hline PFP 102-SY & Geometric diameter range, 10 to $20 \mu \mathrm{m}$ \\
\hline
\end{tabular}




\section{TABLE 6.4. Pi Parameters}

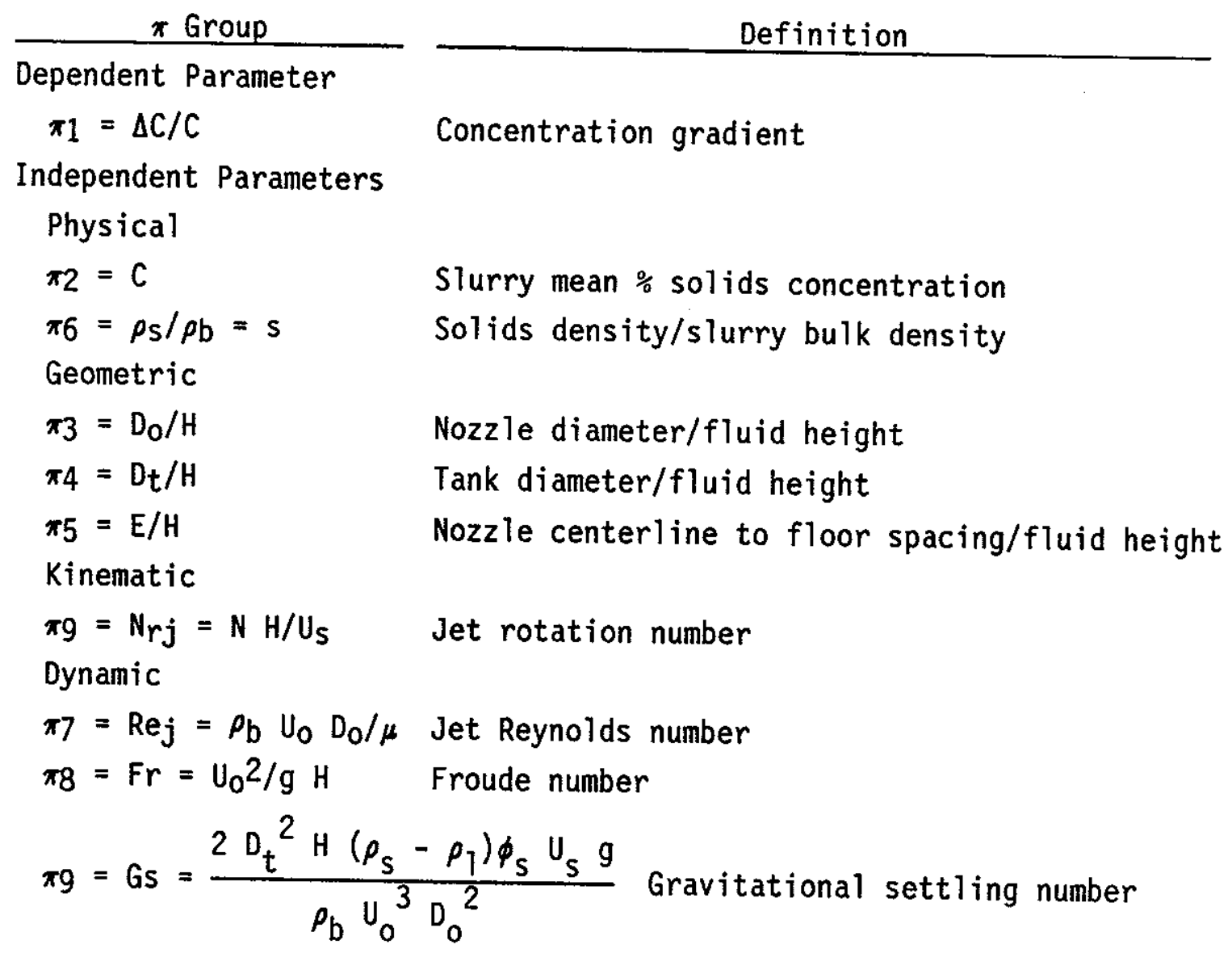

\subsubsection{Simulant Development and Verification}

Simulants will be developed first at bench-scale to meet the required property criteria and then verified at 1/12-scale prior to and during the experiments. The relative importance of the simulant properties is determined by comparing how each one affects the retrieval mechanism. The property priority defined for slurry mixing is

1. $\mu$, bulk viscosity of a well mixed Newtonian slurry

2. particle size distribution

3. $\rho$ b, slurry density

4. $\rho_{S}$, density and shape of solids. 


\section{TABLE 6.5. Prototype Properties}

\begin{tabular}{|c|c|c|}
\hline Property & Definition & Prototype Range \\
\hline \multicolumn{3}{|c|}{ Geometric parameters } \\
\hline$D_{0}$ & nozzle orifice diameter & $0.15 \mathrm{~m}$ (6 in.) \\
\hline$D_{t}$ & tank diameter & $23 \mathrm{~m}(75 \mathrm{ft})$ \\
\hline$E$ & $\begin{array}{l}\text { spacing between floor and } \\
\text { nozzle centerline }\end{array}$ & 0.30 to $0.46 \mathrm{~m}$ (12 to $18 \mathrm{in.}$ ) \\
\hline$H$ & fluid height & 1.2 to $9.1 \mathrm{~m}(4$ to $30 \mathrm{ft})$ \\
\hline$N$ & jet oscillation rate & $0.03 \mathrm{~m} / \mathrm{s}(0.1 \mathrm{ft} / \mathrm{s})$ \\
\hline \multicolumn{3}{|c|}{ Slurry and particle properties } \\
\hline C & mean $\%$ solids concentration & $10 \%$ to $30 \%$ \\
\hline$\rho \mathrm{b}$ & slurry bulk density & 1000 to $1500 \mathrm{~kg} / \mathrm{m}^{3}(\mathrm{a})$ \\
\hline$\rho_{\mathrm{S}}$ & solids density(b) & 2200 to $2800 \mathrm{~kg} / \mathrm{m}^{3}$ \\
\hline$\mu \mathrm{b}$ & slurry viscosity & $\begin{array}{l}0.002 \text { to } 0.05 \mathrm{~Pa}-\mathrm{s} \\
(2 \mathrm{cP} \text { to } 50 \mathrm{cP})\end{array}$ \\
\hline \multicolumn{3}{|c|}{ Dynamic properties } \\
\hline$U_{0}$ & jet exit velocity & $\begin{aligned} & 25 \% \text { to } 100 \% U_{0} D_{0} \\
& \text { where } U_{0} D_{0}= 2.73 \mathrm{~m}^{2} / \mathrm{s} \\
&\left(29.4 \mathrm{ft}^{2} / \mathrm{s}\right)\end{aligned}$ \\
\hline$U_{S}$ & $\begin{array}{l}\text { unhindered particle settling } \\
\text { velocity }(c)\end{array}$ & $\begin{array}{l}1.4 \times 10^{-3} \mathrm{~mm} / \mathrm{s} \text { to } \\
3.28 \mathrm{~mm} / \mathrm{s}\end{array}$ \\
\hline
\end{tabular}

(a) Taken from Table 6.2.

(b) Solids density is not measured directly in any published waste analysis. This value was estimated based on data from waste from tank 101-AZ. A sample calculation showing the method used to determine the estimate appears in the appendix.

(c) Calculated based on a particle diameter range of $10 \mu \mathrm{m}$ to $100 \mu \mathrm{m}$ and fluid viscosity range from 0.002 to $0.05 \mathrm{~Pa}-\mathrm{s}$ $(2 \mathrm{cP}$ to $50 \mathrm{cP})$.

The slurry viscosity $(\mu)$ will be measured in the laboratory using a Haake(a) viscometer; the particle size distribution will be quantified in the laboratory prior to slurry manufacturing, and the slurry density will be measured in the laboratory. The density of the solids used in the slurry

(a) Haake Buchler Instruments, Incorporated, Saddlebrook, New Jersey. 
TABLE 6.6. Scoping Experiment Parameter Set, Based on Prototype

\begin{tabular}{|c|c|}
\hline Parameter Set & Range for Scoping Study \\
\hline \multicolumn{2}{|l|}{ Dimensionless } \\
\hline $\operatorname{Re}$ & $4.1 \times 10^{4}$ to $1.7 \times 106$ \\
\hline $\mathrm{Fr}$ & 0.22 to 3.6 \\
\hline Gs & $5 \times 10^{-5}$ to 77 \\
\hline \multicolumn{2}{|l|}{ Geometric } \\
\hline Liquid level & $9.1 \mathrm{~m}(30 \mathrm{ft})$ \\
\hline Number of pumps & one mixer pump \\
\hline Tank configuration & without air-lift circulators \\
\hline Nozzle centerline elevation & $0.46 \mathrm{~m}$ (18 in.) \\
\hline
\end{tabular}

will be determined on receipt, prior to actual simulant development efforts. It will be assumed that the solids density does not change when solids are immersed in the liquid. All measurements will be confirmed at laboratory scale prior to and during the experiments.

\subsubsection{Model}

The scaling relationships developed in Section 3.2 are used to define the model in terms of the prototype. The appropriate scaled parameters for the 1/12-scale experiments are summarized in Table 6.7. From the summaries provided in Table 6.7, the scoping experiment parameter range of high and low values is selected, and values are listed in Table 6.8. Property values for the simulant must be chosen to provide the appropriate range for the Reynolds (Re), Froude ( $F r)$, and gravitational settling (Gs) numbers. In addition, the rate of rotation is selected to match both jet rotation numbers $\eta_{r j}$ and $\eta_{r h}$. Because the velocity ratio $\left(U_{s} / U_{0}\right)$ in the scaled experiment matcres that which occurs in the prototype, both jet rotation numbers can be matched simultaneously. The property values anticipated for use in the scoping expeniments are listed in Table 6.9.

\subsubsection{Scoping Experiment Design}

The scoping experiments will be statistically designed to determine whether an adequately homogeneous slurry is maintained in the scaled tank under 
TABLE 6.7. 1/12-Scale Model Configuration

Tank Geometry

Diameter

Distance, pump centerline to tank wall

Fluid depth

Low case

High case

Mixing Pump Dimensions

Nozzle diameter

Distance, tank bottom to nozzle centerline

Distance, pump centerline to nozzle discharge

Distance, tank floor to pump intake

Jet Properties

$U_{0} D_{0}$ at full speed ( $100 \%$ condition)

$\mathrm{U}_{0} \mathrm{D}_{0}$ operating range

Discharge angle from vertical

Rate of pump rotation

\begin{tabular}{ll}
$\frac{\text { Prototype }}{23 \mathrm{~m}(75 \mathrm{ft})}$ & \multicolumn{1}{c}{ Model } \\
$1.9 \mathrm{~m}(75 \mathrm{in})$. \\
$11.4 \mathrm{~m}$ & $0.95 \mathrm{~m}$ \\
$(37.5 \mathrm{ft})$ & $(37.5 \mathrm{in})$.
\end{tabular}

$1.2 \mathrm{~m}(4 \mathrm{ft}) \quad 0.10 \mathrm{~m}$ (4 in.)

$9.1 \mathrm{~m}(30 \mathrm{ft}) 0.76 \mathrm{~m}$ (30 in.)

$\begin{array}{ll}0.15 \mathrm{~m} & 0.01 \mathrm{~m} \\ (0.5 \mathrm{ft}) & (0.5 \mathrm{in.}) \\ 0.30 \mathrm{to} & 0.025 \mathrm{to} \\ 0.46 \mathrm{~m} & 0.038 \mathrm{~m} \\ (1.0 \mathrm{ft} \text { to } & (1.0 \mathrm{in} . \text { to } \\ 1.5 \mathrm{ft}) & 1.5 \mathrm{in.})\end{array}$

$0.44 \mathrm{~m} \quad 0.037 \mathrm{~m}$

(17.5 in.) (1.5 in.)

$0.15 \mathrm{~m}$

$(0.5 \mathrm{ft})$

$0.01 \mathrm{~m}$

(0.5 in.)

$$
\begin{array}{ll}
2.73 \mathrm{~m}^{2} / \mathrm{s} & 0.066 \mathrm{~m} 2 / \mathrm{s} \\
(29.4 \mathrm{ft} 2 / \mathrm{s}) & (0.71 \mathrm{ft} 2 / \mathrm{s}) \\
25 \% \text { to } 100 \% & 0.017 \mathrm{to} \\
& 0.066 \mathrm{~m}^{2} / \mathrm{s} \\
& (0.18 \mathrm{ft} 2 / \mathrm{s} \mathrm{to} \\
& 0.71 \mathrm{ft} 2 / \mathrm{s}) \\
90^{\circ}+3,-0 & \text { no change } \\
1 \mathrm{rpm} & 3.46 \mathrm{rpm}
\end{array}
$$

a variety of tank operating conditions. The homogeneity of the slurry will be measured by comparing the average weight \% solids determined by taking replicate samples from 15 sampling locations within the tank. Samples are proposed to be taken at three radial distances corresponding to radii of $0 \mathrm{~m}$ (0 in.), $0.38 \mathrm{~m}$ (15 in.), and $0.76 \mathrm{~m}$ (30 in.) from the tank center, and three heights corresponding to $0.20 \mathrm{~m}$ ( $8 \mathrm{in.}), 0.43 \mathrm{~m}$ (17 in.), and $0.66 \mathrm{~m}$ (26 in.) 
TABLE 6.8. Scoping Experiment Parameter Set, Based on Model

\begin{tabular}{|c|c|}
\hline Parameter Set & Range for Scoping Study \\
\hline \multicolumn{2}{|l|}{ Dimensionless } \\
\hline $\operatorname{Re}(a)$ & $6.0 \times 10^{3}$ to $4.1 \times 10^{4}$ \\
\hline $\mathrm{Fr}$ & 0.22 to 3.6 \\
\hline Gs (b) & $1.1 \times 10^{-3}$ to 1.90 \\
\hline \multicolumn{2}{|l|}{ Geometric } \\
\hline Liquid level & $0.76 \mathrm{~m}(30 \mathrm{in.})$ \\
\hline Number of pumps & one mixer pump \\
\hline Tank configuration & without air-lift circulators \\
\hline Nozzle centerline elevation & $0.038 \mathrm{~m}(1.5 \mathrm{in.})$ \\
\hline
\end{tabular}

(a) Range limited to region of turbulent jet Reynolds number.

(b) Range required for a balanced test matrix.

IABLE 6.9. Property Value Range to Model Process at 1/12-Scale Slurry and particle properties

C mean weight $\%$ solids concentration $10 \%$ to $30 \%$

“ slurry apparent viscosity

0.002 to $0.0034 \mathrm{~Pa}-\mathrm{s}$

(2 $\mathrm{cP}$ to $3.4 \mathrm{cP}$ )

ob slurry bulk density

1000 to $1500 \mathrm{~kg} / \mathrm{m}^{3}$

os solids density

Is unhindered particle settling velocity $2500 \mathrm{~kg} / \mathrm{m}^{3} \pm 300 \mathrm{~kg} / \mathrm{m}^{3}$

d particle diameter $5.0 \times 10^{-3} \mathrm{~mm} / \mathrm{s}$ to $1.4 \times 10^{-1} \mathrm{~mm} / \mathrm{s}$ $5 \mu \mathrm{m}$ and $20 \mu \mathrm{m}$

from the tank floor. Because both radius and height are varied, homogeneity of the slurry may be determined as a function of radial distance as well as vertical distance. Fow, Kurath, and Pulsipher (1989) reported that bench-scale experiments of a similar nature did not show concentration variation with radius. If this variation is not observed, the sampling locations may be altered. In addition to "grab sample" measurements of concentration, realtime, acoustic or ultrasonic measurements of the local average concentration are proposed. This method, discussed in more detail in Section 9.0, would measure average concentration as a function of height. 
For a scoping experiment composed of three variables (listed in Table 6.10) 23 = eight separate combinations of experiments exist. A full factorial experiment is recommended for two reasons. One reason is that when only three variables are involved a fractional factorial plan does not provide any replicate information. Some replication is required to allow scatter in the data, which arises because of the imprecission in measurements, to be distinguished from real trends. In addition, in this experiment, a fractional factorial test $\mathrm{plan}$ to measure the effect of variables would require all four simulants. Because simulant development is time consuming relative to running tests at different velocities, there is little difference in the cost of a full factorial experiment of eight tests involving four simulants and a fractional factorial of four testing involving four simulants. The test matrix is listed in Table 6.10. In this table, the variable values are denoted as being high or low, thus corresponding with the range of variables listed in Table 6.8 .

It is always important to perform experiments in a random order to reduce the influence of time-related effects such as increased familarity in operating the experiment and systematic changes in simulant. However, because the simulants are difficult to store, the experiments will be conducted, "blocked," according to simulant type.

TABLE 6.10. Test Matrix Example

\begin{tabular}{|c|c|c|c|c|}
\hline Test No. & $U_{0} D_{0}$ Range & Bulk Viscosity & Particle Size & $\begin{array}{l}\text { Simulant } \\
\text { Number }\end{array}$ \\
\hline 1 & Low & Low & Low & 1 \\
\hline 2 & High & Low & Low & 1 \\
\hline 3 & Low & High & Low & 2 \\
\hline 4 & High & High & Low & 2 \\
\hline 5 & Low & Low & High & 3 \\
\hline 6 & High & Low & High & 3 \\
\hline 7 & Low & High & High & 4 \\
\hline 8 & High & High & High & 4 \\
\hline
\end{tabular}




\subsection{EQUIPMENT DESCRIPTION}

The existing 1/12-scale experimental facility, its associated auxiliary equipment, and instrumentation required to characterize tank slurry uniformity are discussed in this section.

\subsubsection{Facility}

A schematic of the proposed test facility is displayed in Figure 6.2.

\subsubsection{1/12-Scale Equipment}

The scoping experiments will be performed in a 1/12-scale model of a double-shell tank. The 1/12-scale tank can be configured to represent component arrangements in actual waste tanks using models of internal components such as air-lift circulators, steam coils, radiation dry wells, and other tank hardware. Air-lift circulators are present in some of the existing tanks and absent in others. At this time it is not possible to state with certainty whether mixing will be enhanced or suppressed when air-lift circulators are present. The study of the effect of air-lift circulators on mixing achieved in the tank will be postponed until the relative importance of dimensionless variables that affect mixing have been determined. The current plan calls for tests with no air-lift circulators in place. The tank, made of 304L stainless steel, is illustrated in Figure 6.3 with simulated air-lift circulators installed.

The 1/12-scale mixing pumps model the operation of the proposed prototype waste tank mixing pump. An assembly drawing of the mixing pump is presented in Figure 6.4. To simulate the operation of the prototype mixing pump, a circulation pump draws the slurry from the tank up the central column of the mixing pump and discharges the slurry through the mixing pump annulus and out two diametrically opposed nozzles. The nozzles are removable to accommodate design variations.

The test facility can accommodate six mixing pumps, each with two nozzles. Any number of pumps can operate simultaneously. The mixing pump height above the floor can be varied. Also, the mixing pumps can either rotate or oscillate at speeds up to $8 \mathrm{rpm}$. 


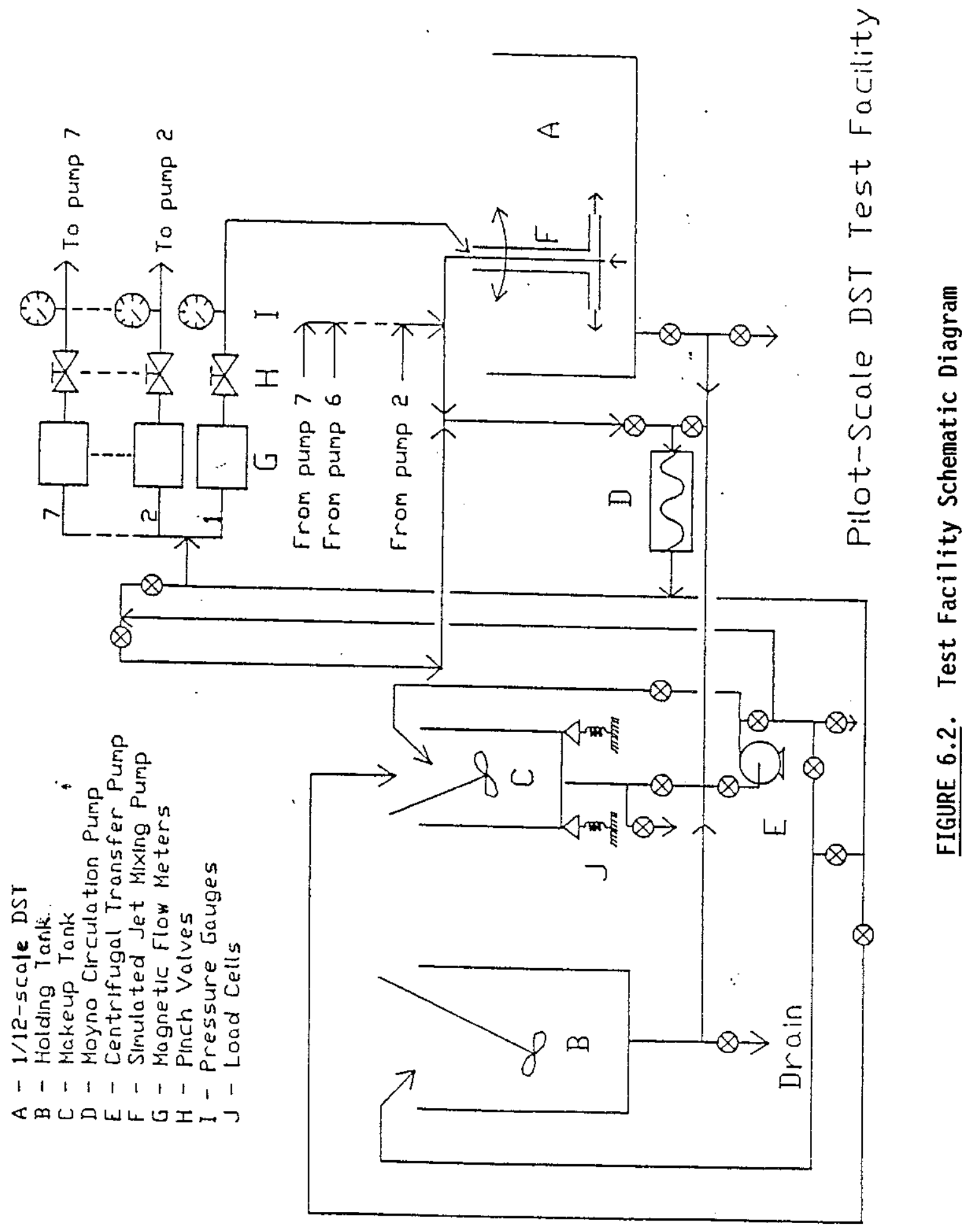

6.14 


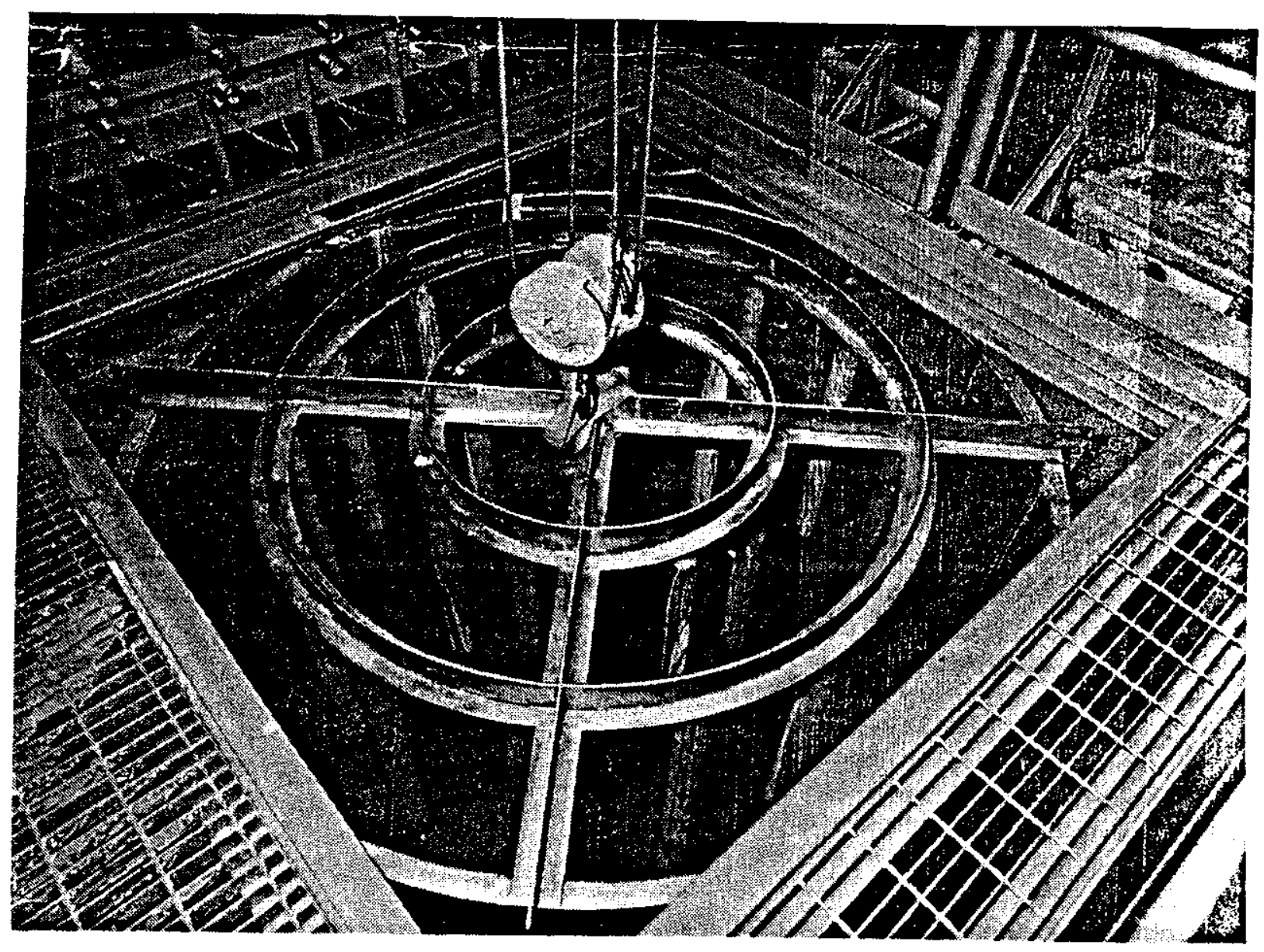

FIGURE 6.3. 1/12-Scale Double-Shell Tank Model

\subsubsection{Simulant Makeup and Transfer}

The facility is equipped to prepare simulated double-shell tank slurries with facility components including makeup tank, holding tank, and circulation and transfer pumps. The makeup tank is equipped with an agitator to mix the simulant prior to transfer to the scaled waste tank. The tank is instrumented with load cells to measure slurry ingredients as well as the mass of slurry transferred into and retrieved from the 1/12-scale tank. A centrifugal pump with a capacity of $3.2 \times 10-3 \mathrm{~m} 3 / \mathrm{s}(50 \mathrm{gal} / \mathrm{min})$ at $15 \mathrm{~m}(50 \mathrm{ft})$ head is used to transfer slurries throughout the test facility. 


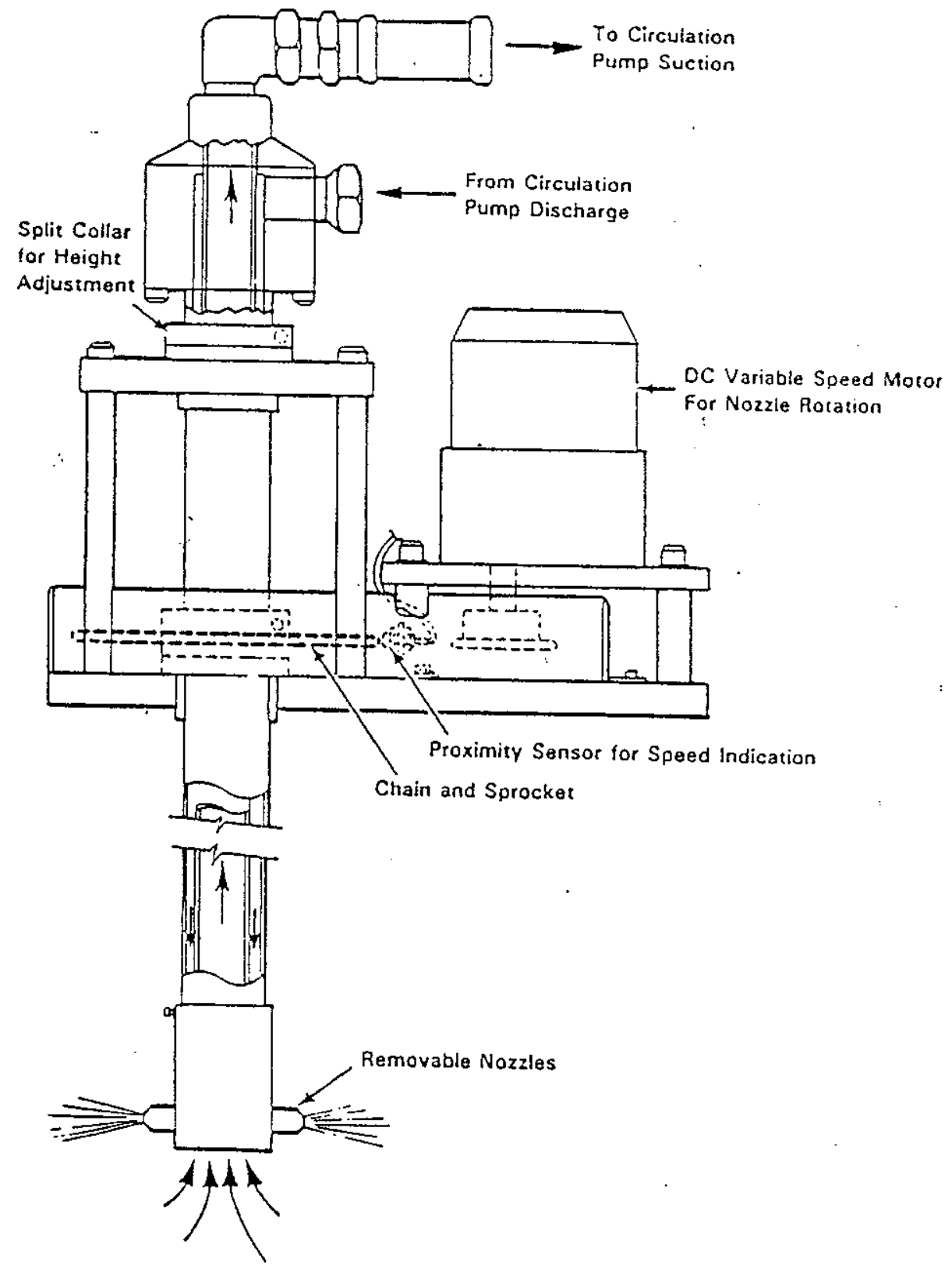

FIGURE 6.4. STurry Mixing Pump Configuration 


\subsubsection{Instrumentation}

Instrumentation is required to measure simulant properties, process conditions, and identify simulant concentration and local velocity patterns. Each mixer pump is equipped with a magnetic flowmeter, manual control valve, and pressure sensor, located in the discharge manifold. Instrumentation use is summarized in Table 6.11.

Two methods are proposed to measure in-tank concentration: grab samples and real-time, ultrasonic, or acoustic measurements. Grab sample measurement locations are displayed in Figure 6.5 ; these measurements will be taken at three different heights and radii. Therefore, concentration can be characterized both horizontally and vertically. The major difference is

\section{TABLE 6.11. Instrumentation}

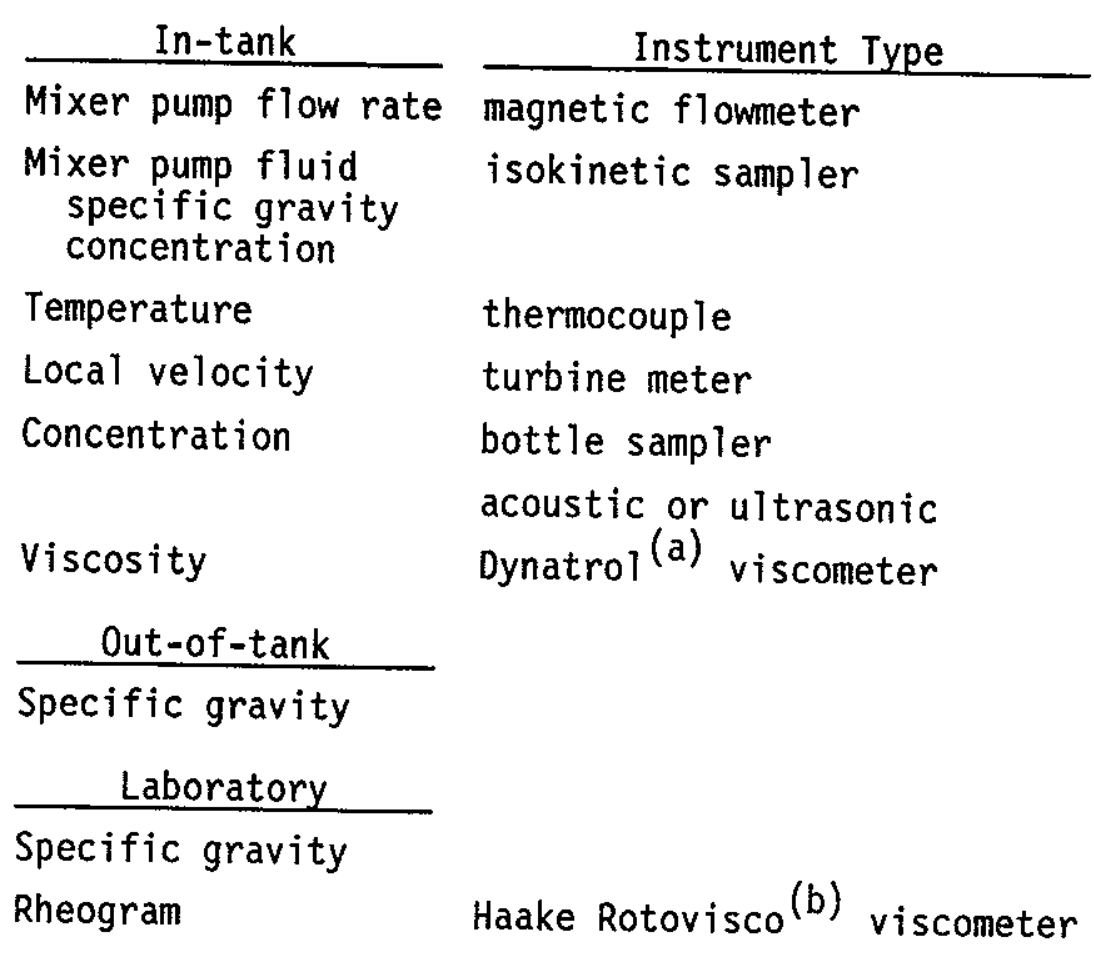
(a) Registered tradename of Automation Products Incorporated,
Houston, Texas.

(b) Registered tradename of Haake Buchler Instruments, Incorporated, Saddlebrook, New Jersey. 

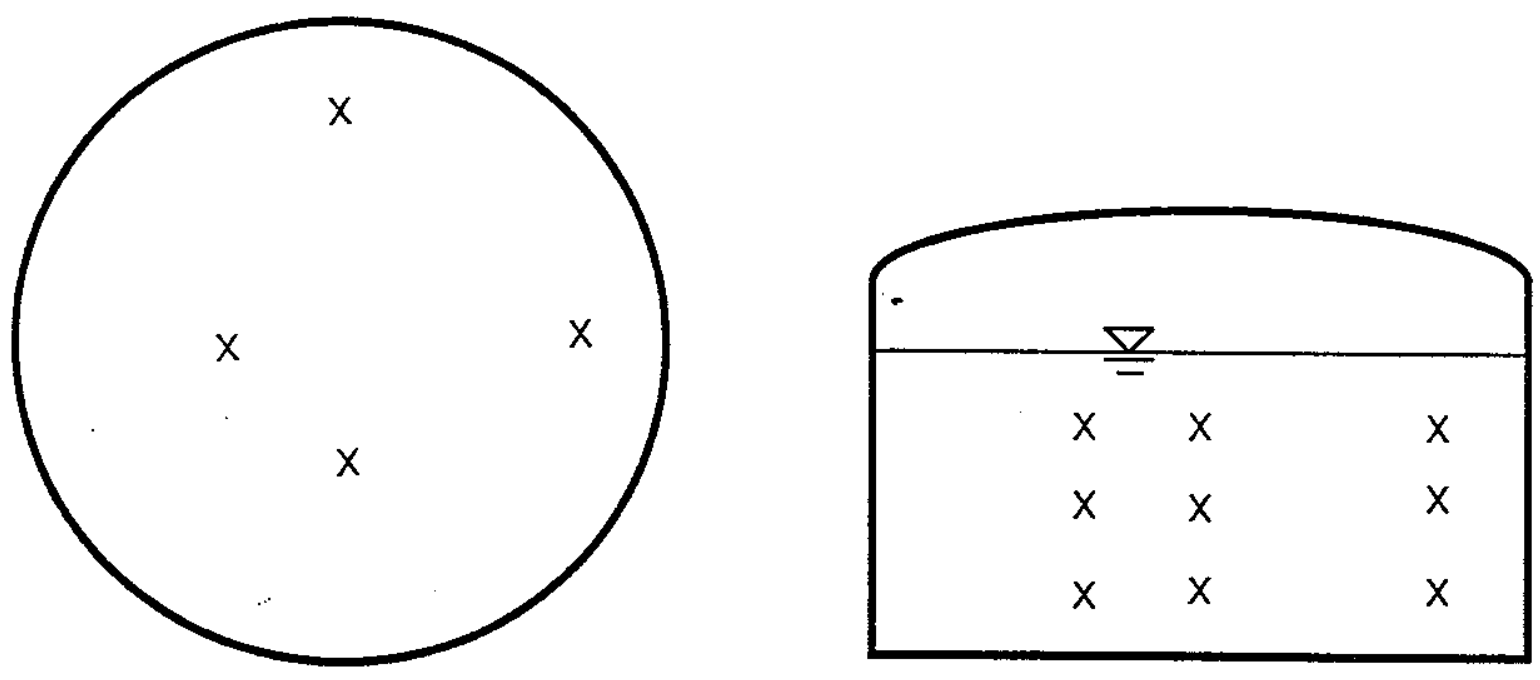

Top view

Side view

FIGURE 6.5. Proposed Concentration "Grab Sample" Measurement Locations

anticipated to be observed vertically; particle settling that would introduce a vertical concentration gradient may occur. However the placement will also allow the radial or angular variations in concentration to be detected. Grab samples will be taken using a bottle-and-rod tank sampler (Figure 6.6). Three 60-ml polyethylene bottles will be secured to the long pole locations at the specified depths in the tank. Current plans call for uncorking the bottles, allowing fluid to enter, and recorking after $10 \mathrm{~s}$.

Grab sampling is simple to implement and requires no calibration. The weight $\%$ solids can be determined by first weighing the total sample in a bottle and then filtering the sample, drying the solids, and weighing the mass of solids remaining. If the simulant contains dissolved solids, it may also be necessary to wash the solids prior to drying and weighing them. It is currently expected that the largest viscosities can be obtained using water as the supernate; washing of the solids is not expected to be necessary. 


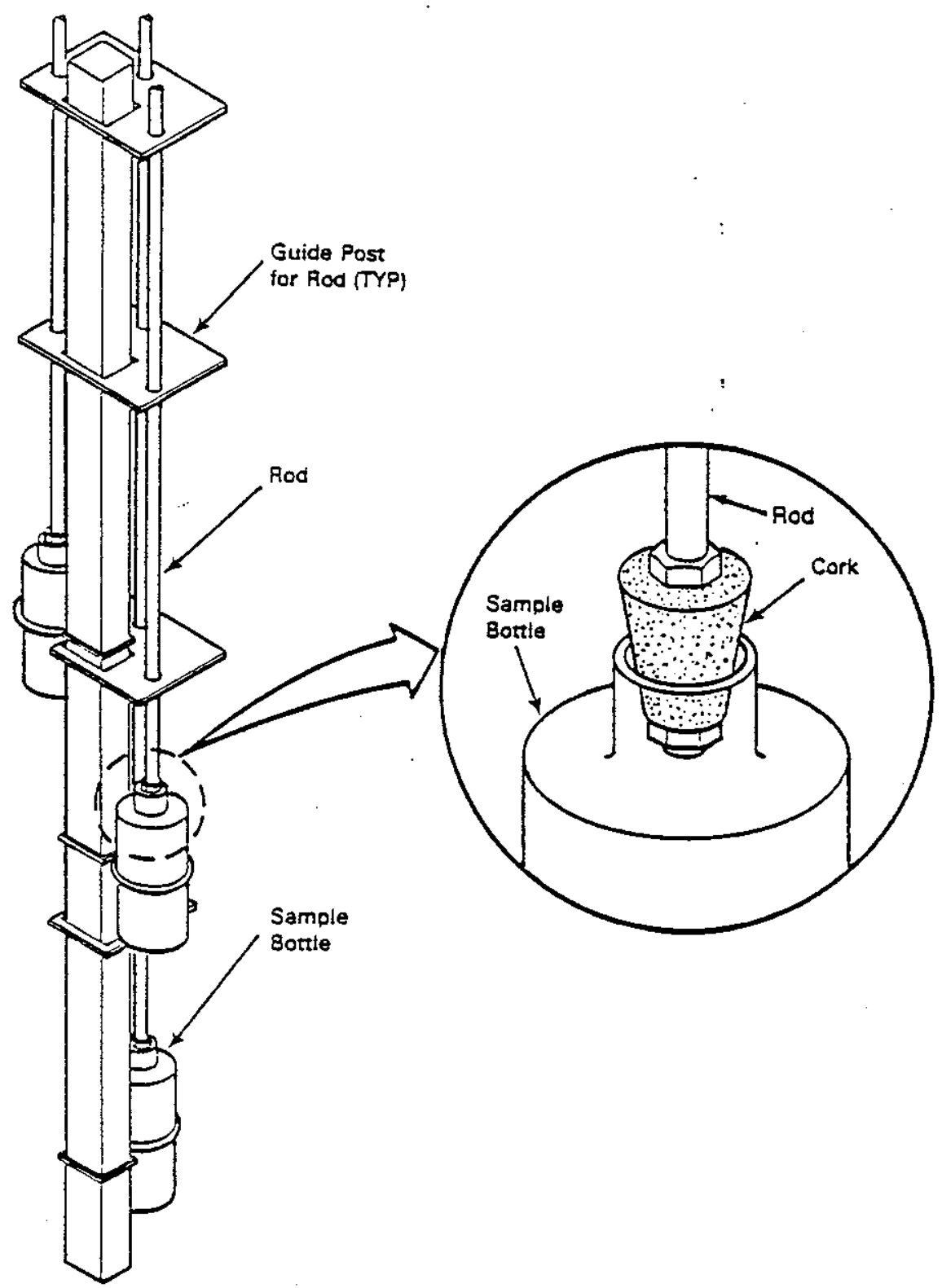

FIGURE 6.6. Schematic of Bottle-and-Rod Tank Sampler

One drawback of grab samples is that it is not possible to be certain that the fluid that enters the sampling device contains the same amount of solids as fluid in the vicinity of the bottle. This phenomenon occurs because the inertia of the particles may cause them to lead or lag the fluid. This problem may be significant when particles are large but is less significant when small particles are contained in the slurry. This deficiency is sometimes overcome by taking samples isokinetically, that is by drawing fluid at the 
same velocity as the local fluid. However, this requires knowledge of the velocity in the region of the sampling device, which is also difficult to obtain. In the proposed sampling method, samples will not be obtained isokinetically because the velocity near the bottle will not be known. However, particles in the proposed slurries are small; consequently, the bias at each sample location is expected to be small.

Another drawback of grab samples is that the bottle assembly disturbs the flow pattern and may affect the solids concentration distribution, particularly in the region of the sample bottle. This problem can be minimized by using extremely small sampling devices, but can only be eliminated by use of a nonintrusive method.

Acoustic and ultrasonic methods are being investigated to overcome the deficiencies of grab sampling. These types of methods would not require matching the velocity in the vicinity of the measuring device and would introduce minimal disturbance.

Turbine meters will be installed around the perimeter of the tank to observe vertical components of slurry bulk velocity in the tank induced by the mixer pumps. Velocity data can be used to make comparisons between the computer model and the experimental data.

Viscosity will be monitored continuously to detect whether the simulant properties are changing as a function of operating time. This would be done by installing the Dynatrol(a) viscometer in the mixer pump flow line. The relationship between the effective viscosity measured by the Dynatrol ${ }^{(a)}$ and actual simulant properties would be determined prior to testing. The simulant measurements can also be used to confirm that simulant conditions are similar when cases are duplicated.

\subsection{DATA ANALYSIS APPROACH}

Data will be analyzed in the scaled experiment to characterize the effects of process variables and simulant characteristics on the concentration gradient.

(a) Registered tradename of Automation Products Incorporated, Houston, Texas. 


\subsubsection{Process Measurements}

Process conditions will be measured continuously to determine the amount of fluctuation in the experiment operation. Variables such as mixer pump flow rate, oscillation rate, and temperature of the tank contents should remain stable throughout the sampling period. The process data can be used to normalize the real-time acoustic measurements of average concentration to account for minor variations in process conditions.

\subsubsection{Simulant Property Measurements}

Simulant properties will be measured at both laboratory scale during simulant development and at 1/12-scale during the uniformity experiments. Depending upon the length of the test, several measurements may be made during the run. A simulant development goal would be to design a simulant with properties that are not time variant. The effects of temperature on the simulant properties would be determined prior to performing the experiments at $1 / 12$-scale.

\subsubsection{Statistical Analysis Requirements for Concentration Measurements}

In the current study, it is necessary to know whether the difference in concentration at different locations in the tank is greater than $2 \%$ or less than $2 \%$ because this is considered the criteria for uniformity. The number of samples that must be taken to be certain that the correct positive (i.e., the slurry in tank is uniform in concentration) or negative (i.e., the slurry in tank is nonuniform in concentration) conclusion is drawn $95 \%$ of the time was determined and is discussed in Section 6.4.3.4. The number of samples required to achieve a high level of confidence is dependent upon several factors including the size of the standard deviation of the concentration reported for the replicate samples, the probability of making erroneous conclusions from statistical tests concerning the homogeneity of the slurry, and the acceptable allowable differences between the local average weight $\%$ of the solids' averages at different locations within the scaled tank.

\subsubsection{Standard Deviation of Replicate Samples and Analyses}

The standard deviation is a measurement of the variability between replicate determinations of tank contents. The tank contents will be 
determined by measuring the weight $\%$ total solids via grab samples as a function of location and potentially by measuring the weight \% solids

ultrasonically or acoustically as a function of height. A potential for random variations exists between replicate samples obtained from the same location and slurry combination. These variations may arise either because the actual concentration may vary in the tank or because of random sampling error. Additionally, variations exist between replicate analyses of the same sample because of the imprecision of the instrumentation and sample preparation techniques.

The standard deviation of replicate determinations of the tank contents must be determined before examining the required number of replicates at each location. Previously conducted work on factors affecting homogeneity in a small-scale feed tank provided an estimate of the standard deviation of weight $\%$ solids (Peterson, McCarthy, and Muhlstein 1986). As a baseline, the standard deviation of weight \% solids can be assumed to be equal to the standard deviation obtained from the bench-scale study, $0.9 \%$ (Peterson, McCarthy, and Muhlstein 1986). In tests to determine the degree of uniformity achieved using agitators, Fow, Kurath, and Pulsipher (1989) report standard deviations for replicate samples of 0.71 wt $\%, 1.08 \mathrm{wt} \%$, and 0.73 wt $\%$ solids for tests in which the tank average concentrations were $51 \%, 44 \%$, and $26 \%$, respectively. The average of these standard deviations is $0.8 \mathrm{wt} \%$, which suggests that the standard deviation obtained in bench-scale tests by Petersen, McCarthy, and Muhlstein (1986) is typical of that which can be expected using grab samples.

\subsubsection{Probability of Erroneous Conclusions}

Any test of an hypothesis that involves sampling poses the chance of making an erroneous conclusion. Consider an examination of homogeneity in a tank. If it were concluded that no differences exist between average weight $\%$ solids at different locations, homogeneity is suggested. If it were concluded that differences exist between the averages of replicate samples taken at two different locations, lack of homogeneity is suggested. The difference that forms the basis of the conclusion is found by comparing the average weight $\%$ total solids in a sample for two location/slurry combinations. Drawing the correct conclusion depends on correctly determining whether any 
differences are statistically significant. Drawing an incorrect conclusion could result in unnecessary down time and additional costs or conversely having a nonhomogeneous mixture that may cause problems when feed is withdrawn from the tank. The acceptable probability of not making a false positive or false negative conclusion is $95 \%$.

\subsubsection{Desired Detectable Differences}

Because the homogeneity of the solution within the tank is determined by examining the differences between average weight $\%$; the size of the differences that could adversely affect waste disposal process quality must be determined. These differences, which should have a high probability of detection, become the desired detectable differences. The desired detectable differences have not been specifically defined for each type of disposal process. However, from discussions with the Westinghouse Hanford Company, the desired detectable differences were identified as approximately $\pm 10 \%(a)$ of the mean concentration. For example, if the actual mean concentration of a slurry sample taken at a particular location is $20 \%$, the measured concentration at that location should be within $10 \%$ of $20 \%$ or $2 \%$ and the measured value should fall between $18 \%$ and $22 \%$.

\subsubsection{Number of Samples per Location or Slurry Combination}

The experiment is designed to resolve the following questions:

1. If the local average concentration at a point in the tank is $18 \%$ and the tank average concentration (which is the volume average of the local average) is $20 \%$, the conclusion drawn on the basis of testing should be that the tank solids distribution is not uniform. This conclusion should be drawn $95 \%$ of the time.

2. If the local average concentration is $20 \%$ and the tank average concentration is $20 \%$, the conclusion that the tank distribution is uniform should be drawn $95 \%$ of the time.

The number of samples required to fulfill these two criteria was determined to be five samples at each location. Because there are 12 sampling locations in the tank, 60 bottle samples would be required for each of the 8 tests. The actual number of samples required to obtain statistically significant test results will be recalculated based on actual sample

(a) Personal communication with E. D. Waters, August 1990. 
variability in replicable samples measured during the first test. If the variability in replicate samples is greater than estimated, more samples will be required; if less, fewer will be required.

Once the number of samples is specified, it is possible to determine the uncertainty interval for the determination of the true value of a measured quantity, provided that the standard deviation $\left(\sigma_{r}\right)$ for individual replicate measurements is known. When one sample is taken and found to have a value of $x_{1}$, it can be determined that the "true value" $\left(x_{t}\right)$ of the quantity to be measured falls within a range of:

$$
x_{1}-1.96 \sigma_{r}<x_{t}<x_{1}+1.96 \sigma_{r}
$$

95\% of the time. The true value will be outside of this range $5 \%$ of the time. When " $N$ " samples are taken, the true value falls in the following range

$$
\bar{x}_{N}-1.96 \sigma_{r} / \sqrt{N} \leq x_{t} \leq \bar{x}_{N}+1.96 \sigma_{r} / \sqrt{N}
$$

where $\bar{x}_{N}=\frac{1}{N} \sum_{i=1}^{N} x_{i}$ is the average over all samples taken.

It should be kept in mind that prior to measurement, the magnitude of the standard deviation $\left(\sigma_{r}\right)$ is not known but is assumed on the basis of previous experience. On the basis of this assumption, it is possible to estimate the uncertainty interval (e95\%) that corresponds to the $95 \%$ confidence interval when a number of samples $(N)$ are taken. This is:

$$
\mathrm{e}_{95 \%} \leq \frac{\sigma_{\mathrm{r}}}{\sqrt{\mathrm{N}}}
$$

where e95\% is the uncertainty interval associated with the $95 \%$ confidence interval. In this experiment, the quantity being measured is the local average concentration. Thus, the true value is the actual local average concentration 
$C(x)$. If five samples are taken and the standard deviation of replicate samples $\left(\sigma_{r}\right)$ is 0.9 wt $\%$ solids, the local average concentration will fall within 0.8 wt $\%$ of the average measured value $95 \%$ of the time. That is the probability that

$$
\bar{C}(x)(\text { wt } \%)-0.8 \text { wt } \% \leq C(x)(w t \%) \leq \bar{C}(x)(\text { wt } \%)+0.8 \text { wt } \%
$$

will be $95 \%$, where $\bar{C}$ is the average of the five measurements taken at $x$ and $C(x)$ is the actual local average concentration at $(x)$. The remaining $5 \%$ of the time the actual concentration will differ from the measured average by more than 0.8 wt \% concentration. This uncertainty interval could be reduced in magnitude by increasing the number of samples or by decreasing the standard deviation in replicate samples. If the actual standard deviation of replicate samples is greater than 0.9 wt $\%$, the $95 \%$ confidence interval will be larger. However, a greater number of samples could then be taken to reduce the interval.

\subsection{RESULTS}

The tank slurry uniformity scoping experiments are designed to permit a sound statistical data analysis. The objectives of the statistical analysis is to determine whether an adequately homogeneous slurry is obtained in the $1 / 12$-scale waste tank model.

Homogeneity of the tank contents will be quantified by comparing the differences between the local average weight \% total solids at different sample locations within the tank. If a statistically significant difference greater than $10 \%$ of the total concentration exists between average concentration of solids measured at any two sample locations, the tank contents will be considered nonhomogeneous. It is likely that the tank contents will be considered homogeneous in the radial and angular direction, but that it will be inhomogeneous in the vertical direction. If the difference between the known average weight \% solids in the tank as a whole based on the simulant composition and the average concentration determined on the basis of 60 grab samples taken from the tank is not found to be statistically significant, then the liquid sampling system will be determined to provide a representative 
sample. It is anticipated that all solids will be suspended in the liquid. However, if a settled bed of solids exists, then the average concentration measured using grab samples would be lower than the average concentration in the simulant as a whole. In this case, comparison of the average concentration based on the samples obtained and the actual average concentration based on the simulant formulation will allow cases in which all solids below the lowest sample location with pure fluid above it, to be recognized as being inhomogeneous.

Projected results from physical and rheological characterization are presented in Section 6.5.1. The proposed usage approach for the statistical analysis of the data is presented in Section 6.5.2. Anticipated results of the homogeneity tests as a function of the test parameters are presented in Section 6.5.3. Predictions of full-scale operation based on the scaled experimental data are presented in Section 6.5.4. Anticipated conclusions and recommendations from the scoping experiments are listed in Section 6.5.5.

\subsubsection{Simulant Characterization}

The simulants' physical and rheological properties will be characterized. A summary of the physical properties, similar to those displayed in Table 6.12, will be presented. The properties listed in Table 6.12 will allow tests to be performed at Froude numbers and gravitational settling numbers that are similar to those that occur in the prototype tanks. The Reynolds number achieved will be lower than that achieved in the prototype. The Reynolds and Froude numbers achieved using these parameters were shown in Figure 3.9 .

Use of a simulant containing particles with a volume mean diameter of $5 \mu \mathrm{m}$ will provide a high value for the gravitational settling number; use of

\section{TABLE 6.12. Anticipated Physical Properties of Simulants}

\begin{tabular}{l} 
Property \\
\hline Total solids, weight \\
Slurry viscosity, cP \\
Volume mean particle \\
diameter, $\mu \mathrm{m}$
\end{tabular}

\begin{tabular}{|c|c|c|c|}
\hline Simulant 1 & Simulant 2 & Simulant 3 & Simulant 4 \\
\hline$\underline{\text { Lab }} 1 / 12$ & $\underline{\text { Lab }} \quad \underline{1 / 12}$ & $\underline{\text { Lab }} \quad 1 / 12$ & $\underline{\operatorname{Lab}} \quad \underline{1 / 12}$ \\
\hline $16 \%$ & $17 \%$ & $20 \%$ & $19 \%$ \\
\hline 2 & 2 & 3.4 & 3.4 \\
\hline 20 & 5 & 20 & 5 \\
\hline
\end{tabular}


a simulant containing particles with a volume mean diameter of $20 \mu \mathrm{m}$ will provide a low gravitational settling number value. Each scenario produces gravitational settling numbers that fall within the range of those that will occur in prototype tanks. In addition, both particles are large enough to ensure that Brownian motion alone will not be enough to induce uniformity. A $5-\mu \mathrm{m}$ particle with a specific gravity of 2.5 suspended in water is expected to diffuse slightly as a result of Brownian motion; this motion will result in some particles being present near the top of the tank at all times. Analysis indicates that the ratio of the concentration at the top of the tank to that at the bottom of the tank will be $c_{\text {top }} / c_{\text {bottom }} \sim \mathrm{e}\left(-10^{6}\right)$ when $2-\mu \mathrm{m}$ diameter particles with a specific gravity of 2.5 are placed in water and are suspended by Brownian motion alone. Greater concentration differences are expected for larger 5- $\mu \mathrm{m}$ diameter particles. This degree of suspension is considered negligible.

Laboratory evaluations of the viscosity will be conducted using a Haake(a) viscometer to determine the effects of shear rate on the apparent viscosity of the slurries tested. Rheograms will be presented for the four simulants. Use of the Haake viscometer will allow verification of Newtonian behavior for the simulant. Rheograms will also be taken during testing and any changes in simulant viscosity that cause it to exhibit non-Newtonian rheology behavior will be reported. In addition, the Dynatrol(b) will be used to detect any real-time shifts in the apparent viscosity that also occur during an individual test. These shifts will be reported if they occur.

\subsubsection{Statistical Analysis of Concentration Data}

The experiment sampling and analysis will be conducted randomly in the sense that the order in which bottles are uncorked and in which the contents of bottles from each experiment are analyzed will be randomized. In addition, the order in which the tests are listed in Table 6.10 will be rearranged by sometimes performing the high speed and sometimes performing the low speed experiments first. However, all tests with the same simulant will be conducted in sequence.

(a) Haake Buchler Instruments, Incorporated, Saddlebrook, New Jersey.

(b) Registered tradename of Automation Products Incorporated, Houston, Texas. 
A $95 \%$ confidence level will be assumed for defining statistical significance. A marginal significance may be noted when events are significant at the $90 \%$ confidence level. Statistical analyses and manipulations will be conducted using SAS(a), a statistical software program.

\subsubsection{Effects of Uniformity Test Parameters}

The homogeneity experiments will be performed to characterize the tank mixer pump operation. The statistical analysis technique Analysis of Variance (ANOVA) will be used to examine the homogeneity of the 1/12-scale model concentration data (Box, Hunter, and Hunter 1987).

The predicted results of the statistical analyses for the homogeneity tests will be summarized in a manner similar to that presented in Table 6.13. If there are no significant differences in the samples from different locations in the tank, the tank contents are determined to be uniform and homogeneous for the slurry concentrations tested. Because this is a scoping study and parameters range from high to low values, the tank contents are not expected to exhibit uniformity for all combinations of parameters tested.

In summary, results from the tank slurry uniformity and homogeneity tests are anticipated to indicate that the mixing pump will provide a homogeneous mixture for the more conservative operating conditions, for example, with one mixing pump operated at a high Froude number.

From the data, linear correlations will be developed to describe the effects of the operating conditions on the variables listed in Table 6.13. An example of one of the plots, $\Delta C / C$ versus $G s$, is illustrated in Figure 6.7 .

\subsubsection{Full-Scale Operation Predictions}

From the linear correlations presented in Section 6.5.3 and scaling relationships presented in Section 3.2, predictions of full-scale operation can be made. Because these predictions are based only on a two-point, low versus high, scoping study, the predictions do not show any nonlinear variation and must be used with care.

(a) Registered tradename of SAS Institute, Incorporated, Cary, North Carolina. 
TABLE 6.13. Estimates of Inhomogeneity from Concentration Measurements

Parameter

High velocity

Mean wt \%

Standard deviation wt \%

Froude number

Reynolds number

Gravitational settling number

Low velocity

Mean wt \%

Standard deviation wt \%

Froude number

Reynolds number

Gravitational settling number

Slurry viscosity, Pa-s

Volume mean particle diameter

$\underline{\text { Simulant } 1}$ Simulant 2 Simulant 3 Simulant 4

$\begin{array}{cccc}16 & 17 & 20 & 19 \\ M & U & M & U \\ 3.58 & 3.58 & 3.58 & 3.58 \\ 4.1 \times 10^{4} & 4.1 \times 10^{4} & 2.4 \times 10^{4} & 2.4 \times 10^{4} \\ 3 \times 10^{-2} & 1.9 \times 10^{-3} & 1.7 \times 10^{-2} & 1.1 \times 10^{-3}\end{array}$

16

N

0.22

$1.0 \times 10^{4}$

1.9

$2.0 \times 10^{-3}$

$20 \mu \mathrm{m}$
17

N

0.22

$1.0 \times 10^{4}$

$1.2 \times 10^{-1}$

$2.0 \times 10-3$

$5 \mu \mathrm{m}$
20

N

0.22

$6.0 \times 10^{4}$

1.1

$3.4 \times 10^{-3}$

$20 \mu \mathrm{m}$
19

N

0.22

$U=$ uniform distribution predicted

$M=$ marginally uniform distribution predicted

$\mathrm{N}=$ nonuniform distribution predicted

\subsubsection{Conclusions and Recommendations}

The data and linear correlations developed in Sections 6.5 .3 and 6.5 .4 should indicate that the parameters can be ranked in terms of importance to provide homogeneity in the waste tank. The parameter rank is anticipated to be as follows:

- gravitational settling number (most influence)

- Froude number

- Reynolds number (least influence).

Both gravitational settling number and Froude number should be extremely important for maintaining tank slurry uniformity. In addition, it is anticipated that mixing will be ensured at $100 \% U_{0} D_{0}$ under all operating 


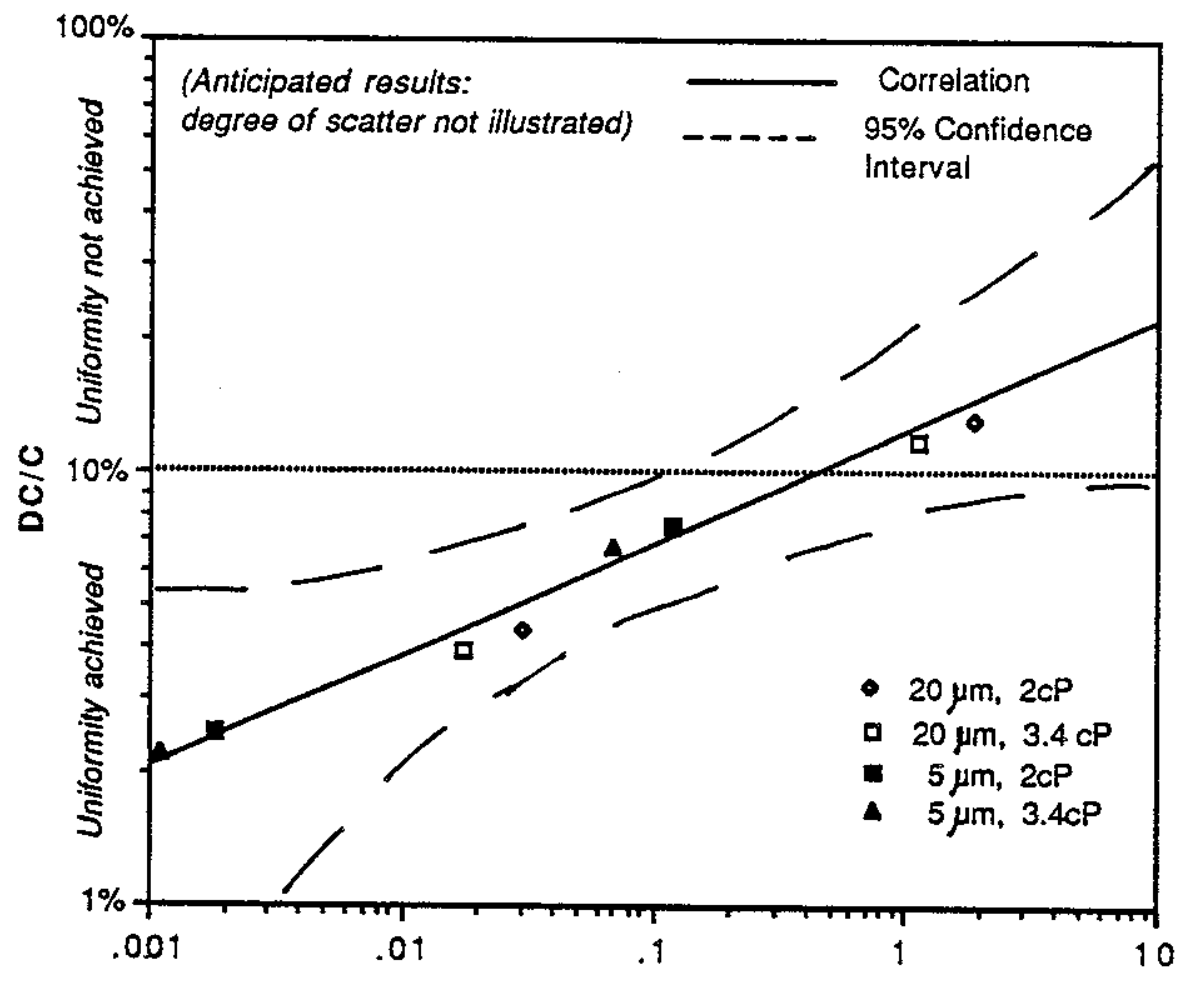

Gravitational Settling number

FIGURE 6.7. Example of Expected Linear Correlation of $\Delta C / C$ versus Gs

scenarios. However, $U_{0} D_{0}$ mixing is not assured at $25 \%$ for all operating conditions, especially those with one centrally located mixing pump.

\subsection{LIMITATIONS}

The following limitations to this proposed scoping study need to be addressed:

- the range of the proposed prototype pump operation is from $25 \%$ to $100 \%$ $U_{0} D_{0}$

- In the $1 / 12$-scale experiments, the Froude numbers will match those achieved when the pump operates at $25 \%$ and $100 \%$ of full speed in the prototype. Because of the limited availability of low viscosity fluids, Reynolds numbers will not match those achieved in the prototype. However, all tests will be conducted at Reynolds numbers that are anticipated to be turbulent. 
- the scoping experiment provides a two-point linear correlation for each variable. The scoping experiment is anticipated to reduce the number of variables to be tested at a larger scale.

None of these limitations are significant when considered in terms of a scoping analysis. If the Reynolds number is found to be significant simultaneously with the Froude number and gravitational settling number, then defining experiments can be done by increasing the experiment scale. If only the Froude and gravitational settling numbers are found to be significant, the defining experiments can be conducted at 1/12-scale provided that the correlations produced are limited to Reynolds numbers in the turbulent range. If a wider range in speed of operation is desired, the test will be conducted at a larger scale to allow the range of applicability of the correlations to be broadened. During the defining experiments, the $U_{0} D_{0}$ range can be increased to cover the entire range of pump operations provided that the scale selected is sufficiently large to ensure that the flow remains turbulent. During the defining experiments, a reduced number of variables will be exercised over a wider range of conditions than in the scoping study to develop the required nonlinear correlations. 



\subsection{NUMERICAL MODEL DEVELOPMENT FOR TANK MIXING ANALYSIS}

The TEMPEST code has an extensive history of application to a wide range of complex engineered and natural systems. Preliminary analysis directed toward tank uniformity and mixing in double-shell tanks was conducted in FY90 and is discussed in Section 5.0. In this section, further numerical model development for tank mixing analysis is discussed. Code development objectives are listed in Section 7.1. The development approach is outlined in Section 7.2. Examples of results are presented in Section 7.3 and modeling considerations for the long term are discussed in Section 7.4.

\subsection{OBJECTIVES}

The primary objective of numerical simulation modeling is to obtain a qualified analysis tool to describe mixing phenomena by jet action in doubleshell tanks. In the short term, model qualification is based on planned 1/12scale mixing experiments with a single, centrally located, dual-jet mixing pump. Successful completion of this case is to be followed by evaluating modeling approaches appropriate to describe multipump configurations. In the long term, it is an objective to qualify TEMPEST as a QA Impact Level II code. (a) Steps referenced to Figure 4.1 involved in attaining the short-term objectives include

1. evaluating simulation and modeling approaches at $1 / 12$ - to full-scale geometric scaling [Step 3a]

2. performing preliminary analysis to ascertain correctness of coded logic and physics applicable to the planned scaled experiments and modifying and testing the logic as necessary [Step 4a]

3. calculating preliminary "blind" predictions of planned scaled experiments [Step 6a]

4. performing pre- and post-experiment analysis and simulation of "as-run" scaled experiments to validate analysis approaches [Step 6a]

5. evaluating agreement/disagreement between analysis and experiments to provide the basis for decision points in the strategy plan [Steps 7 and
[S

(a) Defined in Procedures for Quality Assurance Program, PNL-MA-70, Vol. 1. 
6. extending analysis to full-scale prototype, if decisions are made to do so $[$ Steps 9b, 11a, 13a, 14].

Intermediate-term objectives of determining TEMPEST applicability to multipump configurations [Steps 9c, 11b, 12a] requires additional feasibility studies and numerical experiments because these simulations are anticipated to require use of boundary fitted coordinates. Validation in these configurations require additional experimental data in requisite geometries.

Attaining the long-term objective of validating TEMPEST for QA Impact Level II analysis of tank mixing requires more stringent code analysis [Step 16b]. QA Impact Level II requirements for qualifying software are documented and necessary steps have to be taken to adequately plan for software configuration management and validation simulations. A decision point for pursuing this option is included in the strategy plan [Step 15] (Figure 4.1).

\subsection{APPROACH}

Each task in the numerical simulation portion of this strategy plan consists of three parts that are necessarily intertwined. The first part describes preliminary investigations to determine the correctness of coded logic. The second part describes validation studies based on scaled data. The third part describes application to full-scale prototype tank geometries. Decision points at the end of each task allow for re-evaluation of planned directions.

\subsubsection{Preliminary Qualification towards Rotating Jet Simulation}

The applicability and correctness of logic coding and physics currently implemented in the TEMPEST/TX code being used in this work is to be investigated [Step 4a]. This investigation includes testing the code to determine if logic in place in the code is appropriate and correct as it applies to passive constituent species transport. Tests include solids transport with a specified constant settling velocity, coupling effects in properties determination (such as solids specific gravity) in calculation of density and constituent concentration distribution and calculation of viscosity, and implementation of the rotating jet as a specified/prescribed flow boundary 
condition. Each of these effects is presently coded into the program logic, but they have not been used and/or tested recently. Logic correction and associated testing are to be done if necessary.

Note that passive constituent species transport here implies coupling to properties only through code-user prescribed effects. This coupling is done by the code-user defining functional relationships of concentration dependent viscosity, for example. No implicit or explicit effects such as particle size distribution, particle-to-particle interactions, non-Newtonian yield stress, or settled layer/wall adherence are presently included in the solved transport equations. Addressing these effects is recommended as further extensions to the present work and should be pursued as required if satisfactory conclusions are reached from initial work [Step 4a].

To test the coded logic and physical effects, several numerical experiments (test problems) are to be designed and analyzed. To test the particle settling velocity model, a two-dimensional analysis will be conducted in which an initial uniform distribution of a solids constituent will be allowed to settle in an unperturbed, stationary fluid. It is expected that the solids will settle with known regularity and result in a settled layer at a code-user prescribed packing factor. In conjunction, it may be necessary to prescribe the concentration-dependency of settling velocity to prevent a numerical anomaly referred to as over-packing.

To test concentration-dependent viscosity coding, a two-dimensional flow channel simulation will be conducted. In this geometry, an analytical solution is available for comparison with the predicted velocity distribution. A similar simulation will be conducted to determine the correctness of the coupling of solids specific gravity and concentration in computation of density. Correctness will be determined by comparison to hand calculations of density for a given concentration.

Implementation of the rotating jet as a prescribed flow boundary condition will require innovative use of a currently available boundary condition capability [Step 6a]. This implementation will be tested with numerical experiments in a two dimensional flat plane in cylindrical coordinates with the objective of confirming the approach. In direct 
conjunction, this simulation test will verify the appropriateness of doing the analysis in a $180^{\circ}$ sector of the tank by prescribing periodic boundary conditions at $0^{\circ}$ and $180^{\circ}$. Also in doing this two-dimensional test, noding resolution will be investigated to determine the relation of spread rate of the jet to spread rate of the cylindrical grid.

Appropriate logic and code modification will be made, should it be required as a result of these initial tests.

Subsequent to accomplishment of the above two-dimensional tests, a $180^{\circ}$ section of the 1/12-scale experiment tank will be modeled and a "blind" calculation of a planned 1/12-scale scoping experiment will be performed [Step 6a]. Conditions for this first simulation with a rotating jet will assume a uniformly mixed state without settling solids. This simulation will be the base case upon which additional 1/12-scale simulations of experimental conditions will be performed.

Performance of the above described testing is imperative to ascertaining that pertinent aspects of the TEMPEST code are computing correctly.

\subsubsection{1/12-Scale Experiment Simulations}

Successful accomplishment of preliminary code testing described in Section 7.2.1 allows for the simulation of conditions planned in the 1/12scaled experiments [Step 6a]. Simulation will be conducted for the three corner points of the experiment Reynolds number ( $R e$ )/Froude number (Fr) region of interest (see Figure 3.9) which includes: Point A--low Re/low Fr, Point B- low Re/high Fr, and Point C--high Re/low Fr. At least the first of these comparisons will be conducted as a "blind" calculation at planned conditions. Comparison of computed results to measured data will be evaluated as a test. of the code and a test of the methodology to set up and simulate a set of conditions.

Data from the planned scaled experiments are obtained at fixed locations. Careful evaluation of simulation results will be made and recomputing with "as-run" conditions may be necessary. A decision point is provided to allow re-evaluation of planned directions of the numerical simulation based on the agreement/disagreement of the predictions and experimental data [Step 8]. 
Assuming successful agreement between predictions and measurements, and a decision point conclusion to continue with numerical simulation, analysis could proceed in several directions depending on the nature of the scaled experiments. It would be most useful to determine from experiments the lowest possible operating conditions for the pump to maintain "uniform" conditions and to determine that the numerical simulations can predict the same conditions. At that point, the numerical simulations could be most appropriately extended to the geometrically similar full-scale prototype.

\subsubsection{Single Pump Full-Scale Prototype Simulation}

Assuming that continuance of the numerical simulation path is chosen as a viable one, extension of the modeling approach to simulation of the fullscale prototype is planned. At a minimum, simulation will be conducted at the three bounding corner points of the full-scale Reynolds number (Re)/Froude number (Fr) region of interest (see Figure 3.9): Point A--low Re/low Fr, Point $\mathrm{B}-$-low Re/high $\mathrm{Fr}$, and Point C--high Re/low Fr. Simulation at other conditions will be dependent upon decisions made during the course of the project.

\subsubsection{Multiple Pump Simulation}

Simulation of the single, dual jet, centrally located mixing pump modeling the scaled experiments and prototype is planned. Alternate operating scenarios and planned experiments require that multipump configurations be considered [Steps 9c, 11b, 12b, 13a]. These configurations may include two to four mixing pumps in a diametrically opposed configuration of two dual-jet pumps or four dual-jet pumps. In this latter case, it is expected that the pumps will be located symmetrically at a given distance from the center of the tank. Modeling of these configurations will require some innovation and development of techniques.

In the single, centrally located mixing pump situation, geometry of the problem lends itself to simulation within natural cylindrical coordinates with the pump located at the center of the coordinate system. If the pumps are not situated at the center of the tank, it will be necessary to develop a computational grid system that combines the cylindrical geometry of the tank outer wall with the basic cylindrical nature in the immediate surroundings of 
each pump. Such a grid system is commonly referred to as boundary fitted coordinates (BFC). Furthermore, the configuration of even two pumps on a common diametrical line may require that a full tank be modeled. This is because if the pumps are rotating, periodic symmetry boundaries may not be appropriate. If the tanks are out of phase, either in rotation speed or in relative jet angle with respect to diametrical lines between pumps, periodic conditions are definitely not appropriate and the full tank has to be modeled.

A computational analys is capability to simulate fluid dynamics in boundary fitted coordinates is available in TEMPEST/TX. Associated grid generation, pre-processing, and post-processing tools called PRESIM and POSSIM(a), software developed by Battelle, are also available. With these tools, it will be possible to investigate the feasibility of and (to develop modeling approaches to) simulation of the multipump configurations. It will be necessary to perform preliminary analys is in hypothesized pump configurations to determine appropriate grid layout, grid resolution, and computational requirements. Preliminary code testing of the mixing tank application such as that planned for the centrally located, single pump configuration will have to be done because boundary fitted coordinates present a new set of problems that are most directly associated with the grid system. In Figure 7.1 a preliminary example of the planar nature in a quarter section of a four pump case of a boundary fitted grid is presented.

\subsection{PRESENTATION OF RESULTS}

Numerical simulation of governing transport equations provides extensive field data. The data is in two forms. First there is "snapshot" data that consists of field data of all primary and some secondary variables. These data consist of arrays of data at selected times in a time-dependent calculation. Primary field data includes three velocity components from which directed velocity vectors can be determined and scalar quantities such as species concentration distribution (up to nine components in either mass or volume fractions), temperature, pressure, turbulent kinetic energy and

(a) PRESIM and POSSIM are unpublished, copyrighted software of Battelle Memorial Institute, 1990. 


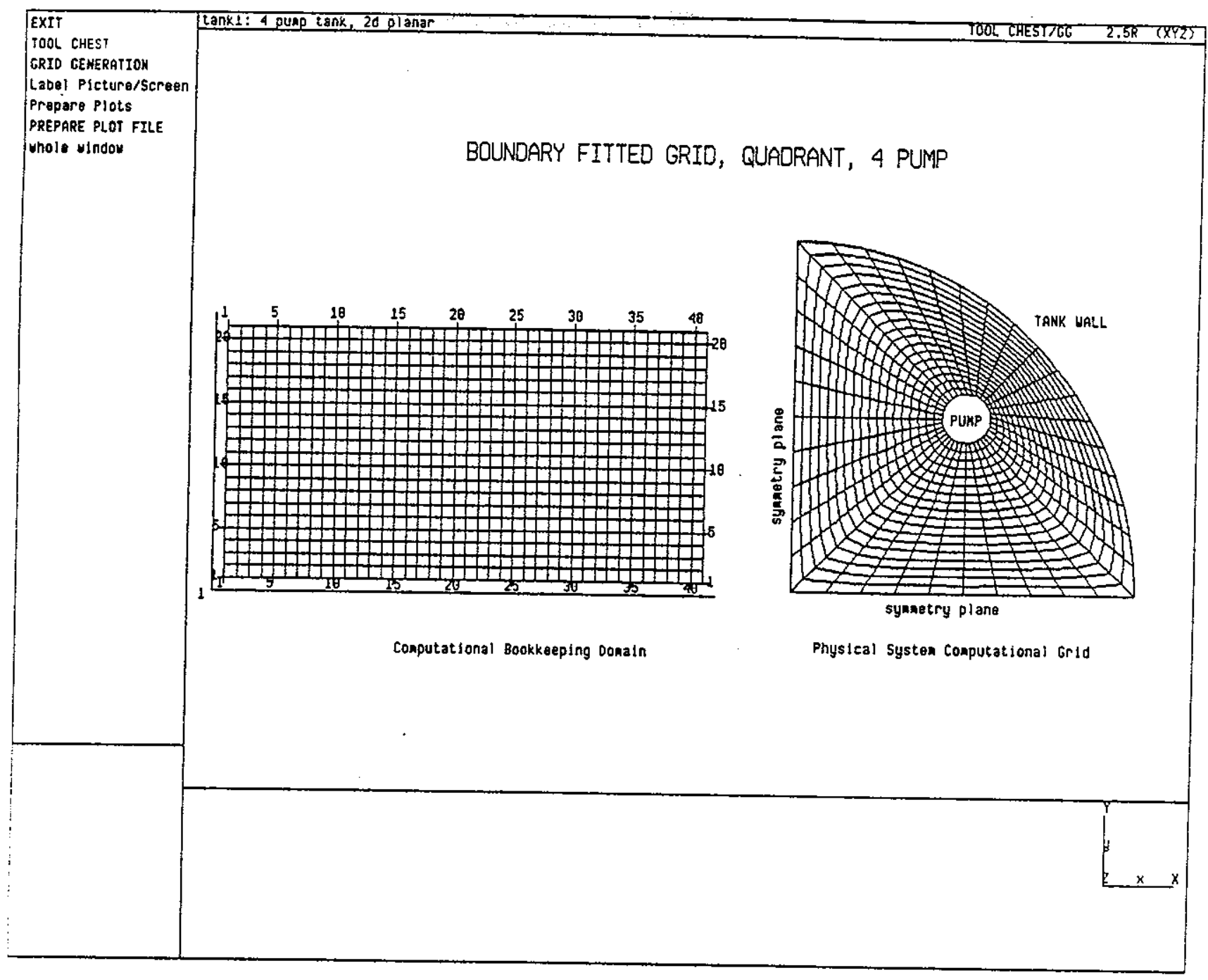

\section{FIGURE 7.1. Example of Boundary Fitted Grid}

dissipation, density, and molecular and turbulent viscosity. A representative example of a species concentration distribution in the form of contours of constant mass fraction overlayed on planar projected velocity vectors is presented in Figure 7.2. Such figures can be generated in each plane of the simulation normal to each of the three coordinate directions.

"Snapshot" field data can also be used to generate profile plots. These are generally in the form of distribution of a variable with position in the simulation domain with an example of such a profile plot shown in Figure 7.3. Profile plots of any of the dependent or state variables can be generated. 


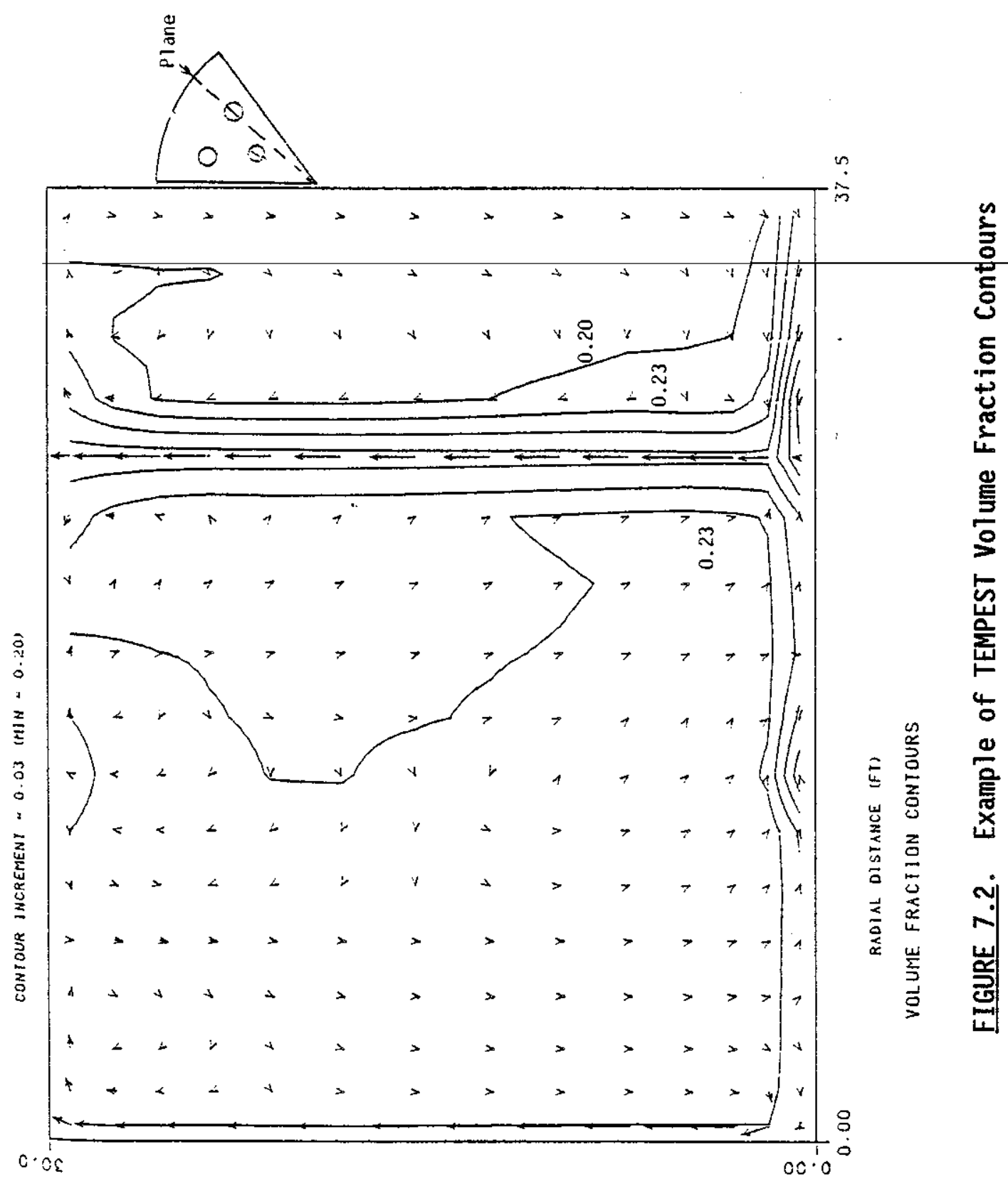

(jj) ZJNYIS!G TYO!IYIA 


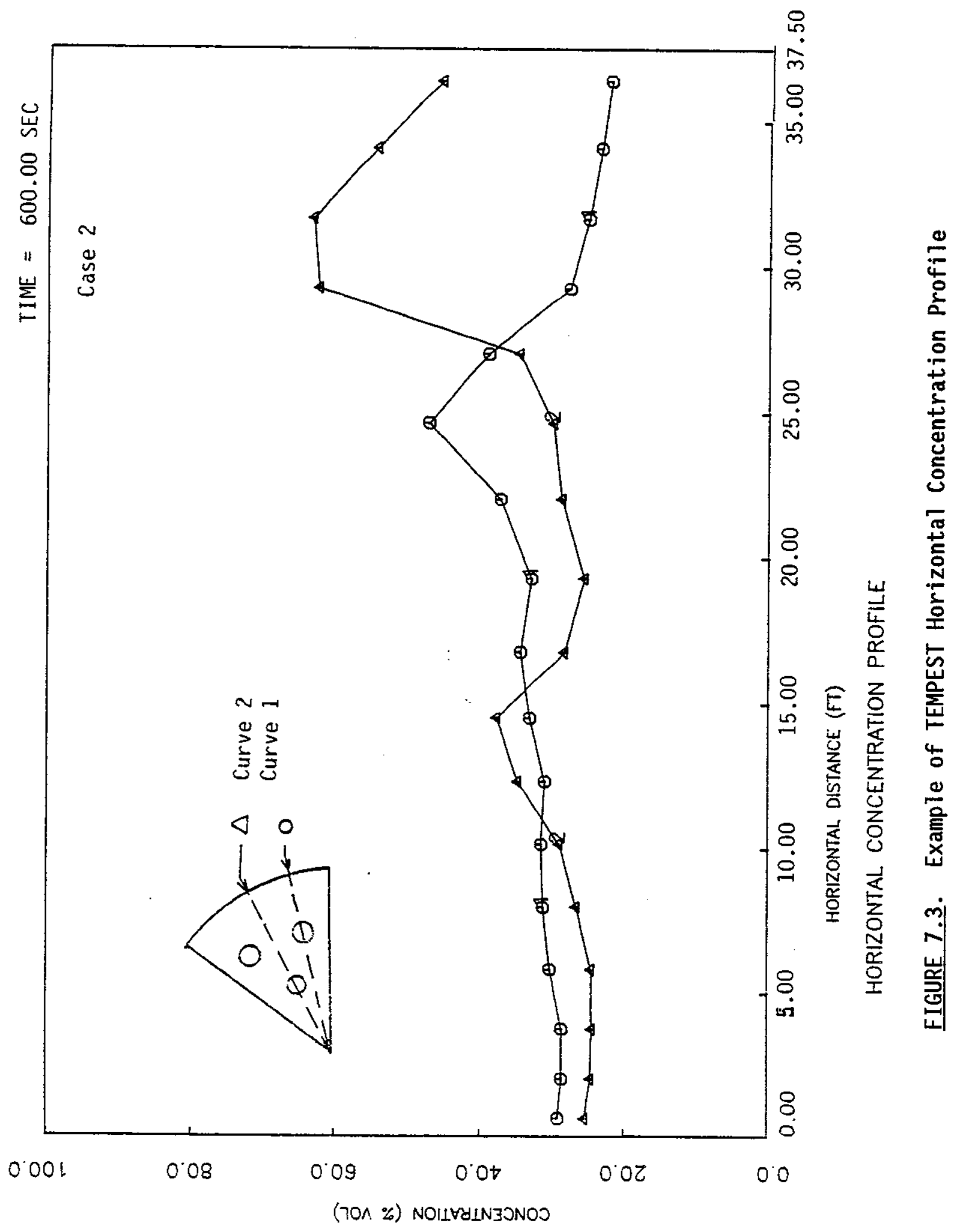


The second type of data regularly generated is "monitor" data in the form of time variation of a dependent or state variable. TEMPEST/TX presently has the ability to monitor 34 variables at up to 60 locations in a computational domain. During a simulation model setup, these locations will be correlated with experimental measurement locations, as discussed in Section 6.3.2. An example of the time dependency of a species mass fraction at four selected locations in an air-lift recirculated waste tank is presented in Figure 7.4 .

In addition to the most regular types of data plots discussed above, additional types of graphical results are becoming available with some ease and regularity. Examples include three-dimensional surface plots, volume contouring, and particle tracking. Each of these types of plots offers incremental understanding of computed results. In addition, it is possible to generate color graphics, slide shows, and video movies of predicted phenomena.

\subsection{CONSIDERATIONS FOR THE LONG TERM}

The program outlined above is ample to address the problem of current interest: determining tank uniformity considerations for the case of a dual jet, centrally located mixing pump in the case of pre-assumed uniformity. There are, however, several other considerations that should also be addressed. These considerations occur both in the physics and in application of these modeling techniques to other tanks and mixing pump configurations that may or may not exhibit similar characteristics.

First to address the problem of physics. There are an inordinate number of physical effects that may or may not affect the current problem. If the tank is assumed to be fully "mixable" such that the primary consideration herein is in the maintenance of uniformity of the solids, then the plan outlined above is a good one. In alternate consideration, however, if for example, the solids do settle sufficiently to reform a settled layer, then the current simulation treatment of the settled layer will probably not be completely appropriate because it inherently assumes that the settled layer 


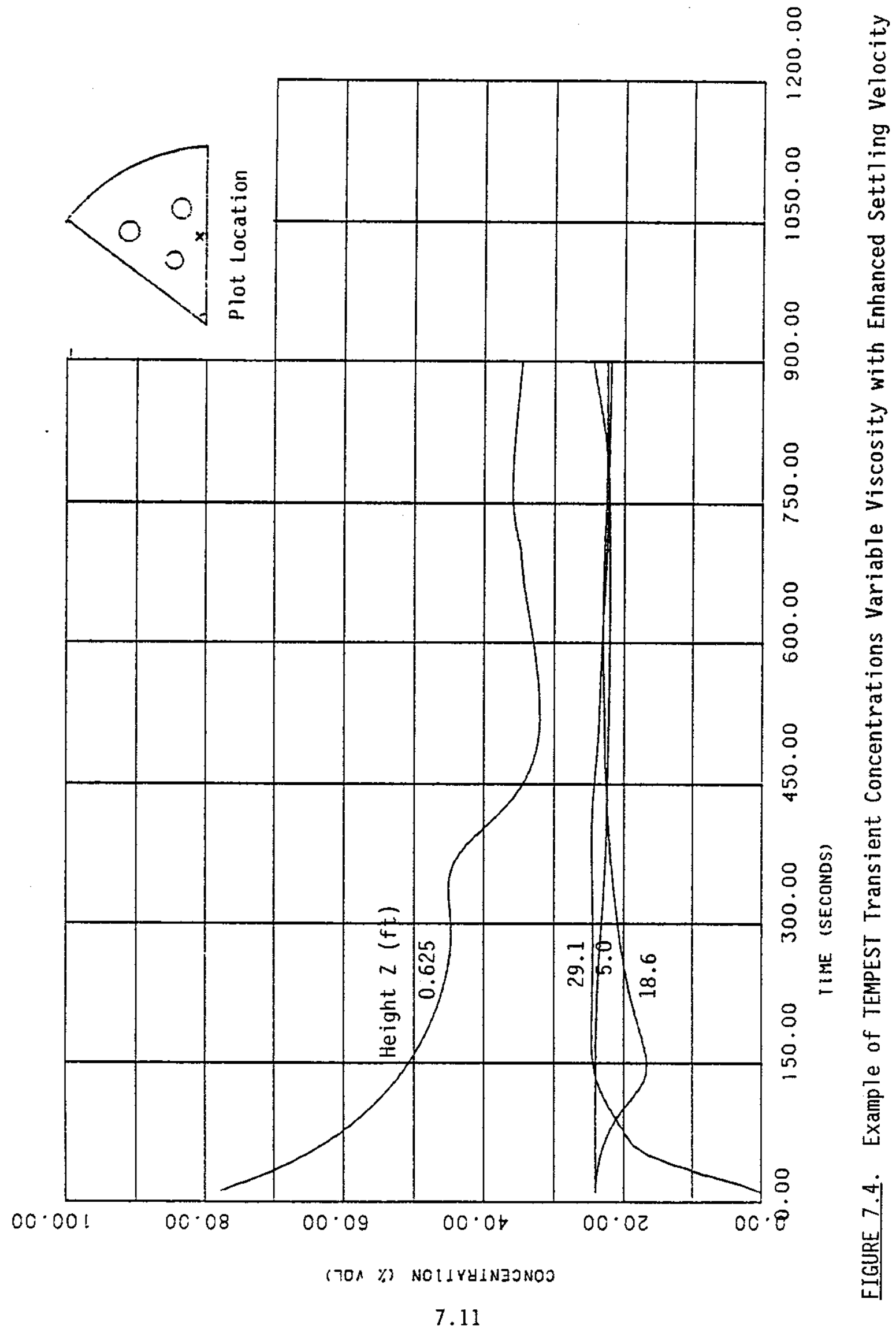


remains fluidized. In the stationary (as opposed to fluidized) settled situation it would be necessary to further consider the mechanisms of settling/adherence at the tank bottom and incorporate these mechanism into the computed transport simulation. Treatment of this effect requires additional model development.

Particle/particle and particle/fluid property interactions may be much more complicated than those proposed to be treated in the above outlined program. If the fluid is indeed non-Newtonian, does it have a yield stress? If so, this is an effect that TEMPEST does not currently treat. (TEMPEST can model a power-law non-Newtonian fluid.) Incorporation of yield stress into fluid property definition and into numerical simulation is not a trivial matter. While the mathematics of such a situation are understood, the application of these mathematics to discrete computation is difficult. This is primarily because the solution domain is discretized into finite volumes that do not move in space. With a yield stress, the location of the moving/ nonmoving interface as it relates to the location of fixed grid volumes must be resolved. One approach around this is to extend the simulation capability to an adaptive grid, that is a grid that adapts to an interface such that a grid line is at the shearing boundary.

Incorporation of such capabilities also requires rather extensive development but considering the nature of some settled layers of material in the waste storage tanks, giving consideration to development of such an analysis capability is not unreasonable.

This approach may also be very useful to analyze jet-induced resuspension if the appropriate particle/fluid/wall physics were tenable.

The general area of jet resolution is also of concern. To adequately resolve a jet spread rate and centerline decay rate, on the order of $10 \mathrm{compu}$ tational cells are necessary within the length and half-width of the jet! Furthermore, it is well documented that the $k-\epsilon$ level of turbulence model can only reasonably resolve the correct spread rate of a round jet in an infinite medium. It is not clear, however, whether this level of resolution is necessary to adequately model the macro mechanism of full-tank recirculation caused by conserving jet momentum. This question of jet resolution deserves 
to be investigated further as it applies to the present problem. Some discussion of this is included in Section 5.0.

A decision point [Step 15] is included to address the question of whether the TEMPEST code is to be used as a QA Impact Level II analysis tool in future analysis of the tanks. If it is, or is to be considered, a plan should be formulated to define the requirements and qualification path necessary to arrive at that level of software configuration control. The lead time to complete such an effort is long and, therefore, costly. 



\subsection{TANK SLURRY UNIFORMITY DEFINITION AND RETRIEVAL EXPERIMENTS}

Defining experiments are proposed, based on the anticipated results of the scoping experiments presented in Section 6.0, to determine the effects of the parameter set found to influence tank slurry uniformity. It is not currently known whether or not the defining experiments will be required to achieve the goals of assuring sufficient uniformity of the contents of waste tanks using the proposed jet mixers. The specific requirements and tests to be performed are also not known because the degree of uniformity achieved, the number of important dimensionless parameters, and the specific dimensionless parameters that affect mixing most strongly are not currently known. In a defining experiment, the effects of a limited number of parameters are evaluated extensively over the operating range of interest.

It is recommended that the defining experiments be conducted at a larger scale because a larger scale would allow tests to be performed at pump speeds that are equivalent to lower operating speeds in the prototype. At 1/12-scale, the lowest speeds cannot be tested without undue risk that the flow field will be laminar. Tests at 1/6-scale would allow correlations to be developed that are valid at jet nozzle velocities as low as $5 \%$ of the full-speed pump velocity. This test plan proposes the use of tests at $1 / 6$-scale to determine if a correlation is required. The lowest test velocity proposed is a jet nozzle velocity equivalent to $15 \%$ of the full-speed jet nozzle velocity; operation at this velocity will provide a measure of safety in applying the developed correlation to predict the degree of uniformity achieved when the pumps are operating at $25 \%$, which is the realistic lower bound for prototype operation.

In this presentation the scale chosen for the defining experiments is $1 / 6$ scale; this recommendation will be evaluated after the results at $1 / 12$-scale are analyzed. These defining experimental results can be used to predict mixing behavior at full-scale as well as to compare with the TEMPEST computer code results, as described in Sections 4.0 and 7.0. In the following subsections the defining and retrieval experiment objectives, test approach, results, and limitations are defined. The test equipment and instrumentation 
required for the 1/6-scale experiments are similar to that required for the 1/12-scale experiments and the data analysis approach is also similar in both scales; refer to Sections 6.3 and Section 6.4 for the pertinent discussions.

\subsection{EXPERIMENT OBJECTIVES}

The defining experiment objectives are closely linked with the objectives of the TEMPEST computer modeling task. The defining experiment objectives are to:

- provide data over the mixing pump operating range to develop correlations for the dimensionless relationships found to be important in the scoping experiments: gravitational settling number (Gs) and Froude number (Fr)

- provide correlations over the operating range of interest to describe the effects of dimensionless relationships and physical parameters

- scale prototype correlations from the experimental data

- define the prototype operating region of the experimental data set corresponding to the region where tank slurry uniformity could occur

- provide experimental data for TEMPEST code comparison

- evaluate the need for non-Newtonian uniformity experiments.

The retrieval experiment objectives are to:

- evaluate the uniformity of the solids distribution in the slurry during slurry retrieval experiments using both top and bottom removal locations

- investigate whether slurry uniformity in the tank is necessary for retrieval uniformity.

\subsection{TEST APPROACH}

The prototype waste tank, waste characteristics, prototype design basis, and simulant development and verification summarized in Section 6.0 are applicable to this experiment; refer to Sections 6.2.1, 6.2.2 and 6.2.3 for these details. The $1 / 6$-scale model of the problem is presented in Section 8.2.1; the defining experiment design and test matrix are discussed in Section 8.2.2. 


\subsubsection{Modeling STurry Uniformity at 1/6-Scale}

The scaling relationships developed in Section 3.2 are used to define the model in terms of the prototype. It is currently anticipated that tests conducted at 1/12-scale will show that the degree of homogeneity achieved in the tank will not be affected by the Reynolds number provided that the jet Reynolds number exceeds 6000 . The defining experiment is designed to study the effects of Froude number (Fr) and gravitational settling number (Gs). The actual defining experiment matrix will depend on which parameters are found to affect tank slurry homogeneity; consequently the defining experiment actually conducted, based on the results of the scoping study, may differ from the anticipated defining experiment described here. The appropriate scaled parameters for the 1/6-scale experiments are summarized in Table 8.1. From the summaries provided in Table 8.1, the defining experiment parameter range is selected, and values are listed in Table 8.2. If it has been determined that the Reynolds number does not affect the degree of homogeneity in the tank, it will not be necessary to explore the effect of Reynolds number further. In this case, it will not be necessary to use simulants with different viscosities. A simulant with a viscosity of $0.002 \mathrm{~Pa}-\mathrm{s}(2 \mathrm{cP})$ will be specified in the 1/6-scale experiment. However, other property values for the simulant must be chosen to provide the appropriate range for the Froude number ( $F r)$ and gravitational settling number (Gs). The property values anticipated to be used for the defining experiments are listed in Table 8.3.

\subsubsection{Defining Experiment Design}

The defining experiments will be statistically designed to determine whether an adequately homogeneous slurry is obtained in the scaled tank under a variety of tank mixing pump operating conditions. The homogeneity of the slurry will be measured by comparing the replicate average weight \% solids of 12 samples taken from sampling locations within the tank to the average concentration of the tank as a whole. Samples are proposed to be taken at two radial distances corresponding to radii of $0.76 \mathrm{~m}(30 \mathrm{in.})$ and $1.5 \mathrm{~m}$ (60 in.) from the tank center, and three heights corresponding to $0.30 \mathrm{~m}$ 
TABLE 8.1. 1/6-Scale Model Configuration

\begin{tabular}{|c|c|c|}
\hline Tank Geometry & Prototype & Mode $]$ \\
\hline Diameter & $\begin{array}{l}23 \mathrm{~m} \\
\left(75^{\mathrm{ft}}\right)\end{array}$ & $3.8 \mathrm{~m}$ in.) \\
\hline Distance, pump centerline to tank wall & $\begin{array}{l}11.4 \mathrm{~m} \\
(37.5 \mathrm{ft})\end{array}$ & $\begin{array}{l}1.9 \mathrm{~m} \\
(75 \mathrm{in.})\end{array}$ \\
\hline \multicolumn{3}{|l|}{ Fluid depth } \\
\hline Low case & $(4.2 \mathrm{~m})$ & $\begin{array}{l}0.2 \mathrm{~m} \\
(8 \mathrm{in.})\end{array}$ \\
\hline High case & $\begin{array}{l}9.1 \mathrm{~m} \\
(30 \mathrm{ft})\end{array}$ & $\begin{array}{l}1.5 \mathrm{~m} \\
(60 \mathrm{in.})\end{array}$ \\
\hline \multicolumn{3}{|l|}{ Mixing Pump Dimensions } \\
\hline Nozzle diameter & $\begin{array}{l}0.15 \mathrm{~m} \\
(0.5 \mathrm{ft})\end{array}$ & $\begin{array}{l}0.025 \mathrm{~m} \\
(1.0 \mathrm{in.})\end{array}$ \\
\hline Distance, tank bottom to nozzle centerline & $\begin{array}{l}0.30 \mathrm{~m} \text { or } \\
0.46 \mathrm{~m} \\
(1.0 \mathrm{ft} \text { or } \\
1.5 \mathrm{ft})\end{array}$ & $\begin{array}{l}0.051 \mathrm{~m} \text { or } \\
0.076 \mathrm{~m} \\
(2.0 \mathrm{in} \text {. or } \\
3.0 \mathrm{in.})\end{array}$ \\
\hline Distance, pump centerline to nozzle discharge & $\begin{array}{l}0.44 \mathrm{~m} \\
(17.5 \mathrm{in.})\end{array}$ & $\begin{array}{l}0.074 \mathrm{~m} \\
(2.9 \mathrm{in.})\end{array}$ \\
\hline $\begin{array}{c}\text { Distance, tank floor to pump intake } \\
\text { Jet Properties }\end{array}$ & $\begin{array}{l}0.15 \mathrm{~m} \\
(0.5 \mathrm{ft})\end{array}$ & $\begin{array}{l}0.025 \mathrm{~m} \\
(1.0 \mathrm{in.})\end{array}$ \\
\hline $\mathrm{U}_{0} D_{0}$ at $100 \%$ condition & $\begin{array}{l}2.73 \mathrm{~m}^{2} / \mathrm{s} \\
\left(29.4 \mathrm{ft}^{2} / \mathrm{s}\right)\end{array}$ & $\begin{array}{l}0.186 \mathrm{~m}^{2} / \mathrm{s} \\
\left(2.0 \mathrm{ft}^{2} / \mathrm{s}\right)\end{array}$ \\
\hline$U_{0} D_{0}$ operating range & $25 \%$ to $100 \%$ & $15 \%$ to $100 \%$ (a \\
\hline Discharge angle from vertical & $90^{\circ}+3-0$ & no change \\
\hline
\end{tabular}

(a) Prototype operating range is $25 \%$ to $100 \% U_{0} D_{0} ; 15 \%$ is recommended as the lower bound during the defining experiments to provide a factor of safety during these $1 / 6$-scale experiments.

(12 in.), $0.76 \mathrm{~m}$ ( 30 in.), and $1.27 \mathrm{~m}$ (50 in.) from the tank floor. Because both radius and height are varied, homogeneity of the slurry may be determined as a function of radial distance as well as height. Fow, Kurath, and Pulsipher (1989) reported that bench-scale experiments of a similar nature did not show homogeneity variation with radius. If this variation is not observed in the 
TABLE 8.2. Defining Experiment Parameter Set, Based on Model

\begin{tabular}{|c|c|}
\hline Parameter Set & Range for Scoping Study \\
\hline Dimensionless (a) & \\
\hline Froude number & $9.0 \times 10^{-3}$ to 3.6 \\
\hline $\begin{array}{c}\text { Gravitational settling number } \\
\text { Geometric }\end{array}$ & $5.3 \times 10^{-3}$ to 38.7 \\
\hline Liquid level & $\begin{array}{l}0.20 \mathrm{~m}, 0.76 \mathrm{~m}, 1.5 \mathrm{~m} \\
(8 \mathrm{in.}, 30 \mathrm{in}, \text { or } 60 \mathrm{in} .)\end{array}$ \\
\hline $\begin{array}{l}\text { Number of pumps } \\
\text { Tank configuration }\end{array}$ & $\begin{array}{l}\text { one, three, or four mixer pumps } \\
\text { with and without air-lift circulators }\end{array}$ \\
\hline
\end{tabular}

(a) Reynolds number is predicted to be less important for defining
experiments.

TABLE 8.3. Property Value Range to Model Process at 1/6-Scale

\begin{tabular}{|c|c|c|}
\hline & urry and Particle Properties & Range \\
\hline C & $\begin{array}{l}\text { mean weight } \% \text { solids } \\
\text { concentration }\end{array}$ & $10 \%$ to $30 \%$ \\
\hline & slurry viscosity & $0.002 \mathrm{~Pa}-\mathrm{s}(2 \mathrm{cP})$ \\
\hline$\rho \mathrm{b}$ & slurry bulk density & 1000 to $1500 \mathrm{~kg} / \mathrm{m}^{3}$ \\
\hline$\rho_{\mathrm{S}}$ & solids density & $2500 \mathrm{~kg} / \mathrm{m}^{3}=300 \mathrm{~kg} / \mathrm{m}^{3}$ \\
\hline$U_{S}$ & $\begin{array}{l}\text { unhindered particle settling } \\
\text { velocity }\end{array}$ & $3.4 \times 10^{-2} \mathrm{~mm} / \mathrm{s}$ to $0.85 \mathrm{~mm} / \mathrm{s}$ \\
\hline & particle diameter & $10 \mu \mathrm{m}, 15 \mu \mathrm{m}, 50 \mu \mathrm{m}$ \\
\hline
\end{tabular}

scoping experiments, the sampling locations may be altered. In addition to "grab sample" measurements of concentration, real-time, acoustic or ultrasonic measurements of local average concentration are proposed. This proposed realtime method, discussed in more detail in Section 9.0, would measure the local average concentration as a function of height. In addition, information discussing the variation in concentration with time could be obtained using this information. 
The defining experiment is performed to obtain correlations that may be used to predict the degree of inhomogeneity achieved in the full-scale prototype. The effects of the Froude number (Fr), the gravitational settling number (Gs), and the level of the tank contents ( $H)$ may be nonlinear, and may also interact. In addition, pump configurations and the presence of tank components will need to be investigated. Consequently, it will be necessary to perform tests at a minimum of three levels for each parameter. It is proposed that the tests be performed as follows.

A series of 15 tests, in which the solids homogeneity achieved in three simulants of equal viscosity but differing in particle settling velocity, should be measured at five nozzle exit velocities. These experiments should be performed at one tank slurry level using one pump configuration without air-lift circulators. Because the most challenging configuration for achieving homogeneity is expected to be a full tank with one pump, it is recommended that this series of tests be performed with this configuration. The five nozzle exit velocities will correspond to five Froude numbers; use of three simulants containing different particle sizes will provide three values of the gravitational settling number at each Froude number tested. This series of tests would be sufficient to produce a correlation in which the effects of the Froude number and gravitational settling number are observed based on the degree of solids inhomogeneity achieved using one pump in a full tank without air-lift circulators.

The target properties of the three proposed simulants are listed in Table 8.4. Use of simulants 1,2 , and 3 will result in Froude and gravitational settling numbers that fall in the ranges that are anticipated when double-shell tank wastes are retrieved. Simulants 1,2, and 3 will mimic the settling characteristics of a number of combinations of solids diameters and slurry viscosities in the prototype including the settling characteristics that occur in a full-scale tank containing a slurry in which the mean solids diameter is $100 \mu \mathrm{m}$ and the slurry viscosities $0.05 \mathrm{~Pa}-\mathrm{s}, 0.021 \mathrm{~Pa}-\mathrm{s}$, and $0.002 \mathrm{~Pa}-\mathrm{s}$ (50 $C P, 21 c P$, and $2 c P$ ) for simulants 1,2, and 3, respectively, smaller particle 
TABLE 8.4. Target Properties for Simulants to be Used in 1/6-Scale Tests

\begin{tabular}{|c|c|c|c|c|c|c|c|c|}
\hline Simulant & $\begin{array}{c}\begin{array}{c}\text { Slurry } \\
\text { Viscosity, } \\
\text { Pa-s (cP) }\end{array} \\
\end{array}$ & $\begin{array}{l}\text { Particle } \\
\text { Diaater, } \\
\end{array}$ & $\begin{array}{r}\text { Slurry } \\
\text { Density, } \\
\mathrm{kg} / \mathrm{m}^{3} \\
\end{array}$ & $\begin{array}{l}\text { Solids } \\
\text { Density, } \\
\mathrm{kg} / \mathbf{m}^{3} \\
\end{array}$ & $\begin{array}{l}\text { Wtx } \\
\text { Solids }\end{array}$ & $\begin{array}{c}\text { Unhindered } \\
\text { Settling } \\
\text { Velocity, } \\
\text { m/s } \\
\end{array}$ & $\begin{array}{l}\text { Froude } \\
\text { Number } \\
\text { Range }\end{array}$ & $\begin{array}{c}\text { Gravitational } \\
\text { Settling } \\
\text { Number } \\
\text { Range } \\
\end{array}$ \\
\hline 1 & 0.662 (2) & 10 & 1250 & 2590 & 18 & $3.4 \times 10-2$ & 0.98 to 3.58 & 6.695 to 1.6 \\
\hline 2 & $0.962(2)$ & 15 & 1250 & 2506 & 18 & $7.6 \times 10-2$ & 9.68 to 3.58 & 0.012 to 3.5 \\
\hline 3 & $0.002(2)$ & 50 & 1258 & 2508 & 18 & $8.5 \times 16-1$ & 0.88 to 3.58 & 9.13 to 39 \\
\hline
\end{tabular}

sizes should be selected if later efforts indicate that the solids do not agglomerate during resuspension attempts and that solids diameters during resuspension are smaller than $100 \mu \mathrm{m}$. The viscosities of $0.05 \mathrm{~Pa}-\mathrm{s}$ (50 cP) and $0.002 \mathrm{~Pa}-\mathrm{S}(2 \mathrm{CP})$ are thought to bracket the viscosities that will exist in the waste tanks after sludge mobilization. Tests using the $0.021 \mathrm{~Pa}-\mathrm{s}$ (21 CP) fluid will allow nonlinearities in the effect of the gravitational settling number to be detected. In addition, the gravitational settling numbers achieved using this size particle and simulant viscosity will match a number of the values tested in the 1/12-scale experiment.

The Froude numbers and gravitational settling numbers that will be achieved using the simulants described in Table 8.4 are shown in Figure 8.1. The test matrix illustrated in Figure 8.1 is a statistically balanced $3 \times 5$ factorial design. Values achieved in the 1/12-scale experiment and those that are expected to occur in the waste tanks are also shown. The range of particle sizes selected will provide data in the low range of the gravitational settling parameter; use of smaller particles would lead to larger gravitational settling numbers. It is currently expected that greater degrees of inhomogeneity will be detected at large values of the gravitational settling number. Consequently, measurement in the regions where suspension is more difficult will provide conservative results.

The series of 15 experiments could be repeated at each of the tank slurry levels and pump configurations to provide correlations for each tank slurry level, presence of tank components, and pump configuration. This would require 270 experiments (i.e., $15 \times 3 \times 2 \times 3$ ). It is recommended that the effects 


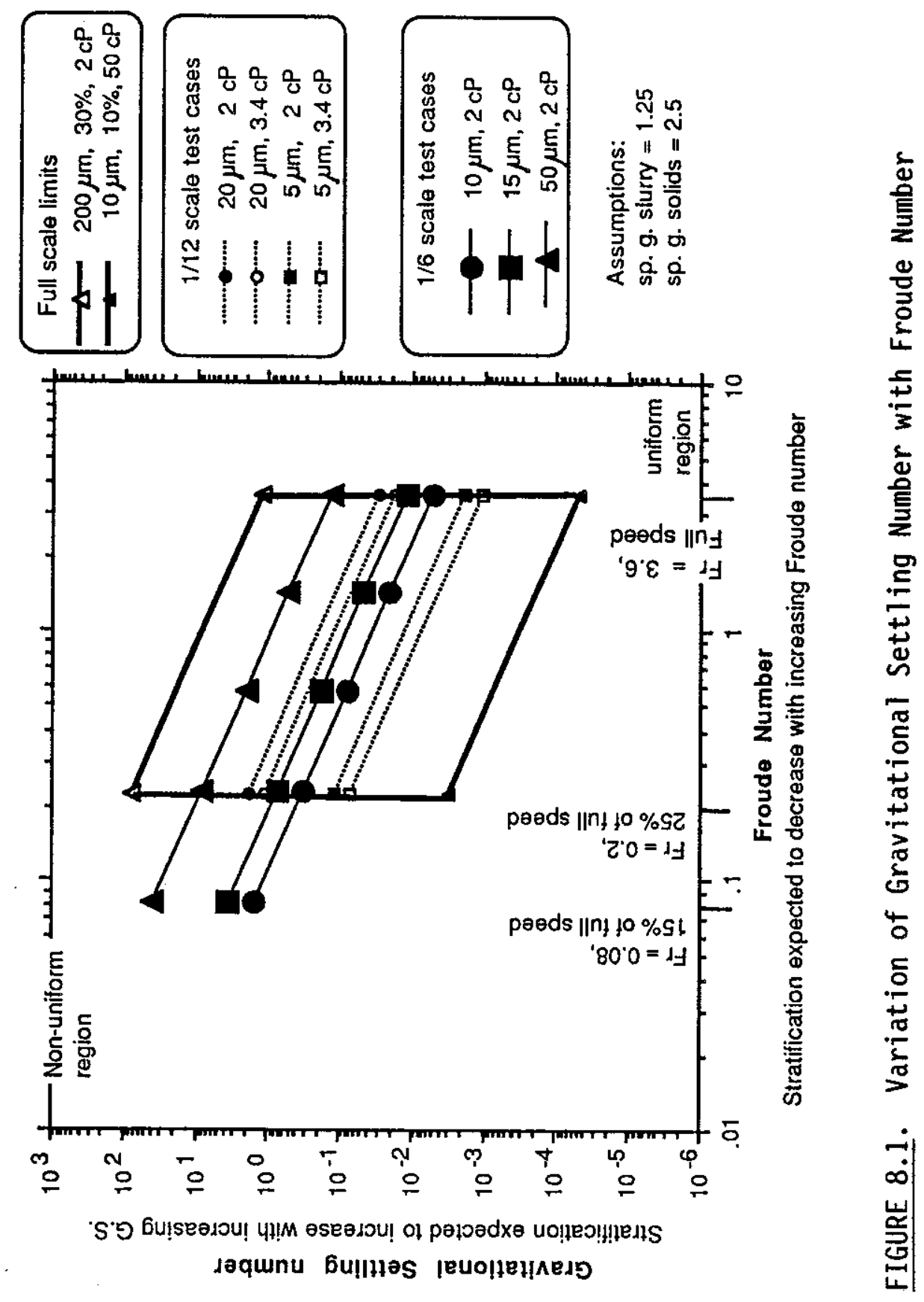


of increasing the number of pumps and reducing the tank slurry level be determined by performing the tests noted in Table 8.5 at three of the five test velocities using a reduced matrix; the proposed tests are marked with an $x$. This matrix will allow determination of the effect of increasing the number of pumps at the maximum fill level and the effect of decreasing the fill level when one pump is used. Testing in this manner will allow the number of additional tests to be reduced to 15 , resulting in a total of 30 tests. If tanks with and without tank components are included, the total would be 60 tests.

Tests at the maximum fill level using the minimum number of pumps are recommended because this case is thought to be the most challenging in terms of maintaining resuspension. Additional tests using a different pump configuration would be recommended if more precise predictions of tank mixing pump operation with a specific pump configuration are desired.

It is always important to perform experiments in a random order to reduce the influence of time-related effects such as operator influence and systematic changes in simulant. However, because the simulants are difficult to store, the experiments will be conducted, "blocked", according to simulant type.

Because the experimental test matrix is balanced, blocking can be done, while still maintaining some degree of randomness for the other variables.

IABLE 8.5. Tests to Determine the Effect of Tank Slurry Level and Number of Pumps (a) in the 1/6-Scale Defining Experiment

$\begin{array}{rccc}\text { Height, in. } & \frac{\text { One Pump }}{60} & \frac{\text { Three Pumps }}{\mathrm{x}} & \frac{\text { Four Pumps }}{\mathrm{x}} \\ 30 & \mathrm{x} & & \mathrm{x} \\ 8 & \mathrm{x} & & \mathrm{x}\end{array}$

(a) These tests are to be performed at the maximum, the intermediate, and the minimum test velocity. 


\subsubsection{Waste Retrieval Experiments}

Because the goal of the tank mixing experiments is to provide a uniform process feed for future waste processing, it is important to show that a uniform concentration in the scaled tank will also provide a uniform concentration during waste retrieval. Currently two methods of waste retrieval are proposed. In one method, a slurry transfer pump (shown in Figure 1.2) located near the bottom of the tank pumps out slurry. In another method, a floating transfer line located near the tank slurry surface is used to pump out slurry. Both of these methods will be characterized in the waste retrieval experiments. After each uniformity test, with fluid height $(H)$ of $1.5 \mathrm{~m}$ ( 60 in.), the tank will be emptied by either one of these methods. The concentration of the slurry in the transfer line will be measured in-line using a Dynatrol(a) instrument capable of characterizing in-line flow weight \% solids concentration and using isokinetic sampling.

It is anticipated that the maximum degree of inhomogeneity achieved during retrieval will differ somewhat from the spatial inhomogeneity observed in the tank. The concentration profiles of settling solids in turbulent flows may often be estimated by an exponential function, particularly when the mechanism for distributing the solids is diffusive in nature. Typical concentration profiles showing the manner in which the solids concentration will vary with the fractional height from the bottom of the tank are shown in Figure 8.2. The concentration as a fraction of mean solids concentration in the tank is illustrated for three cases. In the first, the concentration at the top and bottom of the tank differ by $1 \%$, in the second by $10 \%$ and in the last by $100 \%$ of the mean concentration.

Although it is not clear that an exponential function will describe solids distribution during suspension of solids in the tank wastes, an analysis to determine the typical variation in the concentration at the withdrawal point during retrieval was performed based on an exponential concentration profile. Hypothetical values of the concentration difference between the top and bottom

(a) Registered trade name of Automation Products Inc., Houston, Texas 


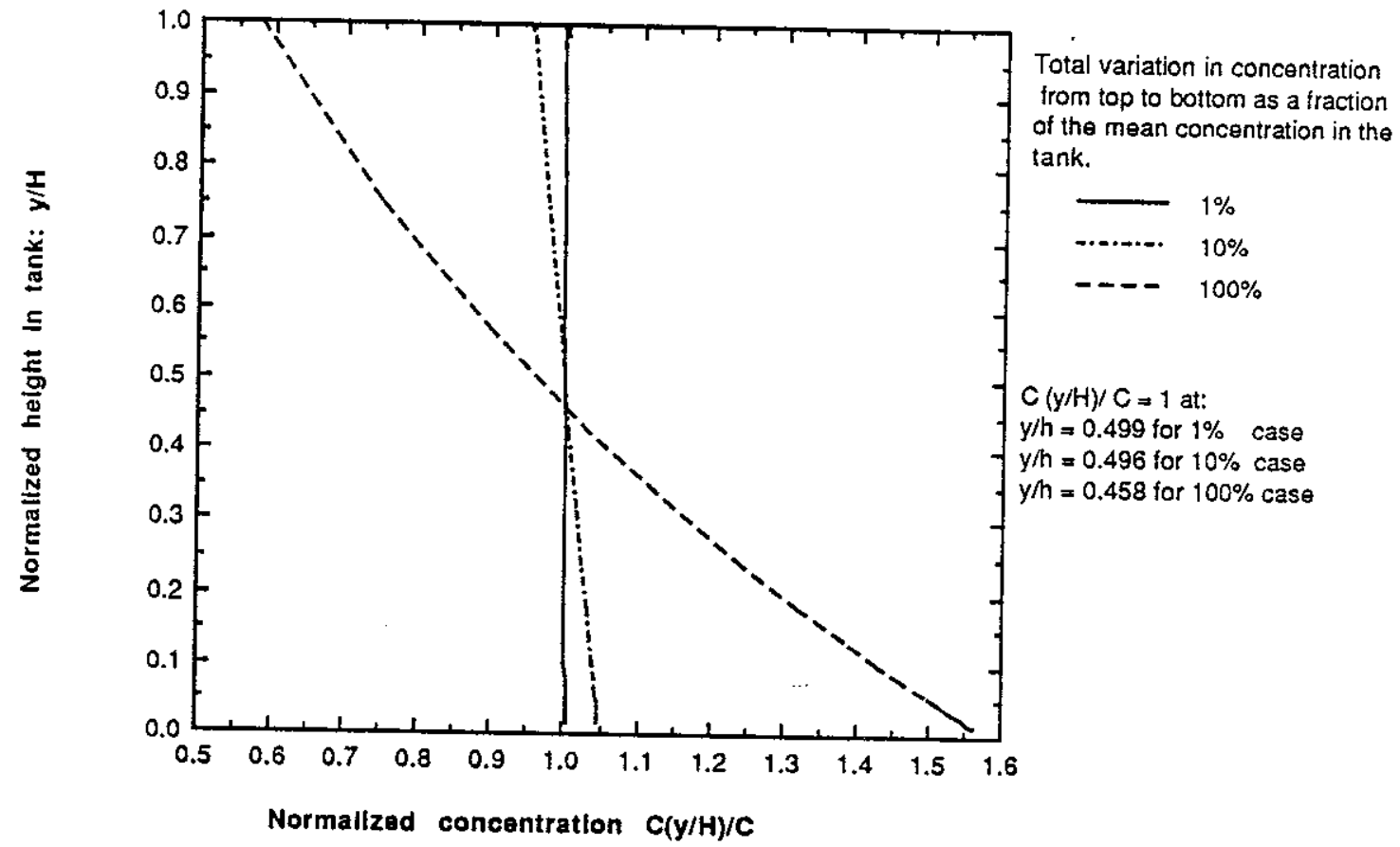

\section{FIGURE 8.2. Typical Concentration Profiles as a Function of Height}

and the withdrawal location were selected to illustrate the relationship between the concentration of retrieved slurry and the spatial distribution of the slurry in the tank. A more exact analysis is not appropriate at this time for two reasons. First, the concentration variation in the tank affects the results significantly and no reliable information on this quantity will be known until after the completion of the studies at 1/6-scale. Second, it has not yet been determined that an exponential function describes the variation of solids concentration in the tank. However, an analysis of this type can be used to relate the spatial concentration variations measured in the tank to the concentration variations in slurry retrieved from the tank; a more refined analysis may be performed once the actual spatial concentration distribution is determined on the basis of experiments performed and TEMPEST evaluations. The results are illustrated here to justify the reason for measuring the concentration of the slurry at the withdrawal site. 
For each concentration profile, there is a tank location at which the concentration matches the mean concentration in the tank. Slurry withdrawn from this location would have the same concentration as the entire average tank concentration; this location might be considered to be the optimum location for withdrawal of slurry. The optimum site occurs at a distance from the bottom of the tank that depends on the degree of inhomogeneity in the solids concentration. When the solids inhomogeneity is small, the optimum occurs at the tank center; when the inhomogeneity is large, the optimum occurs lower in the tank. The variation of the optimal withdrawal location as a function of the concentration difference between the top and bottom of the tank is shown in Figure 8.3. The maximum optimal withdrawal location is onehalf the height of the tank contents; the minimum is the bottom of the tank.

As slurry is withdrawn, the slurry level decreases. The relations describing the spatial concentration profile were used to estimate variation in the mean concentration in the waste tank and the variation in the

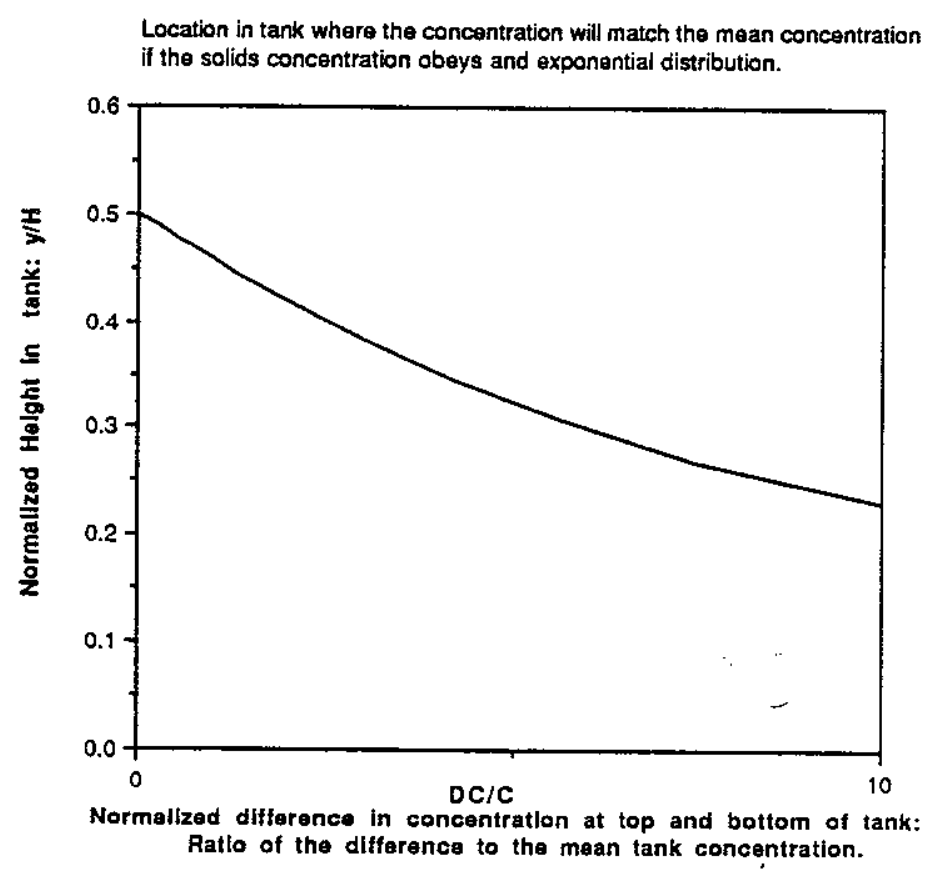

FIGURE 8.3. Optimum Retrieval Location as a Function of Inhomogeneity 
concentration of retrieved slurry as a function of slurry level. The results of an analysis are shown in Figure 8.4. It was assumed in performing this estimate that the magnitude of particle diffusivity is unaffected by the tank level. A case was analyzed where solids are withdrawn from a point located one-quarter of the initial tank contents level from the bottom of the tank and in which the initial difference between the top and bottom concentration was $10 \%$. The concentration of the retrieved slurry was found to be $2.5 \%$ greater than the average tank slurry concentration during the initial stages of retrieval. This concentration was found to fall as the tank was emptied. When the tank contents reached the level of the withdrawal point, calculation was terminated.

The mean tank concentration also varies with time. In the initial stages of retrieval, the point at which slurry is withdrawn is below the location of average concentration. As a result, the slurry withdrawn from the tank is

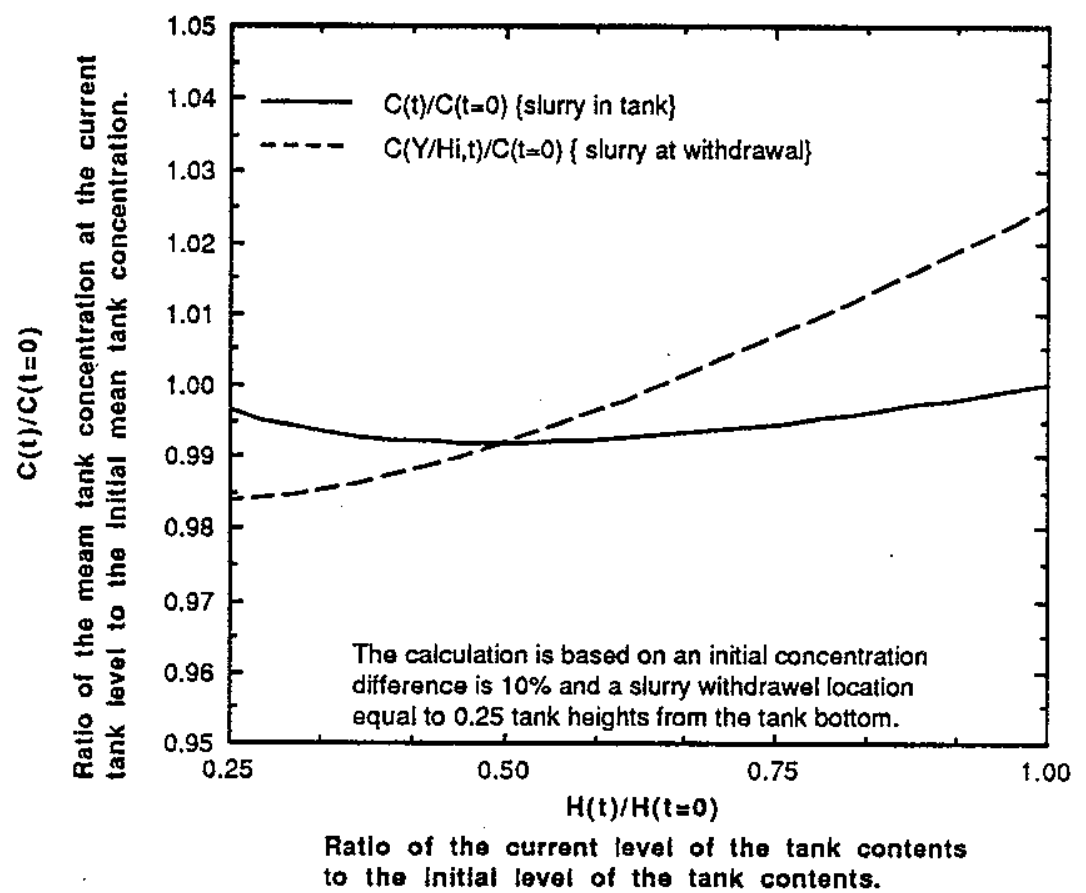

FIGURE 8.4. Variation in Slurry Density as a Function of Remaining Slurry Height 
more concentrated than the average concentration in the tank. As a result, the overall tank concentration decreases with time. However, once the tank slurry level falls sufficiently, the withdrawal location is above the location at which the local average matches the tank average. At this point the concentration of the withdrawn slurry is less than the average concentration of the tank and the tank slurry concentration increases. The concentration of the retrieved slurry when the tank slurry level reaches withdrawal location is slightly greater than $98 \%$. Thus, although the original spatial variation in the tank contents was $10 \%$, the variation in the concentration of the retrieved slurry is approximately $4 \%$.

The results of this analysis show that the variation in the concentration in the retrieved slurry and the spatial variation in the slurry in the tank can differ substantially. Because the differences will depend on the location of the retrieval port; it is likely that more uniform feed may be achieved by making an appropriate choice of the withdrawal location. If the tanks contain two withdrawal ports, it would be desirable to select the location that provides the more uniform feed. It is also possible that a fraction of the slurry be withdrawn from each port. However, the optimal fraction removed from each port cannot be recommended until more information about the distribution of slurry in the tank is obtained. It is recommended that the relationship between the distribution of slurry in the tank and the concentration of removed slurry be examined during the defining experiment to allow this type of analysis to be refined.

\subsection{RESULTS}

The defining experiments are designed to permit a sound statistical analysis of the data. The objectives of the statistical design are to determine whether an adequately homogeneous slurry is maintained in the 1/6scale waste tank model and whether slurry retrieval operations provide for homogeneous transfer.

Homogeneity of the tank contents will be quantified by comparing the size of the differences between the local average weight \% total solids 
measured at different sample locations within the tank. If a statistically significant difference exists between any of the averages, the tank contents will be considered nonhomogeneous. If an insignificant difference exists between the average weight \% solids and the average of those samples obtained from the sample locations, then each liquid sampling system will be determined to provide a representative sample.

Projected results from physical and rheological characterization are similar to those presented in Section 6.5.1. The proposed approach of the statistical analysis of the data is similar to that presented in Section 6.5.2. Anticipated results for the homogeneity tests as a function of the test parameters are presented in Section 8.3.1. Predictions of full-scale operation based on the scaled experimental data are presented in Section 8.3.2. Anticipated conclusions and recommendations derived from the defining experiments are listed in Section 8.3.3.

\subsubsection{Effects of Uniformity Test Parameters and Tank Slurry Retrieval Experiments}

The homogeneity experiments will be performed to characterize the tank mixer pump operation. The statistical analysis technique of Analys is of Variance, ANOVA, (Box, Hunter, and Hunter 1987) will be used to examine the homogeneity of the 1/6-scale model concentration data.

The predicted results of the statistical analyses for the homogeneity tests will be summarized in a similar manner to that presented in Table 8.6. If the nonhomogeneous standard deviations are not statistically different from the standard deviations of replicate samples, the average total solids at the different locations will not be significantly different from each other. This conclusion means that the tank slurry concentration appears to be uniform/homogeneous for the slurry concentrations tested.

The predicted results of the statistical analyses for the waste retrieval tests will be summarized in a similar manner to that presented in Table 8.7. Experiments at $1 / 6-$ scale to characterize waste retrieval will be conducted based on a liquid height range of $0.2 \mathrm{~m}$ ( $8 \mathrm{in.})$ to $1.5 \mathrm{~m}$ (60 in). 
TABLE 8.6. Estimates of the Degree of Inhomogeneity from Concentration Measurements for One Pump Configuration and Tank Component Configurations

\begin{tabular}{|c|c|c|c|c|c|}
\hline Simulant & $\begin{array}{c}\text { Fu11 } \\
\text { Speed } \\
\mathrm{Fr}=3.6 \\
\end{array}$ & $\begin{array}{c}70 \% \\
\text { Speed } \\
\mathrm{Fr}=1.4 \\
\end{array}$ & $\begin{array}{c}50 \% \\
\text { Speed } \\
\mathrm{Fr}=0.6 \\
\end{array}$ & $\begin{array}{c}25 \% \\
\text { Speed } \\
\mathrm{Fr}=0.2 \\
\end{array}$ & $\begin{array}{c}15 \% \\
\text { Speed } \\
\mathrm{Fr}=0.08 \\
\end{array}$ \\
\hline $\begin{array}{l}1 \mathrm{dp}=10 \mu \mathrm{m} \\
\text { mean wt\% } \\
\text { std. dev. wt\% } \\
\text { Gs }\end{array}$ & $\begin{array}{l}16 \\
U \\
0.01\end{array}$ & $\begin{array}{c}16 \\
U \\
0.02\end{array}$ & $\begin{array}{l}15.5 \\
M \\
0.32\end{array}$ & $\begin{array}{l}16.5 \\
M \\
0.32\end{array}$ & $\begin{array}{l}15.5 \\
N \\
1.56\end{array}$ \\
\hline $\begin{array}{l}2 \mathrm{dp}=15 \mu \mathrm{m} \\
\text { mean wt\% } \\
\text { std. dev. wt\% } \\
\text { Gs }\end{array}$ & $\begin{array}{l}17.5 \\
0.12\end{array}$ & $\begin{array}{l}16.5 \\
U \\
0.05\end{array}$ & $\begin{array}{l}16 \\
M \\
0.02\end{array}$ & $\begin{array}{l}16.5 \\
N \\
0.7\end{array}$ & $\begin{array}{l}16.5 \\
N \\
3.4\end{array}$ \\
\hline $\begin{array}{l}3 \mathrm{dp}=50 \mu \mathrm{m} \\
\text { mean wt\% } \\
\text { std. dev. wt\% } \\
\text { Gs }\end{array}$ & $\begin{array}{l}18 \\
M \\
0.13\end{array}$ & $\begin{array}{l}17.5 \\
M^{M .51}\end{array}$ & $\begin{array}{l}17 \\
N \\
2.0\end{array}$ & $\begin{array}{l}17.5 \\
N^{N} .0\end{array}$ & $\begin{array}{r}18 \\
N \\
38\end{array}$ \\
\hline
\end{tabular}

Concentration will also be plotted as a function of removal time. Plots similar to the one presented in Figure 8.5 will show the variation of concentration at the retrieval point with the height of the tank contents, bracketed by the $95 \%$ confidence interval.

The results from the tank slurry uniformity/homogeneity tests are anticipated to indicate that the mixing pump will provide a homogeneous mixture when the pump operates at full speed. Uniformity may or may not be achieved at lower speeds. Under more conservative operating conditions, for example when four mixing pumps are operated at a high Froude number, uniformity is expected to be achieved.

From the data, correlations will be developed to describe the effects of the operating conditions on the variables listed in Table 8.6. An example of the plots, $\Delta C / C$ versus $G$ and $\Delta C / C$ versus $F r$, are shown in Figures 8.6 and 8.7 . 
TABLE 8.7. Estimates of Inhomogeneity from Waste Retrieval Experiments for Various Mixer Pump Configurations and One Tank Component Configuration

\begin{tabular}{|c|c|c|c|c|c|}
\hline Simulant & $\begin{array}{c}\text { Full } \\
\text { Speed } \\
\mathrm{Fr}=3.6\end{array}$ & $\begin{array}{c}70 \% \\
\text { Speed } \\
\mathrm{Fr}=1.4 \\
\end{array}$ & $\begin{array}{c}50 \% \\
\text { Speed } \\
\mathrm{Fr}=0.6 \\
\end{array}$ & $\begin{array}{c}25 \% \\
\text { Speed } \\
\mathrm{Fr}=0.2 \\
\end{array}$ & $\begin{array}{c}15 \% \\
\text { Speed } \\
F r=0.08\end{array}$ \\
\hline $\begin{array}{l}1 \mathrm{dp}=10 \mu \mathrm{m} \\
\text { mean } w t \% \\
\text { std. dev. wt\% } \\
\text { Gs }\end{array}$ & $\begin{array}{l}16 \\
U \\
0.01\end{array}$ & $\begin{array}{l}16 \\
U \\
0.02\end{array}$ & $\begin{array}{c}15.5 \\
U \\
0.32\end{array}$ & $\begin{array}{l}16.5 \\
M \\
0.32\end{array}$ & $\begin{array}{l}15.5 \\
M \\
1.56\end{array}$ \\
\hline $\begin{array}{l}2 \mathrm{dp}=15 \mu \mathrm{m} \\
\text { mean wt } \% \\
\text { std. dev. wt\% } \\
\text { Gs }\end{array}$ & $\begin{array}{c}17.5 \\
U \\
0.12\end{array}$ & $\begin{array}{c}16.5 \\
U \\
0.05\end{array}$ & $\begin{array}{c}16 \\
U \\
0.02\end{array}$ & $\begin{array}{l}16.5 \\
M \\
0.7\end{array}$ & $\begin{array}{l}16.5 \\
N \\
3.4\end{array}$ \\
\hline $\begin{array}{l}3 \mathrm{dp}=50 \mu \mathrm{m} \\
\text { mean wt } \% \\
\text { std. dev. wt\% } \\
\text { Gs }\end{array}$ & $\begin{array}{c}18 \\
U \\
0.13\end{array}$ & $\begin{array}{l}17.5 \\
U \\
0.51\end{array}$ & $\begin{array}{c}17 \\
M \\
2.0\end{array}$ & $\begin{array}{l}17.5 \\
M \\
8.0\end{array}$ & $\begin{array}{r}18 \\
N \\
38\end{array}$ \\
\hline
\end{tabular}

$U=$ uniform distribution predicted.

$N=$ nonuniform distribution predicted.

$M=$ marginally uniform distribution predicted.

\subsubsection{Full-Scale Operation Predictions}

Once data has been collected and analyzed, it will be possible to provide correlations for the prediction of the degree of uniformity achieved in the tanks. These predictions are based on a three level experiment and will show nonlinear variation.

\subsubsection{Conclusions and Recommendations}

The data and nonlinear correlations developed in Sections 8.3.1 and 8.3.2 can be used to bound the region of uniform operation based on the experimental region. The correlations and data may be analyzed to determine what the appropriate $U_{0} D_{0}$ percentage is for operating the tank in various configurations. In addition, the waste retrieval data coupled with the tank slurry uniformity data can be used to recommend acceptable ranges for prototype operation. 


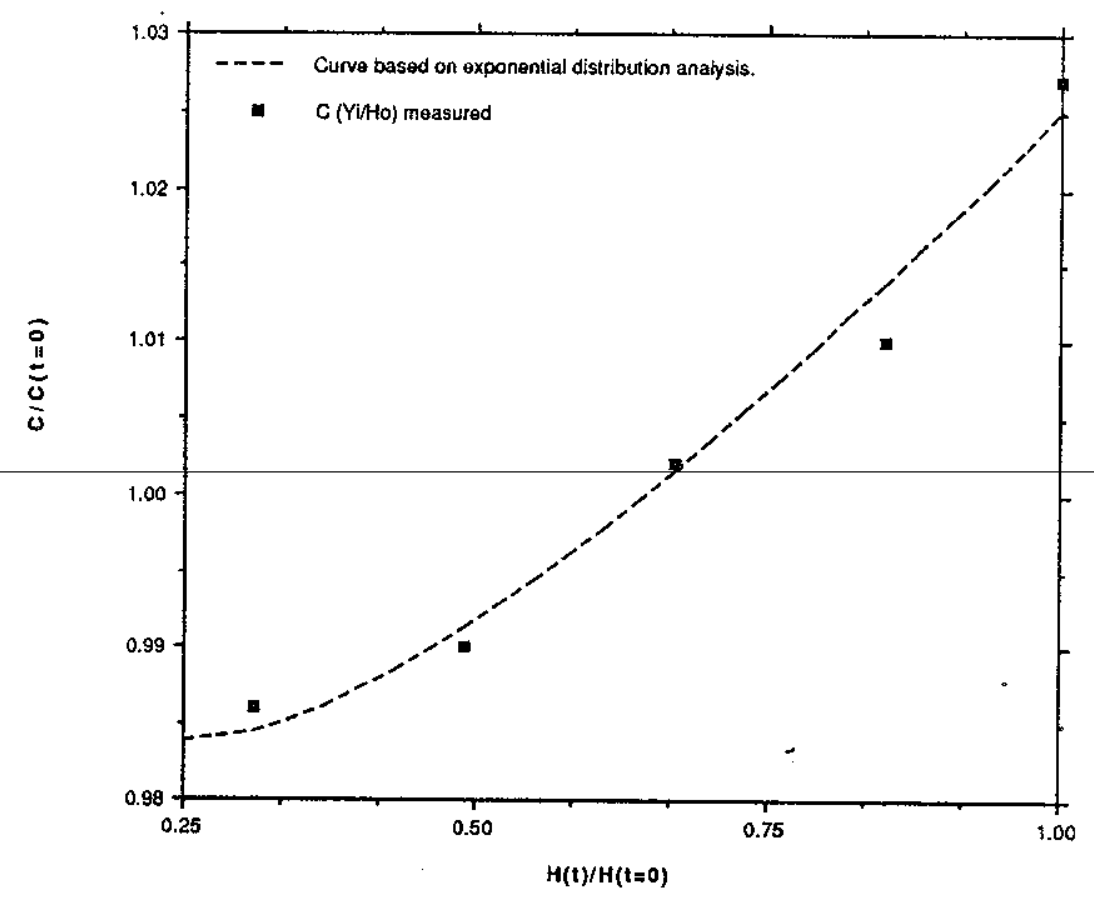
FIGURE 8.5. Example of Concentration versus Height Plot
for Waste Retrieval Experiments

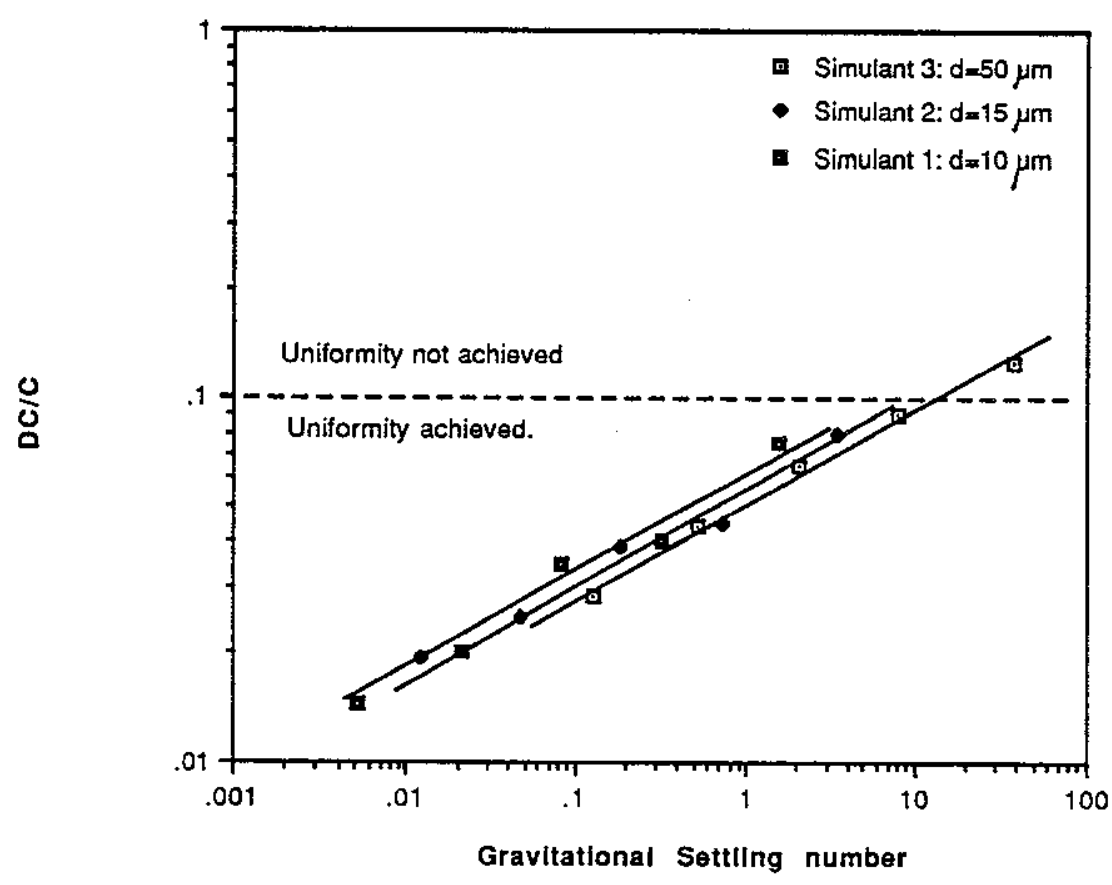

$10 \%$ concentration difference

FIGURE 8.6. Example of Correlation of $\Delta C / C$ versus Gs

\subsection{8}




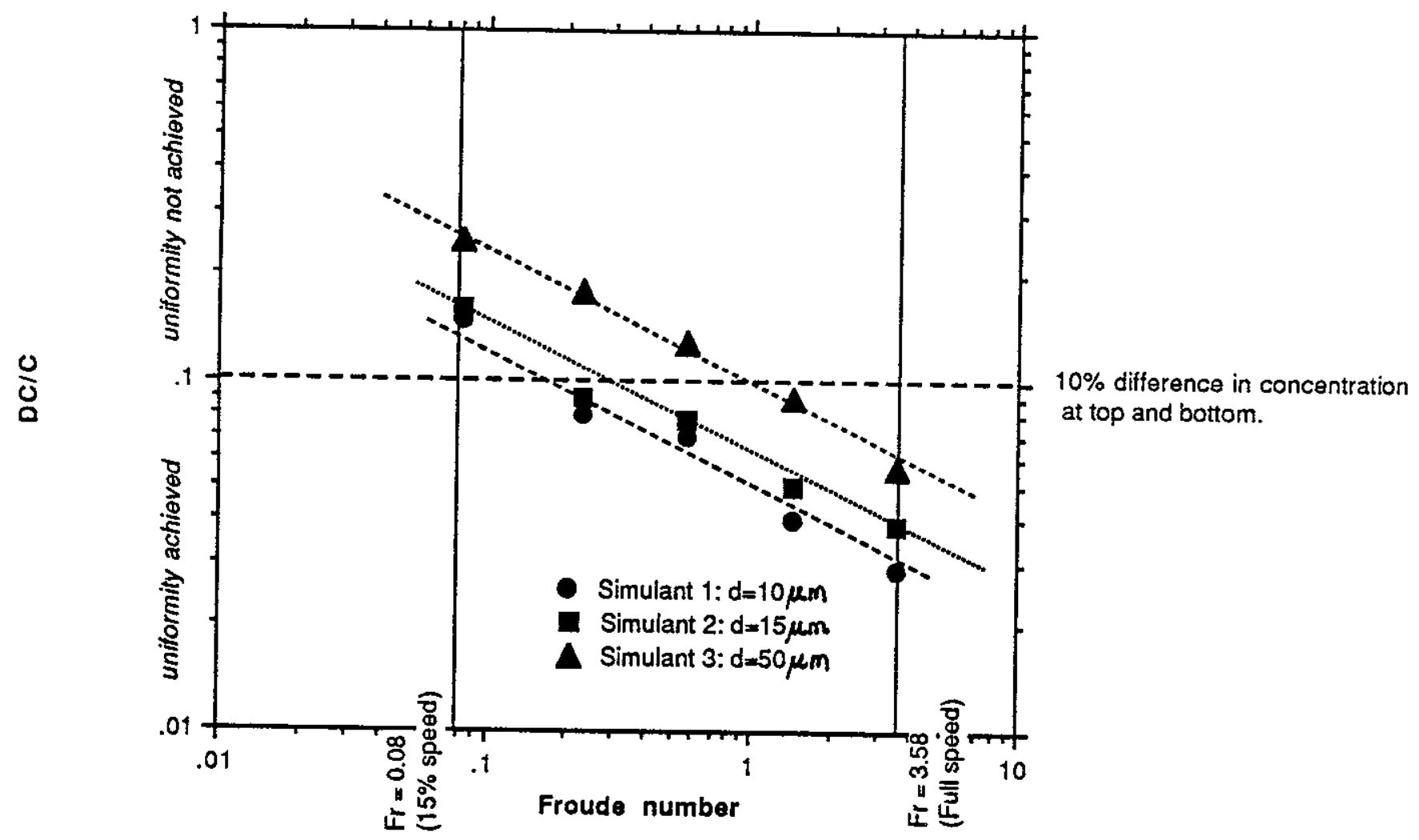

FIGURE 8.7. Example of Correlation of $\Delta C / C$ versus $\mathrm{Fr}$

\subsection{LIMITATIONS}

The following limitations to this proposed defining study need to be addressed:

- the data is based on analyses conducted using Newtonian simulants

- The correlations will be valid for operation at pump speeds between $15 \%$ and $100 \%$ of the full-speed nozzle exit velocity surrently proposed by Westinghouse Hanford Company.

None of these limitations are currently considered to be significant. After completion of the scoping experiments, the range of nozzle exit velocities can be broadened to cover a wider range as required in the defining experiments. Currently, the maximum proposed full-speed nozzle exit velocity provides a $U_{0} D_{0}$ 
equal to $2.73 \mathrm{~m} 2 / \mathrm{s}(29.4 \mathrm{ft} 2 / \mathrm{s})$. The proposed pump speed could be increased slightly if scoping experiments indicate that this is required. In this case, defining experiments would be performed at higher speeds. This is not currently anticipated because particle settling velocities in the prototype are small relative to nozzle exit velocity. 


\subsection{REAL-TIME MEASUREMENT OF SLURRY CONCENTRATION}

The mean variation of solids concentration at various locations in the prototype tank are currently measured using grab samples that are examined using analytic methods. Laboratory analysis, while very accurate, requires several hours to obtain information describing the solids concentration. In addition, the real-time variation in the concentration at a particular location in the tank is difficult to measure using grab samples. Real-time variations that might result from jet rotation are often impossible to distinguish from scatter because of the lack of resolution in the technique and the difficulties involved in timing the actual grab. Real-time measurement of the concentration distribution in the tank would overcome both disadvantages caused by using bottle samples.

Real-time analysis would permit the distribution of solids in the tank to be known during testing, thereby allowing the detection of variation in the solids distribution with time caused by the jet rotation. Real-time analysis would allow measurements over several cycles to be averaged and would allow the peak concentration to be detected and reported. Thus, if the solids concentration has a peak when the jet axis is in the measurement region, this peak could be detected by averaging the concentration over several cycles. In addition, mean changes in the solids distribution that are unrelated to the location of the jet axis could also be reported.

A cyclic steady-state distribution will be achieved after a number of jet rotations. Use of real-time measurement will allow the changes in distribution with time to be monitored and will allow verification of the steady-state conditions. This cannot be done using grab samples because the laboratory analyses cannot be performed quickly enough. Thus, real-time analysis of the solids concentration will allow verification of the steady-state condition prior to taking the actual measurements of interest and can be used to ensure that the differences detected during the various experiments are not a result of failure to achieve steady-state conditions. 
The advantages of real-time measurement are sufficient to make use of a real-time technique advisable. Two techniques will be explored to determine their viability for possible use as real-time analysis methods. The first technique that appears to be applicable to the measurement of concentration distribution is based on acoustical principles. The second technique is to measure turbidity.

The attenuation of an ultrasonic pulse in a slurry is expected to vary as a function of the mean slurry density. Because mean slurry density changes with concentration of solids, the amplitude of the ultrasonic pulse is expected to differ between regions of high and low solids concentration. The attenuation of ultrasound varies because the amount of ultrasound that is scattered by suspended particles in the slurry varies with concentration of solids. One method of measuring the attenuation of ultrasound involves using a fixed transmitter and a fixed receiver. The amplitude of ultrasound transmitted between the transmitter and receiver would be measured for several different concentrations of slurry. Once this calibration curve was established, the amplitude of ultrasound could be measured any time during a cycle to determine slurry solids concentration.

Provided the acoustic technique proves sufficiently reliable and accurate for this application, the technique could be used to monitor the slurry concentration in the tank. The concentration at different spatial locations could be monitored by use of transmitters and receivers placed at various locations in the tank. However, the technique must be investigated to determine whether it is sufficiently accurate and reliable for this experiment.

The acoustic technique may have the further advantage of allowing the velocity of the solids to be measured in the tank. Solids velocities can be measured by measuring the Doppler shift of sound that is reflected from the moving solids. The procedure followed would be to transmit a sound pulse into the slurry. Some of the signal would be scattered by each particle in the slurry and could be detected by a receiver placed near the transmitter. Because the time of flight of the signal between the receiver and transmitter is a function of the total distance traveled, the delay between signal 
transmitted and the received signal is proportional to the distance between the scattering solids and the transmitter. Consequently, both the velocity determined from the magnitude of the Doppler shift, and the location at which the velocity occurred would be known. Each sound pulse would provide a measurement of the velocity component in the direction parallel to the sound transmission line at an instant in time. Thus, a great deal of velocity information could be obtained in this manner. This technique has been used to measure the velocity of blood in veins, but it is not currently known whether it would be useful at a larger scale. It is possible that the greater degree of attenuation expected over longer distances may diminish the technique's utility. However, the technique appears sufficiently promising to explore further.

A table top demonstration using an ultrasonic transmitter and receiver was conducted to observe the applicability of this method for detecting concentration differences. The demonstration was conducted in a small rectangular reservoir; the receiver and transmitter were submerged in water and separated by $0.15 \mathrm{~m}(0.5 \mathrm{ft})$. When activated, a voltage signal with amplitude proportional to the transmission in clear water was observed. Sand was sprinkled into the reservior to observe attenuation when particulate is present. A small magnetic stirrer was placed in the bottom of the reservoir to agitate the particulate. The amplitude of the observed voltage signal was reduced in magnitude with the addition of particulate. In this demonstration, the ultrasonic transmitter and receiver were matched in frequency; however, the frequency was not optimized for detection of solids in the fluid. The transmitter and receiver are each approximately $0.01 \mathrm{~m}$ ( 0.5 in.) in diameter. Ultrasonic detection can operate in two separate modes: one with a receiver transmitter pair, the other mode, pulse echo, requires just one sensor.

Based on the results of the table top experiment, several potential applications of ultrasound for characterization of slurries in tanks may be useful:

- to measure the slurry concentration as a function of height in the tank. This application would be accomplished by having several transmitter/ receiver pairs at various heights in the tank to measure the concentration in horizontal planes. 
- to measure the distance to an obstruction in the tank. This application could be used to measure the effectiveness of the mixer pump to resuspend sludge in the real time. A sensor, operating in the pulse-echo mode, would be mounted on the mixer pump shaft to monitor the distance from the pump to the sludge layer.

- to determine the interface between the supernatant and the sludge layer. This measurement could be accomplished in two ways, first by using a vertical application of pulse-echo from the liquid surface to the sludge layer, second by using a horizontal application of a series of transmitter/receiver pairs to detect the concentration in horizontal planes.

Based on the qualitative results from this proof of principle table top experiment, it is recommended that ultrasonic techniques be developed to provide real-time measurement of slurry concentration in the scoping and defining experiments. Providing this type of real-time measurement in support of the 1/12-scale scoping and 1/6-scale defining experiments will provide more useful data for comparsion with the TEMPEST computer model, and will also develop the measurement techniques to support full-scale waste retrieval activities.

A second technique that could be used is to measure turbidity of the slurry with a turbidity meter. This analytic technique is used to determine relative concentrations of solids in water and may be applicable to this problem. The technique cannot be performed as quickly as the acoustic technique; however, measuring solids with a turbidity meter could be more accurate than the acoustic technique. The use of a turbidity meter is documented as a standard analytic method (Franson 1981).

Lab-scale efforts in this area are recommended to quantify the three methods: 1) grab samples discussed in Section 6, 2) ultrasonic measurements, and 3) turbidity measurements. In addition, the literature will be searched to determine whether other useful techniques have been reported that may be applied to the uniformity tests. Only techniques that have already been successful in measuring the concentration or velocity of solids in slurries will be considered. 


\section{REFERENCES}

Albertson, M. L., Y. B. Dai, R. A. Jensen, and H. Rouse. 1950. "Diffusion of Submerged Jets." ASCE Transactions 115:639-697.

Bamberger, J. A., J. M. Bates, and E. D. Waters. 1990. Final Report Experimental Characterization of Jet Static Forces Impacting Waste Tank Components. PNL-7394, Pacific Northwest Laboratory, Richland, Washington.

Box, G. E. P., W. G. Hunter, and J. S. Hunter. 1987. Statistics for Experimenters. John Wiley and Sons, New York.

Dickey, D. A., and J. G. Fenic. 1976. "Dimensional Analysis for Fluid Agitation Systems." Chem. Eng. January 5, 1976, pp. 7-13.

Eyler, L. L. 1983. TEMPEST Computer Code Simulation of Helium Transport in the Containment Systems Test Facility. PNL-4843, Pacific Northwest

Laboratory, Richland, Washington.

Fossett, H., et al. 1949. "The Application of Free Jets to the Mixing of Fluids in Bulk." Proc. I. Mech. E. 160:128.

Fosset, H., and L. E. Prosser. 1951. "The Application of Free Jets to the Mixing of Fluids in Bulk." Trans. Inst. Chem. Engr. 29:322.

Fow, C. L., D. E. Kurath, and B. A. Pulsipher. 1989. Evaluation of the Mixing.System for the West Valley Melter Feed Hold Tank. PNL-6724, Pacific Northwest Laboratory, Richland, Washington. Fox, E. A., and V. E. Gex. 1956. "Single-Phase Blending of Liquids." AIChE
J. 2(4):539-544.

Franson, M. A. H. ed. 1981. Standard Methods for the Examination of Water and Waste Water. 15th ed., American Public Health Association, Washington,

Gates L. E., J. R. Morton, and P. L. Fondy. 1976. "Selecting Agitator Systems to Suspend Solids in Liquids." Chem. Eng. May 24, 1976, pp. 31-37.

Gore R. A., and C. T. Crowe. 1990. Turbulence In Slurry Pipe Flow. LA-UR-90-856, Los Alamos National Laboratory, Los Alamos, New Mexico.

Kramers, H., G. M. Baars, and W. H. Knoll. 1953. Chem. Eng. Sci. 2:35.

Marr, G. R. 1959. The Dynamical Behavior of Stirred Tanks. Ph.D. Thesis, Princeton University, Princeton, New Jersey. 
Marr, G. R., and E. F. Johnson. 1963. "The Pumping Capacity of Impellers in Stirred Tanks." AIChE J. 9(3):383-385.

Norwood, K. W., and A. B. Metzner. 1960. "Flow Patterns and Mixing Rates in Agitated Vessels." AIChE J. 6(3):432-437.

Peterson, M. E., D. McCarthy, and K. D. Muhlstein. 1986. Design of Mixing System for Simulated High-Level Nuclear Waste Melter Feed STurries. PNL-5745, Pacific Northwest Laboratory, Richland, Washington.

Rajaratnam, N. 1976. Developments in Water Science: Turbulent Jets.

Elsevier Scientific Publishing Company, Amsterdam, The Netherlands.

Trent, D. S., and L. L. Eyler. 1989. TEMPEST A Three-Dimensional TimeDependent Computer Program for Hydrothermal Analysis. Volume 1: Numerical Methods and Input Instructions. PNL-4348, Vol, 1, Rev. 2, Pacific Northwest Laboratory, Richland, Washington.

Uh1, V. W., and J. B. Gray. 1966. Mixing Theory and Practice. Academic Press, New York.

Van de Vusse, J. G. 1955. "Mixing by Agitation of Miscible Liquids." Chem. Eng. Sci. 4:178-200. Pergamon Press Ltd, London, Great Britain.

Van de Vusse, J. G. 1962. "A New Model for the Stirred Tank Reactor." Chem. Eng. Sci. 17:507-521. Pergamon Press Ltd, London, Great Britain. 
APPENDIX

METHOD FOR ESTIMATING SOLIDS DENSITY 

APPENDIX

\section{METHOD FOR ESTIMATING SOLIDS DENSITY}

The solids density is not measured directly in any of the reports describing waste properties listed in Table 3.1. The following method was used to estimate the density of individual solids in tank wastes.

Define

$$
\begin{aligned}
\phi_{1} & =1 \text { iquid volume fraction } \\
\phi_{\mathrm{S}} & =\text { solids volume fraction } \\
\rho 1 & =\text { supernate density }\left(\mathrm{M} / \mathrm{L}^{3}\right) \\
\rho & =\text { slurry density }\left(\mathrm{M} / \mathrm{L}^{3}\right) \\
\rho_{\mathrm{S}} & =\text { solids density }\left(\mathrm{M} / \mathrm{L}^{3}\right) \\
\% \mathrm{wt} \mathrm{ds}_{\mathrm{s}} & =\text { weight } \% \text { dissolved solids in the total slurry } \\
\text { \%wtts } & =\text { weight } \% \text { total solids in the total slurry. }
\end{aligned}
$$

The supernatant in the liquid is composed of a pure liquid that contains dissolved solids. Therefore, the mass of the supernatant may be expressed as

$$
m_{1}=m_{w}+\% w t_{d s} m_{t o t}
$$

where $\quad m_{W}=$ mass of pure liquid (mostly water)

$$
m_{\text {tot }}=\text { total mass of the sample. }
$$

It is possible to determine the total mass of the supernatant by observing that the total slurry mass is equal to the sum of the mass of total solids and the mass of pure liquid.

$$
m_{\text {tot }}=\stackrel{o w}{o w} m_{\text {tot }}+m_{w}
$$

Equation (A.2) may be written as

$$
\begin{aligned}
m_{t o t} & =\left(\% w t_{t s}-\% w t_{d s}\right) m_{t o t}+\left(m_{w}+\% w t_{d s} m_{t o t}\right) \\
& =\left(\% w t_{t s}-\% w t_{d s}\right) m_{t o t}+m_{1}
\end{aligned}
$$


The mass of the liquid in a volume ( $V$ ) of slurry may also be written as

$$
m_{1}=\rho_{1} \phi 1 \mathrm{~V}
$$

The mass of the total slurry is

$$
\mathrm{m}_{\text {tot }}=\rho \mathrm{V}
$$

Consequently the volume fraction of the liquid is

$$
\phi_{1}=\left\{\left(1-{ }^{\circ} w t_{t s}+{ }^{o w} t_{d s}\right) / \rho 1\right\} \quad\left(m_{t o t} / v\right)
$$

However, mtot/ $V$ is the definition of the slurry density so

$$
\phi_{1}=\left(1-\% w t_{t s}+\% w t_{d s}\right) \rho / \rho 1
$$

Once the liquid volume fraction is known, it is possible to determine the solids volume fraction

$$
\phi_{\mathrm{S}}=1-\phi_{1}
$$

And the solids density may be determined using the relation

$$
\rho=\rho_{1} \phi_{1}+\rho_{\mathrm{S}} \phi_{\mathrm{S}}
$$

or

$$
\rho_{\mathrm{S}}=\left(\rho-\rho_{1} \phi_{1}\right) /\left(1-\phi_{1}\right)
$$

The solids density was calculated for two samples taken from tank 101-AZ. The measured values and the estimated magnitude of the solids density appear in Table A.1. The solids density was found to be $33 \%$ greater than the density of the centrifuged solids. Complete information to determine the solids density was not available for other wastes. Because wastes of greater density are expected to provide more difficulties during resuspension, a typical solids density of $2500 \mathrm{~kg} / \mathrm{m}^{3}\left(2.5 \mathrm{~g} / \mathrm{cm}^{3}\right)$, slightly greater than estimated here, was assumed to be the typical solids density. 
TABLE A.1. Sample Density Calculation

Sample

$60 \%$ solids composite

$30 \%$ solids composite
Slurry Supernate Weight $\%$ Weight Liquid
Density, Density Density, Density, Dissolved \% Total $\mathrm{kg} / \mathrm{m}^{3} \mathrm{~kg} / \mathrm{m}^{3}$ Solids Solids

$1620 \quad 1220$

$1350 \quad 1220$
5.4

18.5
57

41

$\%$

64

86

Solids

Density, $\mathrm{kg} / \mathrm{m}^{3}$

2300

2100 



\section{DISTRIBUTION}

No. of

Copies

ONSITE

19 Pacific Northwest Laboratory

J. A. Bamberger (2)

M. K. Drost

D. L. Eggett

L. L. Eyler

W. 0 . Heath

B. M. Johnson

L. M. Liljegren

N. J. Lombardo

P. S. Lowery

J. L. McElroy

M. R. Powell

J. S. Roberts

P. A. Scott

T. T. Taylor

G. L. Work

G. A. Whyatt

Clearance Administration (2)
No. of

Copies

5 Westinghouse Hanford

L. C. Stegen

E. D. Waters (4) 
